\title{
HIV integrated biological and behavioural surveillance survey (IBBSS) 2010
}

Federal Ministry of Health

Follow this and additional works at: https://knowledgecommons.popcouncil.org/departments_sbsr-hiv

Part of the Demography, Population, and Ecology Commons, Health Policy Commons, Immune System Diseases Commons, International Public Health Commons, Medicine and Health Commons, Public Health Education and Promotion Commons, and the Virus Diseases Commons How does access to this work benefit you? Let us know!

\section{Recommended Citation}

Federal Ministry of Health. 2011. "HIV integrated biological and behavioural surveillance survey (IBBSS) 2010." Abuja: Federal Ministry of Health. 


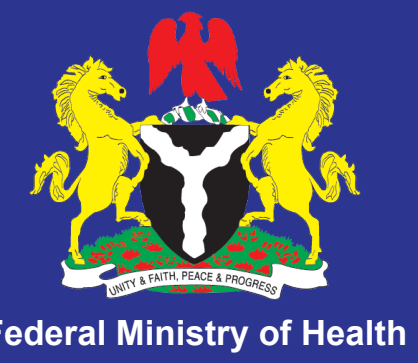

\section{HIV Integrated Biological and}

Behavioural Surveillance Survey

(IBBSS)

2010 



\section{HIV Integrated Biological and Behavioural Surveillance Survey (IBBSS)}

2010 
The 2010 Integrated Biological and Behavioural Surveillance Survey (IBBSS) was implemented by the HIV/AIDS Division of the Federal Ministry of Health in 2010. Family Health International (FHI) provided technical assistance through the GHAIN project, a PEPFAR-funded project in Nigeria providing support to the Government of Nigeria's HIV/AIDS prevention, care, treatment and support programs as well as its HIV surveillance efforts. Funding for the IBBSS was provided by the United States Agency for International Development (USAID) and the President's Emergency Fund for AIDS Relief (PEPFAR). Additional funding and technical assistance were provided by the Enhancing Nigeria's Response to HIV/AIDS project (ENR), a United Kingdom's Department for International Development (DFID)-funded HIV prevention and institutional strengthening program implemented by Society for Family Health and Population Council.

Additional information about the IBBSS may be obtained from the following organizations.

1. HIV and AIDS Division, Federal Ministry of Health. EDO HOUSE, second floor, plot 75, Ralph Sodeide Street, Central Business District, Abuja.

2. The National Agency for the Control of AIDS, Abuja, Nigeria. www.naca.gov.ng

3. FHI Country Office, GODAB Plaza, Plot 1073 J. S. Tarka Street, Garki, Area 3, P.M.B. 44, Abuja, Nigeria.

Tel: 234.94615555. www.fhi.org

4. Society for Family Health, 8 Port Harcourt Crescent, Area 11, Garki, Abuja.

09-4618823-9. www.sfhnigeria.org

5. Population Council, Bassan Plaza, Block B, 3rd Floor, Plot 759, Central Business District Off Herbert Macaulay Way, Abuja, Nigeria.

Tel: +23498706071

\section{Recommended citation:}

Federal Ministry of Health (FMOH). Nigeria Integrated Biological and Behavioural Surveillance Survey 2010. 
LIST OF FIGURES iv

LIST OF TABLES vii

ACRONYMS $x$

FOREWORD $\quad$ xi

ACKNOWLEDGEMENTS Xii

PREFACE Xiii

EXECUTIVE SUMMARY Xiv

1. INTRODUCTION 1

1.1 HIV/AIDS in Nigeria 1

1.2 Rationale 2

1.3 Goal 3

1.3.1 Specific Objectives 3

1.3.1.1 Generate behavioural data 3

1.3.1.2 Generate biological data 3

1.3.1.3 Design and implement a surveillance system 3

1.3.1.4 Provide opportunities for appropriate follow-up for clinical and social support services 3

2. METHODS 4

2.1 Study sites and target populations 4

2.1.1 Study sites 4

2.1.2 Target populations 5

2.1.2.1 Female sex workers (FSW) 5

2.1.2.2 Men who have sex with men (MSM) 5

2.1.2.3 Injecting drug users (IDU) 5

2.1.2.4 Armed Forces (Army, Navy \& Air force), the Police and
Transport Workers (TW)

2.2 Sample size 5

$\begin{array}{lll}2.3 & \text { Sampling procedures } & 6\end{array}$

2.3.1 Armed Forces and Police $\quad 7$

2.3.2 FSW (Brothel-based) 7

2.3.3 FSW (Non brothel-based) 7

2.3.4 MSM and IDU 8

2.3.5 Transport Workers 8

2.4 Refusal for HIV test 8

2.5 Key IBBSS indicators 9

2.6 Pilot study 9 
2.7 Training of personnel

$\begin{array}{lll}2.8 \text { Data collection } & 10\end{array}$

$\begin{array}{lll}2.9 & \text { HIV testing procedures } & 11\end{array}$

2.10 Data management and analysis 11

$\begin{array}{ll}2.10 .1 \text { Field supervision } & 11\end{array}$

2.10.2 Data entry 11

2.10.3 Data cleaning 12

2.10.4 Data management and coding 12

2.10.5 Data analysis 12

2.10.5.1 STATA 12

2.10.5.2 RDSAT 12

2.11 Ethical issues 12

2.12 Study limitations 13

3 RESULTS $\quad 14$

$\begin{array}{lll}3.1 & \text { Characteristics of respondents } & 14\end{array}$

3.2 HIV prevalence among study groups 16

3.2.1 Overall HIV prevalence 16

$\begin{array}{ll}\text { 3.2.2 HIV prevalence by states } & 17\end{array}$

3.2.3 HIV prevalence by selected characteristics 20

3.2.3.1 HIV prevalence by socio-demographic factors 20

3.2.3.2 HIV prevalence by selected risk factors 23

3.2.4 Discussion 26

3.3 Awareness, knowledge and risk perception of HIV and AIDS 27

3.3.1 HIV awareness and knowledge of HIV prevention methods 27

$\begin{array}{ll}\text { 3.3.2 UNGASS indicator } & 27\end{array}$

3.3.3 HIV risk perception 29

3.3.4 Discussion 30

3.4 HIV/STI risk behaviours and self-reported STI symptoms 31

3.4.1 Female sex workers 31

3.4.1.1 Sexual partnerships $\quad 31$

3.4.1.2 Condom use $\quad 32$

3.4.1.3 Self-reported STI symptoms 34

3.4.2 Men who have sex with men (MSM) 35

3.4.2.1 Sexual partnerships $\quad 35$

3.4.2.2 Condom use 36

3.4.2.3 Self-reported STI symptoms

$\begin{array}{ll}3.4 .3 & \text { Injecting drug users } \\ 3.38\end{array}$

3.4.3.1 Sexual partnerships $\quad 38$

$\begin{array}{ll}\text { 3.4.3.2 Condom use } & 38\end{array}$ 
3.4.3.3 Self-reported STI symptoms

3.4.3.4 Female IDU 39

3.4.4 Predominantly male occupational groups 39

3.4.4.1 Sexual partnerships 39

3.4.4.2 Condom use $\quad 40$

3.4.4.3 Self-reported STI symptoms 41

3.4.5 Discussion 41

3.5 Attitudes towards PLWHA 42

3.5.1 Discussion 43

3.6 Exposure to HIV prevention interventions 43

3.6.1 HIV test 43

3.6.2 HIV prevention information and services 45

$\begin{array}{lll}\text { 3.6.3 Discussion } & 47\end{array}$

4 TREND OF SELECTED BEHAVIOURAL INDICATORS 48

4.1 Ever had HIV test 48

4.2 Sex with female sex worker by study group 50

4.3 Consistent condom use 52

4.4 Use of sterile injecting equipment 53

5 DISCUSSION AND RECOMMENDATIONS 54

6 REFERENCES $\quad 58$

7 APPENDIX 59

Appendix I Summary indicators for each of the target groups 59

Appendix II Descriptive state level analysis of behavioural data 61

$\begin{array}{ll}\text { Appendix III List of contributors } & 111\end{array}$ 


\section{LIST OF FIGURES}

Figure 1: HIV Prevalence in Nigeria, (1991 - 2010) 1

Figure 2: Map of Nigeria showing states sampled during the IBBSS 4

Figure 3: Proportion of repondents away from home for at least 1 continuous month in the past 12 months preceding the survey, IBBSS Nigeria 2010

Figure 4: Frequency of alcohol consumption among study groups, IBBSS Nigeria, 201015

Figure 5: Drug use in the last four weeks among study groups, IBBSS Nigeria 2010

Figure 6: HIV prevalence among all study groups, IBBSS Nigeria 2010

Figure 7: HIV prevalence among brothel-based FSW by state, IBBSS Nigeria 2010

Figure 8: HIV prevalence among non-brothel-based FSW by state, IBBSS Nigeria 201018

Figure 9: HIV prevalence among MSM by state, IBBSS Nigeria 2010

Figure 10: HIV prevalence among IDU, IBBSS Nigeria 2010

Figure 11: HIV prevalence among Armed Forces, IBBSS Nigeria 2010

Figure 12: HIV prevalence among Police, IBBSS Nigeria 2010

Figure 13: HIV prevalence among transport workers, IBBSS Nigeria 2010

Figure 14: HIV Prevalence among study groups, IBBSS Nigeria 2007 and 2010

Figure 15: Knowledge of selected HIV prevention methods by group, IBBSS Nigeria 201027

Figure 16: Percentage of study groups who both correctly identify ways of preventing the sexual transmission of HIV and who reject major misconceptions about HIV transmission, IBBSS Nigeria 2010

Figure 17: Proportion of study groups who believe HIV can be transmitted through mosquito bite, IBBSS Nigeria 2010

Figure 18: Proportion of study groups who believe HIV can be transmitted by sharing meal with an infected person, IBBSS Nigeria 2010

Figure 19: Percentage of respondents in the study groups who believe that sharing of toilets with a person who has HIV is a means of contracting HIV IBBSS Nigeria, 2010

Figure 20: Proportion of study groups who perceived themselves at risk of HIV, IBBSS Nigeria 2010

Figure 21: Mean number of clients last day/week of sex work, IBBSS Nigeria 2010

Figure 22: Types of non-commercial sexual partners among FSW in last 12 months preceding the survey, IBBSS Nigeria 2010

Figure 23: Percentage of FSW having sex with more than one boyfriend last 12 months preceding the survey, IBBSS Nigeria 2010

Figure 24: Distribution of brothel-based FSW according to condom use with commercial and other sexual partners, IBBSS Nigeria 2010

Figure 25: Distribution of non-brothel-based FSW according to condom use with commercial and other sexual partners, IBBSS Nigeria 2010

Figure 26: Awareness and usage of female condom by FSW, IBBSS Nigeria 2010

Figure 27: Self reported STI symptoms in the last 12 months preceding the survey by FSW, IBBSS Nigeria 2010 
Figure 28: Self reported STI symptoms by type, by FSW in the last 12 month preceding the survey, IBBSS Nigeria 2010

Figure 29: Distribution of MSM according to different male partner types last 6 months preceding the survey, IBBSS Nigeria 2010

Figure 30: Distribution of MSM by female sexual partners in the last 12 months preceding the survey, IBBSS Nigeria 2010

Figure 31: Condom use as at last anal sex among MSM, IBBSS Nigeria 2010

Figure 32: Condom use at last sex and consistent condom use among MSM by type of partner, IBBSS Nigeria 2010

Figure 33: Self reported STI symptoms among MSM, IBBSS Nigeria 2010

Figure 34: Types of sexual partners among all sexually active IDU in the last 12 months preceding the survey, IBBSS Nigeria 2010

Figure 35: Distribution of male IDU by condom use at last sex by type of sexual partner, IBBSS Nigeria 2010

Figure 36: Self reported STI symptoms among IDU, IBBSS Nigeria 2010

Figure 37: Types of sexual partners among predominantly male occupational groups, IBBSS Nigeria 2010

Figure 38: Male occupational group reporting sex with more than one non-regular partner in the last 12 months preceding the survey, IBBSS Nigeria 2010

Figure 39: Condom use at last sex by type of sexual partner, male occupational groups IBBSS Nigeria 2010

Figure 40: Self reported STI symptoms among the predominantly male occupational groups, IBBSS Nigeria 2010

Figure 41: Self reported STI by type among predominantly male occupational groups, IBBSS Nigeria 2010

Figure 42: Distribution of study groups by desire to keep HIV infection secret, IBBSS Nigeria 2010

Figure 43: Distribution of study groups according to those ever tested for HIV, IBBSS Nigeria 2010

Figure 44: Distribution of study groups according to those who tested for HIV and received results, IBBSS Nigeria 2010

Figure 45: Distribution of study groups according to those tested for HIV in the last 12 months preceding the survey, IBBSS Nigeria 2010

Figure 46: Percent of HIV positive respondents who know their status, IBBSS Nigeria 2010

Figure 47: Distribution of FSW according to HIV prevention services received in the last 12 months preceding the survey, IBBSS Nigeria 2010

Figure 48: Distribution of MSM according to HIV prevention services received in the last 12 months preceding the survey, IBBSS Nigeria 2010

Figure 49: Distribution of IDU according to HIV prevention services received in the last 12 months preceding the survey, IBBSS Nigeria 2010

Figure 50: Distribution of predominantly male occupational groups according to HIV prevention services received in the last 12 months preceding the survey 
Figure 51: Proportion of Armed Forces who have ever tested for HIV by state,

(2005-2010) IBBSS Nigeria 2010

Figure 52: Proportion of Police who have ever tested for HIV by state, (2005-2010) IBBSS

Nigeria 2010

Figure 53: Proportion of transport workers who have ever tested for HIV by state, (20052010) IBBSS Nigeria 2010

Figure 54: Proportion of FSW who have ever tested for HIV by state, (2005-2010) IBBSS

Nigeria 2010

Figure 55: Proportion of IDU who have ever tested for HIV by state, (2005-2010) IBBSS

Nigeria 2010

Figure 56: Proportion of MSM who have ever tested for HIV by state, (2005-2010) IBBSS Nigeria 2010

Figure 57: Proportion of Armed Forces who have had sex with a FSW in the past 12 months by state, (2005-2010) IBBSS Nigeria 2010

Figure 58: Proportion of the Police who have had sex with a FSW in the past 12 months by state, (2005-2010) IBBSS Nigeria 2010

Figure 59: Proportion of TW who have had sex with a female sex worker in the past 12 months by state, (2005-2010) IBBSS Nigeria 2010

Figure 60: Consistent condom use with clients among FSW in the last 1 month by state, (2005-2010) IBBSS Nigeria 2010

Figure 61: Proportion of MSM who consistently used condom with a non- paying male partner in the last 6 months, (2005-2010) IBBSS Nigeria 2010

Figure 62: Proportion of IDU who reported always use of sterile injecting equipment in the last 1 month prior to the survey by state, (2005-2010) IBBSS Nigeria 2010 
Table 1: Target groups and states

Table 2: Sample size achieved by study groups 6

Table 3: Sampling procedures by study groups 6

Table 4: Percentage of all study groups by socio-demographic distribution, IBBSS Nigeria 2010

Table 5: HIV prevalence by selected socio-demographic characteristics among BBFSW and NBBFSW

Table 6: HIV prevalence and confidence limits by selected socio-demographic characteristics among MSM and IDU

Table 7: HIV prevalence and confidence limits by selected socio-demographic characteristics among Armed Forces, Police and transport workers

Table 8: HIV prevalence by selected risk factors for HIV among brothel and non brothel based FSW

Table 9: HIV prevalence by selected risk factors for HIV among MSM and IDU

Table 10: HIV prevalence by selected risk factors for HIV among Armed Forces, Police and transport workers

Table 11: Reasons for HIV risk perception among study groups who perceived themselves at risk by study group, IBBSS Nigeria 2010

Table 12: Distribution of study groups by attitudes towards PLWHA, IBBSS Nigeria 2010

Table 13: Summary Indicators for FSW, IBBSS Nigeria 2010

Table 14: Summary indicators for MSM, IBBSS Nigeria 2010

Table 15: Summary indicators for IDU, IBBSS Nigeria 2010

Table 16: Summary indicators for Armed Forces and Police, IBBSS Nigeria 2010

Table 17: Characteristics of brothel-based FSW, by state IBBSS Nigeria 2010

Table 18: Number of sexual partners of brothel-based FSW, by state IBBSS Nigeria 2010

Table 19: Sexual history and number of sexual partners among brothel-based FSW, by state IBBSS Nigeria 2010

Table 20: Condom use among brothel-based FSW, by state IBBSS Nigeria 2010

Table 21: HIV knowledge, risk perception and HIV testing among brothel-based FSW, by state IBBSS Nigeria 2010

Table 22: Self reported STI symptoms among brothel-based FSW, by state IBBSS Nigeria 2010

Table 23: STI treatment seeking behavior among brothel-based FSW, by state IBBSS Nigeria 2010

Table 24: Exposure to HIV/AIDS interventions among brothel-based FSW, by state IBBSS Nigeria 2010

Table 25: Alcohol use among brothel-based FSW, by state IBBSS Nigeria 2010

Table 26: Characteristics of non-brothel-based FSW, by state IBBSS Nigeria 2010 
Table 27: Number of sexual partners of non-brothel-based FSW, by state IBBSS Nigeria 2010

Table 28: Sexual history and number of sexual partners among non-brothel-based FSW, by state IBBSS Nigeria 2010

Table 29: Condom use among non-brothel-based FSW, by state IBBSS Nigeria 2010

Table 30: HIV knowledge, risk perception and HIV testing among non-brothel-based FSW, by state IBBSS Nigeria 2010

Table 31: Self reported STI symptoms among non-brothel-based FSW, by state IBBSS Nigeria 2010

Table 32: STI treatment seeking behaviour among non-brothel-based FSW, by state IBBSS Nigeria 2010

Table 33: Exposure to HIV/AIDS interventions among non-brothel-based FSW, by state IBBSS Nigeria 2010

Table 34: Alcohol use among non-brothel-based FSW, by state IBBSS Nigeria 2010

Table 35: Characteristics of MSM, by state IBBSS Nigeria 201076

Table 36: Sexual contacts with male partners among MSM, by state IBBSS Nigeria 2010

Table 37: Condom use with male and female partners among MSM, by state IBBSS Nigeria 2010

Table 38: MSM use of lubricant and by type of lubricant, by state IBBSS Nigeria 2010

Table 39: HIV knowledge, risk perception and HIV testing among MSM, by state IBBSS Nigeria 2010

Table 40: Self reported symptoms among MSM, by state IBBSS Nigeria 2010

Table 41: STI treatment seeking behaviour among MSM, by state IBBSS Nigeria 2010

Table 42: Exposure to HIV/AIDS interventions among MSM, by state IBBSS Nigeria 2010

Table 43: Alcohol use among MSM, by state IBBSS Nigeria 2010

Table 44: Characteristics of Armed Forces, by state IBBSS Nigeria 2010

Table 45: Sexual history and number of sexual partners among Armed Forces, by state IBBSS Nigeria 2010

Table 46: Condom use among the Armed Forces, by state IBBSS Nigeria 2010

Table 47: Knowledge, risk perception and HIV testing among Armed Forces, by state IBBSS Nigeria 2010

Table 48: Self reported symptoms among the Armed Forces, by state IBBSS Nigeria 2010

Table 49: STI treatment seeking behaviour among Armed Forces, by state IBBSS Nigeria 2010

Table 50: Exposure to HIV/AIDS interventions among Armed Forces, by state IBBSS Nigeria 2010 
Table 52: Characteristics of Police, by state IBBSS Nigeria 2010

Table 53: Sexual history and number of sexual partners among Police, by state IBBSS Nigeria 2010

Table 54: Condom use among the Police, by state IBBSS Nigeria 2010

Table 55: Knowledge, risk perception and HIV testing among Police, by state IBBSS Nigeria 2010

Table 56: Self reported STI symptoms among the Police, by state IBBSS Nigeria 2010

Table 57: STI treatment seeking behaviour among Police, by state IBBSS Nigeria 2010

Table 58: Exposure to HIV/AIDS interventions among Police, by state IBBSS Nigeria 2010

Table 59: Alcohol use among Police, by state IBBSS Nigeria 2010

Table 60: Characteristics of transport workers, by state IBBSS Nigeria 2010

Table 61: Sexual history and number of sexual partners among transport workers, by state IBBSS Nigeria 2010

Table 62: Condom use among transport workers, by state IBBSS Nigeria 2010

Table 63: Knowledge, risk perception and HIV testing among transport workers, by state IBBSS Nigeria 2010

Table 64: Self reported STI symptoms among transport workers, by state IBBSS Nigeria 2010

Table 65: STI treatment seeking behaviour among transport workers, by state IBBSS Nigeria 2010

Table 66: Exposure to HIV/AIDS interventions among transport workers, by state IBBSS Nigeria 2010

Table 67: Alcohol use among transport workers, by state IBBSS Nigeria 2010

Table 68: Characteristics of IDU, by state IBBSS Nigeria 2010

Table 69: Sexual history and number of sexual partners among IDU, by state IBBSS Nigeria 2010

Table 70: Condom use among IDU, by state IBBSS Nigeria 2010

Table 71: Knowledge, risk perception and HIV testing among IDU, by state IBBSS Nigeria 2010

Table 72: Self reported STI symptoms among IDU, by state IBBSS Nigeria 2010

Table 73: STI treatment seeking behaviour among IDU, by state IBBSS Nigeria 2010

Table 74: Exposure to HIV/AIDS interventions among IDU, by state IBBSS Nigeria 2010

Table 75: Alcohol use among IDU, by state IBBSS Nigeria 2010 


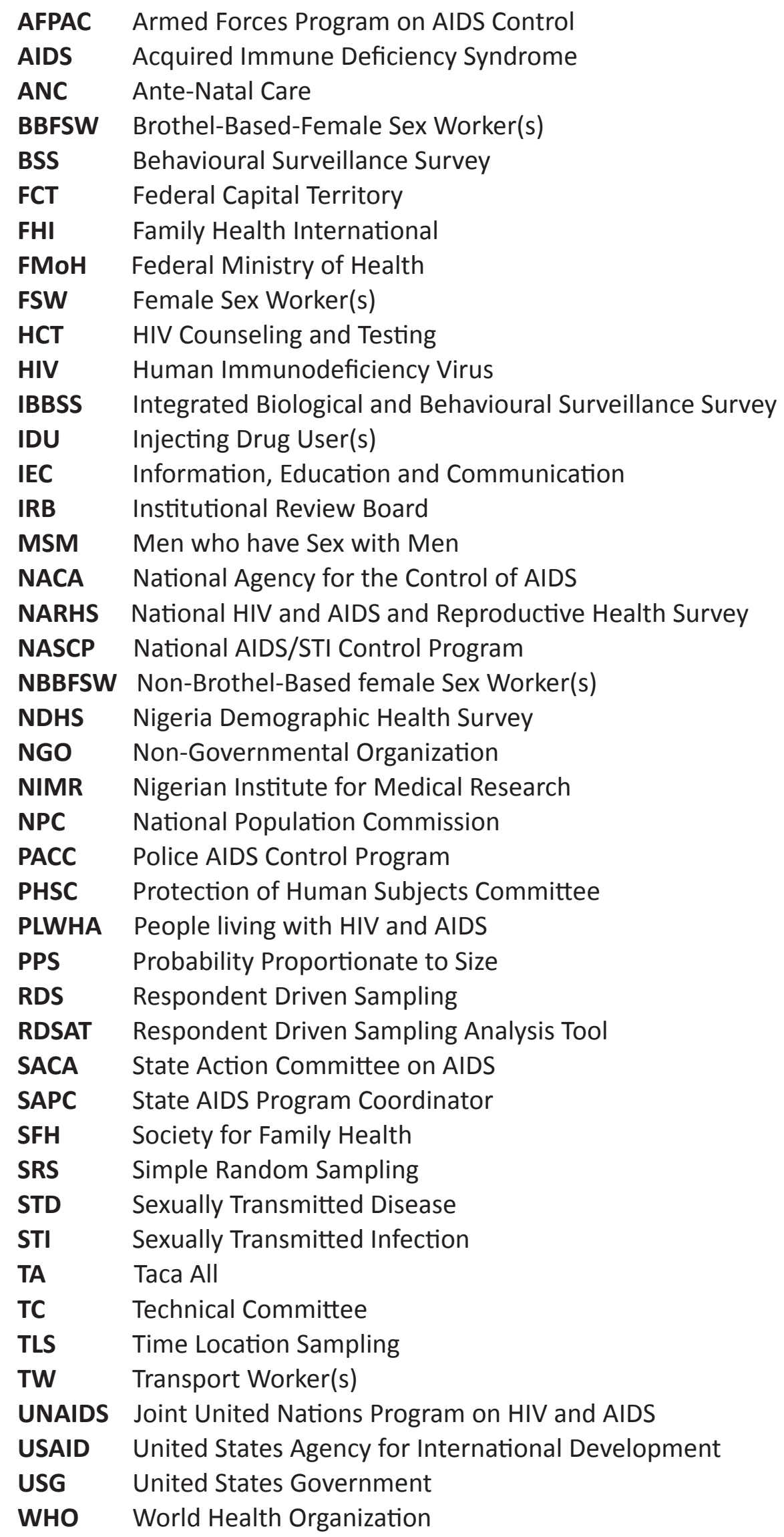




\section{FOREWORD}

Following the discovery of HIV and AIDS in Nigeria more than two decades ago, the Federal Government has put in place various programmes aimed at controlling and mitigating its impact. One of the key strategies to inform these programmes is the continuous monitoring of the HIV epidemic through clinic and population based surveillance.

Though the HIV epidemic in Nigeria is generalised, the first Integrated Biological and Behavioural Surveillance Survey (IBBSS) conducted in 2007 provided robust evidences on the burden of HIV infection and how it affects some groups within the society. In the 2007 IBBSS, probable drivers of HIV and AIDS epidemic and previously unrecognized high-risk groups were identified. Information from the survey has been very useful in the revision of the National HIV Prevention Plan.

The 2010 IBBSS results presented in this report have further brought out sexual behavioural linkages that exist between the high-risk groups and the general population. With improved understanding of this linkages and findings of other national HIV and AIDS research such as mode of transmission (MOT) study, stakeholders can begin to mount appropriate intervention strategies to break the transmission chains and reverse the trends of HIV and AIDS epidemic in the high-risk groups and the general population.

To this end, I hereby recommend this 2010 IBBSS report for elucidation of dynamics of HIV and AIDS transmission among high-risk groups and for the design of appropriate HIV and AIDS intervention-response strategies.

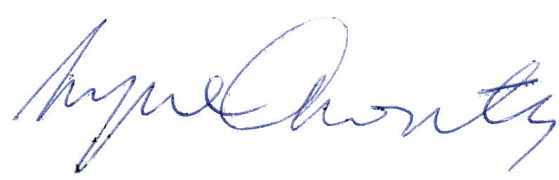

L.N. Awute, mni

Permanent Secretary 


\section{ACKNOWLEDGEMENTS}

The Federal Ministry of Health acknowledges the efforts of all that contributed to the successful conduct of the 2010 Integrated Bio-Behavioural Surveillance Survey (IBBSS) among selected high-risk groups in Nigeria.

The contributions of the State HIV/AIDS Programme Coordinators (SACPs), staff of NPC in the states where the survey was conducted and the efforts of the survey team members including the supervisors, interviewers and counsellor-testers in the generation of high quality data is highly appreciated. We also commend the efforts and cooperation of members of the high-risk groups studied and their organizations to the successful conduct of the survey.

Our special appreciation goes to the members of the survey technical committee whose technical oversight functions guided the survey. The cooperation and support of the ten participating State Ministries of Health, the National Population Commission (NPC) and their state offices involved in the survey are highly appreciated.

The logistic and technical support of the US government through Family Health International/ Global HIV/AIDS Initiative in Nigeria and Society for Family Health (SFH) with Population Council/Enhancing National Response to HIV/AIDS (ENR) of the United Kingdom AIDS for International Development is worthy of commendation.

It is hoped that the findings in this report will assist in advocacy and programme planning towards appropriate and improved interventions for HIV/AIDS response in Nigeria.

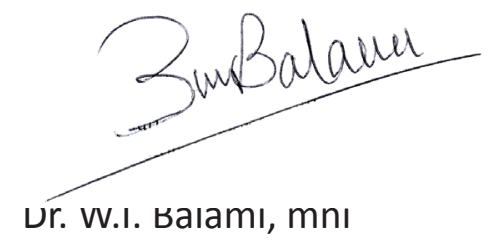

National Coordinator,

National HIV and AIDS Control Programme 
Nigeria has the second highest number of People Living with HIV (PLWH) in sub-Saharan Africa after South Africa. Current estimates from the Ante Natal Care (ANC) HIV sero-prevalence survey conducted in the country in 2010, puts the HIV prevalence at $4.1 \%$. Among the most at risk populations, the 2007 Integrated Biological and Behavioural Surveillance Survey (IBBSS) and 2010 round whose findings are discussed in this report show that Female Sex Workers (FSW)continue to record the highest HIV prevalence (above 20.0\%) followed by men who have sex with men (MSM) (above 13.0\%). While the mode of transmission study conducted in the country attributed $23 \%$ of new cases of HIV to the high-risk groups including FSW, MSM and injecting drug users (IDU), there is plan to conduct a population size estimate of the highrisk groups to understand their contribution to the HIV and AIDS epidemic in Nigeria.

As the highest policy making body on health in Nigeria, the Federal Ministry of Health recognizes the need for research especially in the areas of health including HIV and AIDS and has so far engaged in such. The Ministry has instituted mechanisms for continuous monitoring of HIV epidemic in the country. The mechanisms have included periodic survey among the general population and the most at risk population sub-groups. A main survey being conducted among the high-risk groups is the Integrated Biological and Behavioural Surveillance Survey (IBBSS) whose findings for the 2010 round of the survey (i.e. 2010 IBBSS) are discussed in this report. The findings are very revealing; it has confirmed the high level of HIV infection among members of the high-risk groups as well as the sexual interaction of the groups with the general population. If interpreted in relations to other relevant data, the findings from the 2010 IBBSS will contribute to a better understanding of the HIV and AIDS epidemic in Nigeria.

While I commend the efforts of individuals, organizations and development partners including FHI/GHAIN and ENR that contributed to the successful conduct of the 2010 IBBSS, I hereby recommend this report for use by governments at all levels, development partners, academia, research institutions, Civil Society Organizations (CSOs), Faith Based Organizations (FBOs) and other stakeholders to plan improved interventions among the high-risk groups in Nigeria.

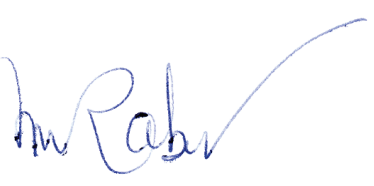

Dr. Mansur Kabir

Head, Department of Public Health. 
$\mathrm{T}$ his report highlights the findings of an integrated biological and behavioural surveillance survey (IBBSS) in Nigeria among groups whose behaviours or occupations often place them at higher risk of contracting sexually transmitted infections (STI), including HIV. The groups surveyed were brothel-based female sex workers (BBFSW), and non-brothel-based female sex workers (NBBFSW), men who have sex with men (MSM), injecting drug users (IDU), transport workers (TW) and men and women in the uniformed services (Armed Forces and the Police). The study took place in nine states (Anambra, Benue, Cross River, Edo, Kaduna, Kano, Lagos, Nassarawa and Oyo) and the Federal Capital Territory (FCT). The main objectives of the study were to assess the knowledge and beliefs of high-risk groups about STI and HIV, determine the prevalence of HIV infection among these groups and obtain data that will permit identification of trends over time. In line with international best practices, different sampling methods were used for different groups, based on factors including the ability to map or obtain lists of group members, peak times and locations where they can be found and interviewed, and other visibility and accessibility considerations. A sample size of 14,987 was achieved, which yielded reliable state-level estimates for most variables of interest.

The highest HIV prevalence of $27.4 \%$ was observed among BBFSW, followed by $21.7 \%$ and $17.2 \%$ among NBBFSW and MSM respectively. The rates in the predominantly male occupational groups and IDU were less than 5\%, ranging from $2.4 \%$ among TW, $2.5 \%$ in the Armed Forces, $2.6 \%$ among the Police to $4.2 \%$ among the IDU.

The observed prevalences showed a general fall for each of the survey groups between 2007 and 2010, with the Armed Forces, Police and TW each having HIV prevalence below that of the general population, estimated from the 2010 ANC sentinel survey. Although the prevalence among the FSW showed a fall over the 2007 figure, they were still more than five times higher than that of the general population.

Among FSW, boyfriend partnership remained at high level (above 60.0\%), while both girlfriend and multiple non-marital partnerships fell among the Armed Forces, Police and TW. There were however state level variations. Consistent condom use with clients remained high among the FSW $(90.5 \%$ for BBFSW and $76.3 \%$ for NBBFSW); however condom use during last sex with boyfriends was low ( $29.7 \%$ and $45.4 \%$ respectively) representing a decrease from 2007 finding.

Among the Armed Forces, Police and TW, condom use during last sex fell between 2007 and 2010. Although awareness of HIV and AIDS was high among these groups, however, correct identification of specific ways of prevention of and misconceptions about HIV transmission/ prevention (UNGASS Indicator 14) is low and appeared not to have changed over the 2007 baseline. Preventive behaviour like condom use with boy/girlfriends was equally low.

The high rate of consistent condom use with clients by FSW and reduction in multiple nonmarital sex partners by the male dominant groups may have contributed to the falling HIV prevalence observed. However, low condom use during sex with boyfriend among FSW represents a potential bridge for transmission of HIV infection to the general population. There was a general increase in exposure to interventions like education on safe sex, since 2007.

In conclusion it is recommended that the results of this survey should be used to inform the design of interventions for the prevention of transmission and mitigation of impacts of HIV and other STI among these populations. A synthesis of findings from other national surveys such as the sentinel HIV prevalence survey among women attending ANC and population based studies (NARHS, NDHS) will greatly assist in characterizing the determinants and deterrents of the HIV epidemic in Nigeria. 


\section{INTRODUCTION}

\subsection{HIV/AIDS in Nigeria}

$\mathrm{O}$ ne of the earliest national responses to the HIV and AIDS epidemic in Nigeria was the setting up of a surveillance system to determine the magnitude of the HIV epidemic, as well as monitor trends of the epidemic. The surveillance involved prevalence for HIV and syphilis among various groups such as women attending antenatal clinics, blood donors, transport workers and patients attending sexually transmitted infections (STI) and tuberculosis (TB) clinics. Later in 2003, behavioural surveillance survey was added on a larger scale to determine and monitor the knowledge, attitudes and behaviour associated with HIV and STI infections among the general population and selected groups of interest.

The Federal Ministry of Health (FMoH), Nigeria, in recognition of the need for continuous monitoring of HIV among populations with higher risk behaviours commissioned the first Integrated Biological and Behavioural Surveillance Survey (IBBSS) in $2007^{1}$.

The 2010 IBBSS provided critical information to track the progress of the HIV epidemic in the selected high-risk groups, by comparing information gathered in 2007 IBBSS among same high-risk groups. It surveyed 14, 987 members of selected high risk groups for HIV. The high risk groups sampled included Female Sex Workers (FSW), Men who have Sex with Men (MSM), Injecting Drug Users (IDU), Transport Workers (TW), members of the Nigerian Armed Forces and members of the Nigerian Police just like the 2007 IBBSS $^{2}$. The HIV knowledge, attitudes and risk behaviours were studied, as well as HIV prevalence. Sample sizes were sufficient to allow reliable state-level estimates for most variables of interest.

Figure 1: HIV prevalence trend in Nigeria (1991-2010)

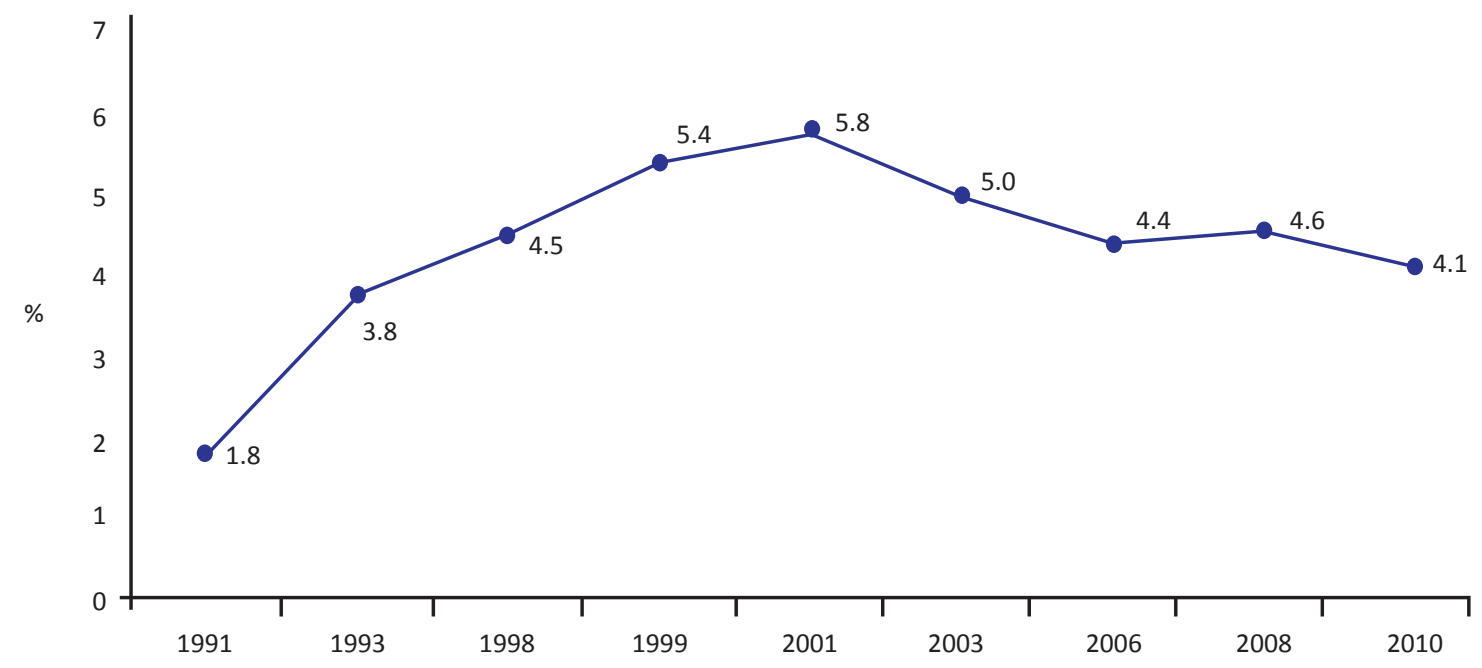

${ }^{1}$ The 2002 and 2005 behavioural surveillance surveys were conducted on a smaller number of groups and did not include the biologic component; the 2007 survey included biological testing.

${ }^{2} \mathrm{HIV} / \mathrm{STI}$ Integrated Biological and Behavioural Surveillance Survey (IBBSS) 2007. FMoH. 
In Nigeria with a population of approximately 140 million, adult HIV prevalence as monitored through antenatal HIV Sentinel Surveillance among pregnant women, increased from $1.8 \%$ in 1991 to $5.8 \%$ in 2001, before dropping to $5.0 \%$ in 2003, 4.4\% in 2005, 4.6 in 2008 and 4.1 in $2010^{3}$ (figure 1). Over the last two decades, the HIV epidemic in Nigeria has gone from affecting only a few populations with higher-risk behaviours ('concentrated' epidemic), to a 'generalized' epidemic in all states. The state of the epidemic in Nigeria varies from state to state, suggesting the importance of collecting state level data to improve the response to HIV programming at the state level.

\subsection{Rationale}

The HIV pandemic has received unprecedented support from donor agencies and it has become imperative to monitor and evaluate the various interventions aimed at controlling the spread of HIV infection. WHO/UNAIDS ${ }^{4,5}$ advocate for the use of second generation surveillance systems to monitor changes in the epidemic in each country. Second generation surveillance systems include HIV and STI biological and risk behaviour surveillance, using resulting data to warn of or explain changes in the levels of infection.

In concentrated epidemics where HIV is over five percent in any sub-population at higher risk of infection (such as drug injectors, FSW, men who have sex with men), surveillance systems monitor infection in those groups and pay particular attention to behavioural links between them and the general population. The 2007 IBBSS provided information on MSM and IDU for the first time and also gave insight into which populations new HIV infections may be coming from.

Considerable gaps remain in the quantity and quality of information available in Nigeria on HIV/AIDS to help understand the underlying dynamics of the HIV epidemic and its likely future course. In particular, data that provide insights into the following questions are needed:

- What are the determinants of new HIV infections in the various at-risk populations? Are there geographic patterns that should influence the response?

- How well is the current response addressing new HIV infections? Is the coverage adequate? Has the response had an impact over time, both in terms of behaviour change and HIV/STI biological markers?

- Where is the HIV/AIDS epidemic likely to go? How has the epidemic changed over time? Does the response need to be adapted to fit evolving patterns of risk and incidence? What are the relative benefits of alternative prevention and care resource allocations in terms of averted infections and costs? What are the long-term impacts of the epidemic?

This study was planned and implemented as a follow up to the 2007 survey by collecting biological and behavioural data from the seven groups previously assessed, and by generating reliable state-level estimates. The survey is designed to be conducted biennially. 


\subsection{Goal}

The main goal of this study is to obtain serological and behavioural information on high risk/ vulnerable population groups which will guide HIV prevention program planning suited to their context.

\subsubsection{Specific Objectives}

1.3.1.1 Generate behavioural data to:

- Assess knowledge and beliefs of high-risk groups about STI's and HIV and AIDS

- Determine the current risk behaviours

- Assess population-level trends in risk behaviours over time

- Identify higher-risk sub-populations among these high-risk groups

1.3.1.2 Generate biological data to:

- Determine the prevalence of HIV infection among the high risk groups

- Determine population-level trends of HIV sero-prevalence among high risk groups over time

1.3.1.3 Design and implement a surveillance system that:

- Obtains data in a standardized format to permit comparisons with previous rounds of behavioural surveillance studies carried out in Nigeria and other countries

- Provides information to guide future program planning

- Establishes a sustainable, cost-effective surveillance platform for future monitoring of behavioural and biological indicators across high-risk groups over time.

1.3.1.4 Provide opportunities for appropriate follow-up for clinical and social support services such that:

- Members of the high risk group have access to sustainable, non-stigmatising HIV prevention services (i.e., counseling and testing, STI services and "prevention with positives" support) including referrals. 


\section{METHODS}

The same methodology as used in the previous round of IBBSS was essentially used for this round. Number of states sampled was increased due to additional funding from DFID through the enabling national response (ENR) project.

\subsection{Study Sites and Target Populations}

\subsubsection{Study sites}

The IBBSS was conducted among seven sub-populations at risk of HIV in nine selected states and the Federal Capital Territory (FCT) of Nigeria. These sub-populations were the female sex workers (FSW) (both brothel-based and nonbrothel-based), men who have sex with men (MSM), injecting drug users (IDU), members of the Armed Forces, Police, and transport workers (TW).
Figure 2: Map of Nigeria showing states sampled during the IBBSS

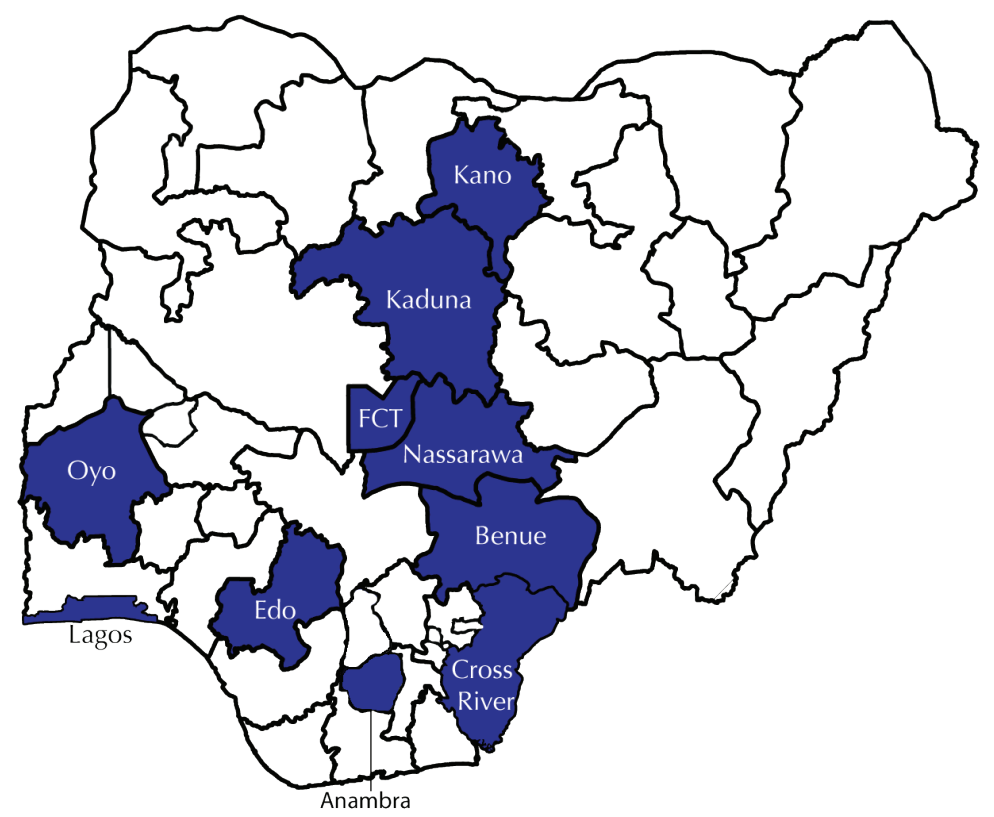

Table 1: Target groups and states

\begin{tabular}{|l|l|}
\hline Target Group & States \\
\hline Brothel-based FSW & Lagos, Kano, Kaduna, Benue, Nasarawa, Edo, Anambra, Cross River, FCT \\
\hline Non-Brothel based FSW & Lagos, Kano, Kaduna, Benue, Nasarawa, Edo, Anambra, Cross River, FCT \\
\hline MSM & Lagos, Kano, Cross River, Kaduna, FCT, Oyo \\
\hline IDU & Lagos, Kano, Cross River, Kaduna, FCT, Oyo \\
\hline Transport Workers & Lagos, Kano, Kaduna, Benue, Nasarawa, Edo, Anambra, Cross River, FCT \\
\hline Armed Forces & Lagos, Kano, Kaduna, Benue, Nasarawa, Edo, Anambra, Cross River, FCT \\
\hline Police & Lagos, Kano, Kaduna, Benue, Nasarawa, Edo, Anambra, Cross River, FCT \\
\hline
\end{tabular}

Note: The 2010 surveys among MSM and IDU were carried out in three states selected in 2007 (Lagos, Cross River and Kano) and three additional states, Kaduna, FCT, and Oyo (DFID/ENR-funded). 


\subsubsection{Target populations}

\subsubsection{Female sex workers (FSW)}

For the purpose of this survey, a FSW, both brothel and non-brothel-based was defined as any female 15 years and above who receives money or other valuable gifts/incentives in exchange for sex in areas such as brothels, bars, restaurants, night clubs, hotels, or on the street. FSW are considered to be at a higher risk of contracting and transmitting HIV because sex work involves a gender power imbalance in negotiating safe sex.

\subsubsection{Men who have sex with men (MSM)}

For the purpose of this survey, an MSM is defined as any male 18 years and above who has engaged in sexual activities with other men in the 12 months preceding the survey. This target group is considered to be at a higher risk of contracting and transmitting HIV because of the elevated biological risk of HIV transmission through unprotected anal sex, multiple partnerships, and the potential for riskier sexual behaviour due to the stigma and discrimination attached to male-to-male sex. More is now known about MSM in Nigeria since the 2007 IBBSS, so six states were chosen for inclusion of MSM in the 2010 survey, namely: Lagos, Kano, Cross River, FCT, Kaduna and Oyo.

\subsubsection{Injecting drug users (IDU)}

For the purpose of this survey, an IDU is defined as any person 18 years and above who has injected drugs recreationally at least once in the past 12 month. This group is considered at higher risk of contracting and spreading HIV primarily through the sharing of needles and syringes, as well as practicing unsafe sex. The number of states where IDU were interviewed was increased from three to six states in the 2010 survey, namely: Lagos, Kano, Cross River, FCT, Kaduna and Oyo.

\subsubsection{Armed Forces (Army, Navy \& Air force), the Police and Transport Workers (TW)}

These groups are considered to be at higher risk of contracting and transmitting HIV because of their job-related mobility which in many countries leads to increased patronage of commercial and casual sex partners. Police and the Armed Forces were eligible for inclusion in the study if they were based at barracks/stations in and around each state's urban centre, regardless of rank. With respect to TW, four categories of workers were identified: (i) long distance drivers/ assistants of heavy duty vehicles (e.g. trailers) that spend more than one day on the road before reaching their final destinations; (ii) inter-state commercial bus and taxi drivers who travel relatively long and medium distances, the majority of whom sleep in the destination towns and not along the routes; (iii) intra-state commercial bus and taxi drivers who operate within a city or between relatively short distances and return to their usual place of residence at the end of each day; and (iv) commercial motorcyclists who transport persons from one place to another within a city for a fee. In the 2010 survey, group iii was dropped from the survey, as they were found to have similar risk of HIV infection with the general population.

\subsection{Sample Size}

The sample size for each target population was calculated to detect differences of $15 \%$ in key behaviours such as consistency of condom use and commercial sex, and to provide reliable estimates for each variable at state-level. The table below shows the final sample sizes achieved in this study for each group and state. 
Table 2: Sample size achieved by study groups and states

\begin{tabular}{|l|c|c|c|c|c|c|c|c|}
\hline \multicolumn{1}{|c|}{ State } & BBSW & NBBSW & MSM & IDU & ARMED FORCES & POLICE & TW & \\
\hline Anambra & 249 & 250 & $*$ & $*$ & 300 & 220 & 312 & \\
\hline Benue & 251 & 247 & $*$ & $*$ & 300 & 207 & 309 & \\
\hline Crossriver & 237 & 250 & 313 & 273 & 300 & 219 & 312 & \\
\hline Edo & 255 & 181 & $*$ & $*$ & 304 & 220 & 313 & \\
\hline FCT & 249 & 249 & 199 & 271 & 300 & 219 & 312 & \\
\hline Kaduna & 250 & 253 & 286 & 262 & 301 & 220 & 312 & \\
\hline Kano & 249 & 267 & 299 & 269 & 297 & 218 & 306 & \\
\hline Lagos & 276 & 250 & 215 & 197 & 278 & 219 & 312 & \\
\hline Nassarawa & 249 & 247 & $*$ & $*$ & 301 & 215 & 312 & \\
\hline Oyo & $\Omega$ & $\Omega$ & 233 & 273 & $\Omega$ & $\Omega$ & $\Omega$ & \\
\hline Total & 2,265 & 2,194 & 1,545 & 1,545 & 2,681 & 2,800 & 1,957 & \\
\hline Grand Total & & & & & & & & 14,987 \\
\hline
\end{tabular}

* IDU and MSM were sampled only in 6 states

$\Omega$ MSM and IDU only were sampled in Oyo State

\subsection{Sampling Procedures}

In order to reach a representative sample of all groups involved in the 2010 IBBSS, a number of different sampling techniques were used depending on the group in question, including simple random sampling (SRS), cluster sampling (probability proportionate to size (PPS) for fixed populations), time-location sampling (TLS) ${ }^{6}$ and respondent-driven sampling (RDS) ${ }^{7}$. For MSM and IDU, the RDS method was used, while a TLS technique was used to select NBBFSW and TW. The BBFSW, Armed Forces, and Police were selected using a two-stage cluster sampling technique. The take all (TA) sampling method was used when the desired sample size was not attainable based on the results of target population mapping.

Table 3: Sampling procedures by study groups and states

\begin{tabular}{|l|c|c|c|c|c|c|c|}
\hline & BBSW & NBBSW & MSM & IDU & ARMED FORCES & POLICE & TW \\
\hline Anambra & PPS & TA & - & - & SRS & SRS & TLS \\
\hline Benue & PPS & TLS & - & - & SRS & SRS & TLS \\
\hline Cross River & TA & TA & RDS & RDS & SRS & SRS & TLS \\
\hline Edo & PPS & TA & RDS & RDS & SRS & SRS & TLS \\
\hline FCT & PPS & TLS & RDS & RDS & SRS & SRS & TLS \\
\hline Kaduna & PPS & TLS & RDS & RDS & SRS & SRS & TLS \\
\hline Kano & PPS & TLS & RDS & RDS & SRS & SRS & TLS \\
\hline Lagos & PPS & TLS & RDS & RDS & SRS & SRS & TLS \\
\hline Nassarawa & PPS & TLS & - & - & SRS & SRS & TLS \\
\hline Oyo & - & - & RDS & RDS & - & - & TLS \\
\hline
\end{tabular}

${ }^{6} \mathrm{TLS}$ is a form of cluster sampling that contains both time and location dimensions. TLS provides the opportunity to reach members of a target population who access certain locations at any point in time.

${ }^{7} \mathrm{RDS}$ is a method that combines "snowball sampling" with a mathematical model that weights the sample to compensate for the fact that the sample was collected in a non-random way. The RDS process starts with the recruitment of the initial seeds each of whom recruits a maximum of two to three members from their population group. 
The real challenges of the study pertained to locating and convincing eligible participants to participate given the often clandestine and socially unacceptable behaviours of some of the target groups (FSW, MSM, IDU), as well as the HIV test. These challenges were addressed by:

- Involving the target populations in the design and recruitment of study participants. A formative research was done among the MSM and IDU target groups before the data collection;

- Working with community leaders, authorities and NGOs to ensure that everyone was informed about the study and that data release is handled in such a manner as to minimize risk and stigma;

- Ensuring strict confidentiality of survey participants;

- Adequate training of field team in all of the survey process; and

- Thorough mapping of the various places where the target groups can be found before the survey. A list of sites where the population groups at higher risk of HIV infection were located and how and when they can be reached for information and services, and the essential distinguishing characteristics of these sites was prepared.

\subsubsection{Armed Forces and Police}

The Armed Forces respondents were selected using a two-stage cluster sampling procedure from the Armed Forces units in urban centres. Clusters were selected using PPS with a fixed number of Armed Forces participants recruited from each cluster. Where lists of personnel at each site could be obtained, simple random sampling was used. The Police respondents were stratified into males and females and $25 \%$ of the sample was female. For the Armed Forces, only males were sampled.

\subsubsection{FSW (Brothel-based)}

The brothel-based FSW were selected using a two-stage cluster sampling procedure (PPS). A team of mapping officers from the National Population Council (NPC) updated the list of brothels where FSW work based on the 2007 IBBSS. For each brothel listed, information was collected on the approximate number of FSW present to permit an estimate of cumulative measure of size. The information on measure of size was used to allocate the sample by PPS. Clusters were selected using PPS with a fixed number of FSW recruited from each cluster. The cluster size of the brothel-based FSW was five and 50 clusters were selected in each state where available. Individual participants were selected from the total number of FSW in the site. When the estimated number of brothel-based FSW in the state was less than the sample size of 250, a "take-all" approach was used in which all of the consenting FSW in the state's urban centre were recruited for the survey.

\subsubsection{FSW (Non-brothel-based)}

The non-brothel-based FSW were recruited using the TLS approach. The TLS is a form of cluster sampling that contains both time and location dimensions. Working through relevant NGOs and States AIDS Program Coordinators (SAPC) in different cities/towns, the list of streets, bars, night clubs and hotels where non-brothel-based FSW usually congregate was updated (including information on the time of the day when they congregate there and the estimated number at each four-hour time segment). TLS clusters were selected using PPS with a fixed number of FSW recruited from each cluster. The cluster size of the non-brothel-based FSW was five and 50 clusters were selected in each state in order to reach the sample size of 250 . When the estimated number of non-brothel-based FSW in the state was less than the sample 
size of 250, a "take-all" approach was used where all of the consenting FSW in the state's urban centre were recruited for the survey.

\subsubsection{MSM and IDU}

The respondent-driven sampling (RDS) method was adopted for the selection of MSM and IDU, because it offers several advantages for hard to reach populations, about whom little is known until the last round of the survey. RDS not only serves to achieve the desired sample size, it permits the identification of networks and characteristics within those networks. The RDS methodology starts with the recruitment of 'seeds' from the members of the target group, who then recruit other members of their personal networks who are also either MSM or IDU.

The seeds were identified by non-governmental organizations during the formative research. The number of seeds recruited varied from state to state across the two groups. An initial four to five seeds were recruited and the number was increased when it was discovered that some of the initial seeds were not recruiting efficiently. These seeds were the first MSM and IDU to be contacted and the objectives of the survey and expectations were explained to them. Once a seed completed all parts of the study (behavioural and biological), he was given three vouchers to recruit his peers into the study. Vouchers were numbered to include the identification number (serial number) of the original recruiter. The number of vouchers given to each recruiter was limited to three. This ensured a broad array of subjects had opportunity to recruit, to prevent the emergence of semi-professional recruiters, and to preclude turf battles over recruitment rights. A total of 1545 MSM and 1545 IDU were recruited for this study.

\subsubsection{Transport Workers (TW)}

The TLS procedure was also adopted among the male TW. TLS clusters were chosen using PPS, so the proportion of each different transport worker sub-type in the survey reflected the actual proportion in the TW population. In collaboration with the TW union and NGOs that have worked with TW, a list of major parks for each category of TW was compiled. For the long distance truckers, truck parking spots were identified along major routes. For other categories of TW, parks were identified in the major cities/towns of destination/operation. The list contained information on the high-and low-peak day and time-periods, and the estimated number of TW onsite during each period. TLS clusters were defined as the location where TW congregate, the day(s) of the week that constitute peak times, and the number of TW present at each four hour interval. TLS clusters were selected using PPS with a fixed number of transport workers recruited from each cluster. The cluster size of the transport workers was five and a total of 44 clusters were selected in each state in order to reach the sample size. Individual participants were selected from the total number of workers on the site on the day and specified time period through a simple randomization exercise. A total of 1957 TW were recruited for the study.

\subsection{Refusal for HIV test}

There were 14,987 individuals selected for this study out of which $10.7 \%$ refused to participate in biological components of the study. Non-brothel-based FSW had the highest refusal rate of $16.6 \%$, followed by MSM at $16.4 \%$, IDU at $14.8 \%$ and brothel-based FSW at $13.6 \%$. The Police, Armed Forces and TW had 7.1\%, 5.9\% and 3.6\% of HIV test refusal respectively. 


\subsection{Key Indicators in the IBBSS}

The following are a selection of key analysis variables selected as part of the survey data analysis plan to facilitate comparison with 2007 data:

- HIV prevalence

- Knowledge about HIV/STI (individual components and UNGASS knowledge indicator for most-at-risk populations)

- Self-reported STI symptoms

- Sex with non-marital partners by type

- Duration of sex work and injecting drug use

- Condom use at last sex in commercial sex

- Condom use at last sex with non-commercial partners by type

- Consistent condom use with commercial and non-commercial partners

- Sharing of injecting equipment among IDU

- Receiving HIV testing and results

- Condom use in anal sex among MSM by type of partner (commercial and noncommercial)

- Attitudes towards PLWHA

- Exposure to interventions

\subsection{Pilot Study}

A one-week pilot test was held in Ogun State, a non-IBBSS state prior to the main survey. This involved testing various parts of the survey process, including the study protocol, the methodology, training and data collection. Members of the TC, including FHI/GHAIN and the ENR team participated in the pilot study. A TC meeting was held to discuss improvements to the survey process, methodology and instrument based on the outcome of the pilot.

\subsection{Training of Personnel}

Two levels of training were implemented: a central training of trainers/supervisors (two sessions, North and South), followed by state-level trainings in each state where the survey was conducted. The valuable experience gained from the one-week pilot exercise was used to feed into the central-level training of supervisors. At this training, state teams were formed and all supervisors were taken through in-depth sessions on the survey objectives and methodology, enhancing their understanding of their roles in the survey, the survey process, and the need for good quality data. The supervisors used were experienced supervisors, many of whom had been involved in the past round of IBBSS. They spent one week in the central-level training in Lokoja, where members of the TC were able to observe and correct common mistakes and areas of weakness prior to teams' departure for their respective state-level training. At both central-and state-level trainings, each question in the questionnaire was reviewed and acted out in role-play, and possible challenges were identified and addressed. The four-day state-level training was conducted for the interviewers and counsellor/testers in each of the states prior to commencement of data collection. Three additional interviewers per state were invited to participate in the training as back-up and a screening process overseen by 
members of the TC ensured that only the most capable interviewers were selected for the main study. Some of the additional interviewers trained were also used as replacements as the need arose.

\subsection{Data Collection}

Data collection flow was consistent across target populations, and included the following steps:

- Interviewer introduced and explained the study to the participant;

- Interviewer obtained consent for behavioural component from the participant;

- Interviewer conducted the behavioural interview;

- Interviewer obtained consent for the biological component from the participant and accompanied participant to counsellor-tester;

- Counsellor-tester conducted pre-test counseling;

- Counsellor-tester obtained finger prick blood sample from the participant on a dried blot spot (DBS) paper, and labelled the sample with the participant's study ID;

- Counsellor-tester conducted a rapid test, and provided client with the results of their HIV tests (if desired);

- DBS samples with corresponding code numbers were then appropriately stored and later sent to the state lab scientist who collated and sent them to FHI office in Abuja;

- Counsellors provided the participants with post-test counseling when the results were provided.

The survey was administered for all target groups through one-on-one, face-to-face interviews in private settings that guaranteed the confidentiality of information provided by the respondent. The survey team for each group in each state consisted of three or four interviewers, one supervisor and two counsellor-testers. Witnessed consent was obtained by a counsellor or supervisor who acknowledged that all necessary information was provided and understood. Interviewers ensured that respondents were not interviewed twice by asking respondents if they were interviewed earlier on in the survey, and using a single team member for screening RDS participants.

Interviews and testing with brothel-based FSW were carried out at the selected brothels. Adequate preparations were made to ensure that each brothel was visited at the time determined during the pre-surveillance mapping exercise to be most suitable to conduct the interviews and testing. Shortly before data collection commenced, members of the survey team updated the data on the selected brothels, established rapport with the gatekeepers and confirmed the best time to conduct interviews. Similar advocacy was paid to gatekeepers of non-brothel-based FSW. Survey teams conducting interviews in street and bar locations and received security support from plain clothes Police as required.

Interviews and testing with the Armed Forces personnel were conducted in the selected units/ barracks. The survey team was guided by members of the Armed Forces Program on AIDS Control (AFPAC) serving on the TC, and following due consultation with the unit commanders. Interviewing and testing with Police was guided by members of the Police Action Committee on AIDS (PACA) serving on the TC, following due consultation with the officers in charge of each police station. The interviews and testing for TW were conducted in the selected timelocation sites (parks). The TW were first screened to prevent interview of one respondent more than once. This is because they are very mobile; the chances of appearing in two or more 
study locations during the period of the study are high.

The MSM and IDU respondents were interviewed and tested at a designated location agreed with key informants during the pre-assessment study. The seed participants recruited and referred additional participants to the study location. Each recruit was also asked to recruit and refer up to three other members of the group they know to the study location until the desired sample size was attained. Marked coupons were used by these respondents to recruit their peers.

\subsection{HIV Testing Procedures}

Rapid HIV testing was done on the field using recommended national parallel algorithm. Determine and Unigold were used first while Stat Pak was used as a tie breaker when there were discordant results from the two tests. The parallel algorithm was used because of the expected higher HIV prevalence (than general population) expected among the high-risk groups. The parallel tests ensured respondents were not pricked twice and assured higher degree of certainty of results given. Pre and post test counseling was conducted on the field and respondents who tested positive were referred for care and treatment while negative respondents were told to repeat test in the nearby VCT centre after 3 months. Dried Blood Spot (DBS) samples were taken simultaneously and stored at room temperature in Ziploc bags containing desiccants and paper indicator. DBS samples collected within a state were sent to the state laboratory scientist who ensures that the samples get to the central collecting site in Abuja. All samples were stored appropriately. The DBS samples will be tested with Elisa and the results reported in a seperate document.

Universal precautions were observed by all during handling of blood and blood products. Personal protective equipment (PPE) (laboratory coats, gloves and eye protectors) were provided for all laboratorians and counsellors handling specimens.

\subsection{Data Management and Analysis}

\subsubsection{Field Supervision}

Every field team had one supervisor. The supervisors reviewed each completed questionnaire immediately after the interview session ended and identified mistakes which were corrected before the respondent left the site. The completed questionnaires were also further reviewed by the State AIDS Program Coordinator and the TC members supervising the teams in each state. The TC provided guidance and oversight to supervisors where necessary. They also supervised the sampling techniques to ensure that the teams adhered to the sampling methods described for the different groups.

\subsubsection{Data Entry}

Data was entered using CS Pro version 3.2. A template for the questionnaire was designed with pre-programmed consistency checks for cross-checking answers, including skips and eligibility criteria. At least $25 \%$ of the questionnaires entered daily by each data entry clerk had the behavioural data re-entered, while $100 \%$ double-data entry was done for the biological data for quality control purposes. The data entry clerks were supervised by four supervisors who reviewed and validated all questionnaires entered.

Coupons used for the MSM and IDU groups were retrieved, the paper-based coupon managers were entered into excel spreadsheet. 


\subsubsection{Data Cleaning}

After data entry, the data was cleaned using STATA 10. Frequency counts were carried out to check consistency and assess cleanness of the data. The data cleaning also included the following:

- Searching for ages outside the age range criteria;

- Cross-checking all corresponding skips to the questionnaire;

- Reviewing the cluster allocations;

- Cross-checking the questionnaire completion responses from the interviewers in the database with the records in the supervisors log to ensure they matched;

- Consistency checks involving cross-checking answers to related questions.

- The coupon numbers and respondents ID were also crossed-checked from the coupons where the numbers did not correspond.

\subsubsection{Data Management and Coding}

Variables were recoded using standard recodes according to the indicators to be measured. Denominators were standardized and composite indicators created. A clean data set was used to generate the necessary tables in accordance with the pre-approved analysis plan.

\subsubsection{Data Analysis}

\subsubsection{STATA}

Data was analyzed using STATA 10. The data analysis focused on highlighting HIV risk factor prevalence at state-and national-levels. HIV prevalence were calculated as the percentages of the samples that were positive and $95 \%$ confidence intervals were determined.

\subsubsection{RDSAT}

RDS relies on peer recruitment; however, peer recruitment can lead to significant selection bias. Selection bias is a threat to the validity of the results obtained for various indicators, including HIV prevalence. For example, if HIV risk is much higher in those who have larger networks (e.g. MSM sex workers or gay-identified MSM) than those with smaller networks, then the un-weighted HIV prevalence is likely to be an overestimate. This is because those with larger networks have a greater probability of getting into the sample. Hence those with larger networks were likely oversampled. If the oversampled group (i.e., the group with larger networks) has a higher HIV prevalence, then the sample (un-weighted) HIV prevalence will be over-estimated. Additionally, with any peer recruitment, it is also likely that people tend to recruit others like themselves, and that some are more efficient at recruiting peers. This may happen with MSM sex workers, for example. This kind of recruitment behaviour may lead to over-sampling of certain sub-groups, leading to a biased sample.

Analysis in the RDSAT software was used for HIV prevalence of MSM and IDU where data was collected using the RDS. It adjusts for selection bias, recruitment patterns, and the differences in network size by reducing the over-representation of those with larger network sizes, in the sample. This ensures proper analytical adjustment of a non-probability sampling methodology.

\subsection{Ethical Issues}

Participation of all respondents in the survey was strictly voluntary. Measures were taken to ensure the respect, dignity and freedom of each individual participating in the study. In order to guarantee the anonymity of each participant, the names of respondents, their addresses 
or other identifying information were not included in the questionnaires or on any biomarker tracking forms. Stickers with numbered codes were used: on the questionnaire, on the DBS samples, on the test forms, and on the HCT referral forms. Informed consent was obtained from each participant. After witnessing verbal informed consent, the form was signed by the supervisor or counsellor. All respondents who tested for HIV were given pre and post-test counseling and results. Those testing positive were referred to a site offering HIV treatment services at no cost to the respondents. Those testing negative where advised as in national guideline to re-test every 3 months. The protocol, consent forms and draft questionnaires were approved by the Nigerian Institute for Medical Research's (NIMR) Institutional Review Board (IRB) in Nigeria and by Family Health International's (FHI) Protection of Human Subjects Committee.

\subsection{Study limitations}

The following are limitations of the study:

Reporting Bias: Similar to most behavioural surveys, the issue of under-reporting risk behaviours among participants of this study must be considered. Due to social stigma, some behaviour such as condom use, male to male sex, anal sex, drug injection, or needle sharing may be under-reported by respondents. For example, the percentage of condom use at last sex among FSW was over $90 \%$ in most states, higher than what was reported by male groups surveyed and this needs to be viewed with some caution, especially as condom use was much lower with regular partners. Many efforts were taken to limit this reporting bias in the 2011 IBBSS, including the anonymity of the surveys, conduct of interviews in private places, the capture of information using a special code rather than identifying information and respondents were encouraged to provide accurate responses before and during the interview.

Incomplete sampling frames: cluster samples were chosen at random based on sampling frames developed through the mapping process conducted by the National Population Commission. This process was to identify places where potential subjects could be reached and sampled. Field work for the mapping exercise was performed over three weeks by staff from the NPC with previous experience in conducting mapping from the 2005 BSS and 2007 IBBSS. It is thus possible that some hidden populations may not be adequately represented in the sampling frames.

Incomplete information needed to calculate national estimates for MSM and IDU: A population size estimate is needed to adequately determine national estimates of HIV prevalence of MSM and IDU recruited through the RDS methodology. It is hoped that the next survey will take this into consideration and apply suitable method for estimating the population estimates of IDU and MSM in each of the selected states. 


\section{RESULTS}

$\mathrm{T}$ his section presents the findings from the 2010 IBBSS by study groups. A total of 14,987 respondents consisting of brothel-based female sex workers (BBFSW), non-brothel-based female sex workers (NBBFSW), transport workers (TW), Men who have Sex with Men (MSM), Injecting Drug Users (IDU), Police and members of the Armed Forces were studied. Weighted data are presented at the national level for all groups except the MSM and IDU, while unweighted data is presented at the state level.

Results are presented in the following subsections: 3.1) characteristics of respondents; 3.2) HIV prevalence; 3.3) HIV awareness, knowledge and risk perception; 3.4) HIV/STI risk behaviours; 3.5) attitude towards PLWHA; 3.6) exposure to HIV prevention intervention.

In addition to the results presented below, detailed state level group characteristics and behavioural data can be found in the appendix.

\subsection{Characteristics of Respondents}

Table 4: Percentage distribution of all study groups by socio-demographic characteristics, IBBSS Nigeria 2010

\begin{tabular}{|c|c|c|c|c|c|c|c|}
\hline CHARACTERISTICS & BBFSW & NBBFSW & MSM & $\begin{array}{l}\text { ARMED } \\
\text { FORCES }\end{array}$ & POLICE & TW & IDU \\
\hline Total & 2,265 & 2,194 & 1,545 & 2,681 & 2,800 & 1,957 & 1,545 \\
\hline \multicolumn{8}{|l|}{ Age (years) } \\
\hline $15-19$ & 5.0 & 11.4 & 13.8 & 0.3 & 0.2 & 1.9 & 2.4 \\
\hline $20-24$ & 27.9 & 36.4 & 39.6 & 9.9 & 7.5 & 9.7 & 18.9 \\
\hline $25-49$ & 67.1 & 52.1 & 46.6 & 89.8 & 92.4 & 88.5 & 78.7 \\
\hline \multicolumn{8}{|l|}{ Sex } \\
\hline Male & 0.0 & 0.0 & 100.0 & 100.0 & 75.4 & 100.0 & 94.6 \\
\hline Female & 100.0 & 100.0 & 0.0 & 0 & 24.6 & 0.0 & 5.4 \\
\hline \multicolumn{8}{|l|}{ Marital status } \\
\hline Currently married & 3.3 & 2.9 & 8.9 & 70.2 & 69.2 & 67.1 & 24.0 \\
\hline Never married & 54.9 & 69.0 & 87.6 & 27.2 & 27.3 & 28.9 & 62.9 \\
\hline Others (separated/divorced/widowed) & 40.5 & 28.1 & 2.6 & 2.3 & 3.2 & 3.7 & 12.9 \\
\hline \multicolumn{8}{|l|}{ Level of education } \\
\hline No formal education & 5.7 & 3.0 & 0.7 & 0.1 & 0.0 & 1.8 & 1.0 \\
\hline Primary $^{*}$ & 23.8 & 11.5 & 9.6 & 3.3 & 5.6 & 34.2 & 18.0 \\
\hline Secondary & 65.6 & 69.5 & 63.8 & 59.3 & 70.4 & 55.1 & 57.9 \\
\hline Tertiary & 4.9 & 16.0 & 26.0 & 37.3 & 24.0 & 8.9 & 23.1 \\
\hline
\end{tabular}

${ }^{*}$ Includes those with Quranic education

Age: MSM had the highest percentage of respondents in the younger age groups compared to other groups, with $39.6 \%$ of them in the age group $20-24$ years and $13.8 \%$ below the age of 20 years. Almost half of the NBBFSW (47.8\%) were less than 25 years, while a third of the BBFSW were under 25 years. Among the NBBFSW 11.4\% were below the age of 20 years compared to $5 \%$ in the BBFSW. Among the Armed Forces, $89.8 \%$ were over the age of 25. This distribution is similar for the Police and TW among whom only $7.7 \%$ and $11.6 \%$ respectively were less than 25 years old. The IDU had a slightly younger age profile with $21.3 \%$ of them being less than 25 years of age.

Sex: Only two groups, Police and IDU, had representatives from both sexes. About a quar- 
ter (24.6\%) of the Police were females and only $5.4 \%$ of IDU were females.

Marital status: Few of the FSW were currently married, with almost similar proportions in both BBFSW and NBBFSW groups at 3.3\% and $2.9 \%$ respectively. Only $8.9 \%$ of MSM were currently married while $87.6 \%$ were neither married nor living with a sex partner. Among the male dominated occupational groups, $70.2 \%$ of the Armed Forces, $69.2 \%$ of the Police and $67.1 \%$ of TW were currently married. About a quarter $(24.0 \%)$ of the IDU were currently married.

Education: The Armed Forces had the highest proportion with tertiary education (37.3\%) followed by the MSM (26.0\%) and the Police (24.0\%). Only $4.9 \%$ of BBFSW had tertiary education.

Figure 3: Proportion of respondents away from home for at least 1 continuous month in the past 12 months preceding the survey, IBBSS Nigeria 2010

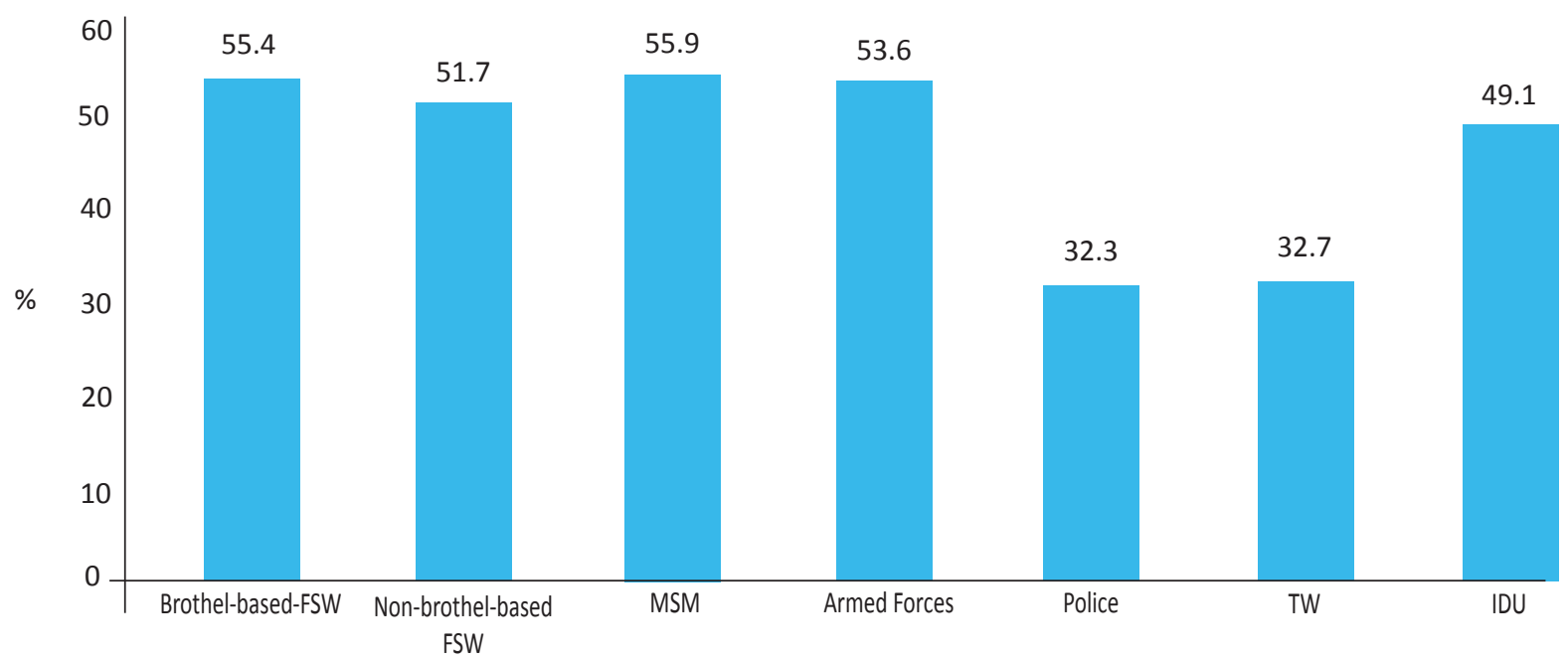

Mobility: The mobility status of respondents was assessed by asking whether they had been away from their home continuously for one month or more in the 12 months preceding the survey date. Increased mobility has been associated with risky sexual behaviour. Figure 3 above shows that all groups were highly mobile. Based on this measure of mobility, the least mobile groups were the Police and TW (32.3\% and 32.7\% respectively). Out of those surveyed, FSW, MSM and Armed Forces were the most likely to have spent a month or more away from home. There were state level differences (see appendix).

Figure 4: Frequency of alcohol consumption among study groups, IBBSS Nigeria, 2010

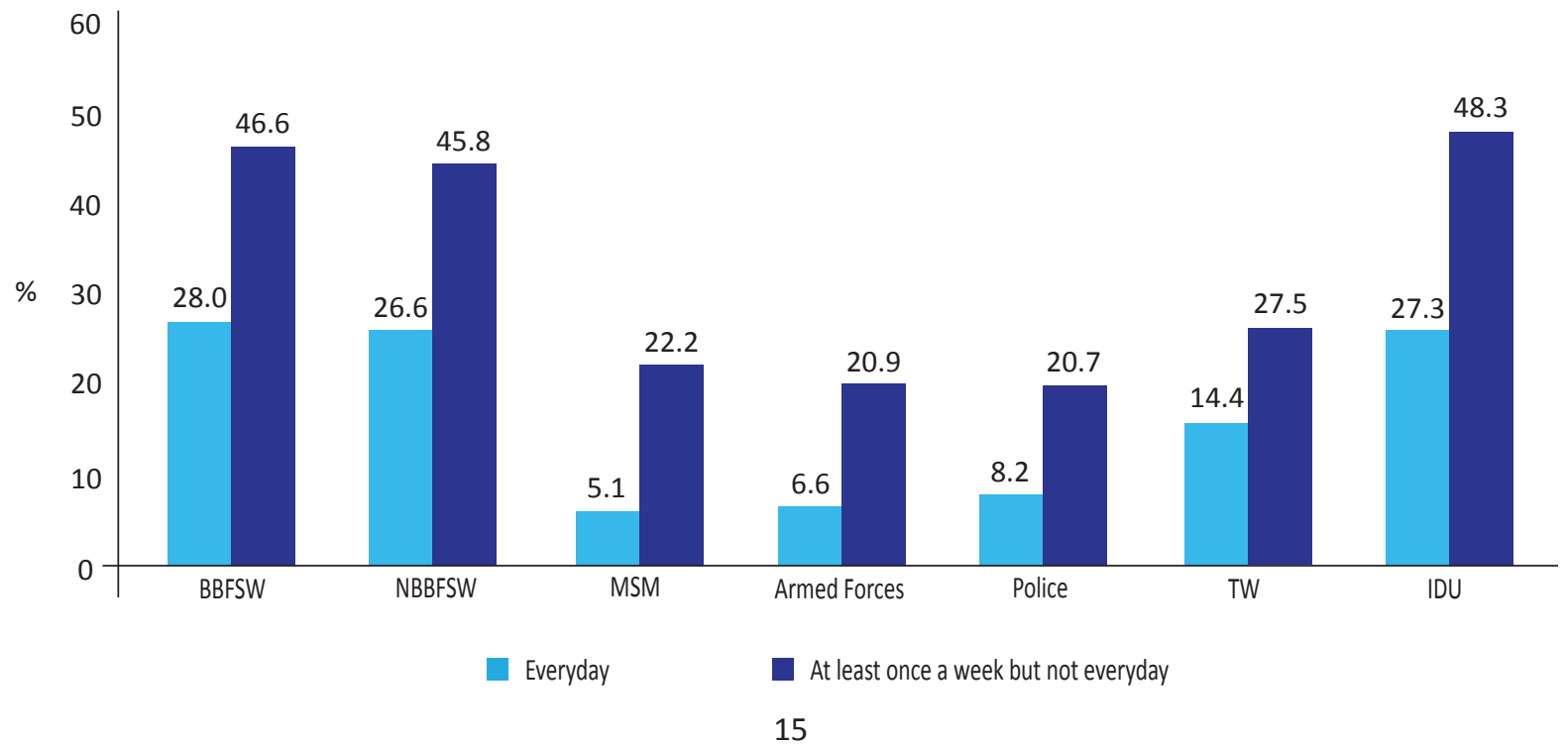


Use of Alcohol: Respondents were asked whether they consume alcohol and how frequently. The FSW and the IDU were more likely to consume alcohol everyday compared to the other study groups (Figure 4).

Figure 5: Drug use in the last four weeks among study groups, IBBSS Nigeria 2010

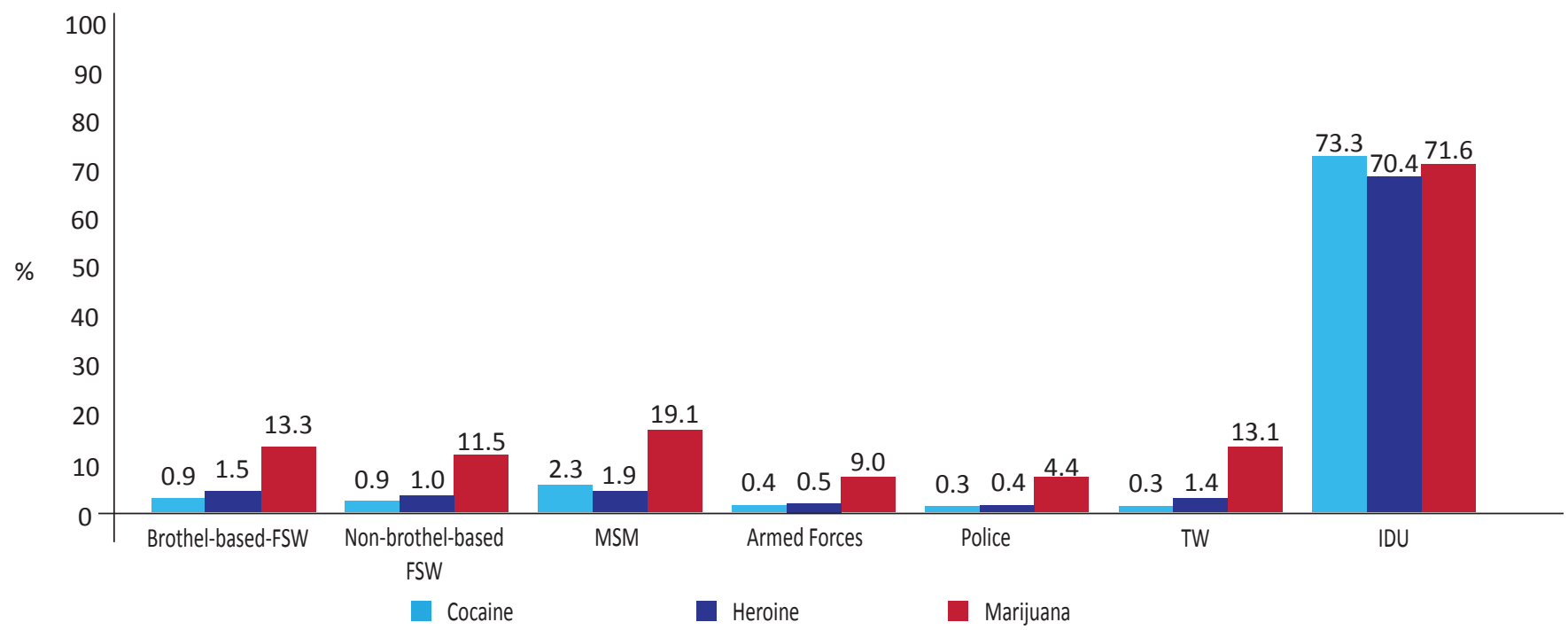

Drug and substance use: Respondents were asked what types of recreational drugs and other substances they had tried in the last four weeks prior to the survey. Figure 5 shows the percentage of respondents who reported use of cocaine, heroin or marijuana during this time period.

Drug use was very high among IDU. Majority of IDU reported using cocaine (73.3\%), as well as heroin $(70.4 \%)$ and marijuana (71.6\%) during the four weeks leading up to the survey. After IDU, MSM were the group with the next highest reported use of a variety of drugs, with $19.1 \%$, $2.3 \%$ and $1.9 \%$ consuming marijuana, cocaine and heroin respectively in the four weeks prior to the survey. A fair proportion of FSW, both brothel and non-brothel-based, reported using marijuana in the four weeks prior to the survey ( $13.3 \%$ and $11.5 \%$ respectively), and $1.0 \%$ had used heroin. Marijuana was also the main drug reportedly used by the predominantly male occupational groups in the four weeks prior to the survey $-13.1 \%$ of TW, 9.0\% Armed Forces personnel and $4.4 \%$ of Police. Apart from marijuana, $1.4 \%$ of TW reported use of heroin.

\subsection{HIV Prevalence among study groups}

\subsubsection{Overall HIV prevalence}

This section describes the pattern of HIV among the study groups. The understanding of the distribution of the HIV infection within the perceived high risk population and analysis of the social and behavioural factors associated with HIV infection can offer insights into subpopulations at higher risk among these high-risk groups. 


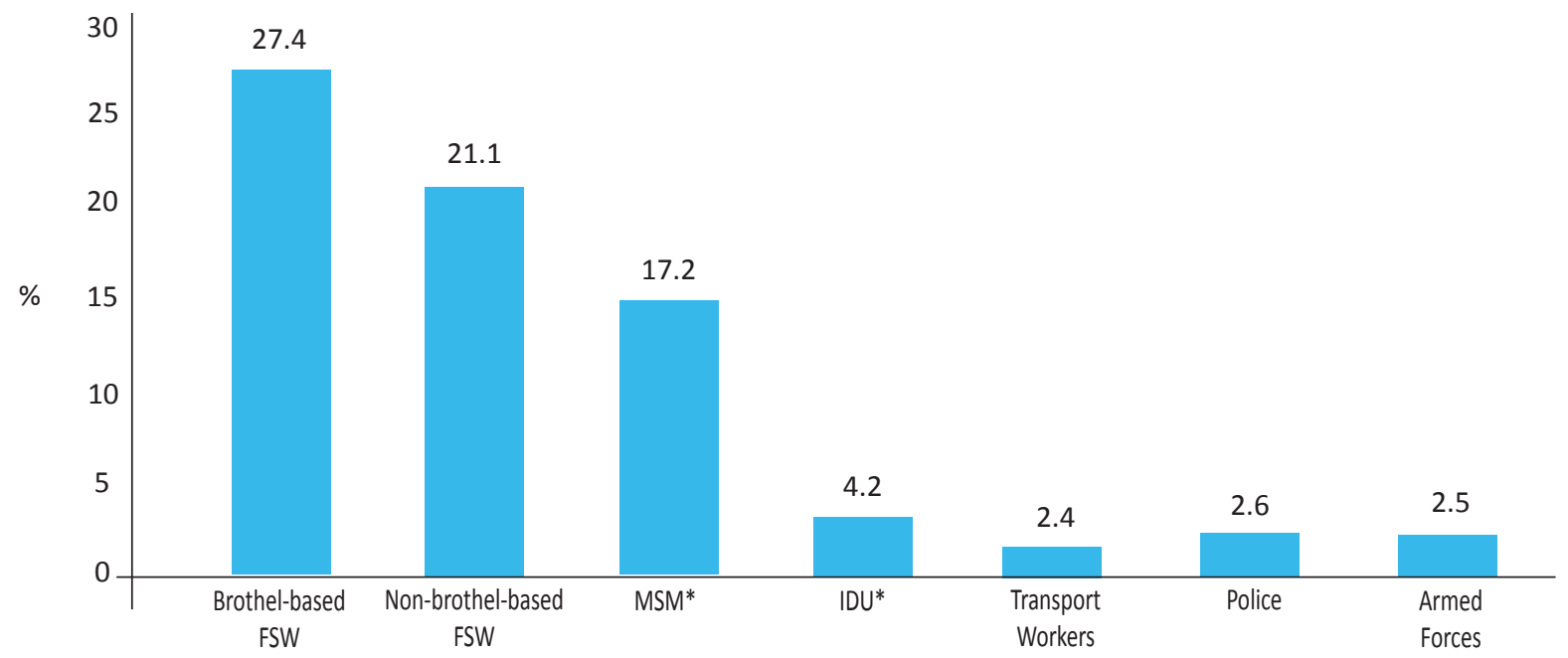

*Population size estimates of MSM and IDU in the sampled states, which are not available, are needed to calculate the weighted national estimates for these groups.

Figure 6 shows the weighted HIV prevalence for all the groups except the MSM and IDU where crude rates are reported. BBFSW and NBBFSW showed the highest HIV prevalence $27.4 \%$ and $21.1 \%$ respectively. The least prevalence was found among the TW (2.4\%).

\subsubsection{HIV prevalence by states}

Figures 7-13 show the state level HIV prevalence which includes RDSAT (weighted) analysis for MSM and IDU at state level. Benue, Nasarawa, Kano, FCT and Kaduna had higher burden of the HIV infection among the FSW compare to other states surveyed. MSM in FCT, Kaduna and Lagos also recorded high HIV prevalence. IDU in FCT, Kano, Kaduna and Oyo had higher prevalence than their counterparts in Lagos and Cross River. Transport workers and Armed Forces in Benue and Nasarawa States had high HIV prevalence compared to other states. However, the Police in Nasarawa, FCT and Kano recorded HIV prevalence higher than other states.

Figure 7: HIV prevalence among brothel-based FSW by state, IBBSS Nigeria 2010

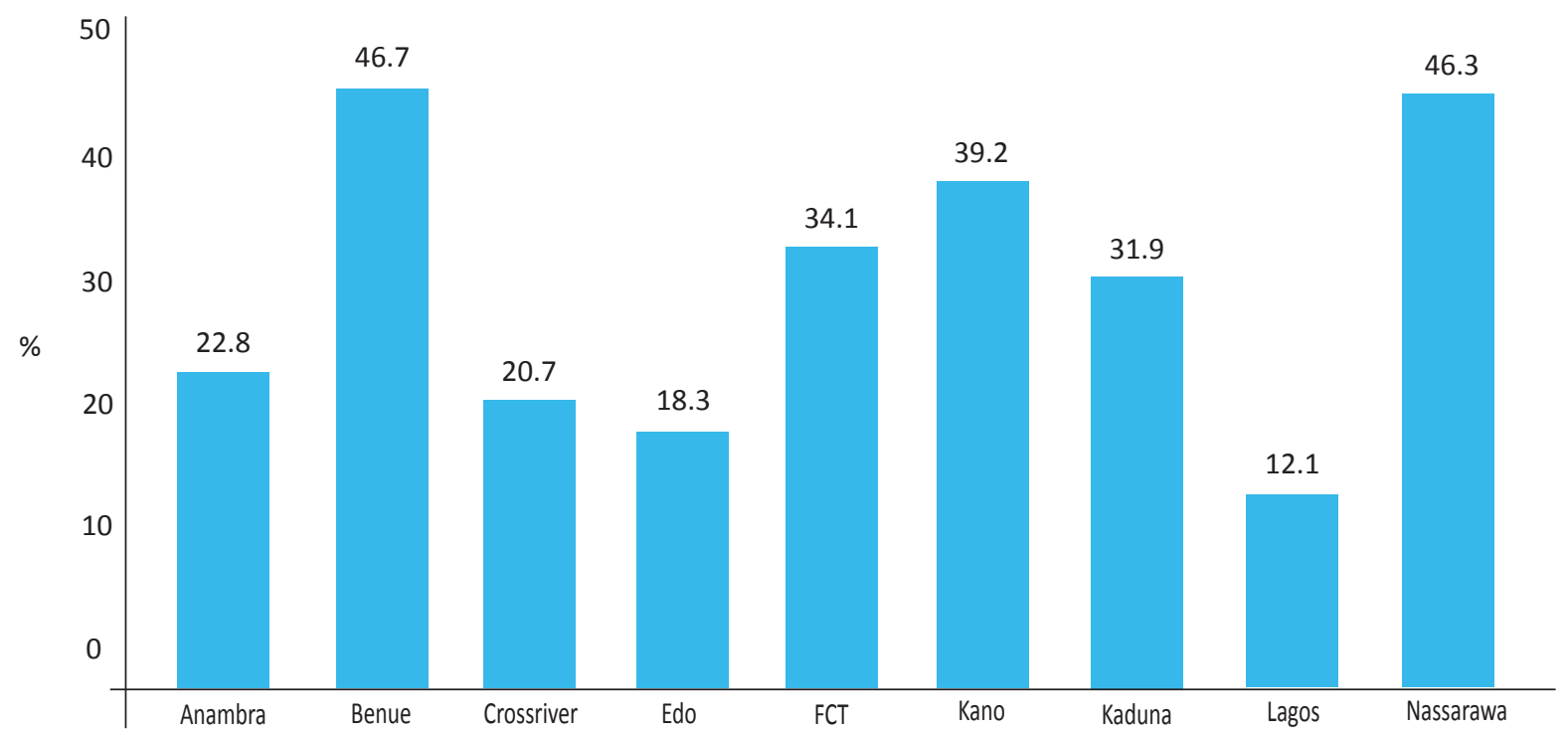


Figure 8: HIV prevalence among non-brothel-based FSW by state, IBBSS Nigeria 2010

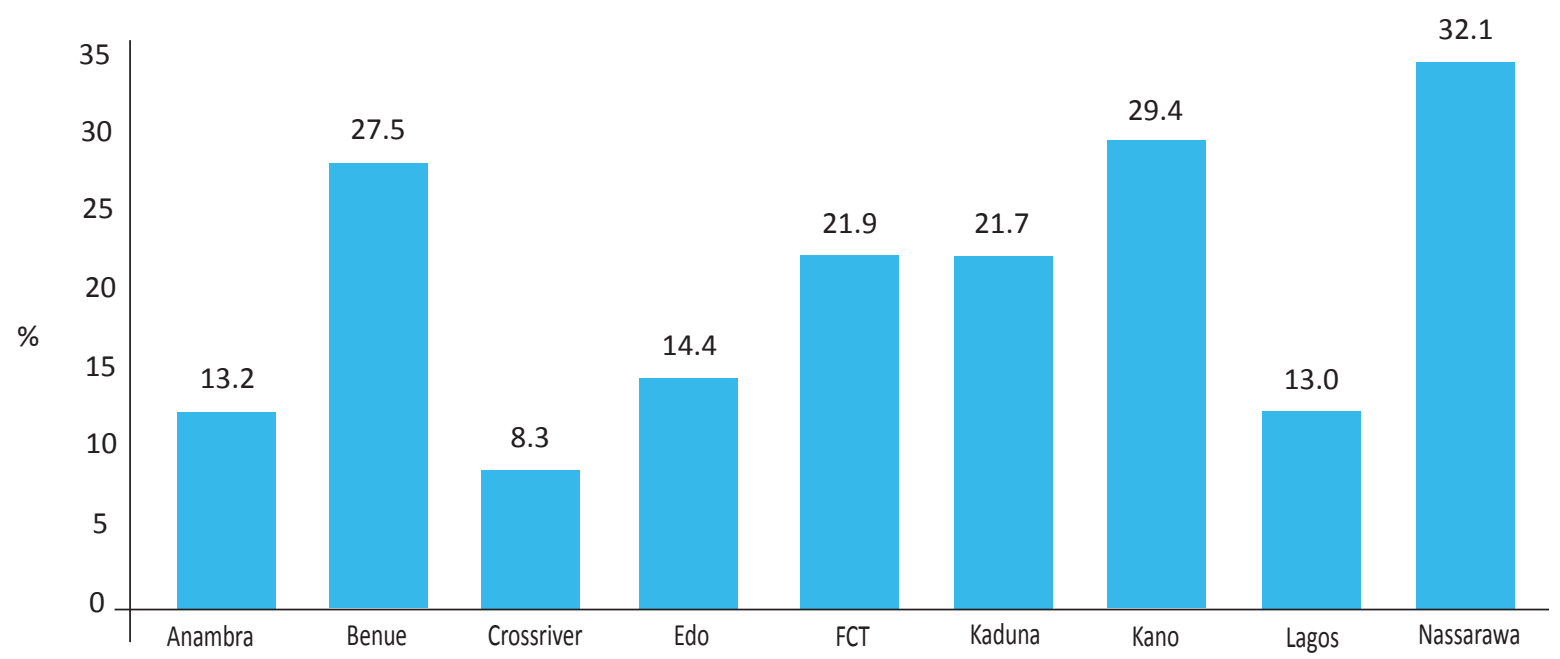

The highest prevalence of HIV among NBBFSW was in Nasarawa (32.1\%) and Kano (29.4\%).

Figure 9: HIV prevalence among MSM by state, IBBSS Nigeria 2010

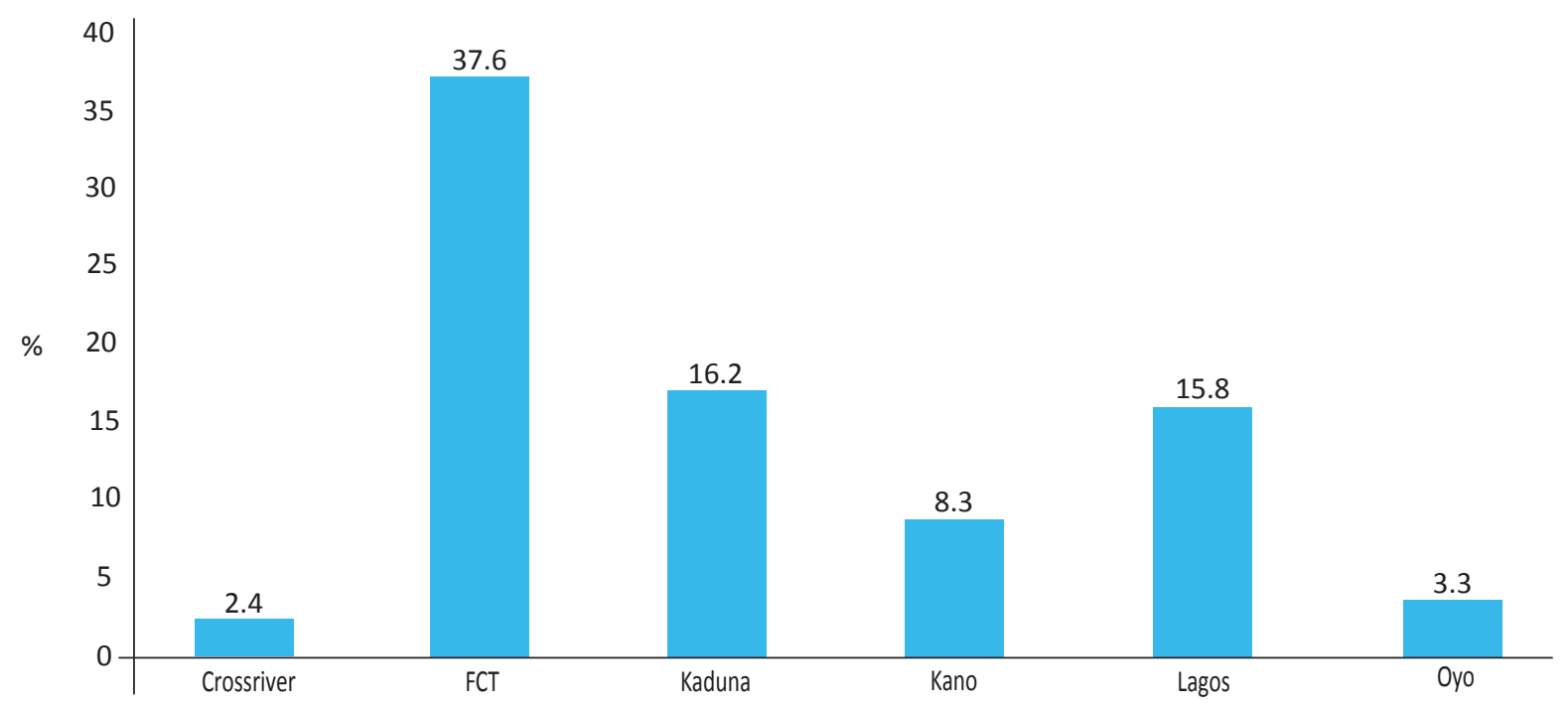

MSM in FCT had the highest HIV prevalence (37.6\%) followed by those in Kaduna (16.2\%).

Figure 10: HIV prevalence among IDU, IBBSS Nigeria 2010

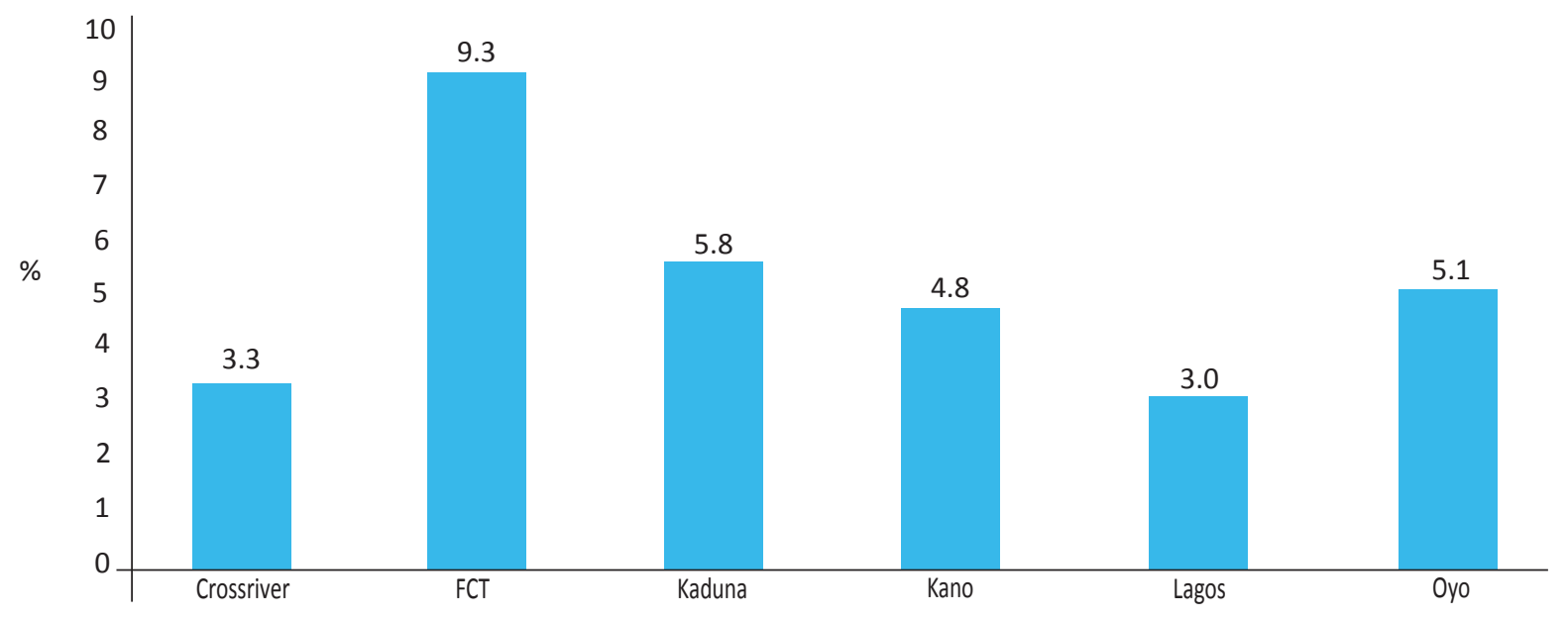


The highest HIV prevalence among IDU was found in FCT (9.3\%) and Kaduna (5.8\%) closely followed by Oyo (5.1\%).

Figure 11: HIV prevalence among Armed Forces, IBBSS Nigeria 2010

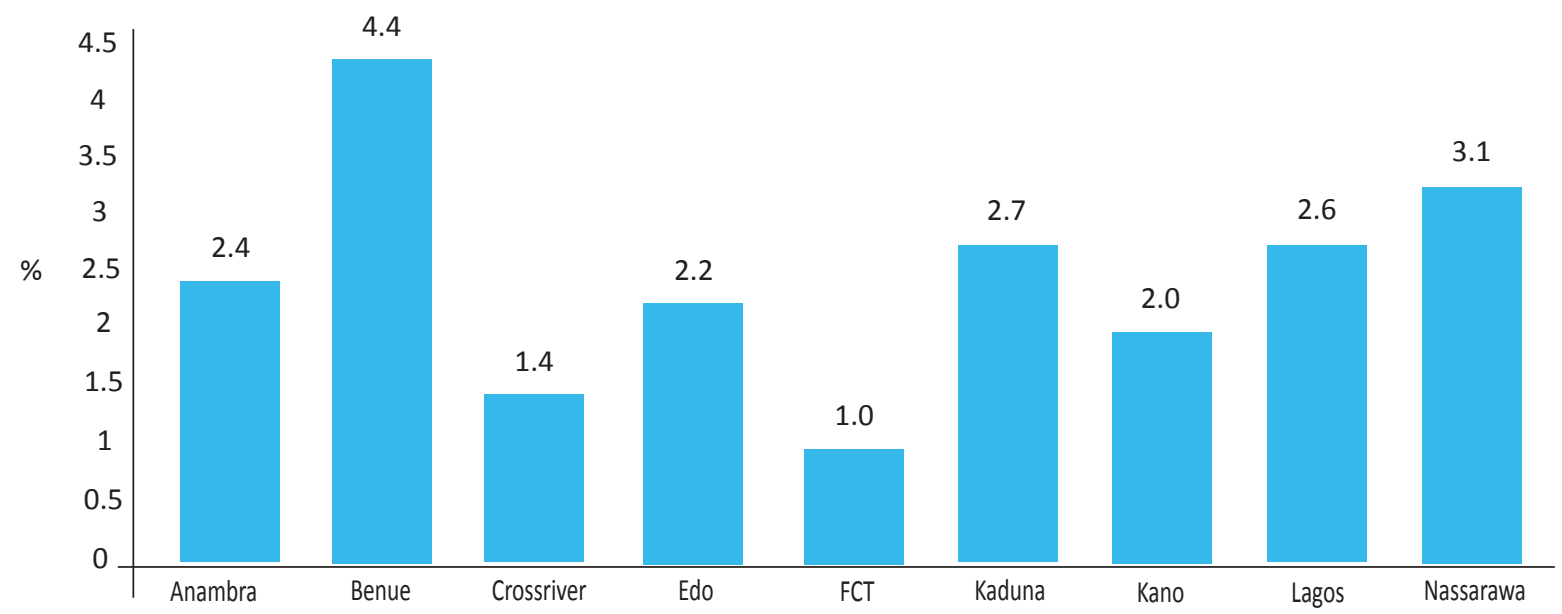

Armed Forces in Benue and Nasarawa (4.4\% and 3.1\% respectively) had the highest HIV prevalence among those surveyed.

Figure 12: HIV prevalence among Police, IBBSS Nigeria 2010

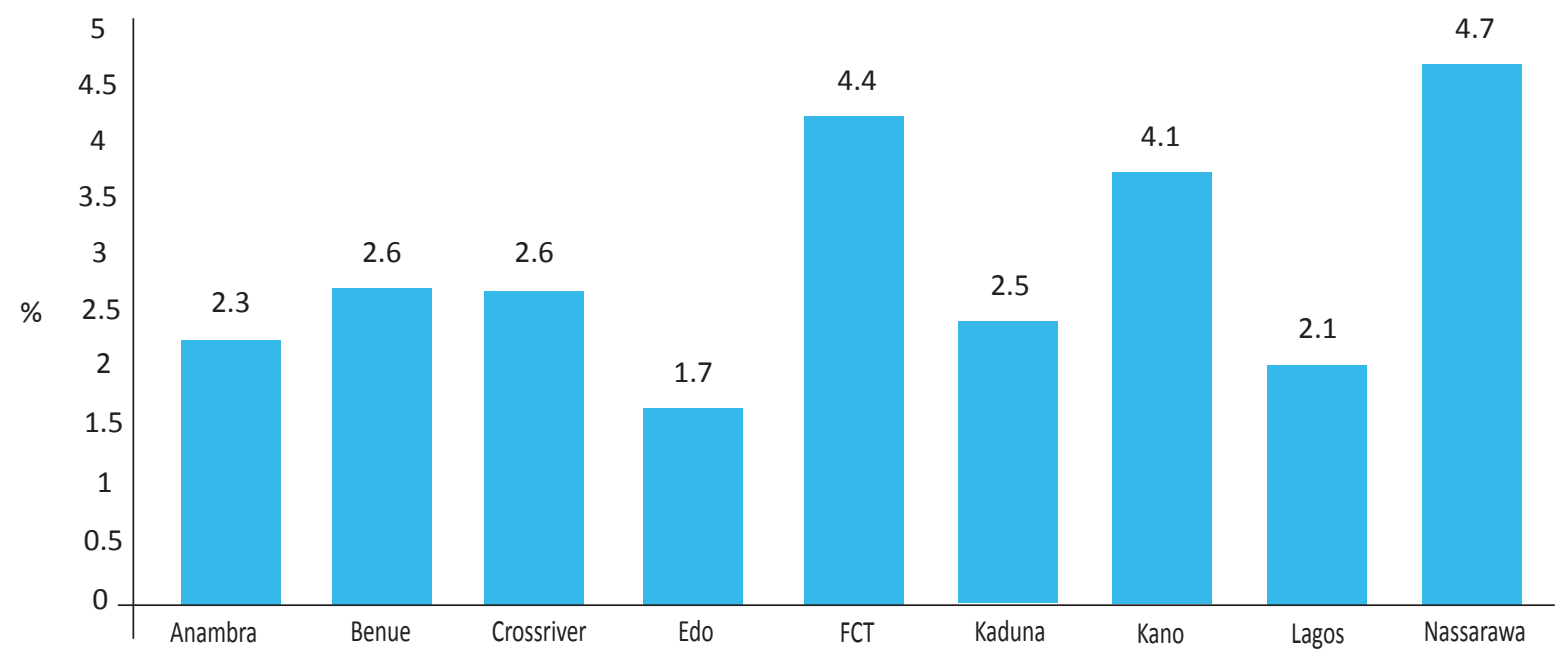

Highest HIV prevalence among the Police was found in Nasarawa, FCT and Kano States, 4.7\%, $4.4 \%$ and $4.1 \%$ respectively. 
Figure 13: HIV prevalence among transport workers, IBBSS Nigeria 2010

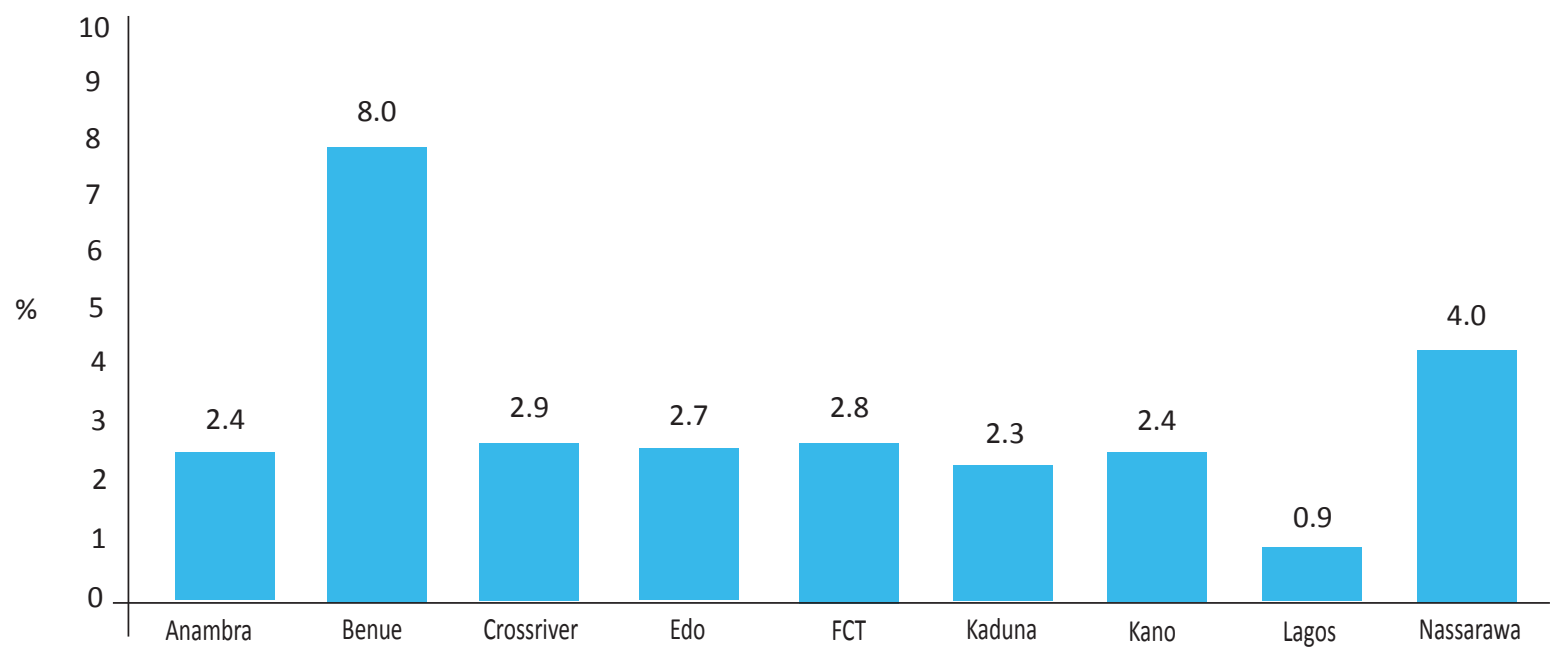

TW in Benue had higher HIV prevalence (8.0\%) compared to other states.

3.2.3 HIV prevalence by selected characteristics

3.2.3.1 HIV prevalence by socio-demographic factors

Table 5: HIV prevalence by selected socio-demographic characteristics among BBFSW and NBBFSW

\begin{tabular}{|c|c|c|c|}
\hline Characteristices & Prevalence & $\mathbf{n}$ & 95\% confidence interval \\
\hline \multicolumn{4}{|l|}{ BBFSW } \\
\hline $\begin{array}{l}\text { Age group (years) } \\
15-19 \\
20-24 \\
25-49\end{array}$ & $\begin{array}{l}24.3 \\
20.3 \\
30.8\end{array}$ & $\begin{array}{l}101 \\
552 \\
1295\end{array}$ & $\begin{array}{l}15.1-33.6 \\
16.7-24.0 \\
28.1-33.5\end{array}$ \\
\hline $\begin{array}{l}\text { Years in sex work } \\
\text { Less than a year } \\
1-2 \\
3-4 \\
5+\end{array}$ & $\begin{array}{l}29.6 \\
26.4 \\
23.7 \\
36.8\end{array}$ & $\begin{array}{l}458 \\
821 \\
369 \\
206\end{array}$ & $\begin{array}{l}25.2-34.1 \\
23.2-29.6 \\
19.1-28.4 \\
29.6-44.0\end{array}$ \\
\hline $\begin{array}{l}\text { Education } \\
\text { No formal education } \\
\text { Primary } \\
\text { Secondary } \\
\text { Tertiary }\end{array}$ & $\begin{array}{l}48.9 \\
35.2 \\
22.8 \\
29.1\end{array}$ & $\begin{array}{l}104 \\
460 \\
1291 \\
93\end{array}$ & $\begin{array}{l}38.4-59.4 \\
30.4-40.0 \\
20.3-25.2 \\
19.1-39.1\end{array}$ \\
\hline $\begin{array}{l}\text { Marital status } \\
\text { Currently married } \\
\text { Never married } \\
\text { Others }\end{array}$ & $\begin{array}{l}36.3 \\
20.4 \\
36.6\end{array}$ & $\begin{array}{l}64 \\
1067 \\
796\end{array}$ & $\begin{array}{l}23.3-49.3 \\
17.8-23.1 \\
33.0-40.1\end{array}$ \\
\hline \multicolumn{4}{|l|}{ NBBFSW } \\
\hline $\begin{array}{l}\text { Age group (years) } \\
15-19 \\
20-24 \\
25-49\end{array}$ & $\begin{array}{l}15.2 \\
18.0 \\
24.8 \\
\end{array}$ & $\begin{array}{l}220 \\
662 \\
937 \\
\end{array}$ & $\begin{array}{l}10.1-20.2 \\
15.0-21.1 \\
21.8-27.7\end{array}$ \\
\hline $\begin{array}{l}\text { Years in sex work } \\
\text { Less than a year } \\
1-2 \\
3-4 \\
5+\end{array}$ & $\begin{array}{l}18.8 \\
19.0 \\
22.6 \\
28.3\end{array}$ & $\begin{array}{l}333 \\
797 \\
300 \\
233\end{array}$ & $\begin{array}{l}14.4-23.2 \\
16.1-21.9 \\
17.4-27.7 \\
22.0-34.5\end{array}$ \\
\hline
\end{tabular}




\begin{tabular}{|l|l|l|l|}
\hline Education & & & \\
No formal education & 29.5 & 56 & $16.5-42.4$ \\
Primary & 34.2 & 209 & $27.4-41.0$ \\
Secondary & 19.8 & 1287 & $17.5-22.1$ \\
Tertiary & 15.1 & 267 & $10.5-19.8$ \\
\hline Marital status & & & \\
Currently married & 14.1 & 52 & $4.0-24.2$ \\
Never married & 18.4 & 1265 & $16.1-20.6$ \\
Others & 28.7 & 481 & $24.4-33.0$ \\
\hline
\end{tabular}

HIV prevalence was highest among respondents aged 25-49 among both BBFSW (30.8\%) and NBBFSW (24.8\%) groups. HIV prevalence increased with years of sex work among the NBBFSW whereas there was no definite pattern among the BBFSW. HIV prevalence was also highest among those with primary and no formal education compared to those with secondary and tertiary education. Those who were divorced or separated had highest HIV prevalence compared to those either never married or currently married.

Table 6: HIV prevalence by selected socio-demographic characteristics among MSM and IDU

\begin{tabular}{|c|c|c|c|}
\hline Characteristics & Prevalence & $\mathbf{n}$ & 95\% confidence interval \\
\hline \multicolumn{4}{|l|}{ MSM } \\
\hline $\begin{array}{l}\text { Age group (years) } \\
18-19 \\
20-24 \\
25-49\end{array}$ & $\begin{array}{l}12.0 \\
16.2 \\
20.0\end{array}$ & $\begin{array}{l}200 \\
537 \\
554\end{array}$ & $\begin{array}{l}7.5-16.5 \\
13.1-19.3 \\
16.7-23.3\end{array}$ \\
\hline $\begin{array}{l}\text { Education } \\
\text { No formal education } \\
\text { Primary } \\
\text { Secondary } \\
\text { Tertiary }\end{array}$ & $\begin{array}{l}* \\
15.1 \\
16.0 \\
20.9\end{array}$ & $\begin{array}{l}7 \\
126 \\
871 \\
287\end{array}$ & $\begin{array}{l}8.8-21.4 \\
13.6-18.4 \\
16.2-25.6\end{array}$ \\
\hline $\begin{array}{l}\text { Marital status } \\
\text { Currently married } \\
\text { Never married } \\
\text { Others }\end{array}$ & $\begin{array}{l}15.0 \\
17.5 \\
14.7\end{array}$ & \begin{tabular}{|l|}
100 \\
1146 \\
34
\end{tabular} & $\begin{array}{l}8.0-22.0 \\
15.3-19.7 \\
2.8-26.6\end{array}$ \\
\hline \multicolumn{4}{|l|}{ IDU } \\
\hline $\begin{array}{l}\text { Age group (years) } \\
18-19 \\
20-24 \\
25-49\end{array}$ & \begin{tabular}{|l}
0 \\
4.0 \\
4.3
\end{tabular} & \begin{tabular}{|l|}
25 \\
248 \\
1044
\end{tabular} & $\begin{array}{l}0 \\
1.6-6.4 \\
3.1-5.5\end{array}$ \\
\hline $\begin{array}{l}\text { Gender } \\
\text { Male } \\
\text { Female }\end{array}$ & \begin{tabular}{|l|}
3.1 \\
21.0
\end{tabular} & $\begin{array}{l}1236 \\
81\end{array}$ & $\begin{array}{l}2.1-4.1 \\
12.1-29.9\end{array}$ \\
\hline $\begin{array}{l}\text { Education } \\
\text { No formal education } \\
\text { Primary } \\
\text { Secondary } \\
\text { Tertiary }\end{array}$ & $\begin{array}{l}* \\
5.4 \\
3.9 \\
3.5\end{array}$ & \begin{tabular}{|l}
16 \\
258 \\
761 \\
282
\end{tabular} & $\begin{array}{l}2.6-8.2 \\
2.5-5.3 \\
1.4-5.6\end{array}$ \\
\hline $\begin{array}{l}\text { Marital status } \\
\text { Currently married } \\
\text { Never married } \\
\text { Others }\end{array}$ & $\begin{array}{l}3.3 \\
3.9 \\
6.9\end{array}$ & $\begin{array}{l}329 \\
811 \\
174\end{array}$ & $\begin{array}{l}1.4-5.2 \\
2.6-5.2 \\
3.1-10.7\end{array}$ \\
\hline
\end{tabular}

* Suppressed due to denominator less than 30 
HIV prevalence increased with increasing age among both MSM and IDU. The prevalence increased with increasing educational status among the MSM while the reverse is the case among the IDU. Female IDU had about 7 times higher HIV prevalence than in their male counterparts. MSM who had never married had the highest HIV prevalence $(17.5 \%)$ while IDU (6.9\%) who were either divorced or separated had the highest HIV prevalence.

Table 7: HIV prevalence by selected socio-demographic characteristics among Armed Forces, Police and transport workers

\begin{tabular}{|c|c|c|c|}
\hline Characteristics & Prevalence & $n$ & 95\% confidence interval \\
\hline \multicolumn{4}{|l|}{ ARMED FORCES } \\
\hline $\begin{array}{l}\text { Age group (years) } \\
18-19 \\
20-24 \\
25-49\end{array}$ & $\begin{array}{l}* \\
0.3 \\
2.6 \\
\end{array}$ & $\begin{array}{l}9 \\
252 \\
2262\end{array}$ & $\begin{array}{l}0.9-4.7 \\
1.7-3.5\end{array}$ \\
\hline $\begin{array}{l}\text { Rank } \\
\text { Junior } \\
\text { Senior }\end{array}$ & $\begin{array}{l}2.5 \\
2.1\end{array}$ & $\begin{array}{l}2357 \\
164\end{array}$ & $\begin{array}{l}1.7-3.4 \\
0.0-2.8\end{array}$ \\
\hline $\begin{array}{l}\text { Education } \\
\text { No formal education } \\
\text { Primary } \\
\text { Secondary } \\
\text { Tertiary }\end{array}$ & $\begin{array}{l}* \\
4.3 \\
2.7 \\
2.1 \\
\end{array}$ & $\begin{array}{l}2 \\
82 \\
1495 \\
944 \\
\end{array}$ & $\begin{array}{l}1.6-11.1 \\
1.5-3.9 \\
1.0-3.2 \\
\end{array}$ \\
\hline $\begin{array}{l}\text { Marital status } \\
\text { Currently married } \\
\text { Never married } \\
\text { Others } \\
\end{array}$ & $\begin{array}{l}2.7 \\
2.2 \\
1.8\end{array}$ & $\begin{array}{l}1761 \\
701 \\
55\end{array}$ & $\begin{array}{l}1.6-3.7 \\
0.6-3.8 \\
0.3-9.6 \\
\end{array}$ \\
\hline \multicolumn{4}{|l|}{ POLICE } \\
\hline $\begin{array}{l}\text { Age group (years) } \\
18-19 \\
20-24 \\
25-49 \\
\end{array}$ & $\begin{array}{l}* \\
0.9 \\
2.7 \\
\end{array}$ & $\begin{array}{l}4 \\
198 \\
2400 \\
\end{array}$ & $\begin{array}{l}0 \\
0.2-3.4 \\
1.7-3.6 \\
\end{array}$ \\
\hline $\begin{array}{l}\text { Gender } \\
\text { Male } \\
\text { Female }\end{array}$ & $\begin{array}{l}2.0 \\
4.5\end{array}$ & $\begin{array}{l}1968 \\
634\end{array}$ & $\begin{array}{l}1.1-3.0 \\
2.5-6.5\end{array}$ \\
\hline $\begin{array}{l}\text { Rank } \\
\text { Junior } \\
\text { Senior }\end{array}$ & $\begin{array}{l}2.7 \\
1.1 \\
\end{array}$ & $\begin{array}{l}2488 \\
102\end{array}$ & $\begin{array}{l}1.7-3.6 \\
0.2-5.5\end{array}$ \\
\hline $\begin{array}{l}\text { Education } \\
\text { No formal education } \\
\text { Primary } \\
\text { Secondary } \\
\text { Tertiary }\end{array}$ & $\begin{array}{l}* \\
2.0 \\
2.9 \\
1.8 \\
\end{array}$ & $\begin{array}{l}0 \\
146 \\
1825 \\
631 \\
\end{array}$ & $\begin{array}{l}0.7-5.8 \\
1.7-4.0 \\
0.4-3.2 \\
\end{array}$ \\
\hline $\begin{array}{l}\text { Marital status } \\
\text { Currently married } \\
\text { Never married } \\
\text { Others }\end{array}$ & $\begin{array}{l}2.4 \\
2.3 \\
10.0\end{array}$ & $\begin{array}{l}1802 \\
712 \\
80\end{array}$ & $\begin{array}{l}1.3-3.5 \\
1.4-3.3 \\
5.2-18.5\end{array}$ \\
\hline \multicolumn{4}{|l|}{ TRANSPORT WORKERS } \\
\hline $\begin{array}{l}\text { Age group (years) } \\
18-19 \\
20-24 \\
25-49 \\
\end{array}$ & $\begin{array}{l}0 \\
0 \\
2.6 \\
\end{array}$ & $\begin{array}{l}34 \\
180 \\
1673 \\
\end{array}$ & $\begin{array}{l}0 \\
0 \\
1.9-3.4\end{array}$ \\
\hline $\begin{array}{l}\text { Categories of TW } \\
\text { Long distance } \\
\text { Short distance }\end{array}$ & $\begin{array}{l}2.8 \\
2.2\end{array}$ & $\begin{array}{l}668 \\
1196\end{array}$ & $\begin{array}{l}1.6-4.0 \\
1.2-3.1\end{array}$ \\
\hline
\end{tabular}




\begin{tabular}{|l|l|l|l|}
\hline Education & & & \\
No formal education & 1.1 & 34 & $0.1-12.0$ \\
Primary & 1.9 & 637 & $0.9-2.9$ \\
Secondary & 2.9 & 1048 & $1.8-4.1$ \\
Tertiary & 1.4 & 168 & $0.1-2.7$ \\
\hline Marital status & & & \\
Currently married & 2.1 & 1271 & $1.3-3.0$ \\
Never married & 2.2 & 540 & $0.9-3.3$ \\
Others & 8.4 & 71 & $0.2-16.5$ \\
\hline
\end{tabular}

HIV prevalence in male predominant groups was highest among respondents between ages 25-49; 2.6\%, 2.7\% and 2.6\% in the Armed Forces, Police and TW respectively. Along educational line, the Police (2.9\%), TW (2.9\%) with secondary education and Armed Forces (4.3\%) with primary education had the highest HIV prevalence. Meanwhile, the widowed, separated or divorced had the highest prevalence in the Police (10.0\%) and TW (8.4\%) whilst those currently married in the Armed Forces had the highest prevalence. However, the prevalence was higher among females (4.5\%) compared with the males (2.0\%) within the police.

\subsubsection{HIV prevalence by selected risk factors}

This section presents results of HIV prevalence by selected risk factors and study groups. Selected risk factors include use of alcohol, knowledge of HIV prevention and sexual behaviour.

Table 8: HIV prevalence by selected risk factors for HIV among brothel and non brothel based FSW

\begin{tabular}{|c|c|c|c|c|}
\hline & Yes & & No & \\
\hline BBFSW & $\%(95 \% \mathrm{Cl})$ & n & $\%(95 \% \mathrm{Cl})$ & n \\
\hline Daily alcohol consumption & $24.0(20.2-27.8)$ & 541 & $28.7(26.2-31.3)$ & 1407 \\
\hline $\begin{array}{l}\text { Correctly identified ways of preventing } \\
\text { the sexual transmission of HIV and } \\
\text { reject major misconceptions about HIV } \\
\text { transmission }\end{array}$ & $21.6(18.1-25.1)$ & 604 & $30.1(27.5-32.8)$ & 1344 \\
\hline Perceives self at high risk of HIV infection & $27.0(23.8-30.2)$ & 811 & $27.6(24.8-30.5)$ & 1137 \\
\hline Had 5 or more clients last day of sex work & $27.6(24.1-31.1)$ & 763 & $27.3(24.6-29.9)$ & 1185 \\
\hline Use condom consistently with clients & $27.4(25.2-29.7)$ & 1777 & $26.7(19.7-33.7)$ & 171 \\
\hline $\begin{array}{l}\text { FSW who reported STI symptoms in past } \\
12 \text { months }\end{array}$ & $32.5(26.7-38.3)$ & 309 & $26.4(24.1-28.7)$ & 1639 \\
\hline \multicolumn{5}{|l|}{ NBBFSW } \\
\hline Daily alcohol consumption & $20.9(17.1-24.7)$ & 500 & $21.2(18.9-23.6)$ & 1319 \\
\hline $\begin{array}{l}\text { Correctly identified ways of preventing } \\
\text { the sexual transmission of HIV and } \\
\text { reject major misconceptions about HIV } \\
\text { transmission }\end{array}$ & $19.2(16.1-22.3)$ & 715 & $22.4(19.8-25.0)$ & 1104 \\
\hline Perceives self at high risk of HIV infection & $21.5(18.2-24.8)$ & 670 & $20.9(18.4-23.4)$ & 1149 \\
\hline Had 5 or more clients last day of sex work & $23.7(14.4-33.0)$ & 90 & $21.0(18.9-23.0)$ & 1729 \\
\hline Use condom consistently with clients & $21.5(19.2-23.8)$ & 1377 & $19.9(16.0-23.9)$ & 442 \\
\hline $\begin{array}{l}\text { FSW who reported STI symptoms in past } \\
12 \text { months }\end{array}$ & $24.0(19.8-28.1)$ & 442 & $20.2(17.9-22.5)$ & 1377 \\
\hline
\end{tabular}

Table 8 describes the pattern of HIV prevalence in relation to selected risk factors. Among the BBFSW, the prevalence among the respondents who could not correctly identify ways of preventing sexual transmission of HIV $(30.1 \%)$ was higher than those who could $(21.6 \%)$. Similarly the prevalence among BBFSW who reported STI symptoms in past 12 months $(32.5 \%)$ was higher than those who did not report symptoms during the same period $(26.4 \%)$. 
Table 9: HIV prevalence by selected risk factors for HIV among MSM and IDU

\begin{tabular}{|c|c|c|c|c|}
\hline & Yes & & No & \\
\hline MSM & $\%(95 \% \mathrm{Cl})$ & $\mathbf{n}$ & $\%(95 \% \mathrm{Cl})$ & $\mathbf{n}$ \\
\hline Daily alcohol consumption & $21.5(11.3-31.8)$ & 65 & $17.0(14.9-19.1)$ & 1226 \\
\hline Condom use last non marital sex & $17.0(13.0-21.2)$ & 317 & $17.0(14.9-19.6)$ & 974 \\
\hline $\begin{array}{l}\text { Correctly identified ways of preventing } \\
\text { the sexual transmission of HIV and } \\
\text { reject major misconceptions about HIV } \\
\text { transmission }\end{array}$ & $19.5(15.7-23.3)$ & 415 & $16.1(13.7-18.5)$ & 876 \\
\hline Perceives self at high risk of HIV infection & $24.1(18.8-29.4)$ & 249 & $15.5(13.3-17.8)$ & 1042 \\
\hline Has more than one non marital partner & $16.5(12.7-20.3)$ & 369 & $17.5(15.0-19.9)$ & 992 \\
\hline Had sex with FSW last 12 months & $15.6(9.7-21.5)$ & 147 & $17.4(15.2-19.6)$ & 1144 \\
\hline Was insertive male partners last 6 months & $14.7(12.4-17.0)$ & 924 & $23.4(19.1-27.8)$ & 367 \\
\hline Was receptive male partners last 6 months & $19.0(16.3-21.7)$ & 785 & $14.4(11.4-17.5)$ & 506 \\
\hline Sold sex to male partners last 6 months & $18.7(15.2-22.2)$ & 477 & $16.3(13.8-18.9)$ & 814 \\
\hline $\begin{array}{l}\text { Paid for anal sex with male partner last } 6 \\
\text { months }\end{array}$ & $16.0(11.8-20.3)$ & 287 & $17.5(15.2-19.9)$ & 1004 \\
\hline Used condom last anal sex & $17.3(14.2-20.3)$ & 602 & $17.1(14.3-19.9)$ & 689 \\
\hline Reported STI symptoms in past 12 months & $21.3(15.6-27.0)$ & 202 & $16.4(14.2-18.6)$ & 1089 \\
\hline \multicolumn{5}{|l|}{ IDU } \\
\hline Daily alcohol consumption & $4.0(1.9-6.0)$ & 353 & $4.3(3.0-5.5)$ & 964 \\
\hline Condom use last non marital sex & $5.6(3.7-7.6)$ & 549 & $3.1(1.9-4.4)$ & 768 \\
\hline $\begin{array}{l}\text { Correctly identified ways of preventing } \\
\text { the sexual transmission of HIV and } \\
\text { reject major misconceptions about HIV } \\
\text { transmission }\end{array}$ & $4.2(2.2-6.2)$ & 403 & $4.2(2.9-5.5)$ & 914 \\
\hline Perceives self at high risk of HIV infection & $6.8(3.9-9.7)$ & 295 & $3.4(2.3-4.5)$ & 1022 \\
\hline Has more than one non marital partner & $4.5(3.0-6.0)$ & 695 & $3.9(2.3-5.4)$ & 622 \\
\hline Had sex with FSW last 12 months & $4.5(2.5-6.5)$ & 397 & $4.0(2.7-5.3)$ & 920 \\
\hline Started injecting age less than 20 years & $3.4(1.2-5.6)$ & 263 & $4.4(3.1-5.6)$ & 1054 \\
\hline Has been injecting for 3 or more years & $3.9(2.6-5.2)$ & 848 & $4.7(2.8-6.6)$ & 469 \\
\hline $\begin{array}{l}\text { Injected more than once in the past } \\
\text { month }\end{array}$ & $4.0(2.5-5.5)$ & 671 & $4.3(2.8-5.9)$ & 646 \\
\hline $\begin{array}{l}\text { Injected with needle used by someone } \\
\text { else in past month }\end{array}$ & $1.5(0.4-5.3)$ & 135 & $4.5(3.3-5.7)$ & 1182 \\
\hline Reported STI symptoms in past 12 months & $6.4(3.2-9.6)$ & 234 & $3.7(2.6-4.8)$ & 1083 \\
\hline
\end{tabular}

Among the IDU, there was no apparent difference in HIV prevalence between the two groups of respondent for all selected risk factors. MSM (24.1\%) and IDU (6.8\%) who perceived themselves at risk of HIV had higher prevalence compared to those who did not, $15.5 \%$ and $3.4 \%$ respectively. 
Table 10: HIV prevalence by selected risk factors for HIV among Armed Forces, Police and transport workers

\begin{tabular}{|c|c|c|c|c|}
\hline & Yes & & No & \\
\hline ARMED FORCES & $\%(95 \% \mathrm{Cl})$ & $n$ & $\%(95 \% \mathrm{Cl})$ & $n$ \\
\hline Daily alcohol consumption & $1.5(0.5-4.7)$ & 169 & $2.6(1.7-3.5)$ & 2354 \\
\hline Condom use last non marital sex & $2.6(0.9-4.4)$ & 838 & $2.5(1.5-3.4)$ & 1685 \\
\hline $\begin{array}{l}\text { Correctly identified ways of preventing } \\
\text { the sexual transmission of HIV and } \\
\text { reject major misconceptions about HIV } \\
\text { transmission }\end{array}$ & $2.4(1.3-3.4)$ & 1459 & $2.7(1.7-4.2)$ & 1064 \\
\hline Perceives self at high risk of HIV infection & $4.4(1.8-7.1)$ & 548 & $2.0(1.2-2.8)$ & 1975 \\
\hline Has more than one non marital partner & $2.6(0.8-4.4)$ & 612 & $2.5(1.5-3.4)$ & 1911 \\
\hline $\begin{array}{l}\text { Had sex with commercial partner last } 12 \\
\text { months }\end{array}$ & $5.2(2.6-10.2)$ & 142 & $2.4(1.5-3.2)$ & 2381 \\
\hline Had STI symptoms in the last 12 months & $7.1(3.6-13.4)$ & 113 & $2.3(1.5-3.2)$ & 2410 \\
\hline \multicolumn{5}{|l|}{ POLICE } \\
\hline Daily alcohol consumption & $1.4(0.3-2.6)$ & 216 & $2.7(1.7-3.7)$ & 2386 \\
\hline Condom use last non marital sex & $1.7(0.8-2.6)$ & 638 & $2.8(1.7-3.9)$ & 1964 \\
\hline $\begin{array}{l}\text { Correctly identified ways of preventing } \\
\text { the sexual transmission of HIV and } \\
\text { reject major misconceptions about HIV } \\
\text { transmission }\end{array}$ & $2.6(1.2-4.1)$ & 1083 & $2.5(1.4-3.7)$ & 1519 \\
\hline Perceives self at high risk of HIV infection & $2.8(1.0-4.6)$ & 557 & $2.5(1.5-3.5)$ & 2045 \\
\hline Has more than one non marital partner & $2.4(1.2-3.6)$ & 501 & $2.6(1.6-3.6)$ & 2101 \\
\hline $\begin{array}{l}\text { Had sex with commercial partner last } 12 \\
\text { months }\end{array}$ & $0.8(0.1-5.2)$ & 98 & $2.7(1.7-3.6)$ & 2504 \\
\hline Had STI symptoms in the last 12 months & $3.8(1.8-5.8)$ & 217 & $2.4(1.5-3.4)$ & 2385 \\
\hline \multicolumn{5}{|l|}{ TRANSPORT WORKERS } \\
\hline Daily alcohol consumption & $3.3(1.4-5.2)$ & 273 & $2.2(1.5-3.0)$ & 1614 \\
\hline Condom use last non marital sex & $2.5(1.0-4.0)$ & 416 & $2.4(1.5-3.2)$ & 1471 \\
\hline $\begin{array}{l}\text { Correctly identified ways of preventing } \\
\text { the sexual transmission of HIV and } \\
\text { reject major misconceptions about HIV } \\
\text { transmission }\end{array}$ & $2.3(1.1-3.6)$ & 560 & $2.4(1.6-3.3)$ & 1327 \\
\hline Perceives self at high risk of HIV infection & $2.3(0.9-3.7)$ & 378 & $2.4(1.6-3.2)$ & 1509 \\
\hline Has more than one non marital partner & $2.7(1.2-4.2)$ & 426 & $2.3(1.5-3.1)$ & 1461 \\
\hline $\begin{array}{l}\text { Had sex with commercial partner last } 12 \\
\text { months }\end{array}$ & $5.3(1.6-9.0)$ & 162 & $2.2(1.4-2.9)$ & 1725 \\
\hline Had STI symptoms in the last 12 months & $5.0(7.6-9.2)$ & 161 & $2.1(1.5-2.7)$ & 1726 \\
\hline
\end{tabular}

Among the police, there was no apparent difference in HIV prevalence among the two groups of respondents for all the selected risk factors. However among the Armed Force and TW, HIV prevalence was found to be higher only among those who had STI symptoms in the last 12 months, $7.1 \%$ and $5.0 \%$ respectively; and among those who had sex with commercial sex partner in the last 12 months, $5.2 \%$ and $5.3 \%$ respectively. 


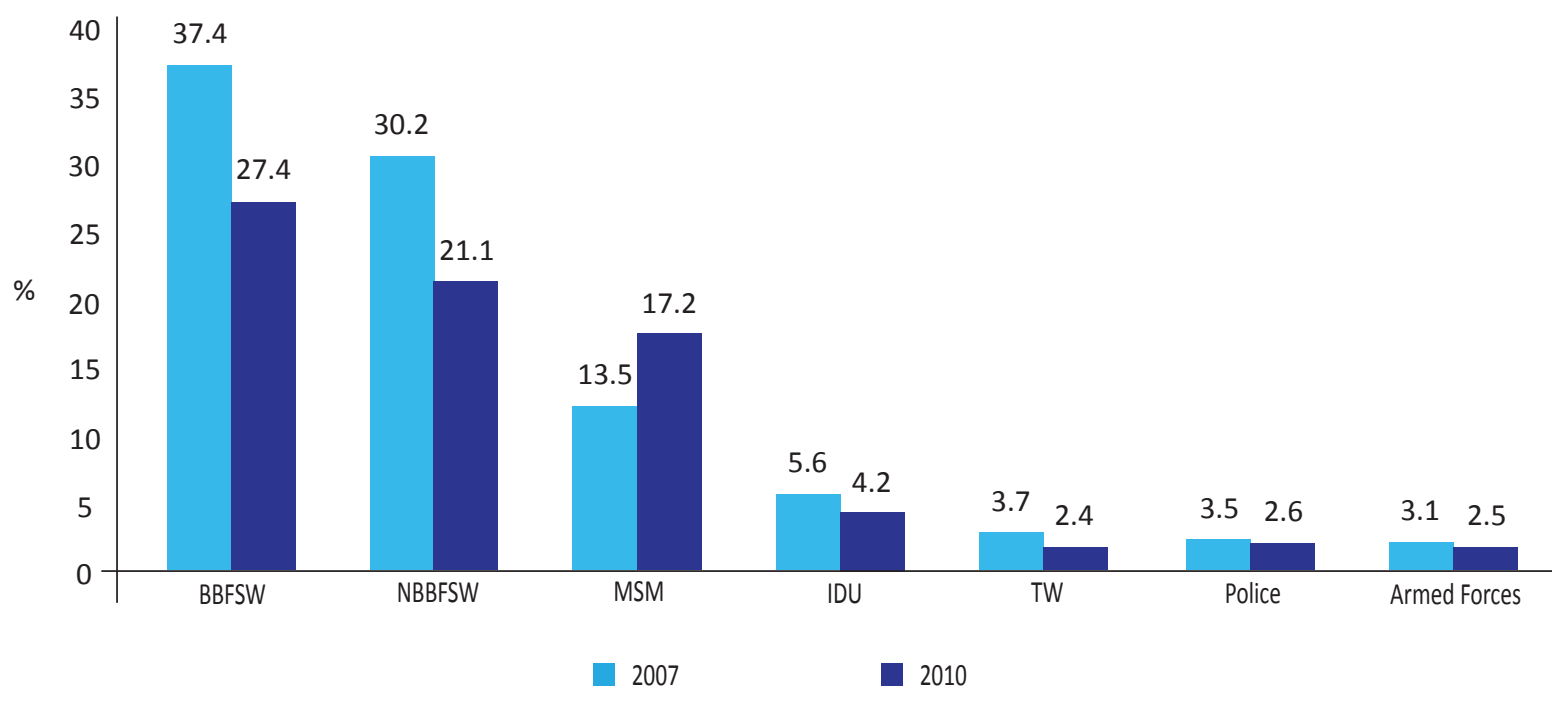

\subsubsection{Discussion}

The brothel-based FSW, non-brothel based FSW and the MSM continued to bear the burden of HIV infection in that order (Figure 4). The HIV prevalence among the male dominated occupational groups such as the Police, Armed Forces and Transport workers is lower than the $4.1 \%$ prevalence reported among women attending ANC (FMOH ANC 2010). The national prevalence of HIV among IDU was $4.2 \%$, which is similar to the HIV prevalence among women attending antenatal clinics.

HIV prevalence among BBFSW, NBBFSW and TW were higher in states such as Nasarawa and Benue with almost half of BBFSW HIV positive. The high HIV prevalence recorded among study groups in these states may be a reflection of the high prevalence in those states, $7.5 \%$ and $12.2 \%$ respectively (FMOH, ANC 2010). HIV prevalence among MSM in the FCT, Kaduna and Lagos was also high at $37.6 \%, 16.2 \%$ and $15.8 \%$ respectively.

Prevalence among BBFSW was highest among those aged 25-49, but among young sex workers (15-19), prevalence was still as high as $24.3 \%$ suggesting that it is likely sex workers get infected early in sex work. The prevalence among sex workers who reported having been in sex work for less than a year was also high (29.6\%). Similar findings are seen among NBBFSW. In contrast, older MSM and IDU are more likely to be infected. Female IDU were also more likely to be HIV infected.

Among the male dominated occupational groups, the pattern shows no particular sociodemographic direction, except in the case of transport workers where long distance transport drivers were more likely to be infected.

The pattern of infection reported in this survey is similar to the 2007 IBBSS findings. 


\subsection{Awareness, Knowledge and Risk Perception of HIV and AIDS}

This section reports awareness of HIV and AIDS, knowledge of HIV transmission and misconceptions about transmission. It also seeks to know respondents' personal assessment of their risk of contracting HIV.

\subsubsection{HIV awareness and knowledge of HIV prevention methods}

Figure 15: Knowledge of selected HIV prevention methods by group, IBBSS Nigeria 2010

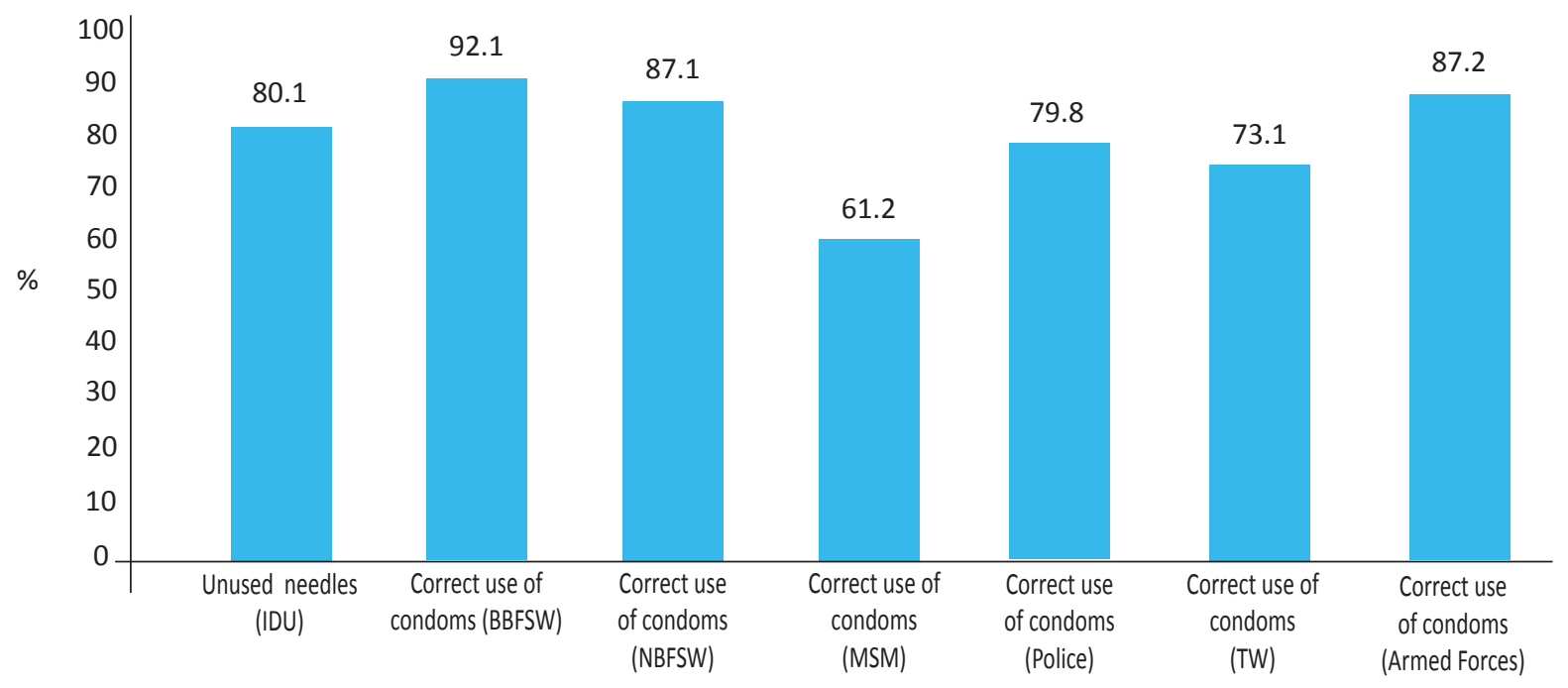

Figure 15 illustrates that knowledge of correct and consistent use of condoms as a means of preventing HIV was fairly high among all groups at risk of sexual transmission, with the exception of MSM. About $80.1 \%$ of IDU knew the importance of not using needles used by someone else for preventing HIV.

3.3.2 Accurate knowledge of prevention of sexual transmission of HIV transmission and rejection of major misconceptions (UNGASS indicator)

Each group was assessed in relation to the UNGASS indicator 14 for most-at-risk populations which requires a respondent had to answer "Yes" to the following questions:

- Can having sex with only one faithful, uninfected partner reduce the risk of HIV transmission?

- Can using condoms reduce the risk of HIV transmission?

- Can a healthy-looking person have HIV?

And answer "No" to the following misconceptions:

- Can a person get HIV from mosquito bites?

- Can a person get HIV by sharing a meal with someone who is infected?

The results are presented in Figure 16 below. State level analysis of each group are presented in the appendix. 
Figure 16: Percentage of study groups who both correctly identify ways of preventing the sexual transmission of HIV and who reject major misconceptions about HIV transmission, IBBSS Nigeria 2010

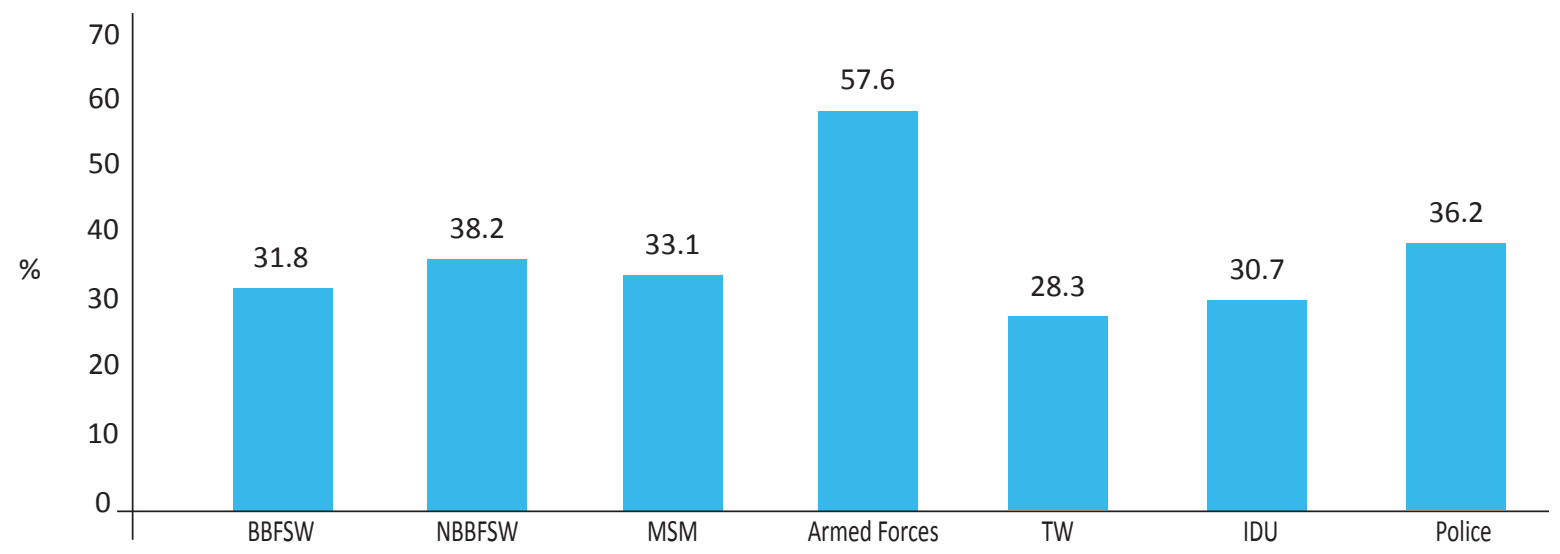

Correct knowledge of prevention of sexual transmission of HIV and rejection of major misconceptions are generally low among all the study groups. The Armed Forces had the highest (57.6\%) knowledge while the TW had the least (28.3\%)(Figure 16).

Further exploration of misconceptions are shown in Figures 17 and 18. However, it was noted that the misconception on possibility of transmission of HIV through sharing of toilet with PLWHA is high (Figure 19).

Figure 17: Proportion of study groups who believe HIV can be transmitted through mosquito bite, IBBSS Nigeria 2010

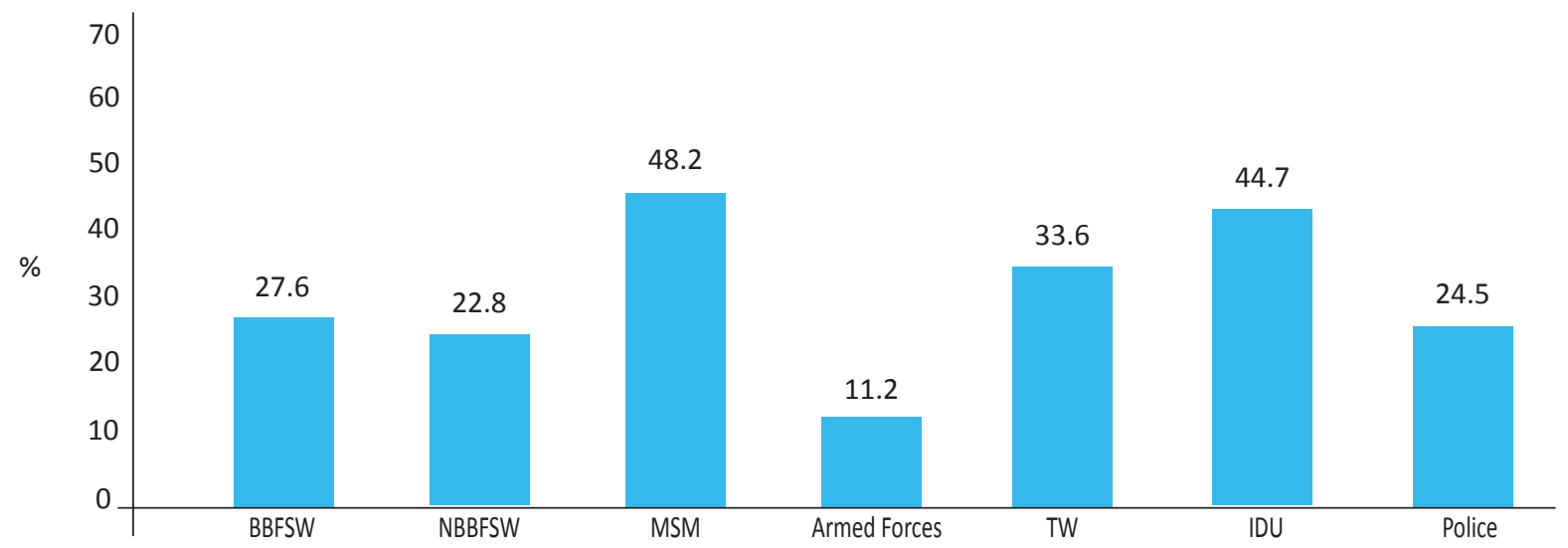

Figure 17 showed MSM as having the highest (48.2\%) proportion of those who believed mosquitoes can transmitt HIV, followed by IDU (44.7\%). The least (11.2\%) was recorded among the Armed Forces. 
Figure 18: Proportion of study groups who believe HIV can be transmitted by sharing meal with an infected person, IBBSS Nigeria 2010

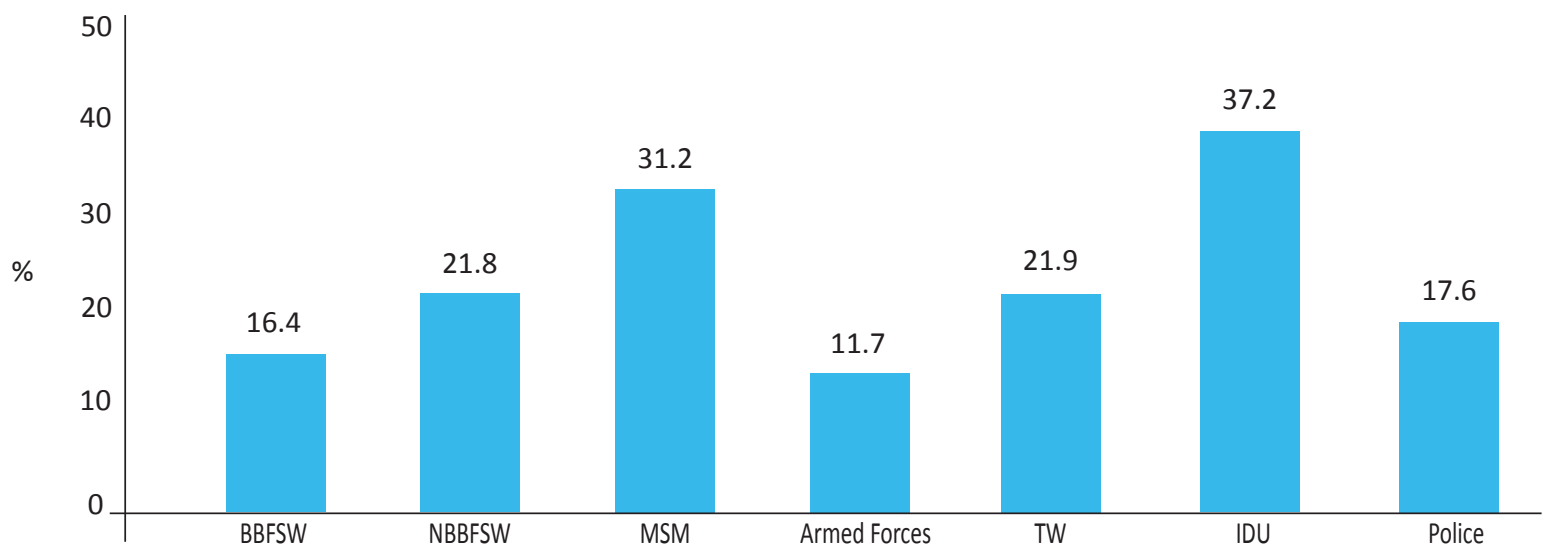

The level of this misconception is generally low among all study groups. IDU had the highest (37.2\%) proportion of members who believed HIV can be transmitted by sharing meal (using the same plate/utensils) with someone who is infected.

Figure 19: Percentage of respondents in the study groups who believe that sharing of toilets with a person who has HIV is a means of contracting HIV, IBBSS Nigeria 2010

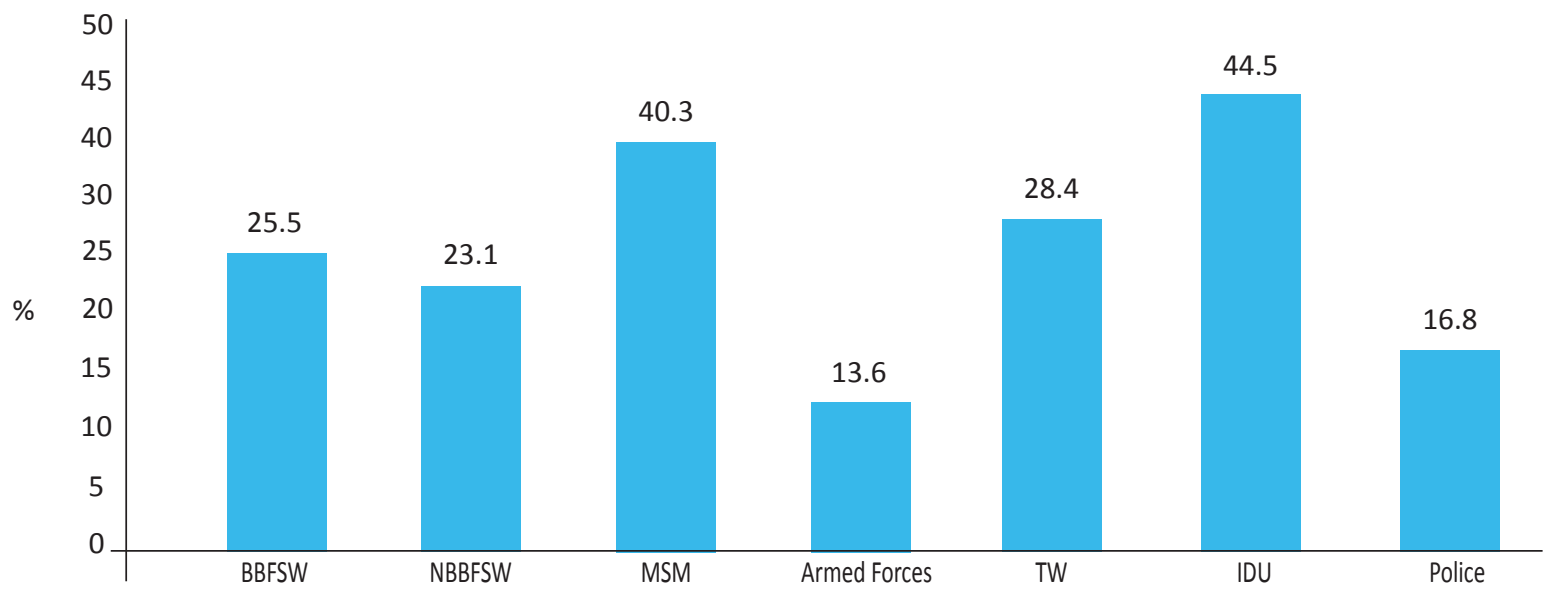

The misconception of transmission of HIV through sharing of toilets with PLWHA was highest among IDU (44.5\%) and is lowest among the Armed Forces (13.6\%).

\subsubsection{HIV Risk Perception}

All respondents were asked whether they perceived themselves to be at risk of HIV infection. Those who answered affirmatively were further prompted for the reasons why they felt they were at risk. 


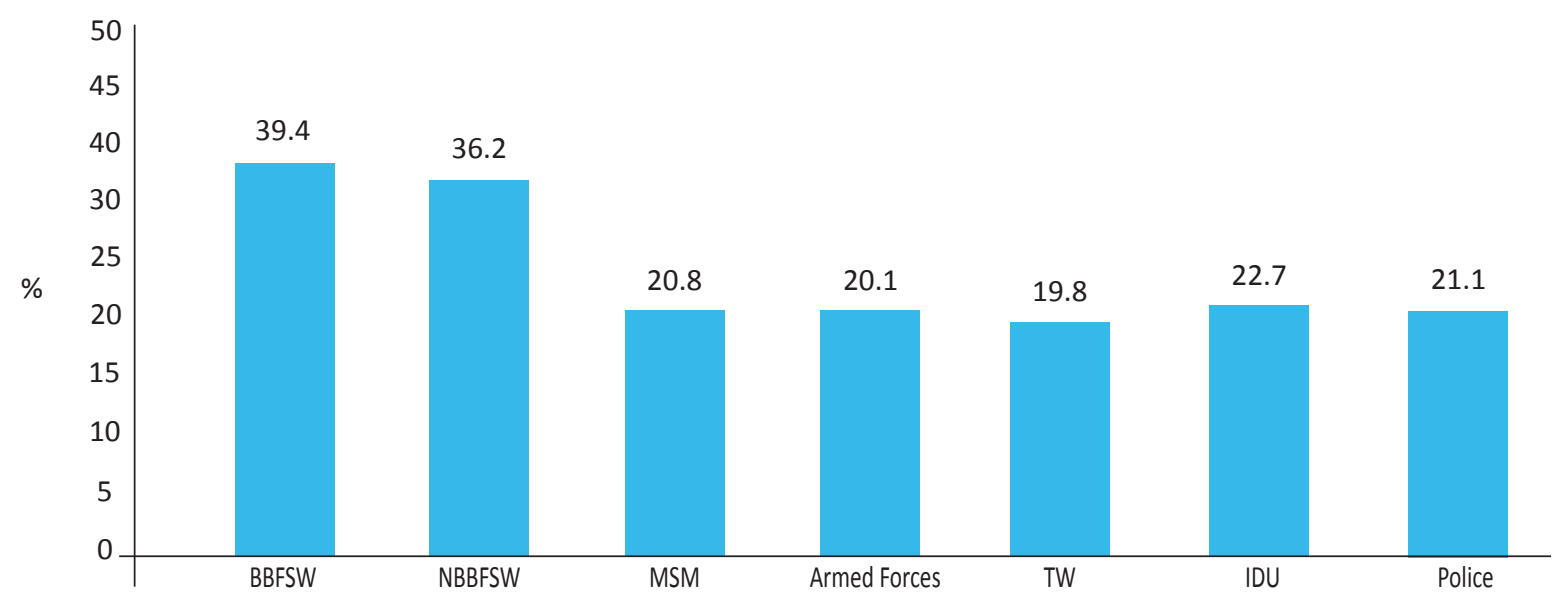

Risk perception was generally low among all the study groups. The highest was over a third of both categories of FSW (BBFSW 39.4\%, NBBFSW 36.2\%). The lowest proportion was recorded among the TW where about a fifth (19.8\%), considered themselves at risk of contracting HIV.

Reasons why respondents across all groups considered themselves at risk of HIV are shown in Table 11.

Table 11: Reasons for HIV risk perception among study groups who perceived themselves at risk by study group, IBBSS Nigeria 2010

\begin{tabular}{|l|l|l|l|l|l|l|l|}
\hline $\begin{array}{l}\text { Reasons for perceiving } \\
\text { themselves at risk of } \\
\text { HIV }\end{array}$ & BBFSW & NBBFSW & MSM & $\begin{array}{l}\text { Armed } \\
\text { Forces }\end{array}$ & TW & IDU & Police \\
\hline $\begin{array}{l}\text { Often change sex } \\
\text { partners }\end{array}$ & 73.2 & 68.9 & 27.0 & 26.9 & 24.4 & 33.3 & 19.5 \\
\hline $\begin{array}{l}\text { Don't always use } \\
\text { condoms }\end{array}$ & 33.0 & 22.2 & 23.9 & 27.7 & 13.0 & 29.1 & 23.0 \\
\hline Use injected narcotics & 1.9 & 5.3 & 7.5 & 5.4 & 3.0 & 19.4 & 13.0 \\
\hline Total (N) & 929 & 793 & 322 & 572 & 394 & 351 & 594 \\
\hline
\end{tabular}

Frequent change in sex partners account for the commonest reason why respondents considered themselves at risk of HIV followed by inconsistent use of condom.

\subsubsection{Discussion}

Majority of respondents were aware of HIV and condom use but knowledge of different means of prevention of HIV transmission was found to be lower and varied considerably among the study groups at state-level (see appendix). Knowledge of correct and consistent use of condoms as a means of preventing HIV was fair among all study groups. Despite the general awareness of HIV and AIDS, the UNGASS indicator for correct knowledge of prevention of sexual transmission of HIV and rejection of misconceptions was generally low among all the study groups except respondents in the Armed Forces where more than half had correct knowledge.

Failure to reject common misconceptions especially that mosquitoes can transmit HIV was quite high among all study groups. In addition, the level of belief in the fact that sharing toilets with an HIV infected person can be a means of contracting HIV was also high. While members of the study groups did perceive themselves at risk of contracting HIV, less than $40 \%$ of all the study groups perceived themselves at risk of contracting HIV. Risk perception was highest 
among BBFSW and NBBFSW.

\subsection{HIV/STI Risk Behaviours and self reported STI symptoms}

The risk behaviours were assessed by sexual partnerships, condom use and self reported STI symptoms. Sexual intercourse has been identified as the main mode of transmission of HIV and other sexually transmitted diseases. The risk behaviours section seeks to identify behaviours that predispose respondents at risk and provides information that can be used for specific interventions. This section reports findings among the different groups. Detailed state level analysis is reported in the appendix.

\subsubsection{Female sex workers}

\subsubsection{Sexual Partnerships}

Types and number of sexual partners and exchange of sex for gifts or favours are considered under this subsection.

The survey attempted to define the various types of sexual partners among study groups. The four types of partners sought for were regular partners, commercial partners, boy/girlfriends and casual sex partners.

The following are the definitions of the different types of sex partners assessed in this study: A regular sex partner is defined as a spouse, or a live-in partner. A commercial sex partner is defined as a sexual partner where sex is exchanged for money, gift or favour. A boyfriend is defined as a non-cohabiting sexual partner. A casual sex partner is any sex partner that is not a regular sex partner, girl/boyfriend and is not a commercial sex partner.

Figure 21: Mean number of clients last day/week of sex work, IBBSS Nigeria 2010

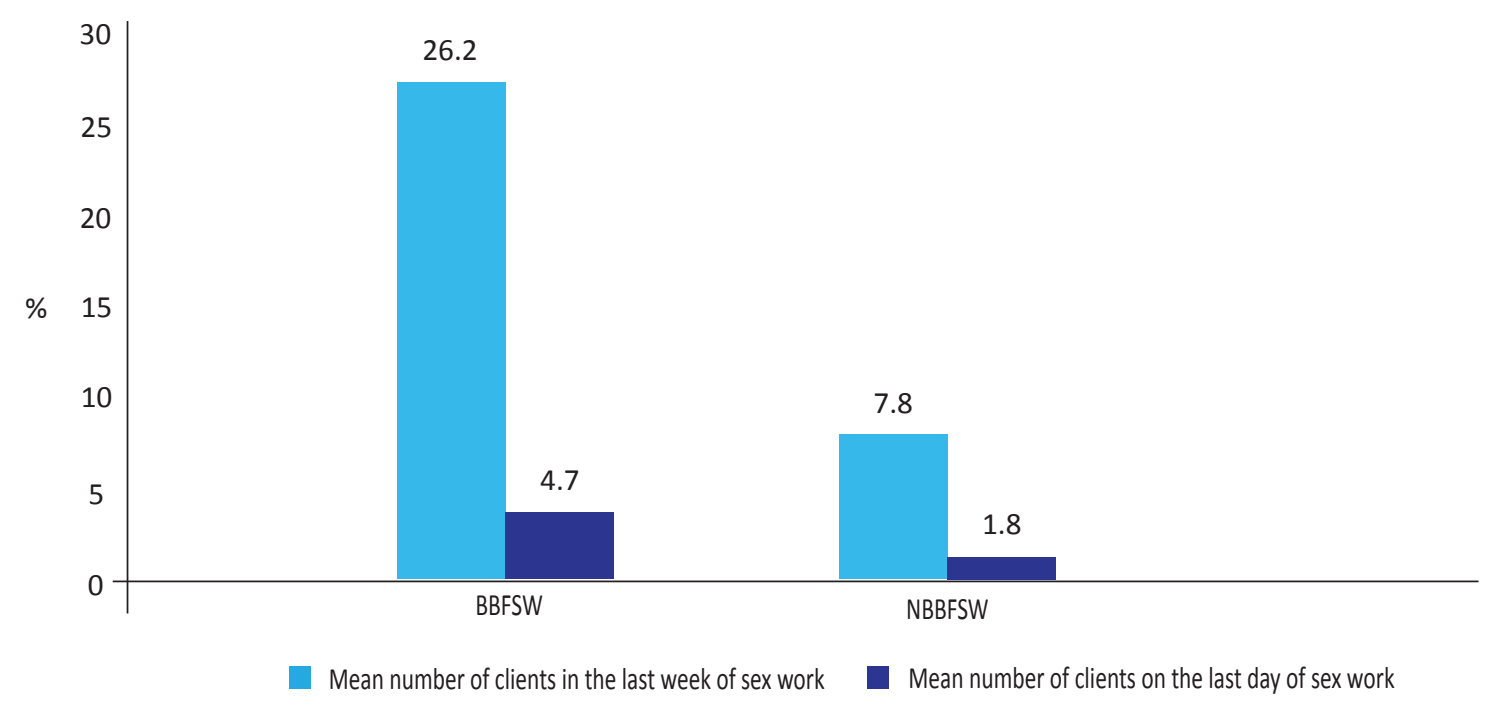

Brothel-based FSW had an average of 26 clients in the last week and about 5 clients in last day of work preceding the survey. Non-brothel based FSW tend to have lower clients with an average of 8 and 2 clients in the last week and last day of work preceding the survey respectively (Figure 21 ).

A non-commercial sex partner is defined as casual, boyfriend and regular sexual partnership. A breakdown of their non-commercial partners over the last 12 months by type is shown in Figure 22. 
Figure 22: Types of non-commercial sexual partners among FSW in last 12 months preceding the survey, IBBSS Nigeria 2010

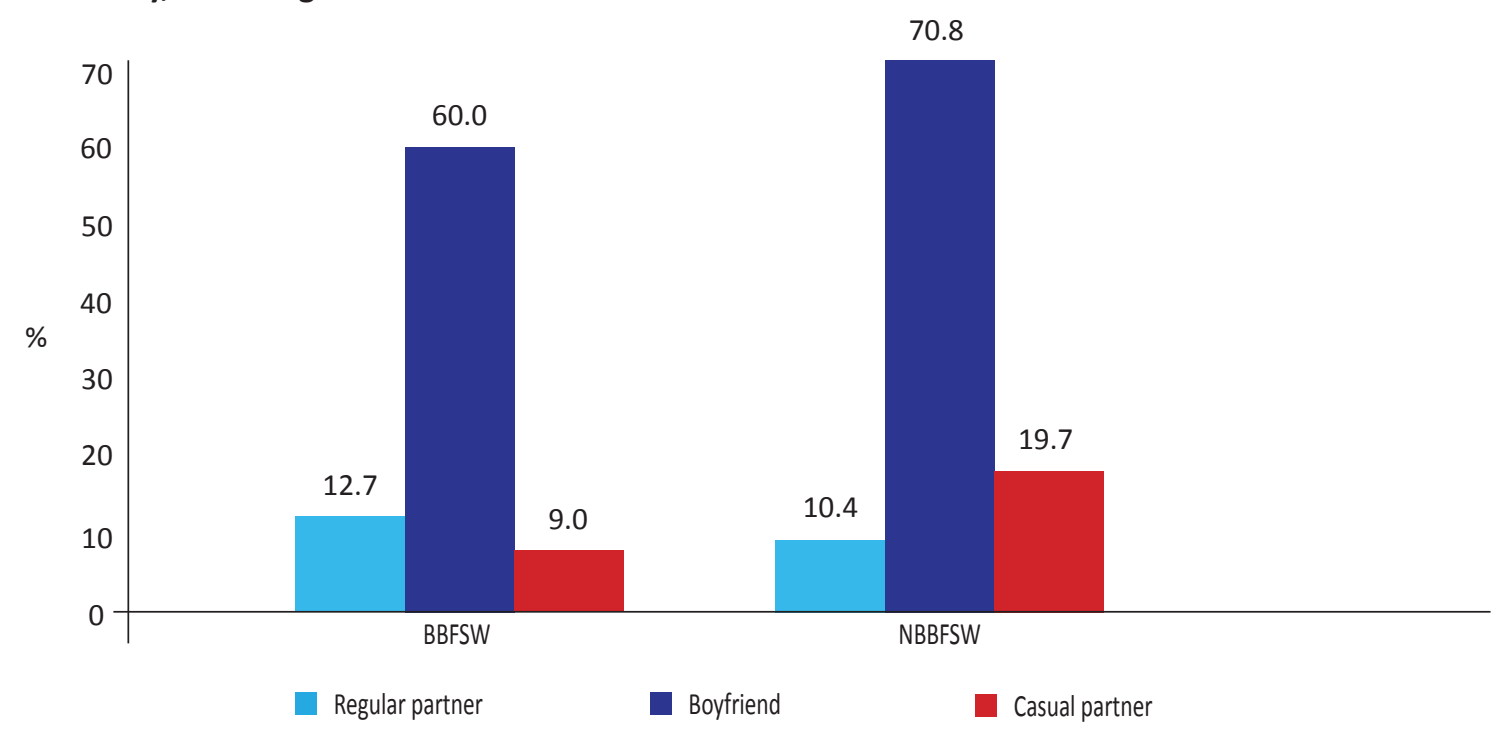

Both BBFSW (60\%) and NBBFSW (71\%) were shown to have had sex with boyfriends in the last 12 months preceding the survey than with other types of non-commercial partners.

Sex with casual partners in the past 12 months was reported by $9.0 \%$ and $20.0 \%$ of BBFSW and NBBFSW respectively. Overall, NBBFSW were shown to have more casual sexual partners than BBFSW.

Figure 23: Percentage of FSW having sex with more than one boyfriend in the last 12 months preceding the survey, IBBSS Nigeria 2010

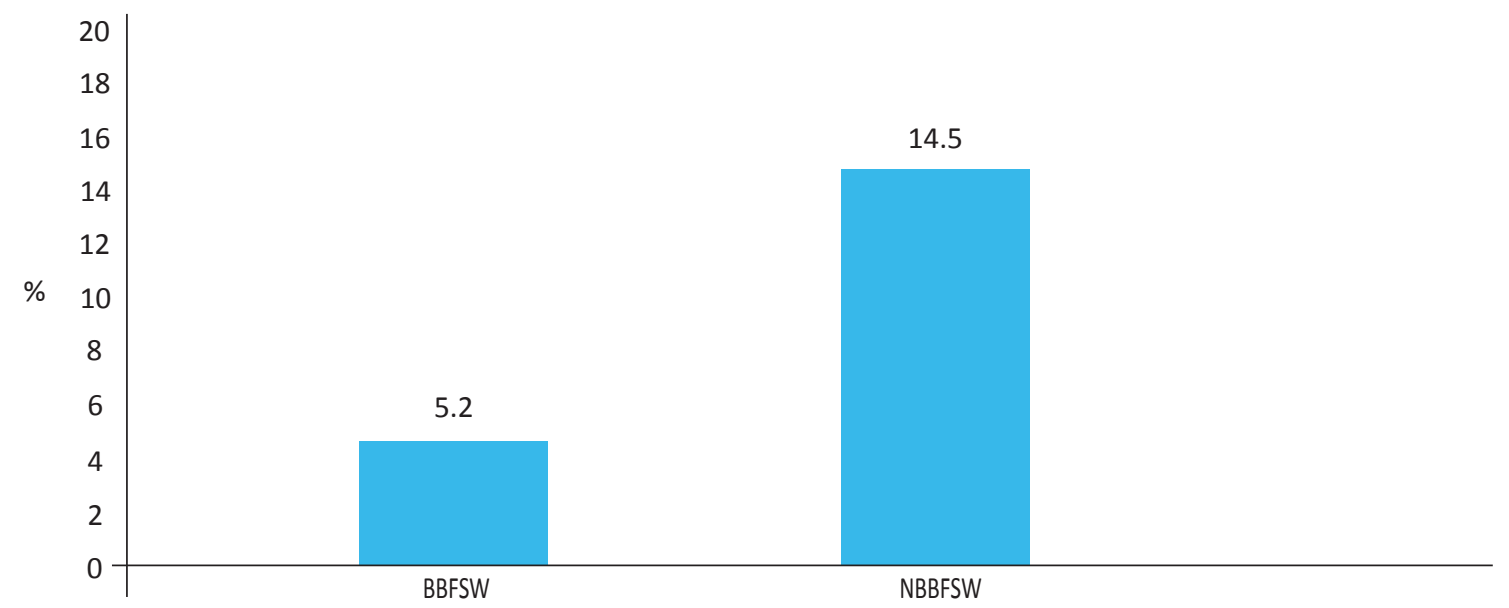

Both categories of FSW were shown to have had sex with more than one boyfriend, however, the proportion was higher among NBBFSW (14.5\%).

\subsubsection{Condom use}

FSW were asked about condom use with different types of partners, both consistently with client over the last 30 days and with other sexual partners over the last 12 months preceding the survey, as well as at last sex. 
Figure 24: Distribution of brothel-based FSW according to condom use with commercial and other sexual partners, IBBSS Nigeria 2010

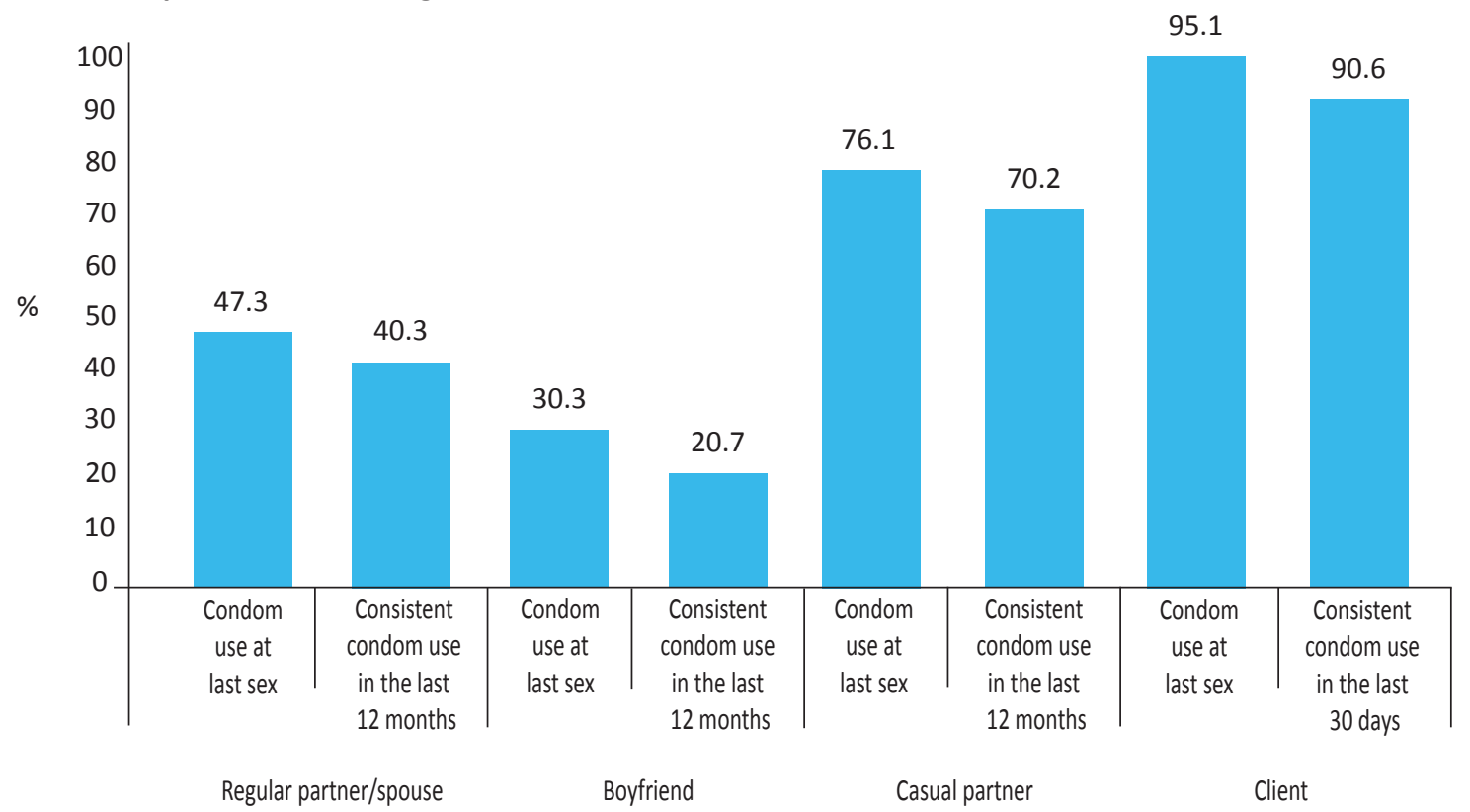

Condom use at last sex was over $90 \%$ in all commercial sex transactions reported by BBFSW and NBBFSW. Consistent condom use in commercial sex in the last 30 days was lower.

Only those FSW that admitted having other non-client sexual partners, were asked about condom use with those partners. Condom use as at last sex with a casual partner was high, around $76 \%$ among both BBFSW and NBBFSW. Condom use at last sex with regular partners and boyfriends is low. Same pattern observed among BBFSW and NBBFSW. Consistent condom use is generally poor (Figure 24 and 25).

Figure 25: Distribution of non-brothel-based FSW according to condom use with commercial and other sexual partners, IBBSS Nigeria 2010

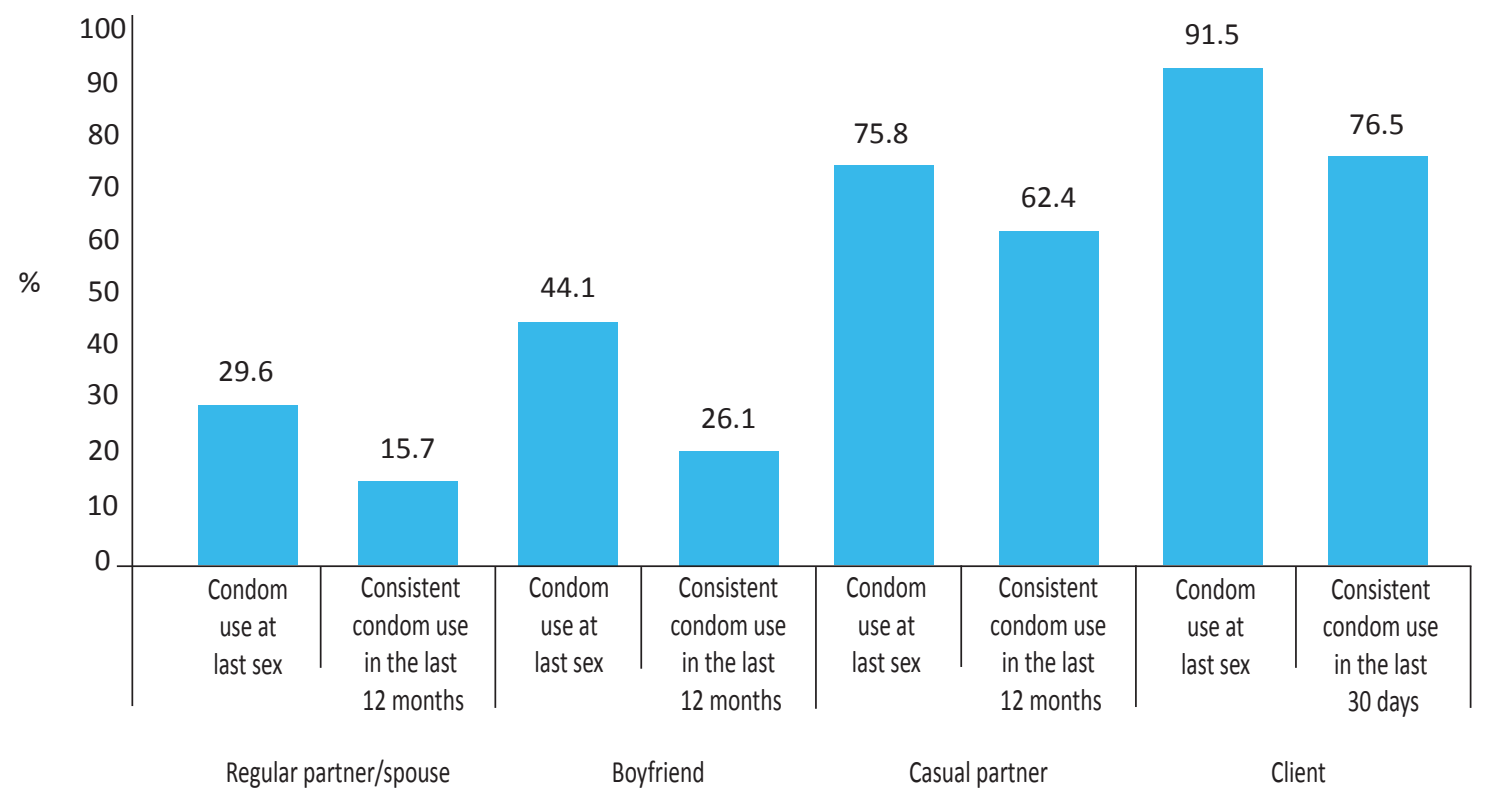


Figure 26: Awareness and usage of female condom by FSW, IBBSS Nigeria 2010

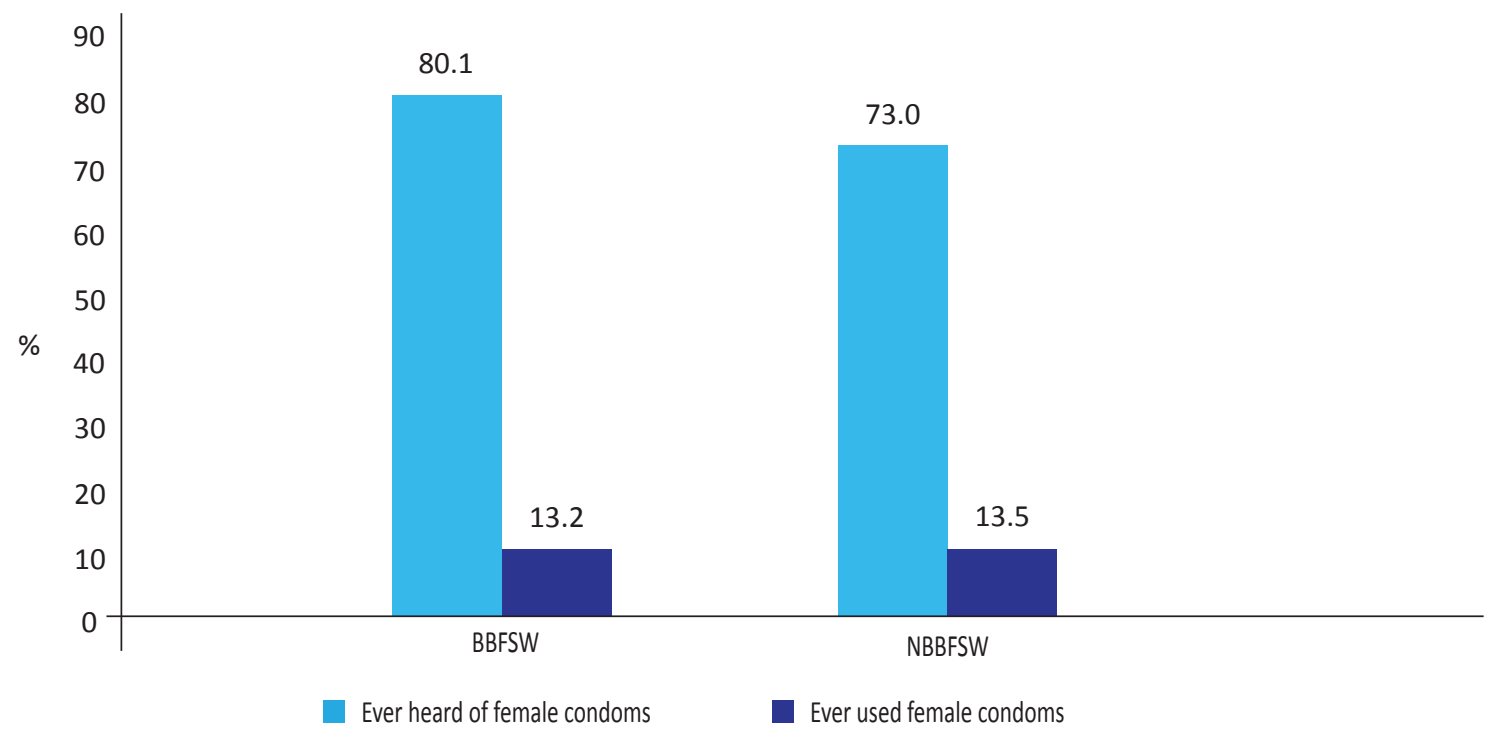

\subsubsection{Self-reported STI symptoms}

The presence of ulcerative STI is known to increase the potential for HIV transmission substantially. Self-reported STI symptoms included in the results presented below are not as valid or reliable as biological indicators of STI prevalence, and are subject to bias based on symptoms not resulting from STI as well as the ability of sub-populations to recognize STI symptoms.

\section{Figure 27: Self reported STI symptoms in the last 12 months preceding the survey by FSW, IBBSS} Nigeria 2010

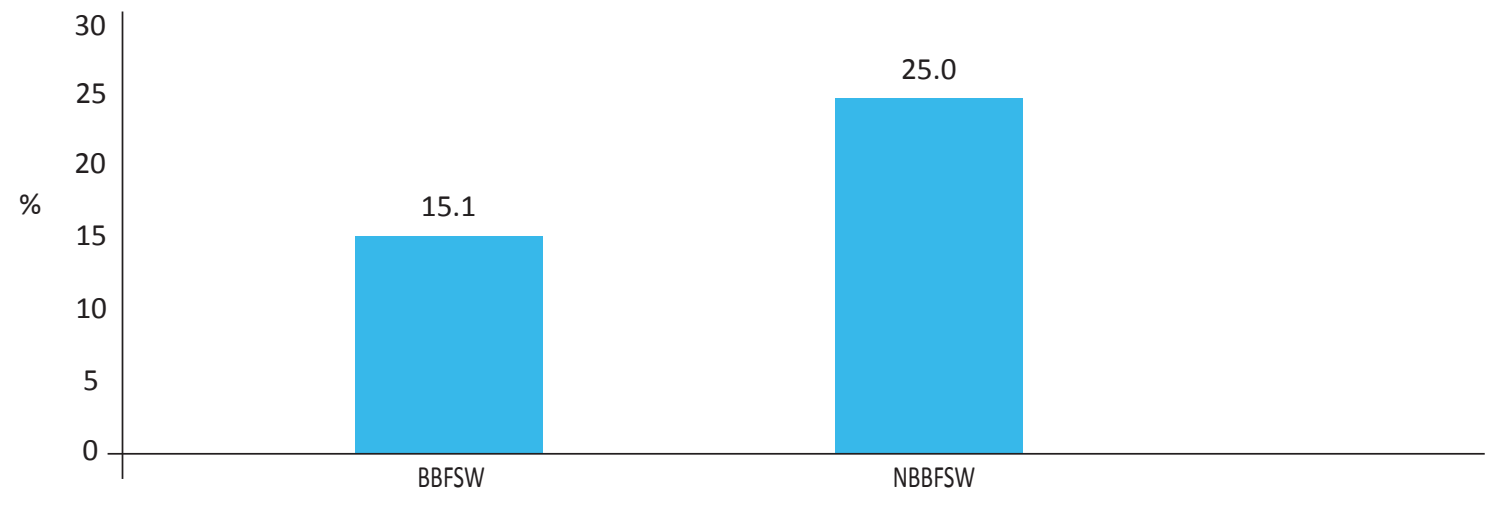

The NBBFSW were shown to have reported an STI symptom in the last 12 months preceding the survey (25\%). 
Figure 28: Self reported STI symptoms by type, by FSW in the last 12 month preceding the survey, IBBSS Nigeria 2010

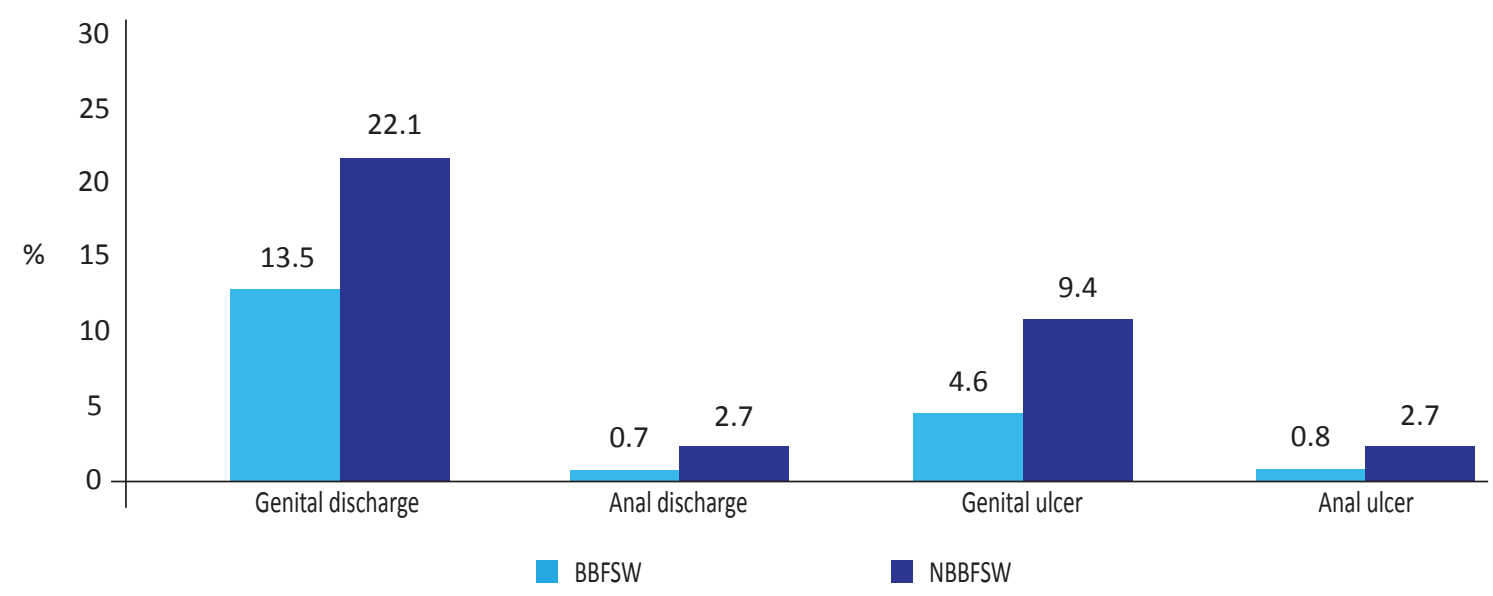

FSW were shown to report unusual genital discharge and genital ulcers/sores than other STI symptoms (Figure 28).

\subsubsection{Men who have sex with men (MSM)*}

\subsubsection{Sexual partnership}

The sexual risk of HIV transmission was assessed for MSM by examining types of sexual partnerships in the past six months and the rates of condom use in these partnerships (Figures 29 to 32$)$.

Figure 29: Distribution of MSM according to different male partner types last 6 months preceding the survey, IBBSS Nigeria 2010

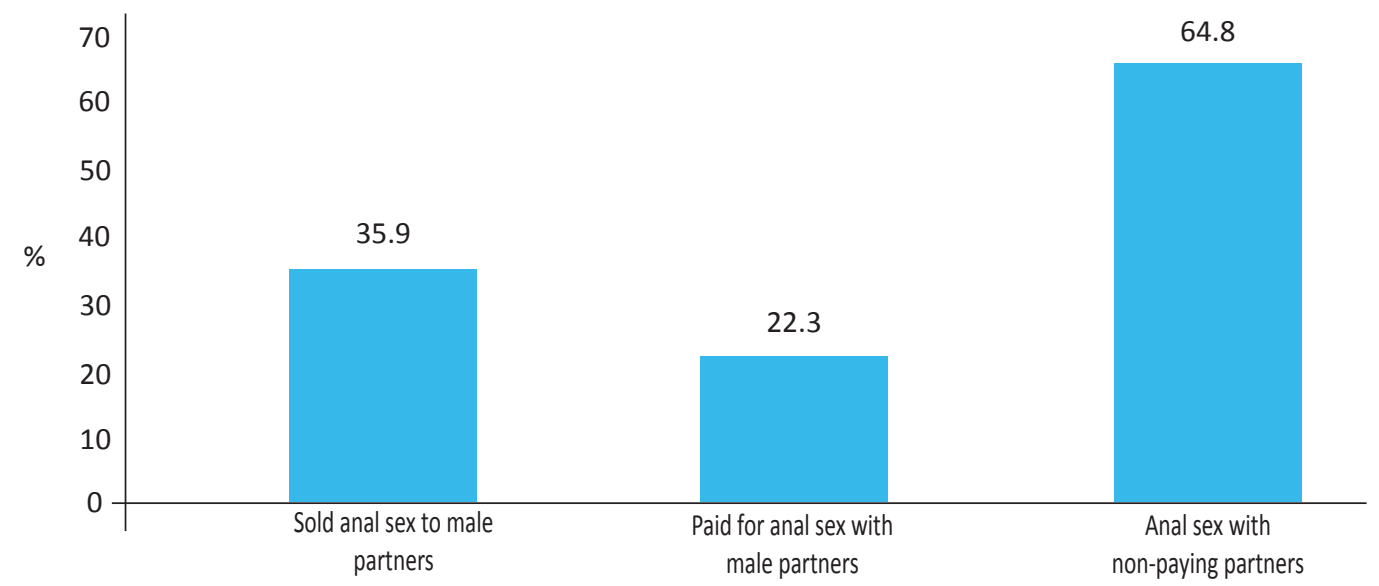

A high percentage (64.8\%) of MSM reported engaging in anal sex with non-paying male partners in the six months preceding the survey, while $35.9 \%$ had sold anal sex to male partners and $22.3 \%$ had paid for anal sex within the same period.

MSM were also asked about their sexual relationships with females including FSW (Figure 30). 
Figure 30: Distribution of MSM by female sexual partners in the last 12 months preceding the survey, IBBSS Nigeria 2010

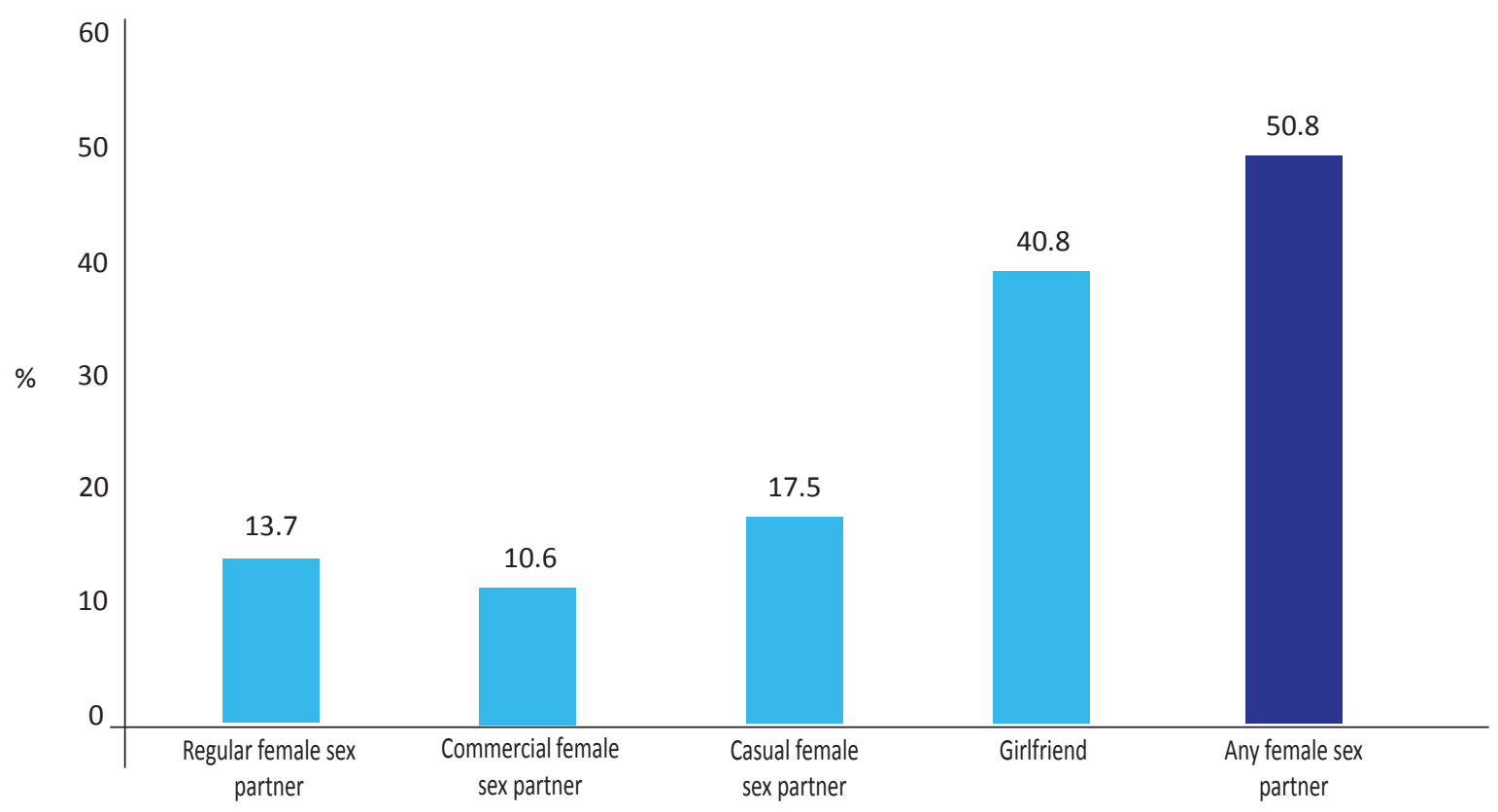

More than $50 \%$ of MSM reported sex with any female partner in the last 12 months preceding the survey. Most (40.8\%) had sex with girlfriends.

\subsubsection{Condom use}

Figure 31: Condom use as at last anal sex among MSM, IBBSS Nigeria 2010

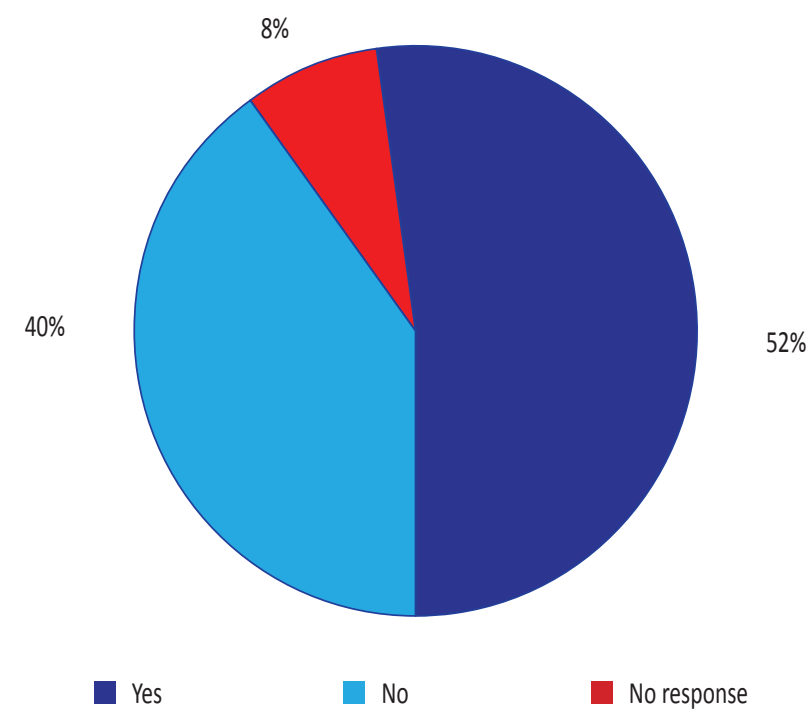

This UNGASS indicator 19 showed that $52 \%$ of MSM surveyed reported use of condom at last anal sex. 
Figure 32: Condom use at last sex and consistent condom use among MSM by type of partner, IBBSS Nigeria 2010

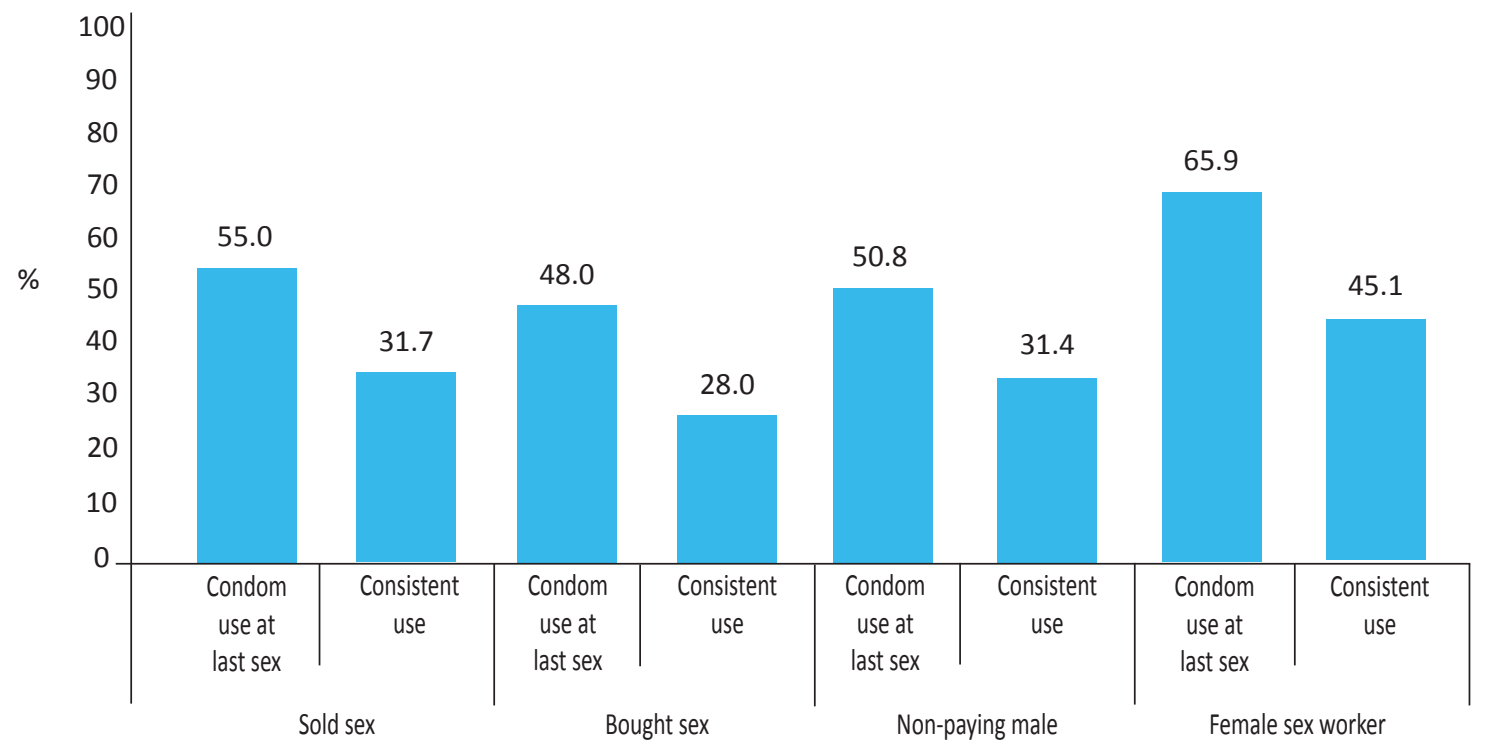

Condom use by MSM during the last sex ranged from $48.0 \%$ with bought sex from male partners to $65.9 \%$ with FSW. Consistent condom use by MSM in the past 6 months with male sexual partners and in the past 12 month with FSW was below $50 \%$. State level variations are detailed in the appendix.

\subsubsection{Self-reported STI symptoms}

Figure 33: Self reported STI symptoms among MSM, IBBSS Nigeria 2010

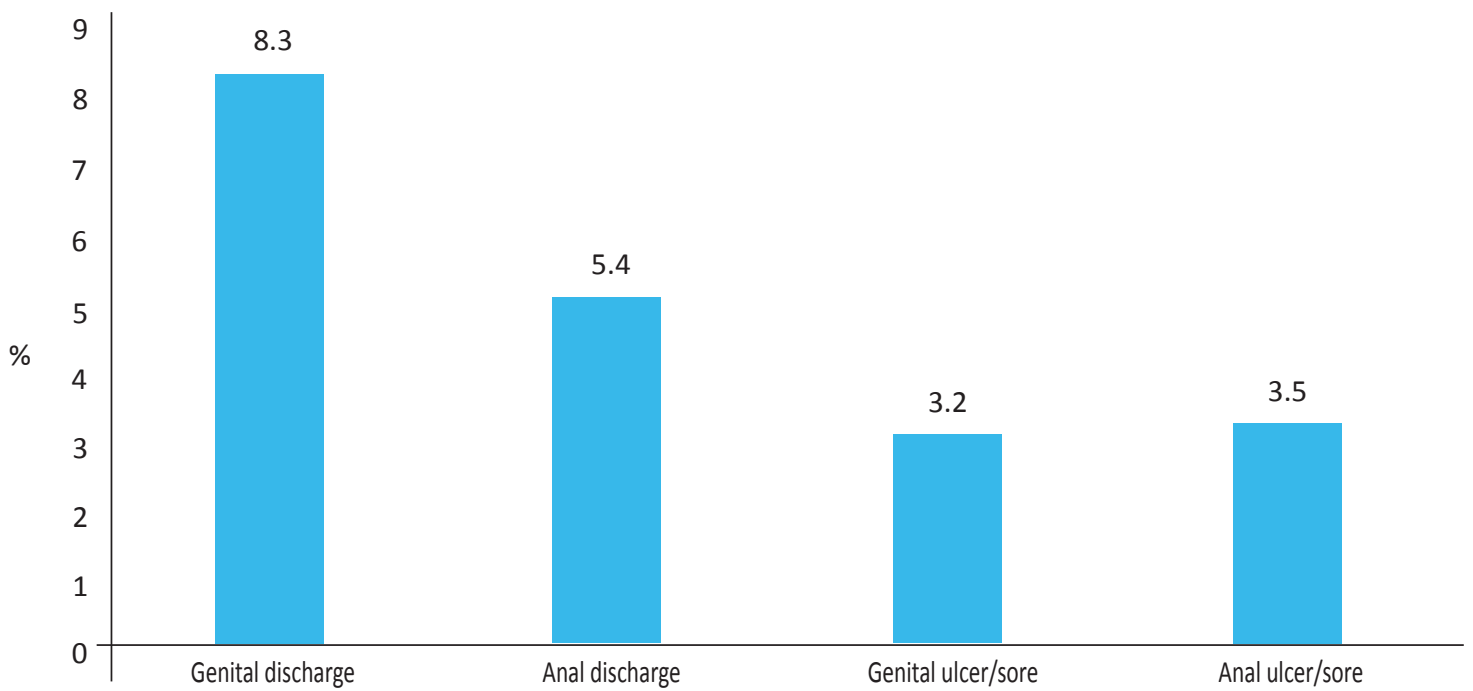

Unusual genital discharge was the most common STI symptom reported by MSM (8.3\%) in the last 12 months preceding the survey, with genital ulcer/sore being the least reported (3.2\%) 


\subsubsection{Injecting Drug Users*}

\subsubsection{Sexual partnerships}

Figure 34: Types of sexual partners among all sexually active IDU in the last 12 months preceding the survey, IBBSS Nigeria 2010

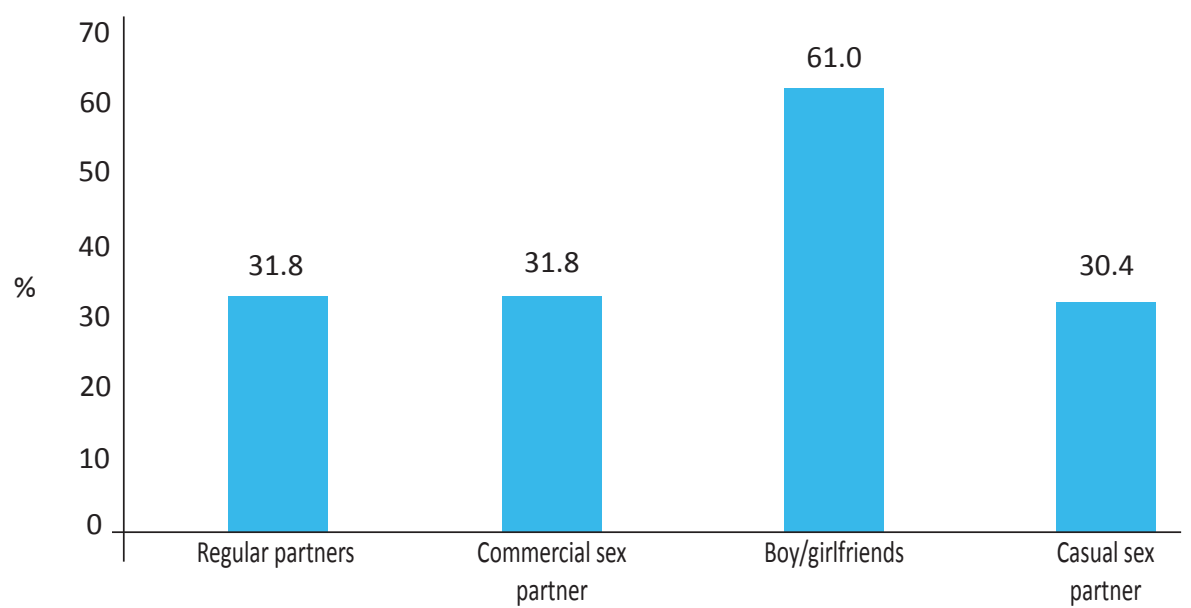

The IDU reported sex with boy/girlfriends (61.0\%) more than other sexual partners.

\subsubsection{Condom use}

Figure 35 shows condom use at last sex reported by IDU for different partner types.

Figure 35: Distribution of male IDU by condom use at last sex by type of sexual partner, IBBSS Nigeria 2010

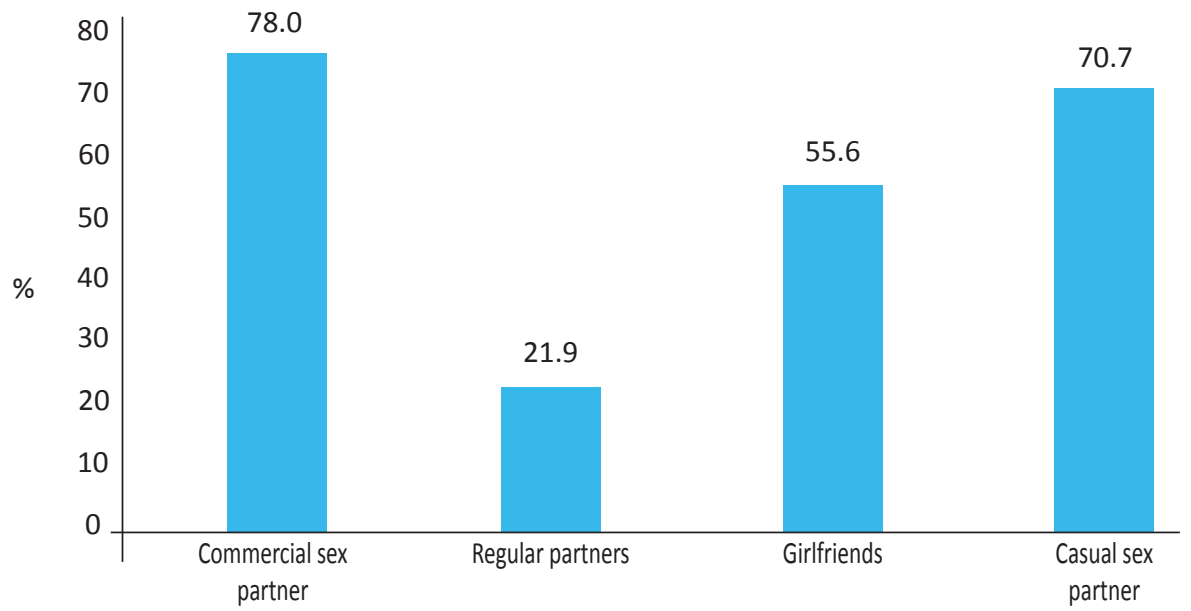

Condom use at last sex with commercial sex workers among male IDU was highest (78.0\%), few female IDU admitted selling sex, however, condom use was not probed. This was closely followed by condom use at last sex with casual partners (70.7\%) compared to condom use at last sex with other types of sexual partners (Figure 35). 


\subsubsection{Self-reported STI symptoms}

Figure 36: Self reported STI symptoms among IDU, IBBSS Nigeria 2010

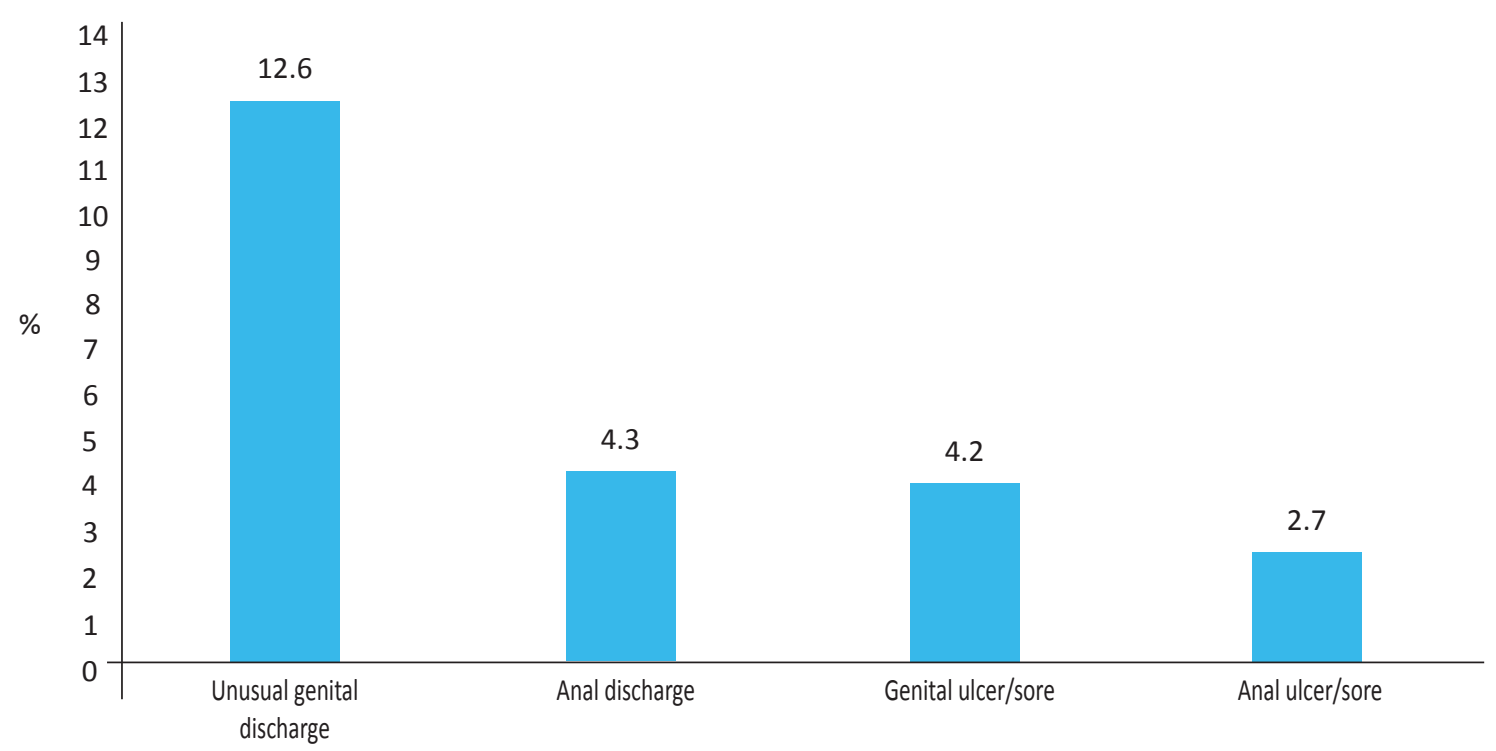

The commonest STI symptom reported by IDU was unusual genital discharge (12.6\%).

\subsubsection{Female IDU}

A gender analysis of commercial sex behaviour, among IDU indicates that only five percent of the IDU sampled were women. Among them, 38.1\% sold sex in the past 12 months.

\subsubsection{Predominantly male occupational groups}

\subsubsection{Sexual partnerships}

All three predominantly male occupational groups namely the Armed Forces, Police (males only), and TW, were asked about their different types of sexual partners in the last 12 months preceding the survey. The results are outlined in Figure 37.

Figure 37: Types of sexual partners among predominantly male occupational groups, IBBSS Nigeria 2010

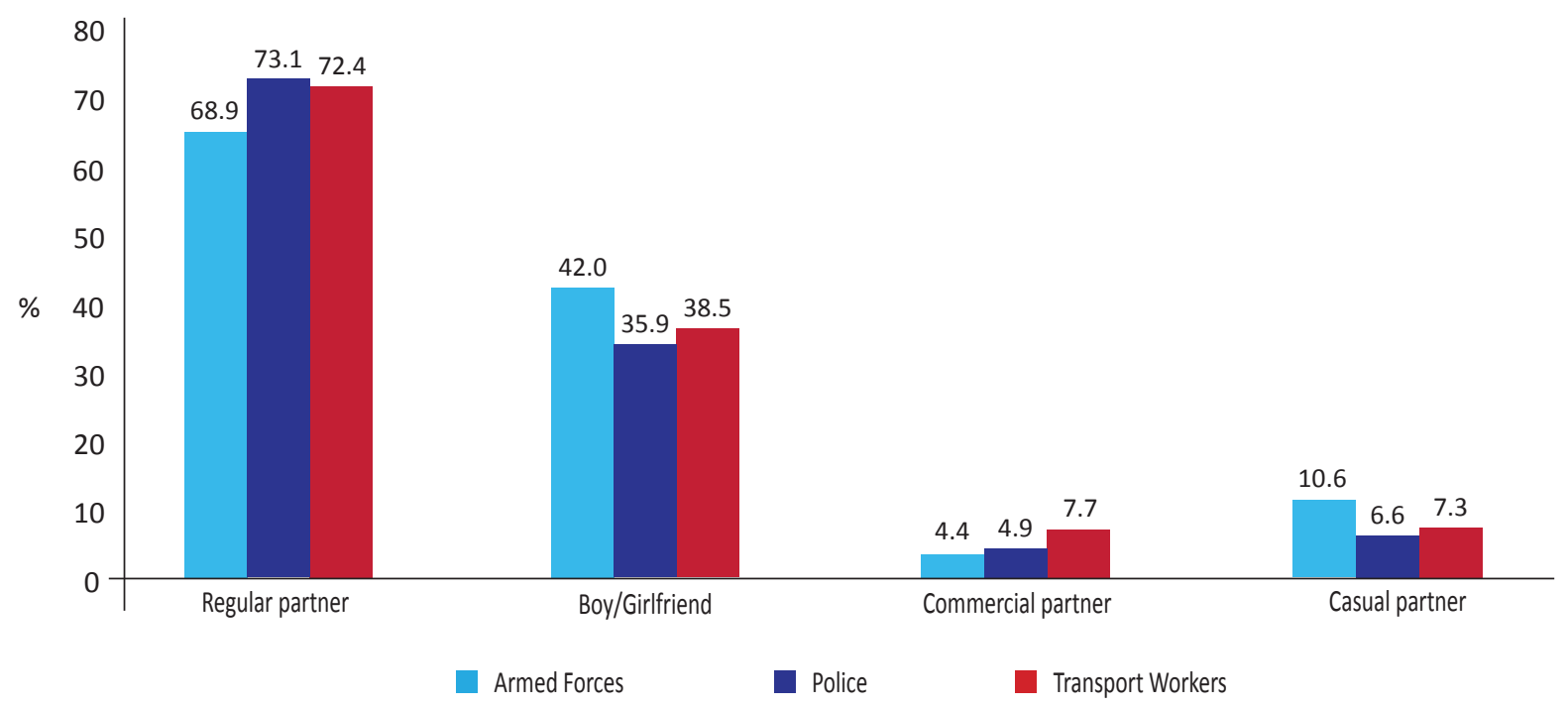

Sexual relationship with boy/girlfriend was the most commonly reported non-marital sex among all the predominantly male occupational groups in the last 12 months preceding the survey. 
Figure 38: Male occupational group reporting sex with more than one non-regular partner in the last 12 months preceding the survey, IBBSS Nigeria 2010

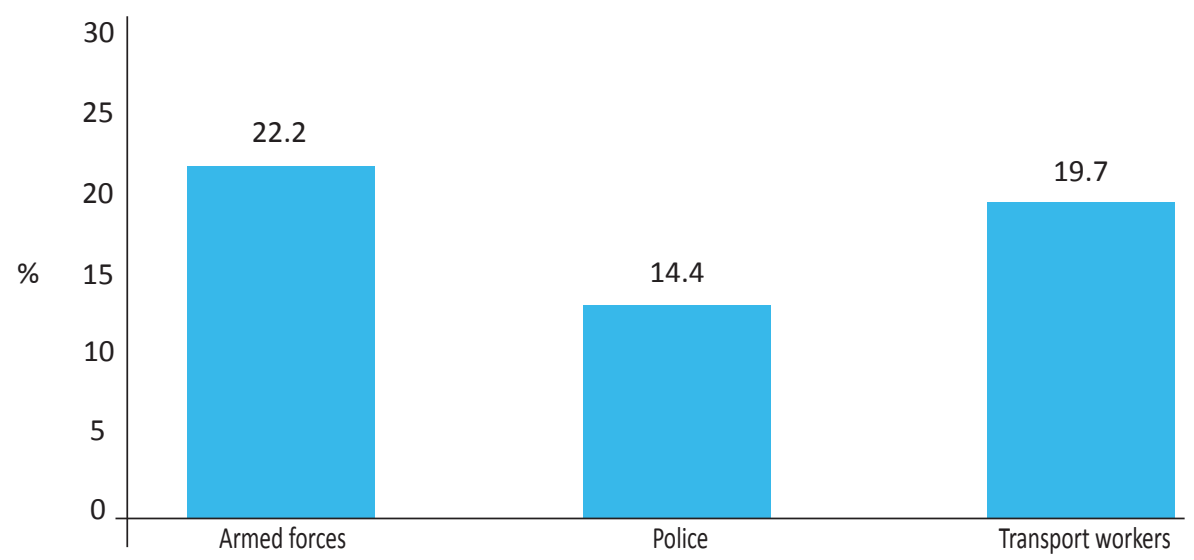

Figure 38 shows the percentage of each predominantly male occupational group reporting sex with more than one non-regular partner in the 12 months preceding the survey. Overall, $22.2 \%$ of Armed Forces, $14.4 \%$ of Police (male and female) and $19.7 \%$ of TW reported sex with more than one non-regular partner (casual, commercial and girl/boyfriend) in the 12 months preceding the survey.

\subsubsection{Condom Use}

To better understand the potential for HIV transmission among these groups, it is necessary to examine condom use with different types of partners (Figure 39 below).

Figure 39: Condom use at last sex by type of sexual partner, male occupational groups IBBSS Nigeria 2010

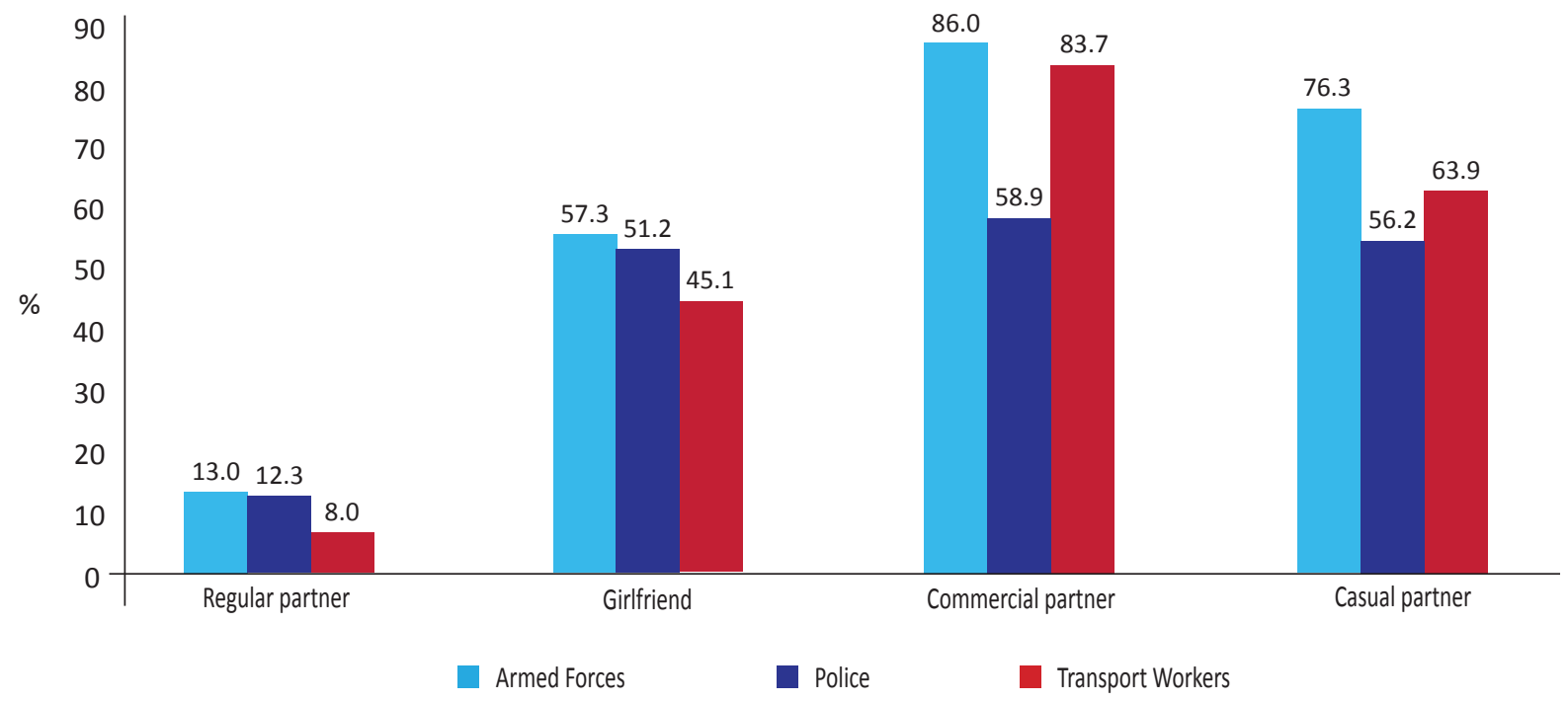

Condom use at last commercial sex was high among the Armed Forces (86\%) and TW (83.7\%) compared to the Police (58.9\%). The Armed Forces group reported the highest percentage (76.3\%) of condom use at last sex with casual partners compared to the Police $(56.2 \%)$ and TW (63.9\%). Though sexual relation with girlfriends was fairly common among all the predominantly male groups, condom use at the last sexual encounters was low. The lowest was recorded among the TW (45.1\%). 


\subsubsection{Self-reported STI symptoms}

Like other groups surveyed, the Armed Forces, Police and TW were asked whether they had experienced any unusual genital discharge or genital ulcer/sore in the last 12 months preceding the survey. The results are presented in Figures 40 and 41 below.

Figure 40: Self reported STI symptom among the predominantly male occupational groups, IBBSS Nigeria 2010

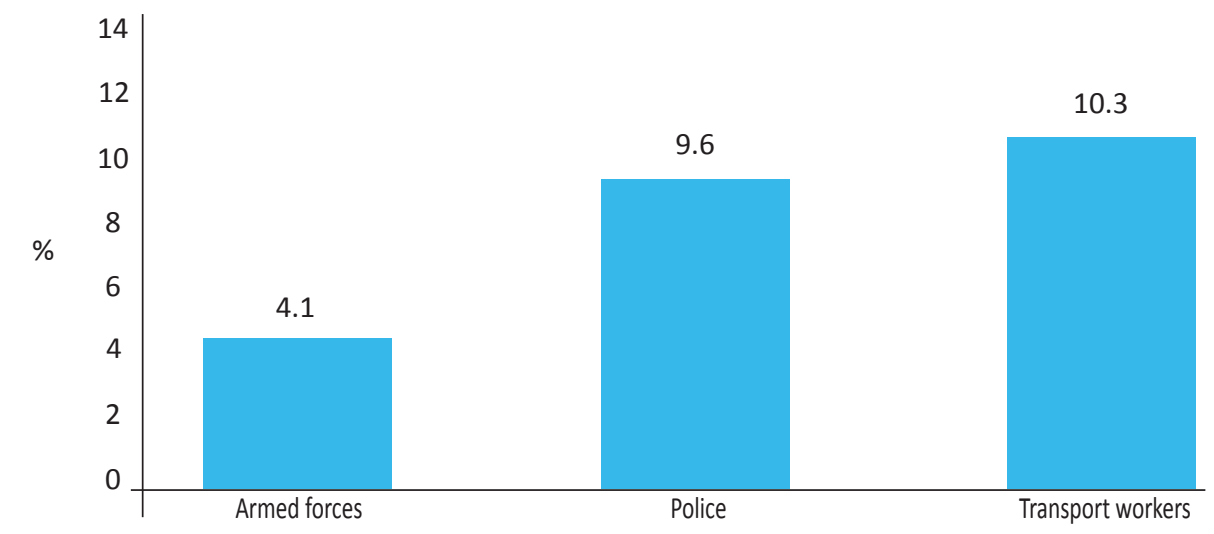

Figure 41: Self reported STI symptoms by type among predominantly male occupational groups, IBBSS Nigeria 2010

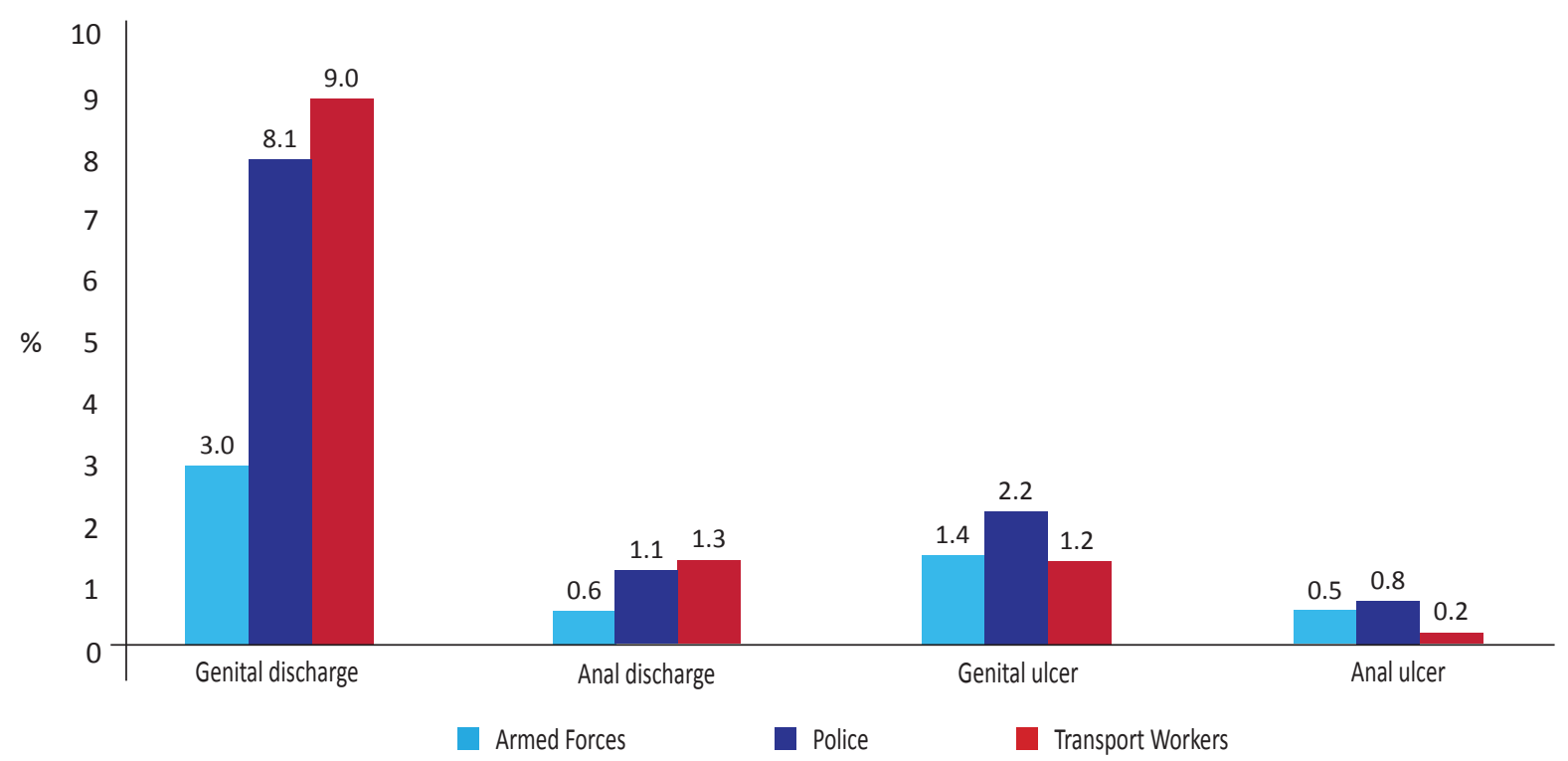

The proportions of the three groups reporting STI symptoms varied (Figure 40). Unusual genital discharge was the most commonly reported symptom (Figure 41 ) with the TW $(9.0 \%)$ and the Police (8.1\%) superseding the Armed Forces (3.0\%) on genital discharge symptom.

\subsubsection{Discussion}

Brothel-based FSW had high client load compared to NBBFSW surveyed. Majority of both categories of FSW had non-paying partners in the last 12 months with boyfriend being the most commonly reported. Reported condom use was high among both BBFSW and NBBFSW with over $90 \%$ and $75 \%$ respectively, using condoms consistently with paying clients. Consistent condom use with boyfriends and regular partners was much lower. NBBFSW had lower levels of condom use with clients but higher levels with boyfriends. Very few FSW had ever used female condoms. NBBFSW were more likely to have self reported STI symptoms in the past 12 months. 
Among MSM, sexual risk behavior was high, with almost two third reporting anal sex in the last 6 months, a third selling anal sex, a quarter reported paying for anal sex and about a tenth reporting sex with a FSW. Half of all MSM sampled had had sex with a female partner in the last 6 months. Condom use during last anal sex with a male partner was low at only 52\% compared to $66 \%$ at last sex with a FSW. Minimal differences existed between condom use at last paying and non-paying anal sex. Despite evidence of risk behavior, self reported STI symptoms was low. In general, reports of unusual genital discharge and genital ulcers/sores among MSM were at levels comparable to the predominantly male occupational groups. MSM were most likely of all groups to report an anal discharge in the last 12 months.

Almost a third of female IDU sold sex in the last 12 months, a feature not commonly reported among male IDU. The noted higher HIV prevalence among female IDU suggests increased risk factors for sexual transmission among them and the potential for wider spread. However, the size of the female IDU population is unknown.

Among the predominantly male occupational groups, majority had regular partners, less than a tenth of each group reported having a commercial female partner. Multiple partnering was generally high over $20 \%$ of all groups had more than one partner in the last 12 months. Condom use at last sex was generally high among all the groups in commercial and casual sex, but lower among more regular partnerships. Transport workers had the highest levels of genital discharge among the occupational groups.

\subsection{Attitudes Towards People Living with HIV and AIDS}

All groups were asked a number of hypothetical questions to assess levels of stigma and discrimination against people living with HIV and AIDS. Table 12 below shows the percentage of responses to each question by group.

Table 12. Distribution of study groups by attitudes towards PLWHA, IBBSS Nigeria 2010

\begin{tabular}{|l|l|l|l|l|l|l|}
\hline & $\begin{array}{l}\text { Willing to care } \\
\text { for a relative } \\
\text { with HIV }\end{array}$ & $\begin{array}{l}\text { HIV+ student } \\
\text { allowed to } \\
\text { attend school } \\
\text { should be } \\
\text { allowed to } \\
\text { teach }\end{array}$ & $\begin{array}{l}\text { PLWHA } \\
\text { buy food } \\
\text { from } \\
\text { PLWHA }\end{array}$ & $\begin{array}{l}\text { Would } \\
\text { eat } \\
\text { with } \\
\text { PLWHA }\end{array}$ & $\begin{array}{l}\text { Would } \\
\text { work } \\
\text { with } \\
\text { PLWHA }\end{array}$ \\
\hline Groups & & & & & \\
\hline Brothel-based FSW & 82.1 & 72.8 & 72.6 & 41.3 & 57.5 & 68.0 \\
\hline Non-brothel-based FSW & 87.3 & 80.2 & 78.8 & 51.7 & 61.1 & 80.8 \\
\hline MSM & 89.6 & 57.9 & 84.7 & 60.9 & 73.8 & 74.1 \\
\hline IDU & 77.8 & 55.1 & 72.9 & 48.2 & 59.7 & 66.3 \\
\hline Armed Forces & 90.1 & 86.4 & 86.0 & 55.4 & 73.8 & 90.3 \\
\hline Police & 88.4 & 84.0 & 86.4 & 52.5 & 70.5 & 89.5 \\
\hline Transport Workers & 83.4 & 86.1 & 74.4 & 44.3 & 55.4 & 72.9 \\
\hline
\end{tabular}

The level of understanding and acceptance of PLWHA varied among the groups. Most of the respondents in all the groups were more willing to care for and work with PLWHA than buy food from or eat with such an individual. There was also a general acceptance of PLWHA student or teacher allowed to attend school or teach. The BBFSW was the least (41.3\%) willing to buy food from a PLWHA followed by TW (44.3\%).

The issue of disclosure about HIV infection was asked during the survey. Respondents were asked if they will want it to remain a secret if a member of their family tested positive to HIV. 


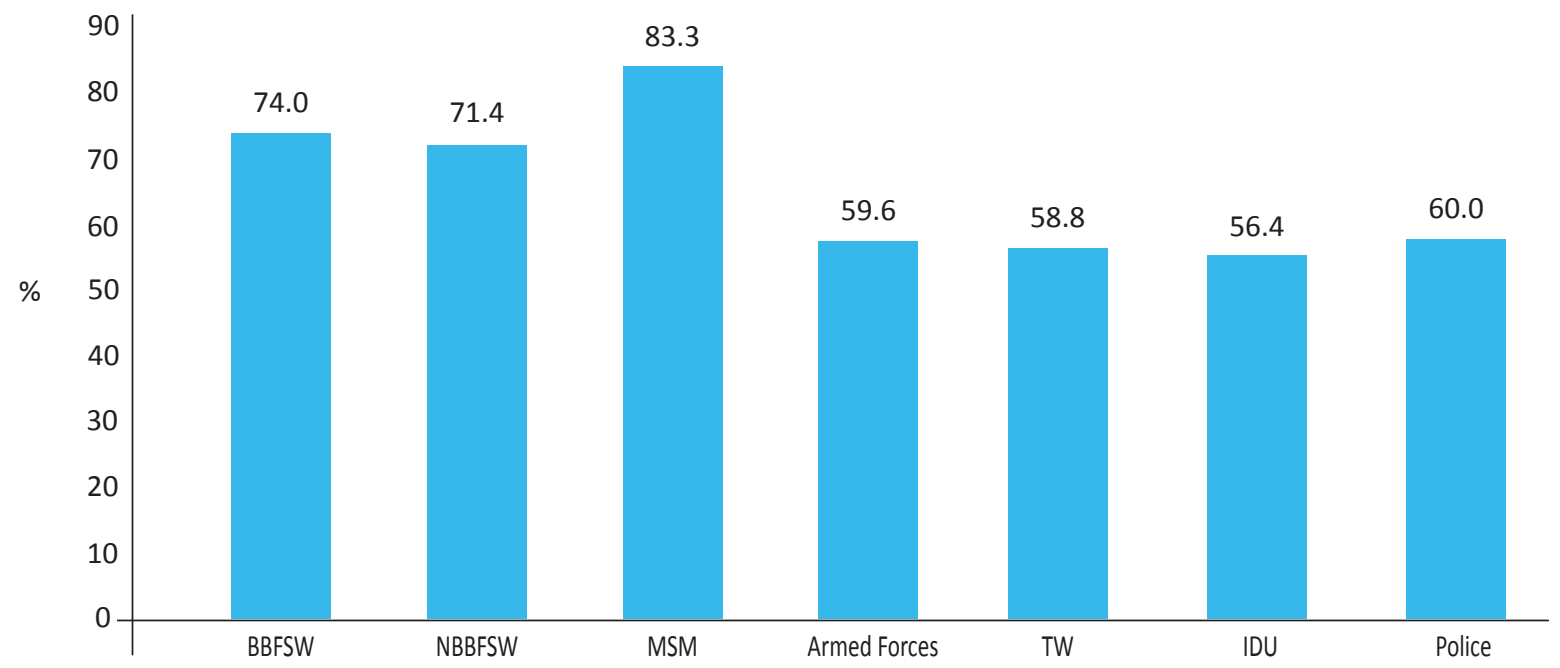

The responses to these questions indicate that while compassion towards PLWHA is generally high, there was high level of fear of disclosure of HIV infection (Table 12, Figure 42).

\subsubsection{Discussion}

In general, tolerance of persons living with HIV and AIDS was generally over $50 \%$ except among BBFSW, IDU and TW. Many groups showed higher levels of tolerance for the societal presence of HIV positive individuals, compared to actual personal contact with a person living with HIV and AIDS such as buying food from an HIV positive person. Compassion towards family and relatives with HIV was generally high among all the groups but very high numbers would prefer to keep the knowledge of an HIV infection in the household secret.

\subsection{Exposure to HIV Prevention Interventions}

The study groups were asked about their exposure to previous HIV test and knowledge of their HIV status (UNGASS indicator 8) and to different types of HIV prevention-related information and services in the last 12 months preceding the survey (UNGASS indicator 9). Denominators used were all members of the study groups.

\subsubsection{HIV test}

In order to protect themselves and to prevent infecting others, it is important for everyone to know their HIV status. Respondents were asked whether they have ever been tested, whether they received results and how recent their HIV test was. State level analysis is presented in the appendix.

Figure 43: Distribution of study groups according to those ever tested for HIV, IBBSS Nigeria 2010

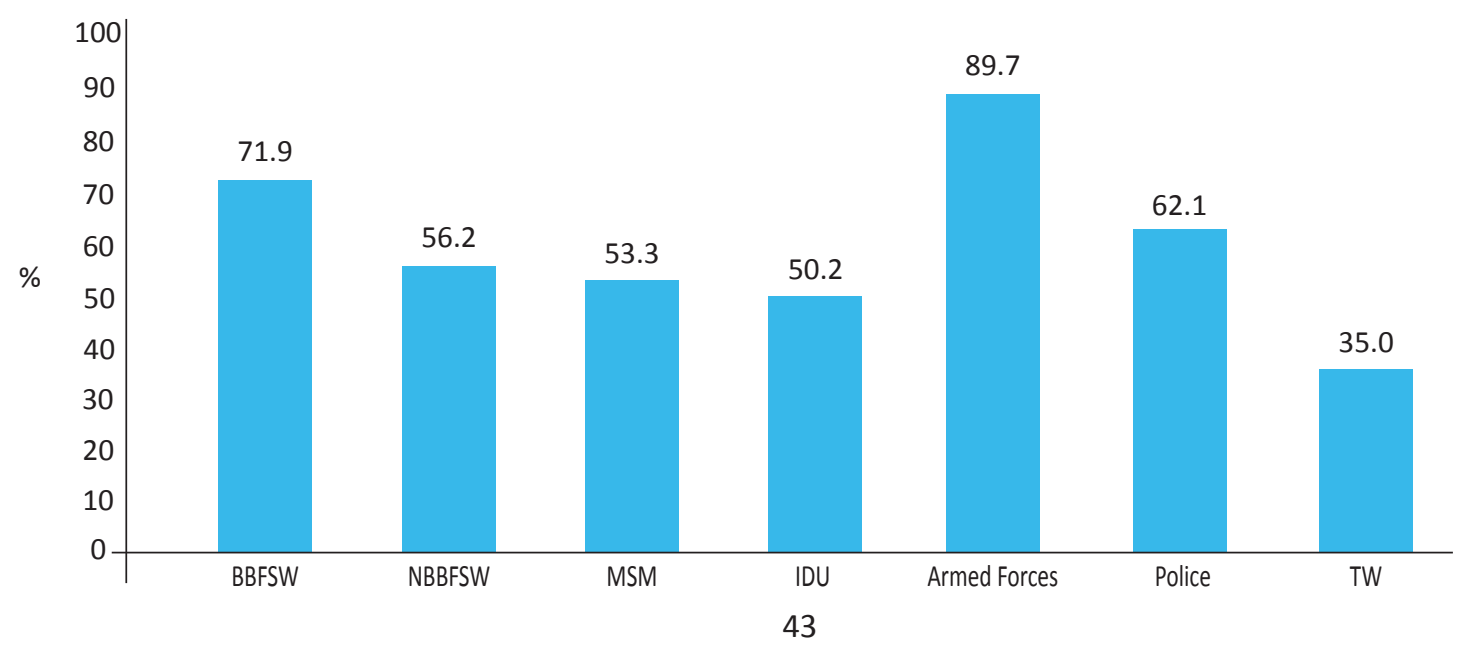


Members of the Armed Forces were the most likely to have ever been tested (89.7\%), closely followed by BBFSW (71.9\%). TW were the least ever tested for HIV, 35.0\% (Figure 43).

Figure 44: Distribution of study groups according to those who tested for HIV and received results, IBBSS Nigeria 2010

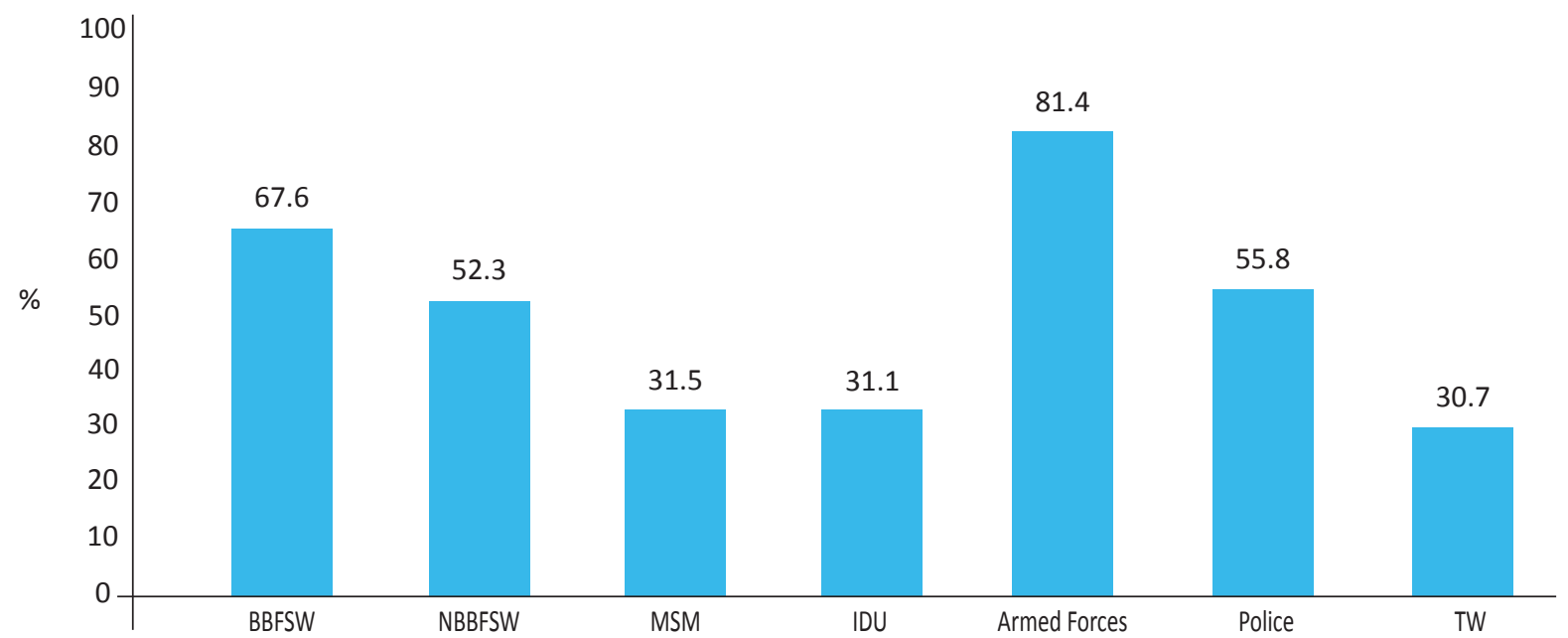

Armed Forces group were more likely to know their HIV status compared to all the other groups studied. The TW, IDU and MSM were the least likely.

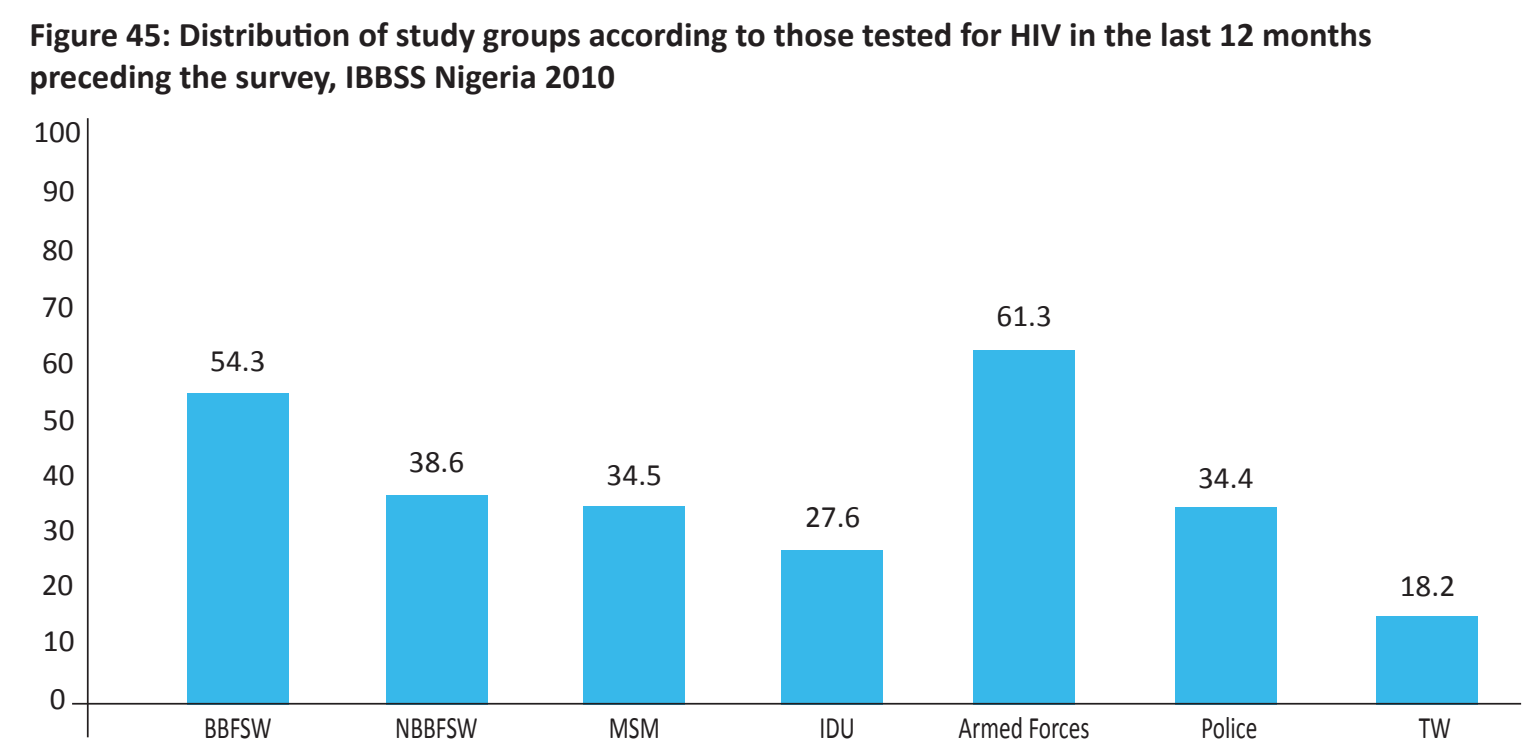

Similar pattern as observed in Figure 44 was seen among those who recently accessed HIV test among the study groups. TW were least likely to have been tested in the last 12 months preceding the survey (18.2\%).

Analysis of those who were HIV positive and who claimed to have been tested and received result was done. The result is shown in figure 46. 
Figure 46: Percent of HIV positive respondents who know their status, IBBSS Nigeria 2010

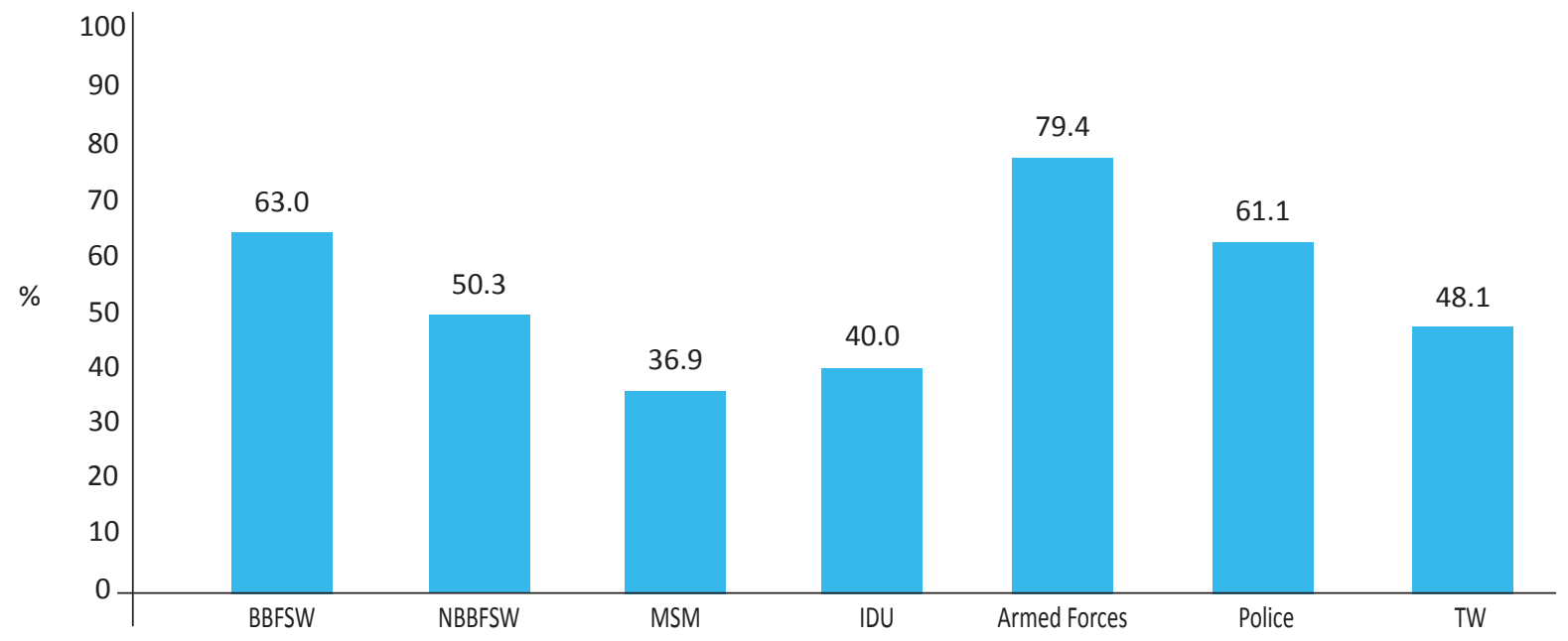

Majority (79.4\%) of members of the Armed Forces who were tested positive during the survey had prior knowledge of their HIV status compared with members of the other groups. HIV positive MSM were the least likely to know their status prior to the survey. Almost half (48.1\%) of the TW group that were positive during the survey already know their status. There were state level variations and these are shown in the appendix.

\subsubsection{HIV prevention information and services}

Interventions assessed were;

a) Information /education about HIV

b) Free condoms

c) Education on safe sex

d) Referral for STI services

e) Referral for VCT services

Figure 47: Distribution of FSW according to HIV prevention services received in the last 12 months preceding the survey, IBBSS Nigeria 2010

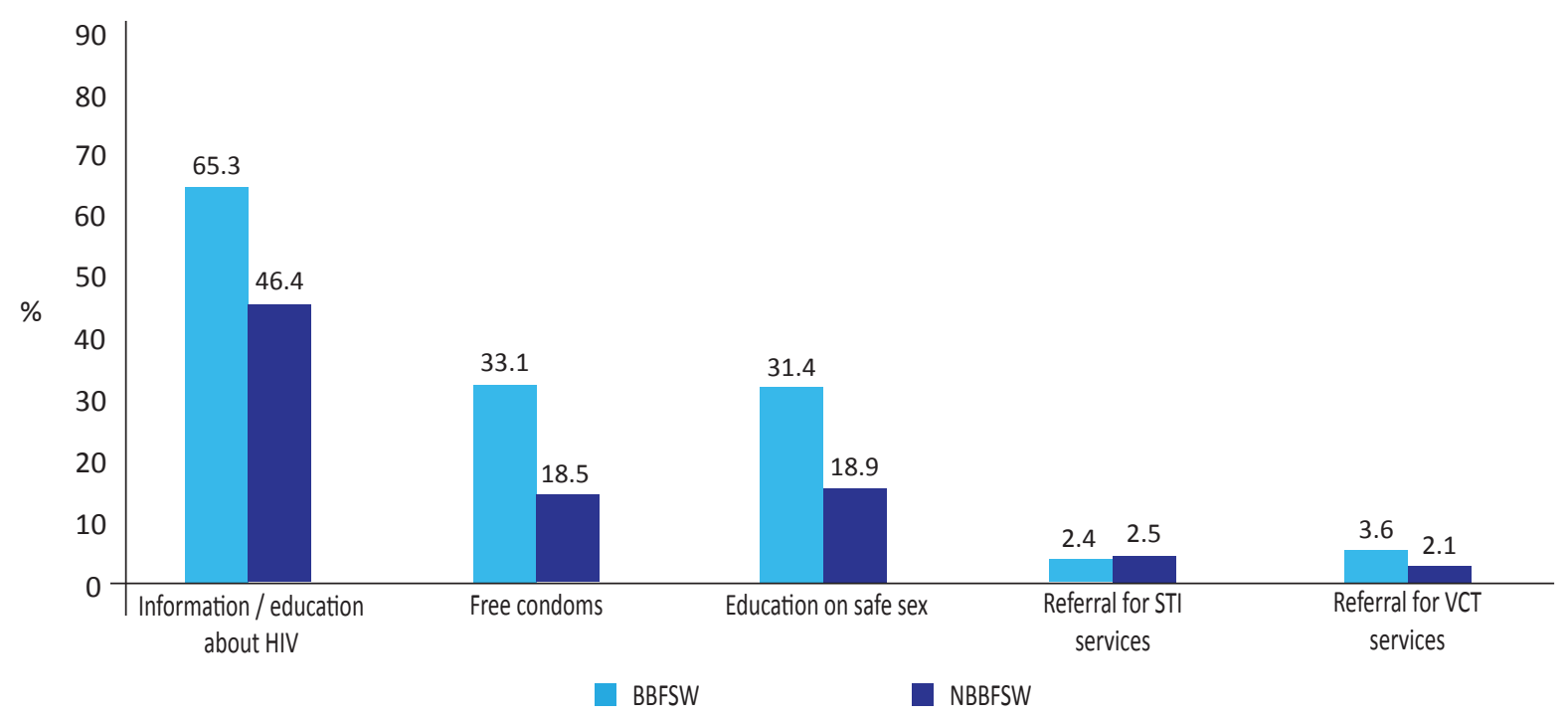


Figure 48: Distribution of MSM according to HIV prevention services received in the last 12 months preceding the survey, IBBSS Nigeria 2010

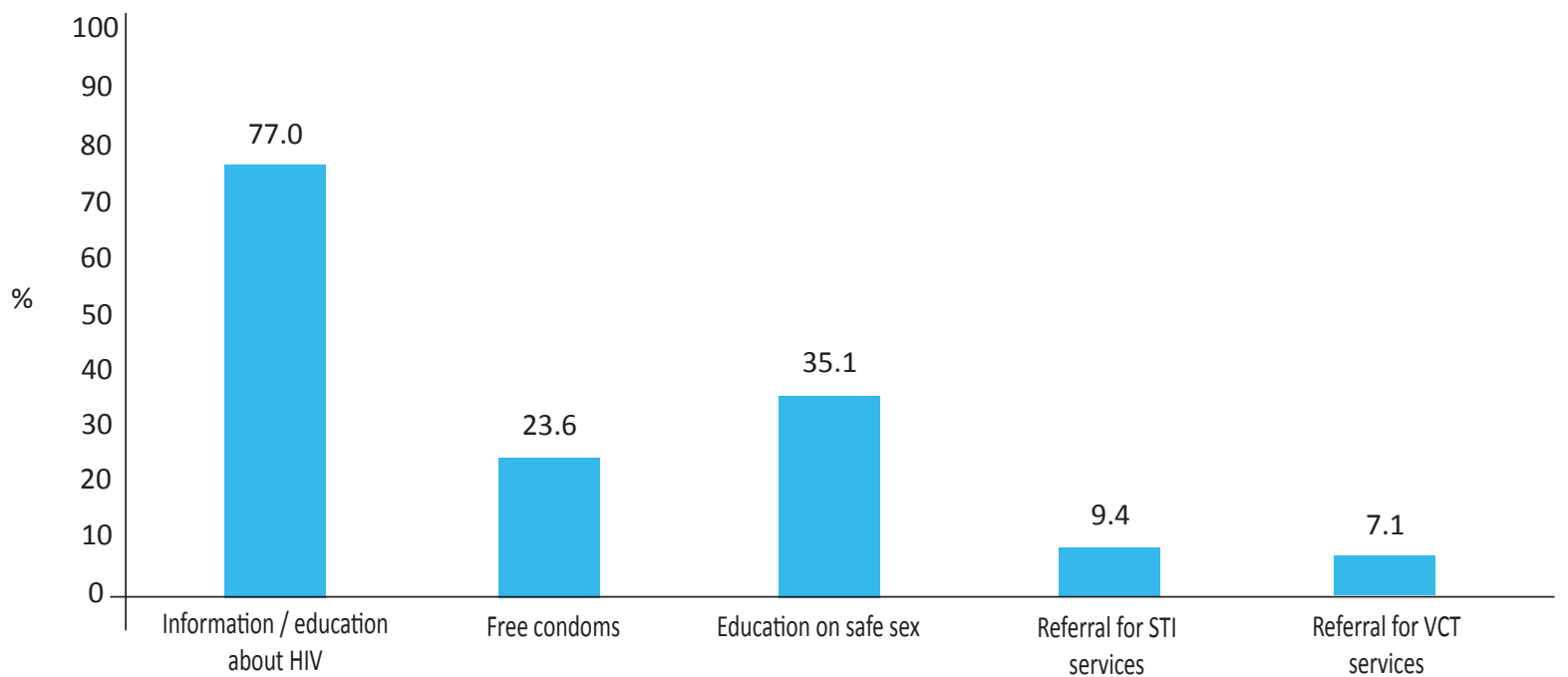

Figure 49: Distribution of IDU according to HIV prevention services received in the last 12 months preceding the survey, IBBSS Nigeria 2010

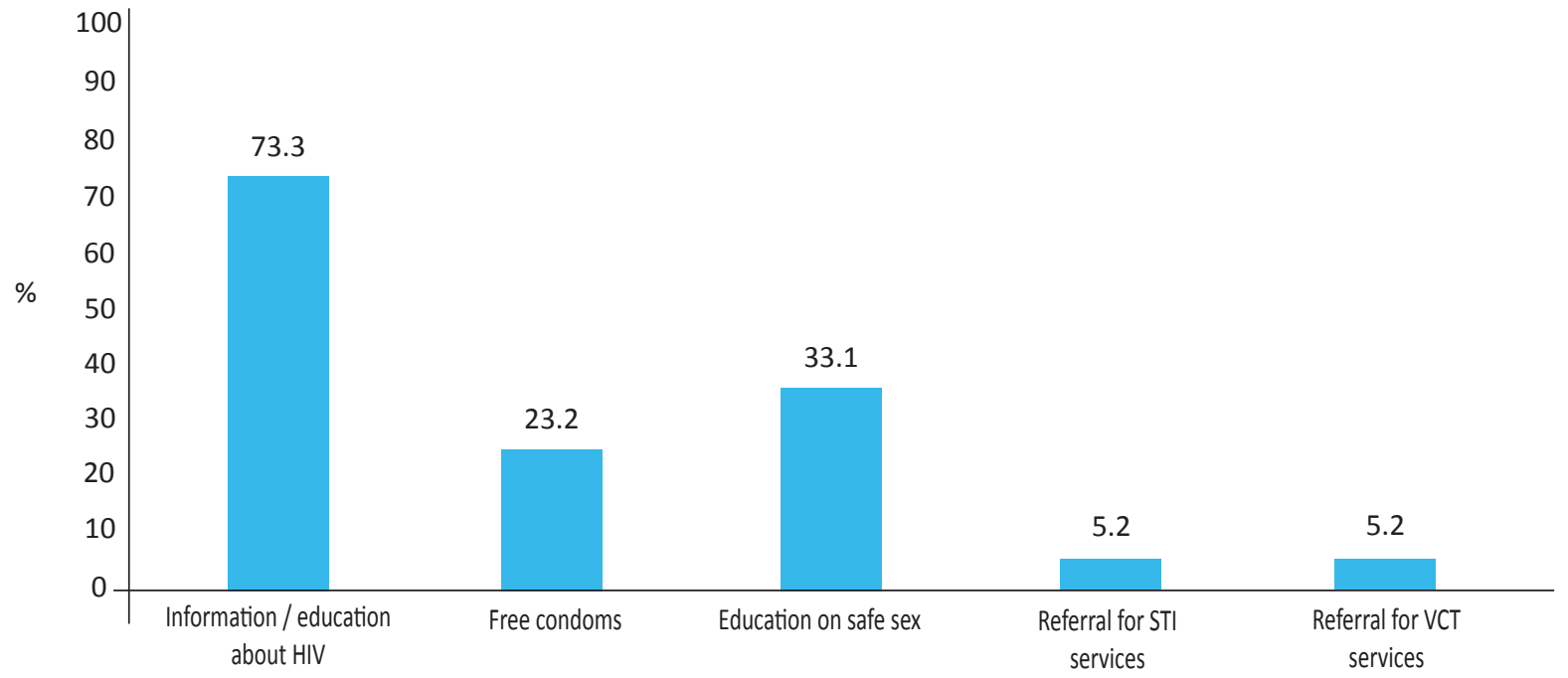

Figure 50: Distribution of predominantly male occupational groups according to HIV prevention services received in the last 12 months preceding the survey, IBBSS Nigeria 2010

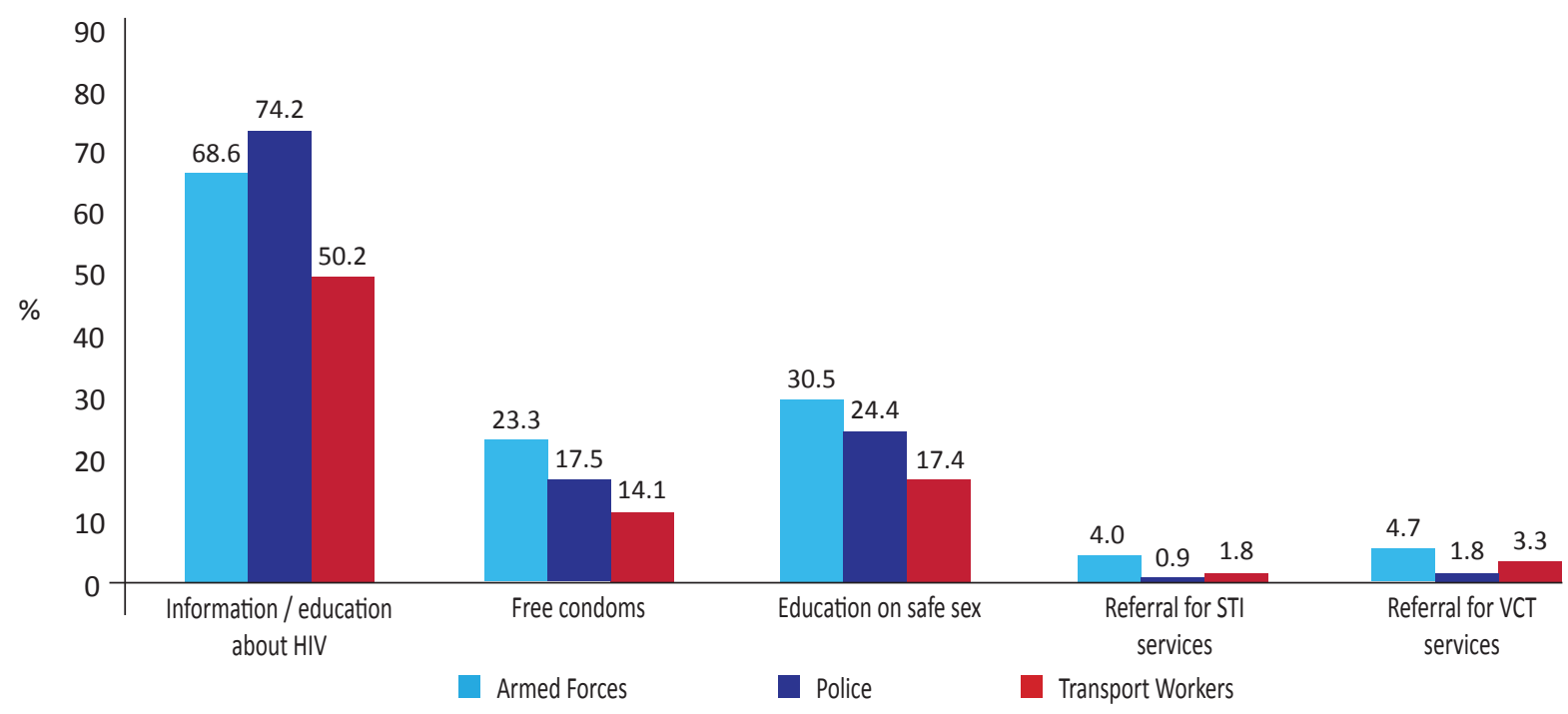


All the groups surveyed were shown to have received HIV information/education than free condoms, safe sex or referral services for STI and VCT. MSM surveyed were more likely than the other groups to report receipt of referral services.

\subsubsection{Discussion}

Evaluation of exposure to different types of HIV/AIDS related services, information and education is critical to further planning and implementation of HIV programs. State level analysis presented in the appendix gives a geographical representation of the services available to the different study groups. The Armed Forces showed good access and utilisation of HIV testing services and this is reflected in the proportion of those who know their HIV status.

A good proportion of all the members of the study groups reported receiving any HIV/AIDS information or education in the last 12 months preceding the survey. However, TW and NBBFSW seemed to be less reached with these services. Referral to STI and HCT services in the past 12 months prior to the survey was very low among all groups. Provision of free condoms and education on safer sex were also low. 


\section{TREND OF SELECTED BEHAVIOURAL INDICATORS}

ata from the 2005 BSS and the 2007 IBBSS were analysed for trend with the 2010 IBBSS on certain indicators in selected states that participated in the three surveys. MSM and IDU were only sampled in 2007 and 2010 and these two points in participating states were compared. All indicators were rounded up to the nearest whole number.

\subsection{Ever had HIV Test}

The proportions of respondents ever tested for HIV were compared.

Figure 51: Proportion of Armed Forces who have ever tested for HIV by state (2005-2010), IBBSS Nigeria 2010

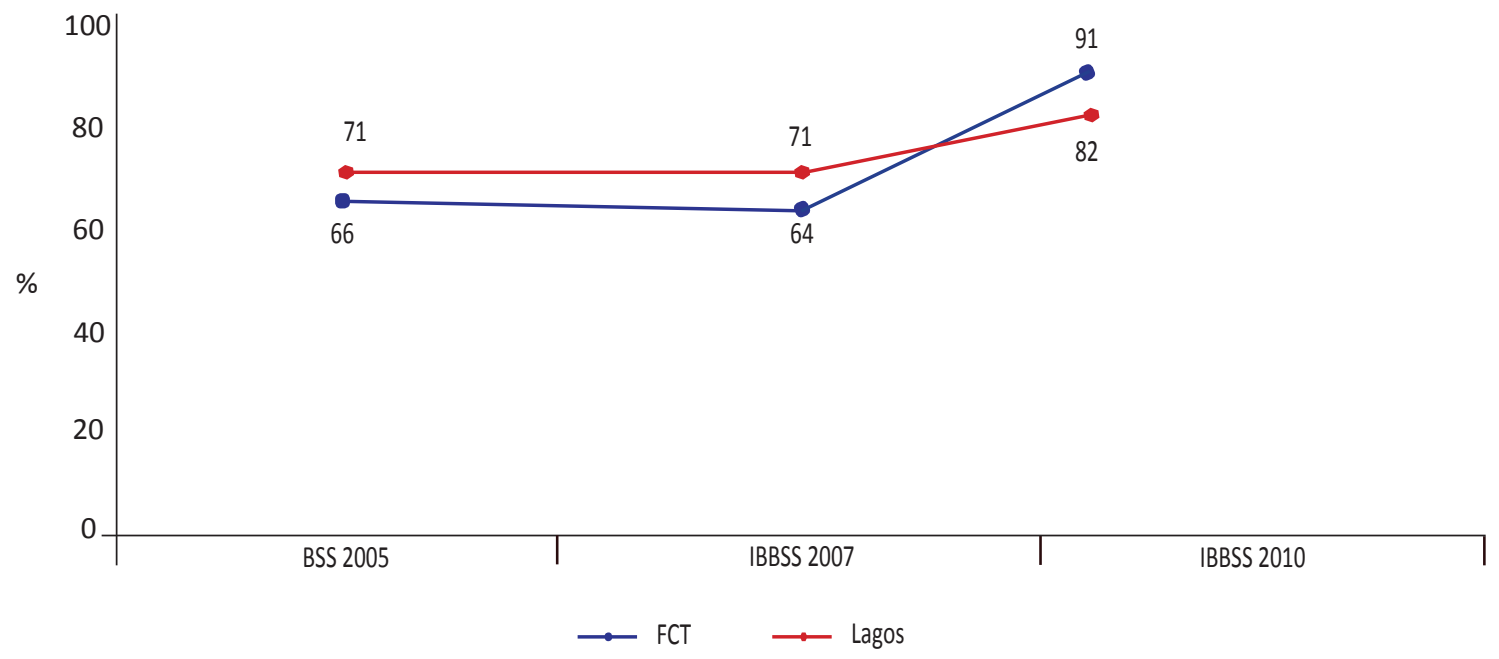

Figure 51 shows the trend in HIV testing among Armed Forces personnel for two states - FCT and Lagos. Overall there appeared to be an increase in the proportions reporting they ever tested, especially more among Armed Forces personnel in the FCT.

Figure 52: Proportion of Police who have ever tested for HIV by state (2005-2010), IBBSS Nigeria 2010

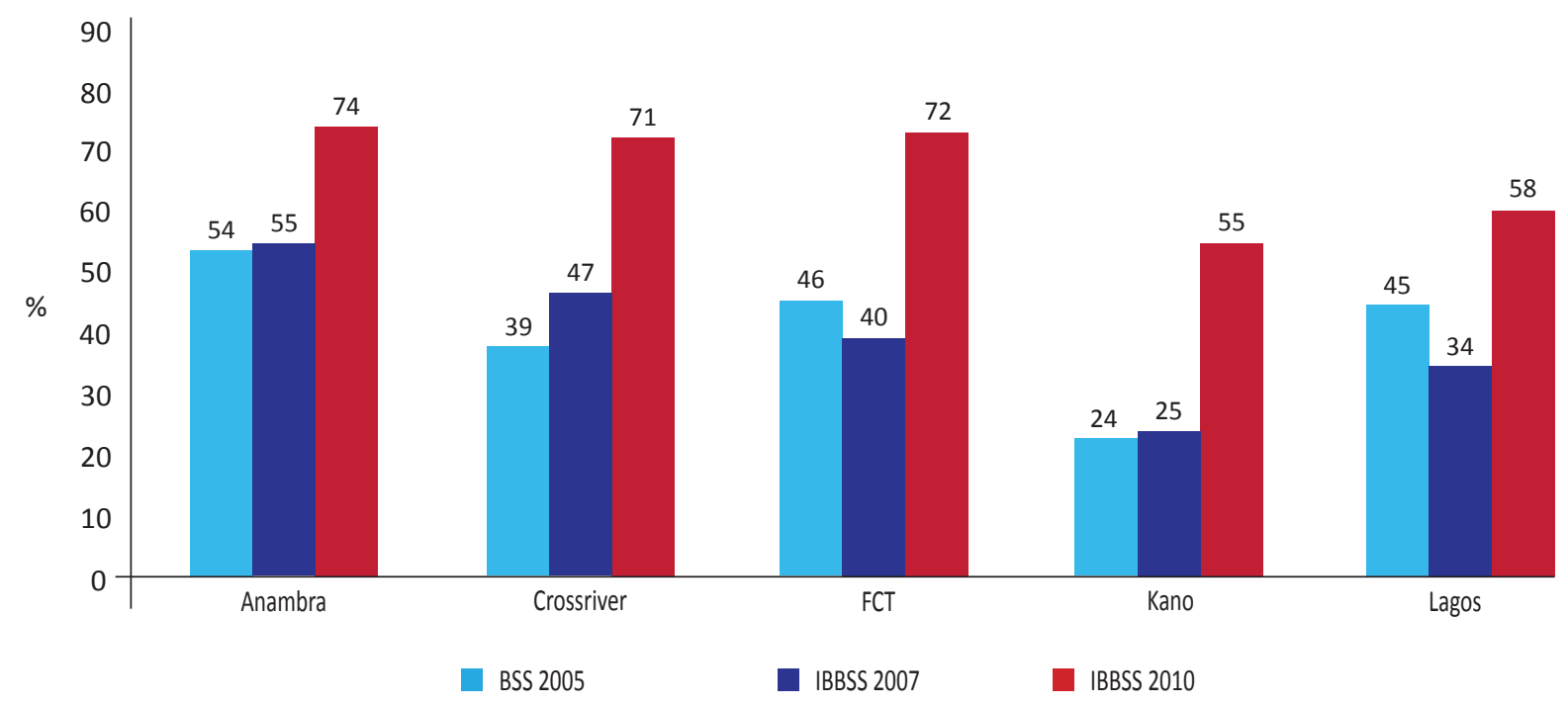


The proportion of Police who have ever tested for HIV was found to increase in all the five states surveyed between 2005 and 2010

Figure 53: Proportion of transport workers who have ever tested for HIV by state (2005-2010), IBBSS Nigeria 2010

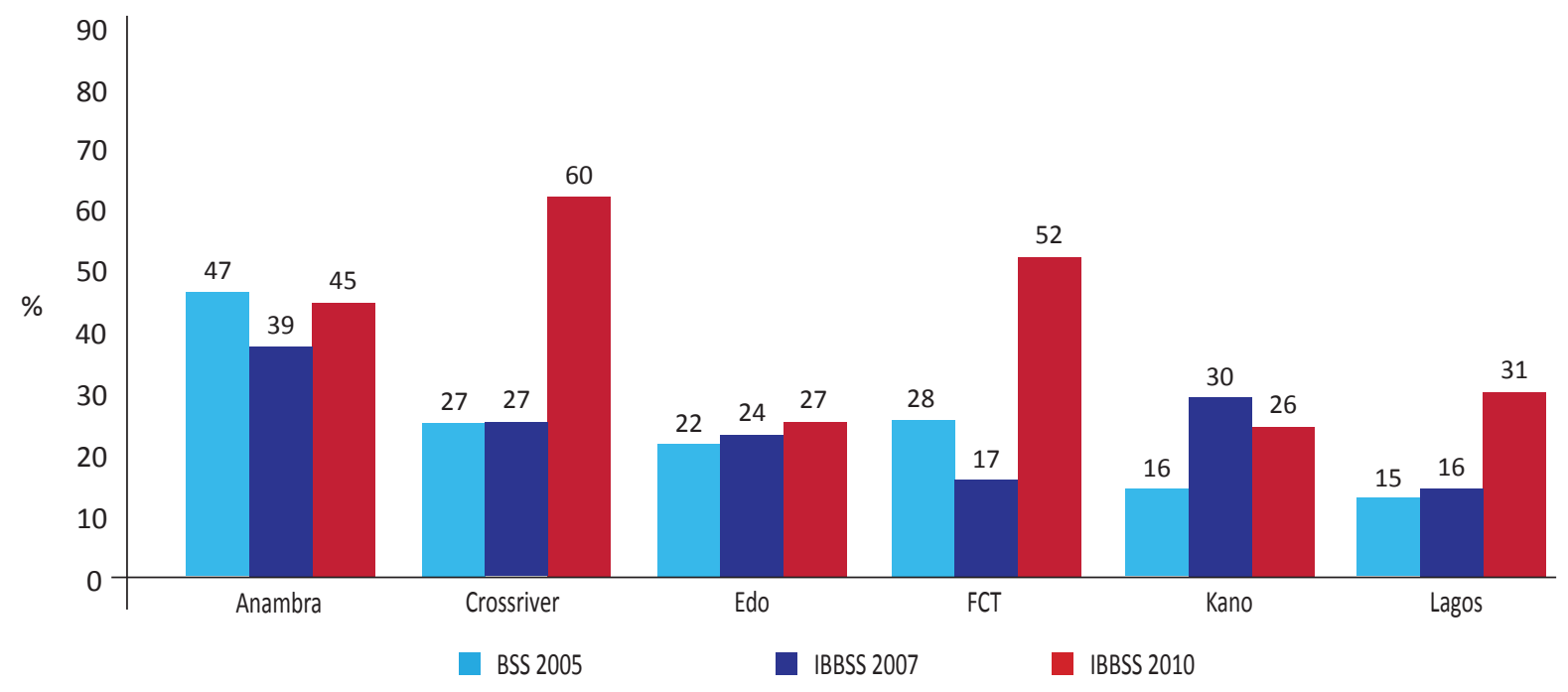

Figure 54: Proportion of FSW who have ever tested for HIV by state (2005-2010), IBBSS Nigeria 2010

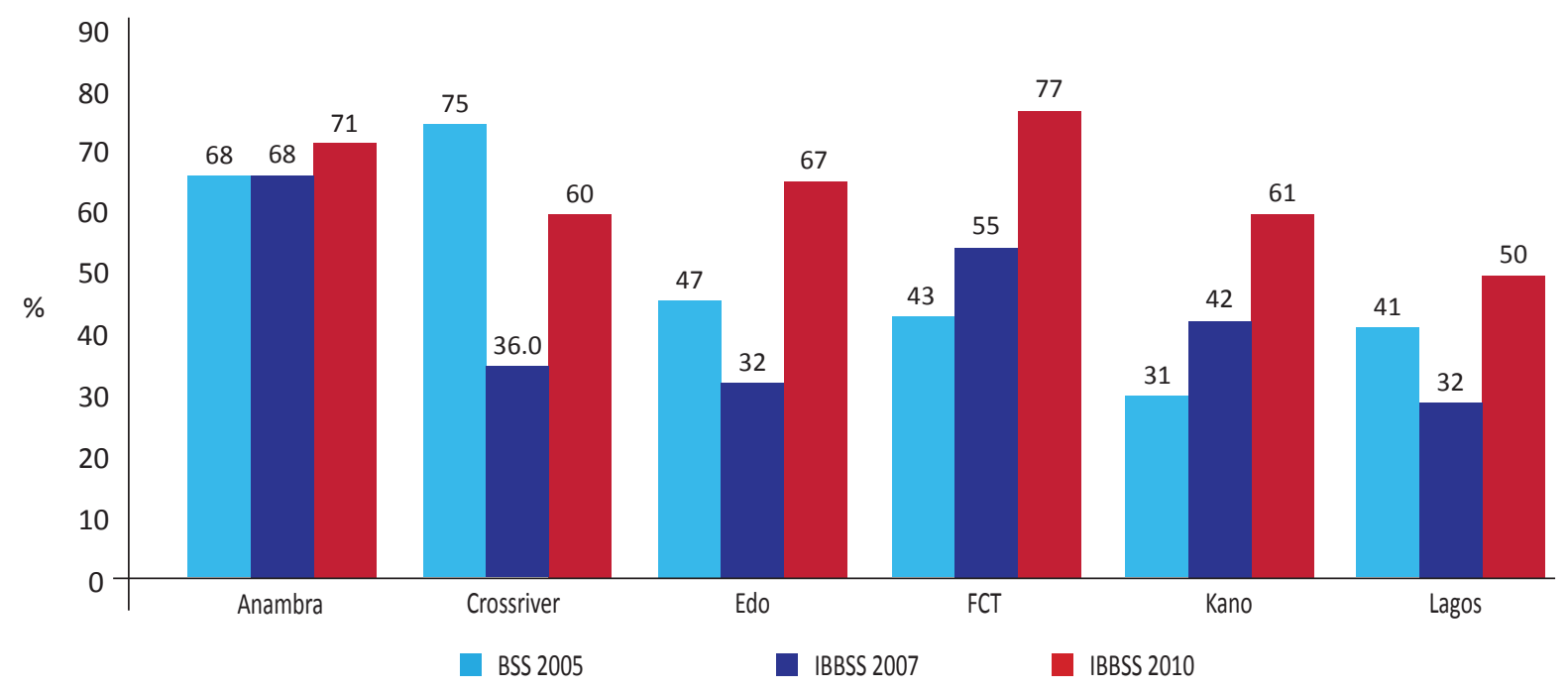

FSW in FCT and Kano had progressive improvements in the proportions reporting they ever had an HIV test across the three time points. The proportion that ever tested almost doubled between the 2005 BSS and the 2010 IBBSS. No appreciable change in HIV test among FSW in Anambra (Figure 54). 
Figure 55: Proportion of IDU who have ever tested for HIV by state (2007-2010), IBBSS Nigeria 2010

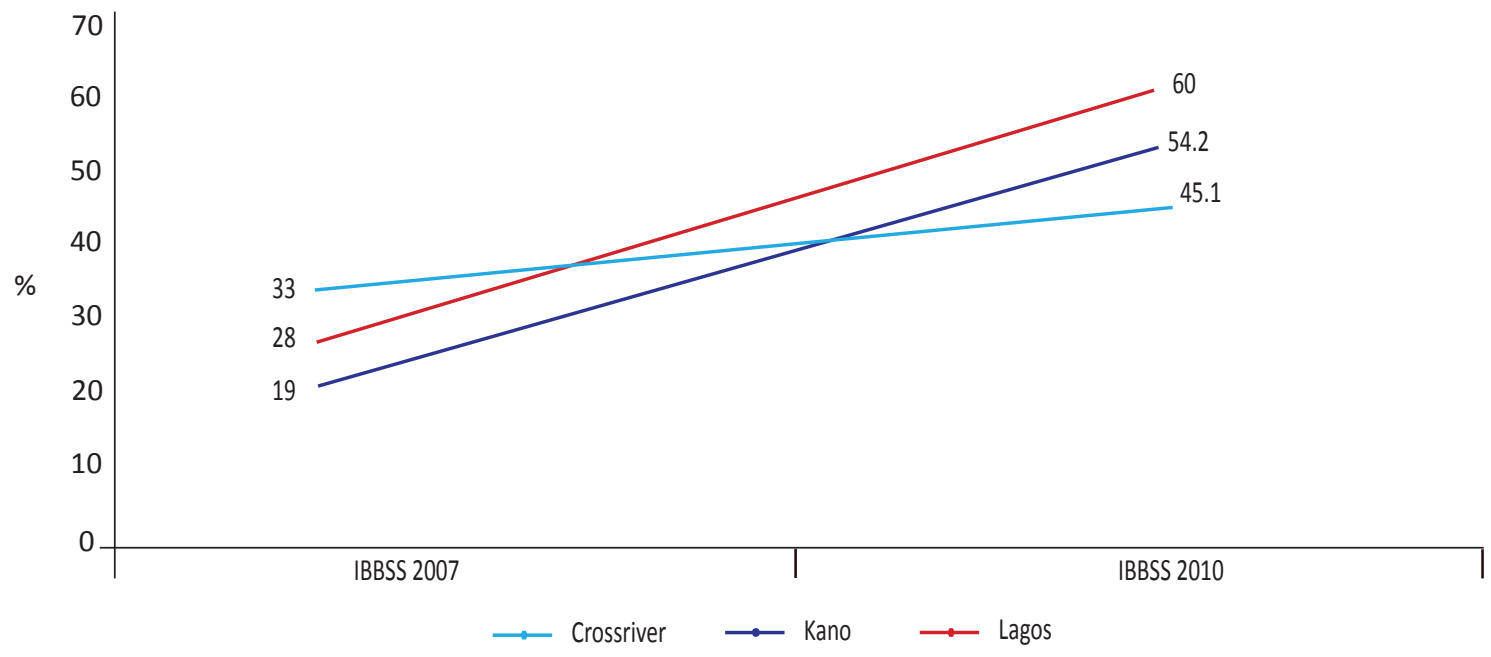

Figure 56: Proportion of MSM who have ever tested for HIV by state (2007-2010), IBBSS Nigeria 2010

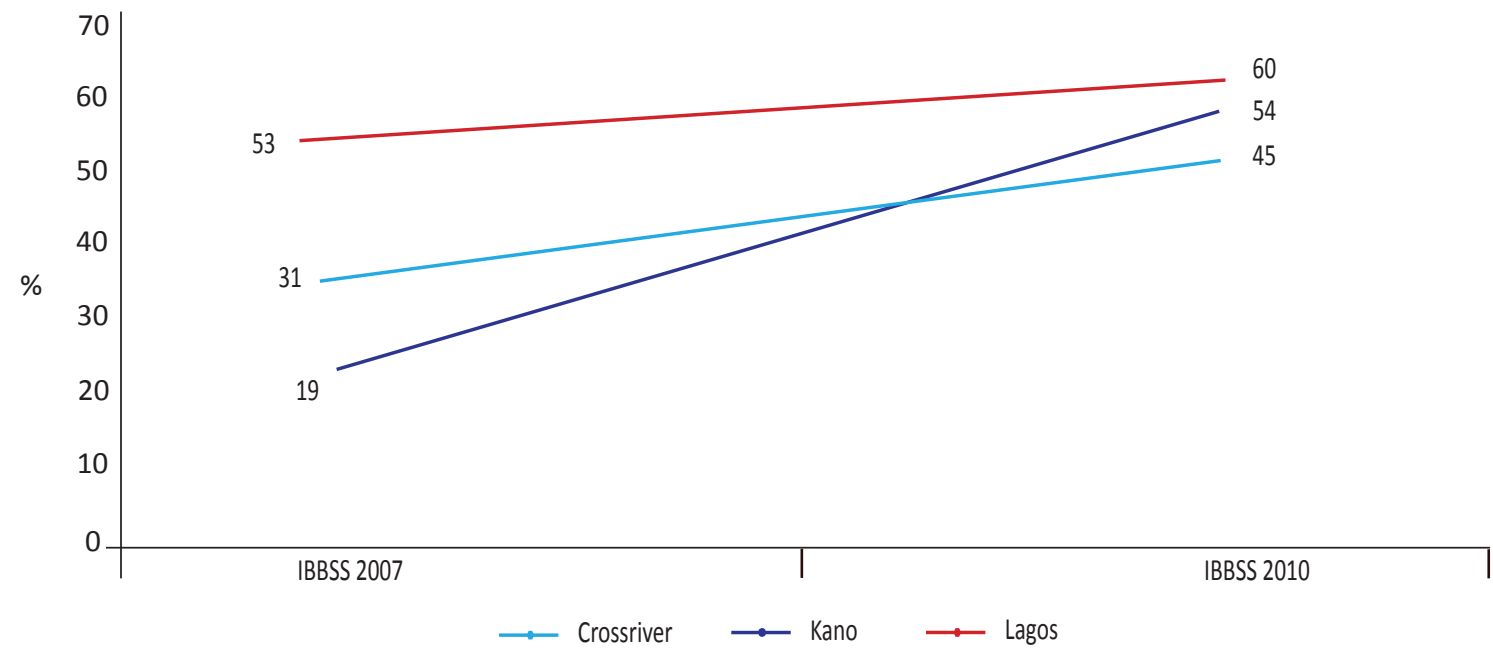

\subsection{Sex with female sex worker by study group}

Figure 57: Proportion of Armed Forces who have had sex with a FSW in the past 12 months by state (2005-2010), IBBSS Nigeria 2010

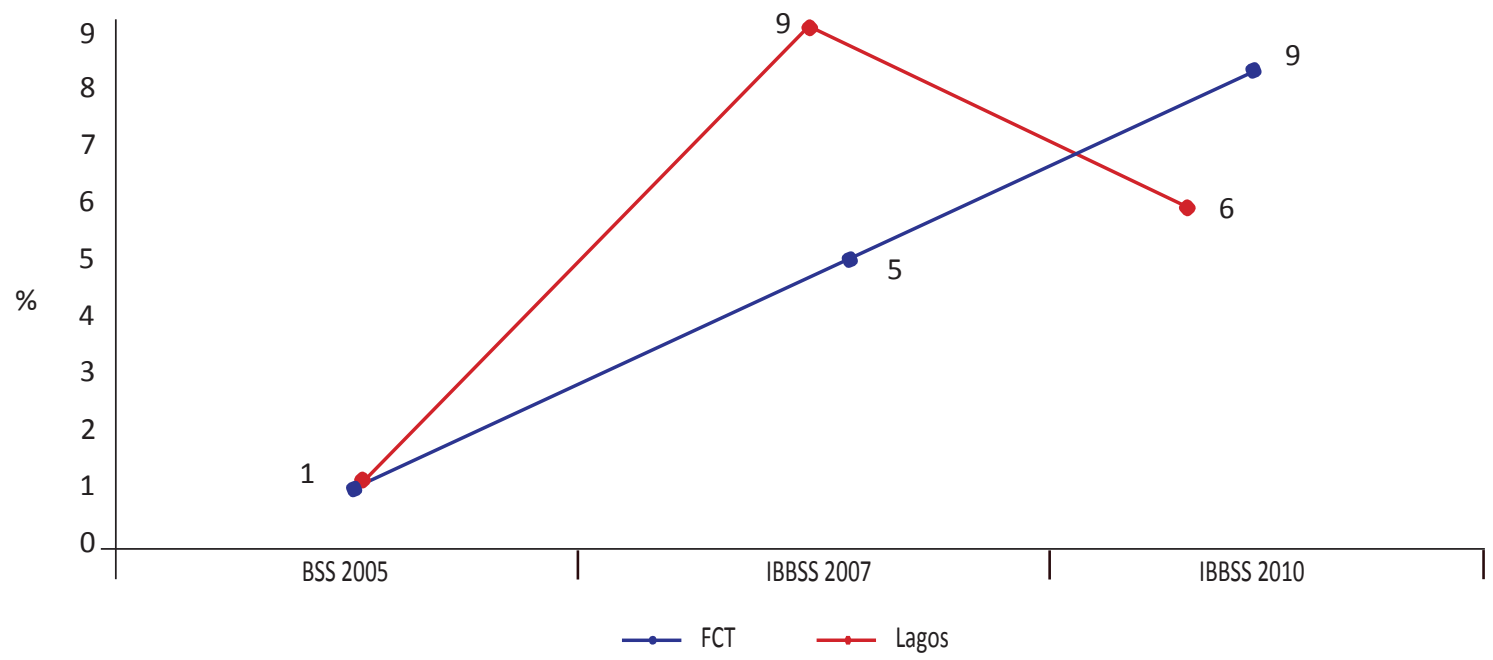


Figure 58: Proportion of the Police who have had sex with a FSW in the past 12 months by state (20052010), IBBSS Nigeria 2010

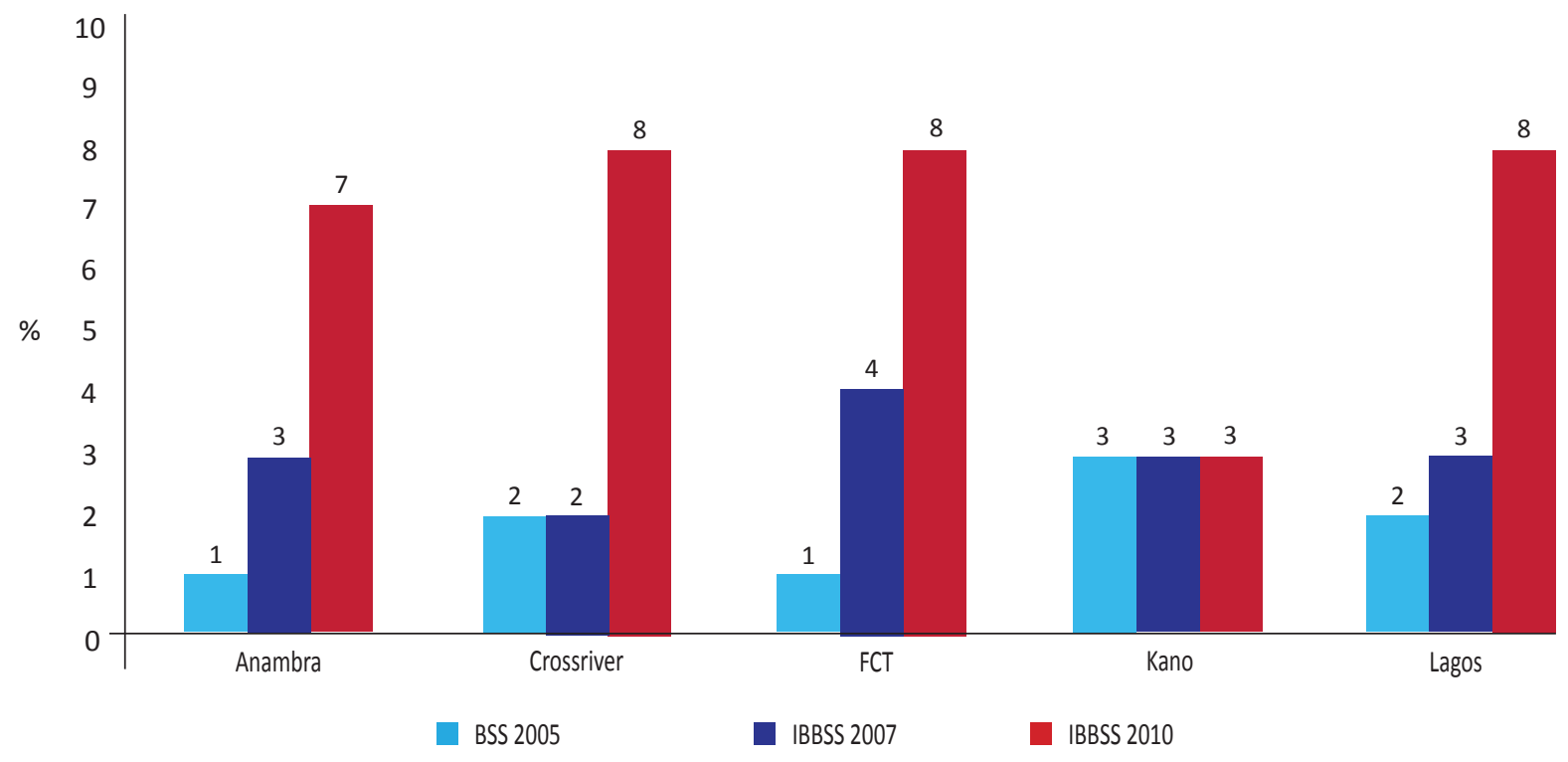

Figure 59: Proportion of TW who have had sex with a female sex worker in the past 12 months by state (2005-2010), IBBSS Nigeria 2010

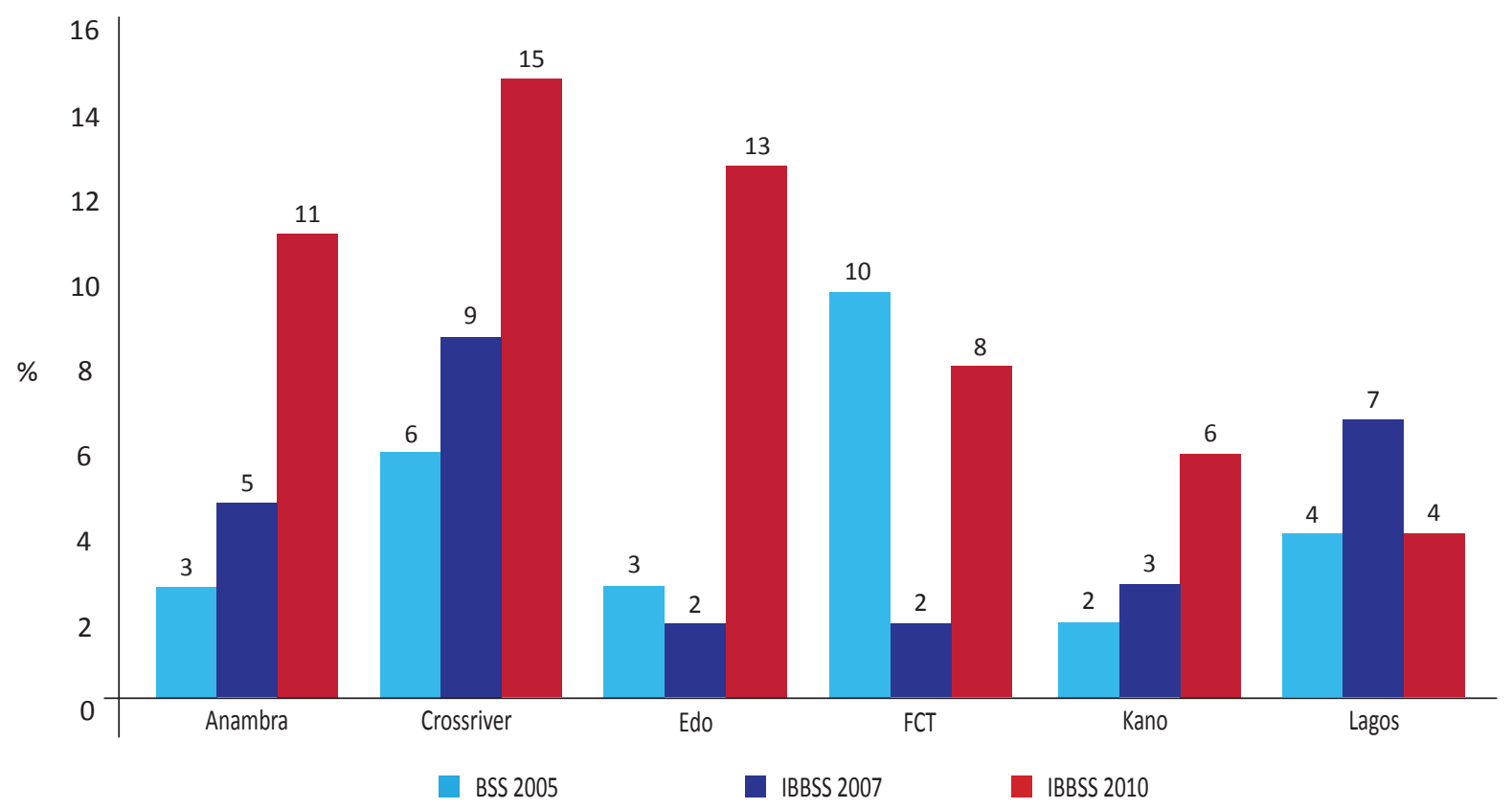

The trends in the proportions reporting they had sex with a FSW 12 months preceding the survey are shown for Armed Forces, Police and TW (Fig. 57 to 59). There were significant increases in the proportion reporting this behaviour for Police in all the states except Kano. TW also showed increase in this behaviour in all states except Lagos. Armed Forces personnel in Lagos showed increase in this indicator between the 2005 BSS and 2007 IBBSS but a decline in 2010, while there was a progressive increase among those in the FCT. None of the target groups had a consistent decline in the level of this indicator. 


\subsection{Consistent condom use}

Figure 60: Consistent condom use with clients among FSW in the last 1 month by state (2005-2010), IBBSS Nigeria 2010

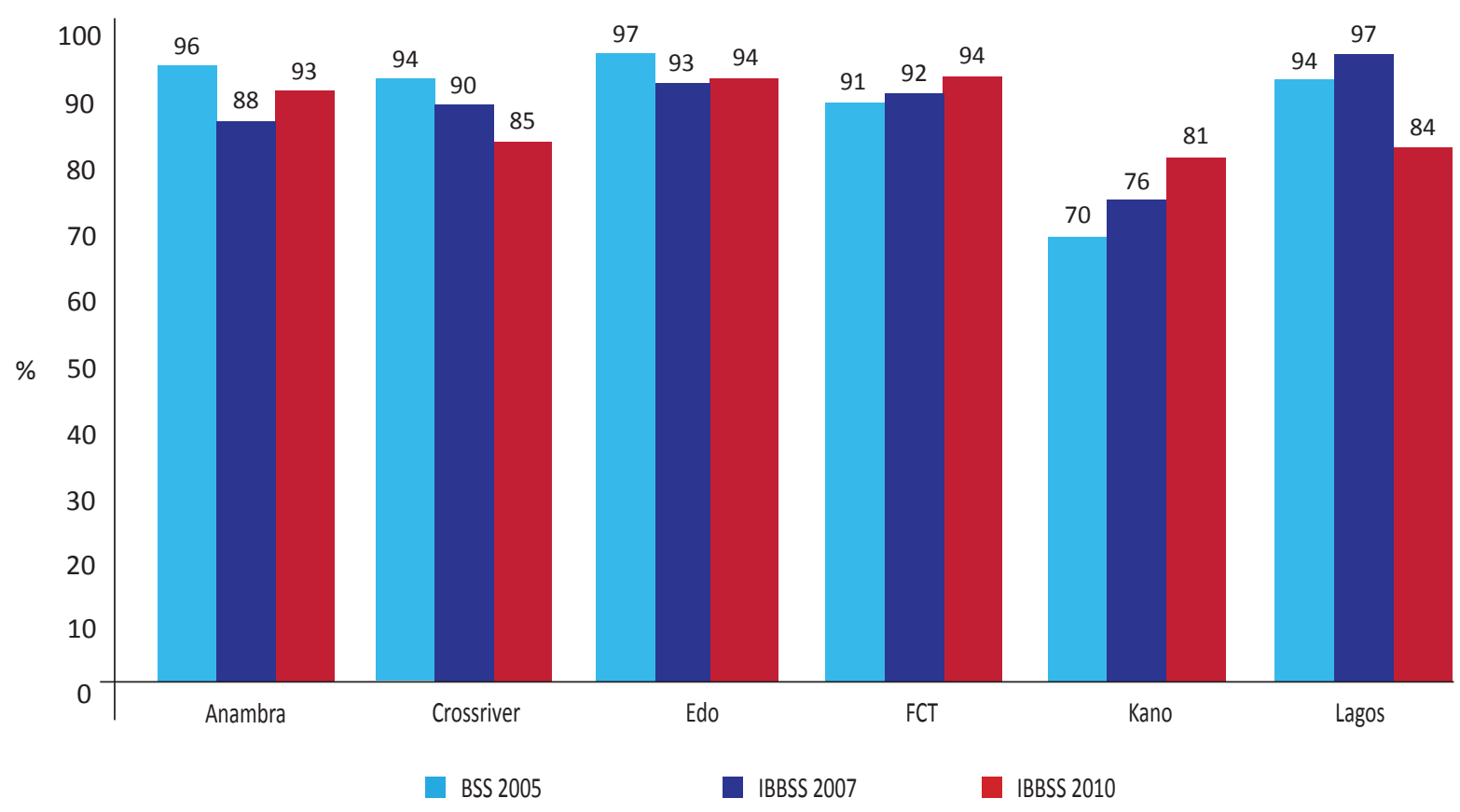

The trend in consistent condom use with client among FSW is shown in Figure 60. There were only modest changes in the figures in the six states studied over the 2005 BSS, the 2007 IBBSS and the 2010 IBBSS, suggesting that consistent condom use with clients has remained over $80 \%$ except in Kano.

Figure 61: Proportion of MSM who consistently used condom with a non- paying male partner in the last 6 months (2007-2010), IBBSS Nigeria 2010

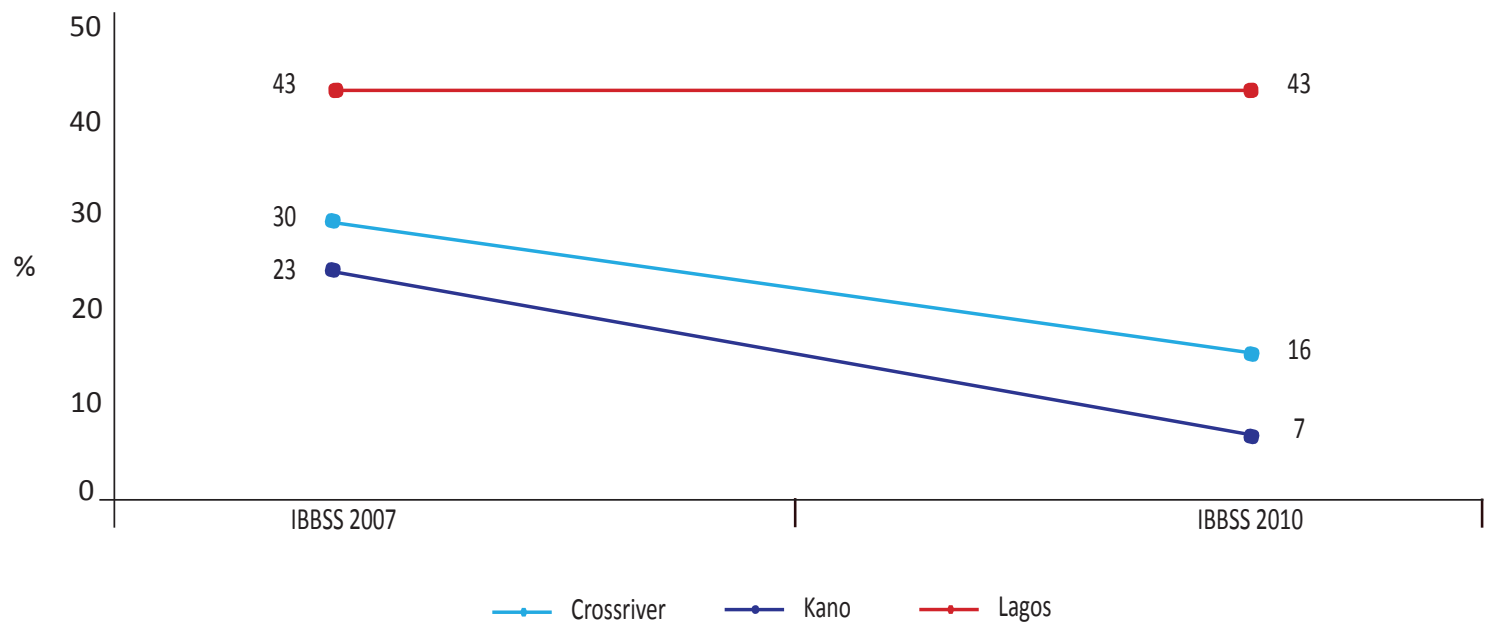

Figure 61 shows the change in the level of consistent condom use with non-paying male partners among MSM between the 2007 and 2010 rounds of the IBBSS. There were lower figures for this indicator in Cross River and Kano States in 2010 compared to 2007, suggesting a drop in consistent condom use with non-paying male partners. Figures in Lagos remained constant. 


\subsection{Use of sterile injecting equipment}

Figure 62: Proportion of IDU who reported always use of sterile injecting equipment in the last 1 month prior to the survey by state (2007-2010), IBBSS Nigeria 2010

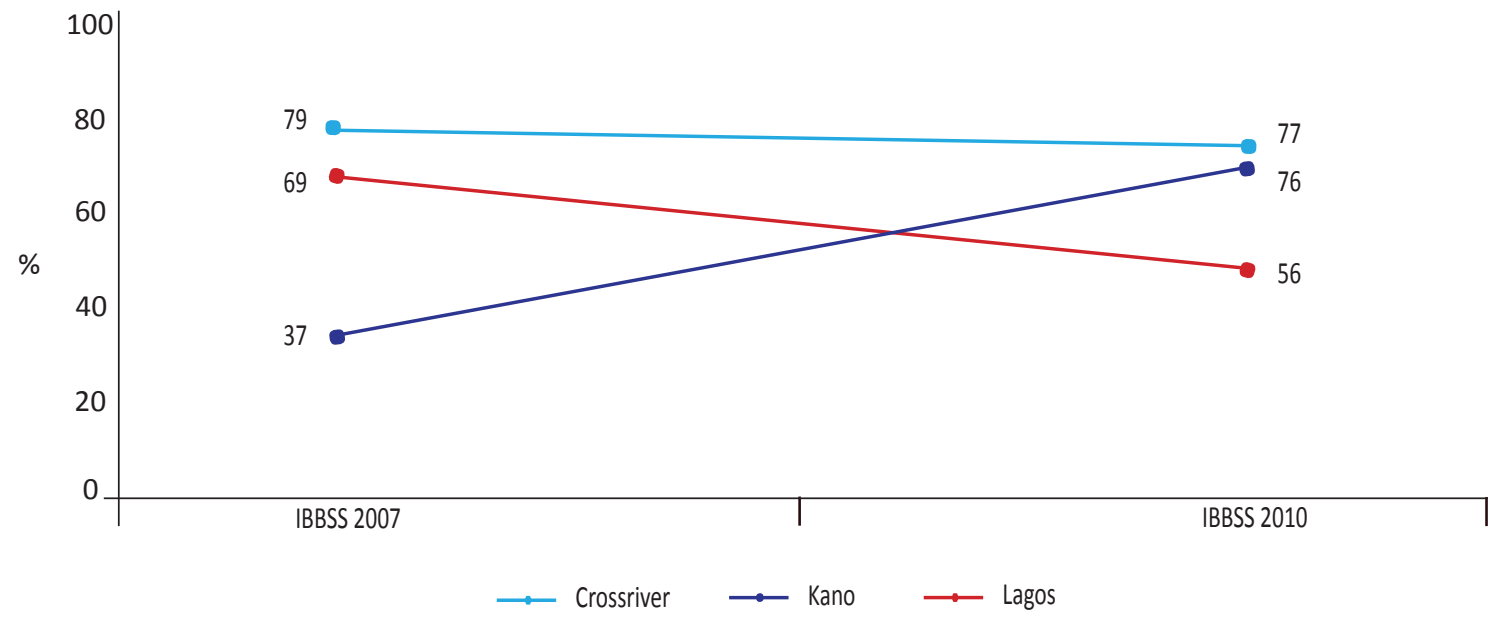

The consistent use of sterile injecting equipments in the past month by IDU for the 2007 and 2010 IBBSS is shown in Figure 62. The proportion reporting such behaviour was higher among IDU in Kano state in the 2010 IBBSS while Cross River and Lagos reported lower figures in 2010 compared to 2007.

In general, values for majority of the indicators show improvement in certain indicators, or maintenance of trends. 


\section{DISCUSSION AND RECOMMENDATIONS}

$\mathrm{T}^{\mathrm{T}}$ 2010 IBBSS provides several new insights into the current state and potential future direction of the HIV epidemic in Nigeria among the study groups. Most important contribution is the continuing insights into HIV prevalence in the study groups investigated.

\section{HIV prevalence and STI symptoms}

There is now concrete evidence of the unequal distribution of the burden of HIV in Nigeria, including among groups about whom little was known (MSM and IDU). FSW still bear the brunt of the HIV epidemic in Nigeria, with HIV prevalence levels among BBFSW as high as $46 \%$ in Benue and Nasarawa States, states which incidentally also have high HIV prevalence among the ANC attendees ( $12.7 \%$ and $7.5 \%$ respectively) used as proxy for the general population (FMOH ANC 2010). MSM in the FCT were also severely affected, with almost one out of every three respondents testing positive for HIV in the IBBSS 2010, which is particularly worrisome as most of those sampled in this group were under the age of 25.

At the other end of the spectrum, all three predominantly male occupational groups returned HIV prevalence levels considerably lower than the 2010 ANC attendees' estimates, $4.1 \%$ (FMOH ANC 2010). The Armed Forces HIV prevalence continues to remain low, at 2.5\% (compared to $3.1 \%$ in 2007 IBBSS). The highest HIV prevalence among the Armed Forces was seen in Benue state, but this was still lower than among other groups within the state. Female Police had higher prevalence (4.5\%) compared to male Police (2.0\%). Transport workers had the lowest prevalence among all the study groups. Despite this, in Benue State the prevalence among transport workers was very high at $8.0 \%$ which probably mirrors the prevalence among the general population. These results may signify the need to re-classify 'high-risk' groups for HIV in Nigeria.

Prevalence was low among IDU suggesting a limited risk of transmission among them. The exception here is in the case of female IDU who had HIV prevalence of $30 \%$.

Another important observation from the 2010 IBBSS was the low level of self reported STI symptoms including genital ulcers/sores and unusual genital discharge in most groups, except in the case of sex workers (both BBFSW and NBBFSW).

\section{FSW}

Data on risk behaviours and trends presented in relation to previous BSS rounds suggest that condom use in commercial sex transactions is generally high. Condom use was far less likely in boyfriend relationships, and the data indicate that these relationships are quite common for both BBFSW and NBBFSW. Higher risk taking through non condom use with boyfriends may be associated with emotional trust and confidence built in the course of a steady relationship. Multiple partnerships of this nature and casual partners coupled with low condom use can act as facilitators for HIV transmission, and could form a bridge to the general population. Despite the high level of condom use with clients among FSW, HIV prevalence remains high among these groups.

An additional important finding was that young sex workers (15 to 19 years of age) and sex workers who have worked for less than one year also have high HIV prevalence. While it cannot be ruled out that this group contracted HIV before sex work, there is a high possibility that many get infected soon after entrance into sex work, likely as a result of poor condom negotiation skills and the larger number of clients and other sexual partners young girls have. 
Education may also play a role in reducing HIV prevalence in this target group. HIV prevalence was highest among FSW with either primary or no formal education. This may explain their poor negotiating skills as their dependence on sex work may be greater, based on their low level of education.

\section{MSM}

MSM reported highly risky sexual behaviour, as condom use in anal sex was low; relatively the same for both paying and non-paying partners, and over one third of the respondents had sold sex in the past six months. Half of MSM surveyed had sexual relationship with at least one female partner in 12 months preceding the survey, suggesting significant bridging with female populations including girlfriends and casual partners and another tenth that patronised FSW.

Consistent condom use was generally low. Of those MSM that sold sex, only about a third used condom consistently in the last 12 months preceding the survey.

\section{IDU}

A third of female IDU reported selling sex. Female IDU sell sex to obtain money to purchase drugs. Careful attention need to be paid to sexual transmission among both male and female groups, as many have links with the wider population. In particular, female IDU should be targeted with innovative HIV prevention messaging. IDU had low level of knowledge of HIV prevention transmission due to high level of misconceptions about HIV transmission, however high proportion of them (82.6\%) used sterile injecting equipments. Condom use at last commercial sex was high compared to last sex with girlfriend though only a fifth of them considered themselves at risk of HIV.

\section{Police}

Despite the low HIV prevalence recorded among the Police, low HIV risk perception, low level of knowledge of HIV prevention transmission and low condom use at last commercial sex are potential risk factors for HIV transmission among the Police.

\section{Armed Forces}

HIV infection levels follow similar trends in the Police in each state. Multiple sexual partnerships were reported by almost a quarter of male members of the Armed Forces in the 12 months leading up to the survey, mainly girlfriends. Condom use was less likely in boyfriend/girlfriend relationships. This would suggest the possibility of spread of HIV infection despite the current low levels of HIV infection among this group across most states, so interventions will need to be maintained among this group to prevent increased transmission rates.

The higher use of condoms by Armed Forces compared with the Police and TW has apparently resulted in a lower report of STI symptoms by the Armed Forces, and this may have impact on HIV transmission among this group.

\section{Transport Workers}

Similar levels of multiple partnering exist among TW as with other predominantly male occupational groups but lower levels of condom use and higher levels of STI symptoms were reported. Promoting STI treatment, free condom distribution and mobile HIV counseling and testing could reduce risks of HIV transmission significantly among these groups, especially in states with higher HIV prevalence. Since the 2007 IBBSS survey report, a considerable number of interventions have commenced among the study groups, MSM in particular. 


\section{General Recommendations}

Since the 2007 IBBSS survey report, a considerable number of interventions have commenced among the study groups, MSM in particular. The demographic and behavioural differences between study groups in various states and the results coming from a single state can significantly differ from national group averages. This gives programme managers, donors and policy makers the opportunity to target prevention and care resources to different groups and geographic areas more effectively in the principle of 'Know your epidemic, Know your response' at the state and national level. These differences are expected to make significant impact on programming at various levels and among various study groups at the state levels.

\section{Group Interactions}

There were limited signs of behavioural interactions between IDU, MSM and FSW, linkages which are believed to be responsible for accelerating HIV epidemics in certain concentrated epidemic settings. There are however significant linkages between each of these groups with the perceived 'general' population such as MSM with girlfriends and FSW with boyfriends. Targeted interventions should address these.

\section{Population Size Estimates}

To better understand the potential for the wider spread of HIV, reliable population size estimates of FSW, MSM and IDU are needed urgently in certain states. These estimates need to be viewed together with results of this report to help target limited prevention and care resources. Future rounds of surveillance should consider estimating the population size of IDU, MSM and FSW and expand their surveillance outside of the states surveyed in 2010.

\section{Accurate HIV Prevention Messaging}

The low accurate knowledge of prevention of sexual transmission of HIV, high level of misconceptions and low self-risk perception for HIV among all the groups need to be addressed. HIV education campaigns must provide appropriate information on HIV prevention and mode of transmission and dispel myths. This may increase self-risk perception for HIV and promote safer sex practices.

\section{Condom Use and Gender-Based Programming}

The discrepancies between responses of FSW and the male groups surveyed regarding condom use in commercial sex will merit further research. The continuing risk of transmission among FSW and high reported use of condom with clients suggest possible over-reporting of condom use. Economic empowerment of females and gender-sensitive HIV programming to decrease dependence on sex work and increase condom negotiating skills are highly recommended.

\section{HIV Test}

Increased access to HIV counselling and testing is recommended as part of intervention for all the study groups. Mobile HCT might be useful among NBBFSW, MSM and IDU.

\section{Linking Testing to Care, Support, and Treatment Services}

Many FSW, IDU, MSM and TW report having ever been tested for HIV and having recently been tested. While it is important for high risk groups to be aware of their HIV status, it is critical that those who are diagnosed as positive are linked to services in care, support, and treatment. Future surveys can also explore the awareness and utilization of care, support, and treatment services among those who know their status. 


\section{Further use of survey data and recommendation for next survey}

Considerable knowledge, behavioural and intervention exposure related data are reported to provide insights into current and future HIV transmission routes. Only a selection of this data was included in the report, highlighting the need for further and ongoing analyses. 


\section{REFERENCES}

1. Federal Ministry of Health Nigeria (2003). National HIV and AIDS and Reproductive Health Survey, 2003, Federal Ministry of Health, Abuja.

2. Federal Ministry of Health Nigeria (2005). National HIV and AIDS and Reproductive Health Survey, 2005, Federal Ministry of Health, Abuja.

3. Federal Ministry of Health (2007) 2008 National HIV sero-prevalence sentinel survey. Federal ministry of Health National AIDS/STI Control Programme.

4. Federal Ministry of Health (2008) 2007 National HIV and AIDS and Reproductive Health Survey Plus. Federal ministry of Health National AIDS/STI Control Programme. 


\section{APPENDIX}

\subsection{Appendix I: Summary indicators for each of the target groups}

\section{Table 13: Summary Indicators for FSW, IBBSS Nigeria 2010}

\begin{tabular}{|l|l|l|}
\hline Indicator & BBFSW (\%) & NBBFSW (\%) \\
\hline $\begin{array}{l}\text { Percentage of all respondents who had a comprehensive and correct } \\
\text { knowledge of HIV prevention methods }\end{array}$ & 31.8 & 38.2 \\
\hline Percentage of FSW who reported daily alcohol use & 28.0 & 26.6 \\
\hline Percentage of FSW who reported marijuana use & 13.3 & 11.5 \\
\hline Percentage of FSW who reported cocaine and/or heroin use & 2.4 & 1.9 \\
\hline Average number of clients per week & 26.2 & 7.8 \\
\hline $\begin{array}{l}\text { Percentage of FSW having sex with more than 1 boyfriend in the last } \\
12 \text { months }\end{array}$ & 5.2 & 14.5 \\
\hline Percentage of FSW with any STI symptom in the last 12 months & 15.1 & \\
\hline Condom use at last sex with client & 95.1 & 25.0 \\
\hline Consistent condom use with clients in the last 1 month & 90.6 & 91.5 \\
\hline Condom use at last sex with boyfriend & 30.3 & 76.5 \\
\hline Consistent condom use with boyfriend in the last 1 month & 20.7 & 44.1 \\
\hline Percentage of FSW who reported being forced to have sex & 3.7 & 26.1 \\
\hline FSW ever tested for HIV & 71.9 & 14.0 \\
\hline FSW tested and received results & 67.6 & 56.2 \\
\hline HIV prevalence & 27.4 & 52.3 \\
\hline
\end{tabular}

Table 14: Summary indicators for MSM, IBBSS Nigeria 2010

\begin{tabular}{|l|l|}
\hline Indicator & $\%$ \\
\hline $\begin{array}{l}\text { Percentage of all respondents who had a comprehensive and correct knowledge of } \\
\text { HIV prevention methods }\end{array}$ & 33.1 \\
\hline Percentage of MSM who reported alcohol use & 5.0 \\
\hline Percentage of MSM who reported marijuana use & 19.1 \\
\hline Percentage of MSM who reported cocaine and/or heroin use & 4.2 \\
\hline Percentage of MSM who had any female sex partner in the last 12 months & 50.8 \\
\hline Percentage of MSM who reported sex with a FSW & 10.6 \\
\hline Percentage of MSM who reported selling anal sex to a male partner & 35.9 \\
\hline Percentage of MSM who reported buying anal sex from a male partner & 22.3 \\
\hline Condom use at last anal sex & 52.0 \\
\hline Condom use at last anal sex with a non-paying partner & 50.8 \\
\hline Condom use at last anal sex with paying partner & 55.0 \\
\hline Condom use at last anal sex with paid partner & 48.0 \\
\hline Condom use at last sex with FSW & 65.9 \\
\hline Percentage of MSM with any STI symptom in the last 12 months & 15.0 \\
\hline MSM ever tested for HIV & 53.3 \\
\hline MSM tested and received results & 31.5 \\
\hline HIV prevalence & 17.2 \\
\hline
\end{tabular}


Table 15: Summary indicators for IDU, IBBSS Nigeria 2010

\begin{tabular}{|l|l|}
\hline Indicator & $\%$ \\
\hline $\begin{array}{l}\text { Percentage of all respondents who had a comprehensive and correct knowledge of } \\
\text { HIV prevention methods }\end{array}$ & 30.7 \\
\hline Percentage of MSM who reported alcohol use & 27.2 \\
\hline Percentage of MSM who reported marijuana use & 71.6 \\
\hline Percentage of MSM who reported cocaine and/or heroin use & 73.3 \\
\hline Percentage of IDU who reported heroin use & 70.4 \\
\hline $\begin{array}{l}\text { Percentage of IDU who reported use of unused needles as a means of HIV preven- } \\
\text { tion }\end{array}$ & 80.1 \\
\hline $\begin{array}{l}\text { Percentage of IDU who used sterile injecting equipment anytime they injected in } \\
\text { the last 12 months }\end{array}$ & \\
\hline Percentage of IDU who reported sex with commercial partners & 31.8 \\
\hline Percentage of female IDU who sold sex in the last 12 months & 38.1 \\
\hline Percentage of IDU who reported condom use at last commercial sex & 78.0 \\
\hline Percentage of IDU who reported condom use at last sex with boy/girlfriend & 55.6 \\
\hline Percentage of IDU who reported condom use at last sex with regular partner & 21.9 \\
\hline Percentage of IDU with any STI symptom in the last 12 months & 17.8 \\
\hline IDU ever tested for HIV & 50.2 \\
\hline IDU tested and received results & 31.1 \\
\hline HIV prevalence & 4.2 \\
\hline
\end{tabular}

Table 16: Summary indicators for Armed Forces and Police, IBBSS Nigeria 2010

\begin{tabular}{|c|c|c|c|}
\hline Indicator & Army (\%) & Police (\%) & TW $(\%)$ \\
\hline $\begin{array}{l}\text { Percentage of all respondents who had a comprehensive and correct } \\
\text { knowledge of HIV prevention methods }\end{array}$ & 57.6 & 36.2 & 28.3 \\
\hline Percentage of all respondents who reported daily use of alcohol & 6.6 & 8.2 & 14.4 \\
\hline Percentage of all respondents who reported use of marijuana & 9.0 & 4.4 & 13.1 \\
\hline $\begin{array}{l}\text { Percentage of all respondents who reported use of cocaine and/or } \\
\text { heroin }\end{array}$ & 0.9 & 0.7 & 1.7 \\
\hline $\begin{array}{l}\text { Percentage of respondents who had more than one non-regular } \\
\text { partner in past } 12 \text { months }\end{array}$ & 22.2 & 14.4 & 19.7 \\
\hline $\begin{array}{l}\text { Percentage of respondents who reported commercial sex in past } 12 \\
\text { months }\end{array}$ & 4.4 & 4.9 & 7.7 \\
\hline $\begin{array}{l}\text { Percentage of male respondents who reported condom use at last } \\
\text { commercial sex }\end{array}$ & 86.0 & 58.9 & 83.7 \\
\hline $\begin{array}{l}\text { Percentage of respondents who reported sex with boy/girlfriend in } \\
\text { the last } 12 \text { months }\end{array}$ & 42.0 & 35.9 & 38.5 \\
\hline $\begin{array}{l}\text { Percentage of respondents who reported condom use at last sex with } \\
\text { girlfriend }\end{array}$ & 57.3 & 51.2 & 45.1 \\
\hline $\begin{array}{l}\text { Percentage of respondents with any STI symptom in the last } 12 \\
\text { months }\end{array}$ & 4.1 & 9.6 & 10.3 \\
\hline Percentage of all respondents who ever had an HIV test & 89.7 & 62.1 & 35.0 \\
\hline $\begin{array}{l}\text { Percentage of all respondents who had an HIV test and received } \\
\text { result }\end{array}$ & 81.4 & 55.8 & 30.7 \\
\hline HIV prevalence & 2.5 & 2.6 & 2.4 \\
\hline
\end{tabular}




\subsection{Appendix II: Descriptive state level analysis of behavioural data}

\subsubsection{Brothel-based female sex workers}

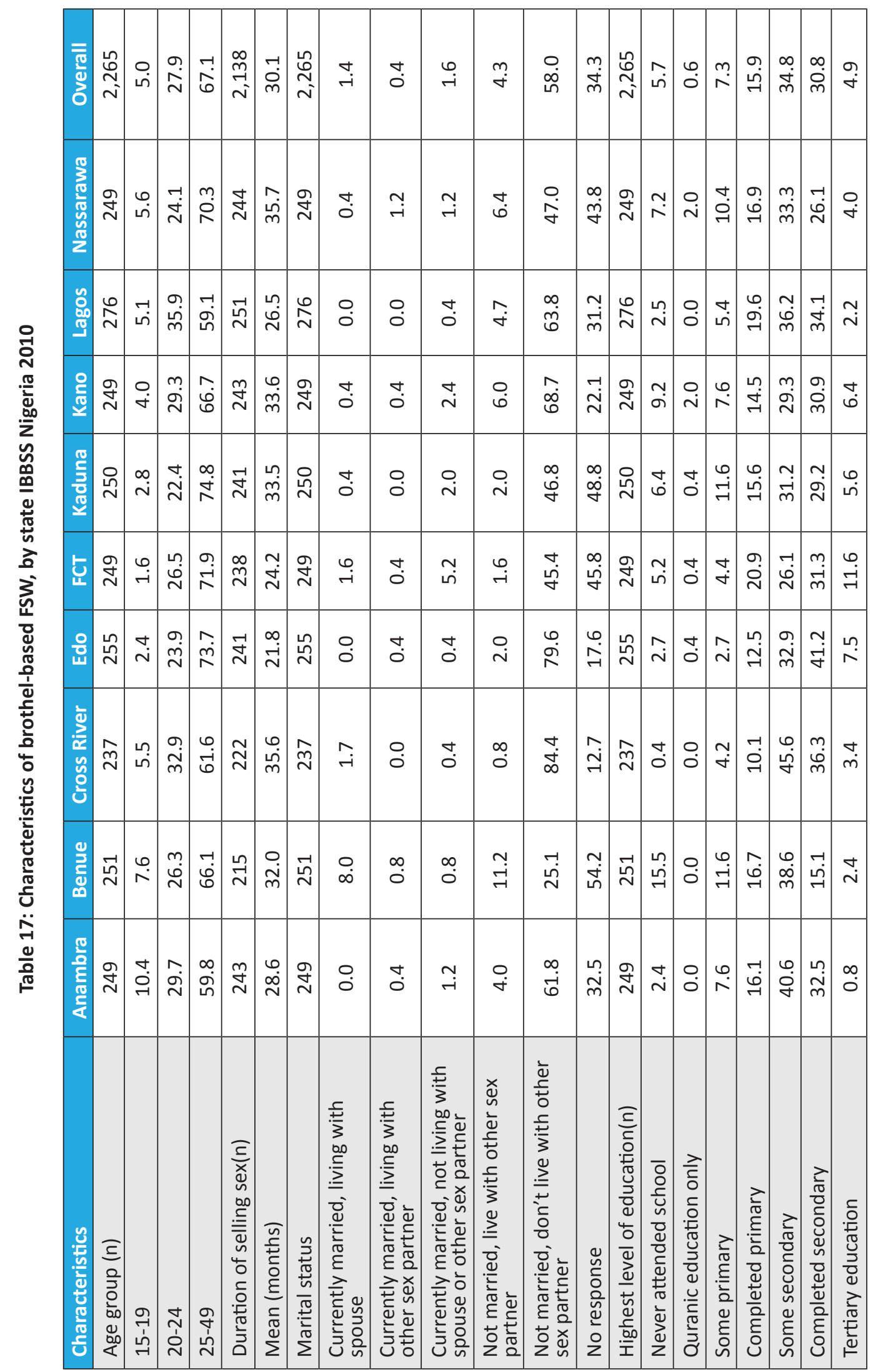




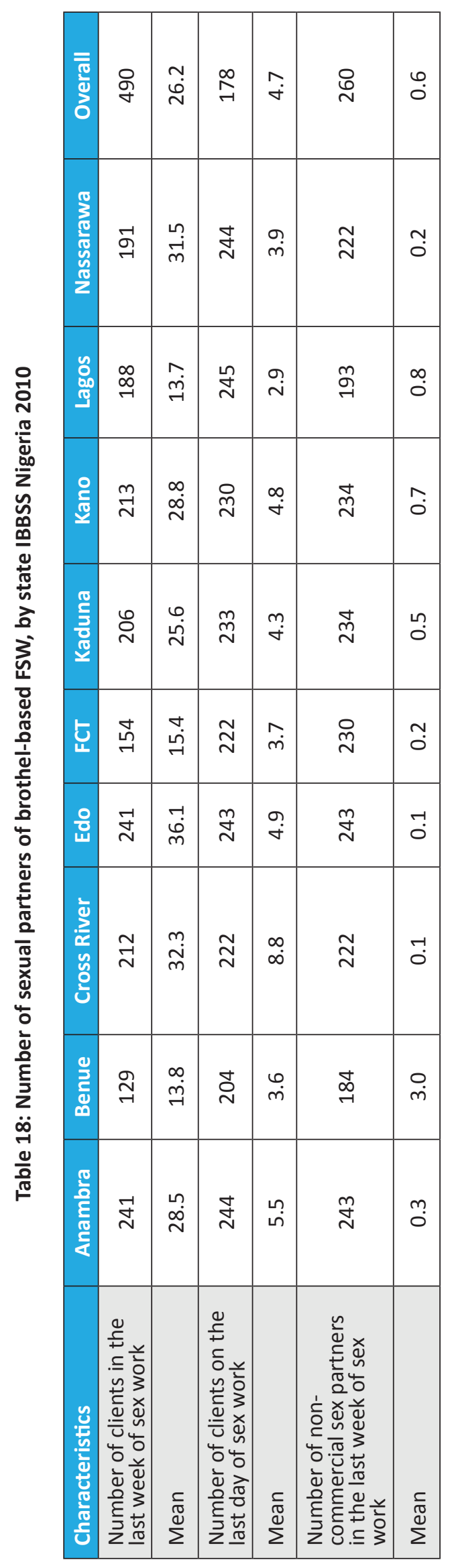




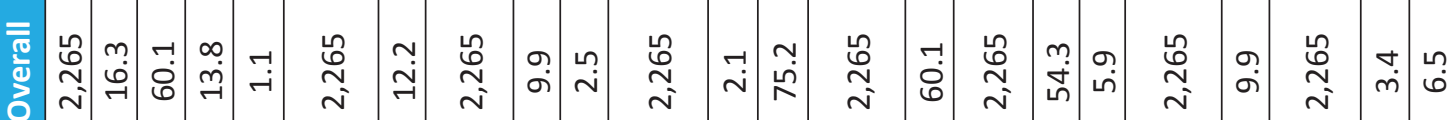

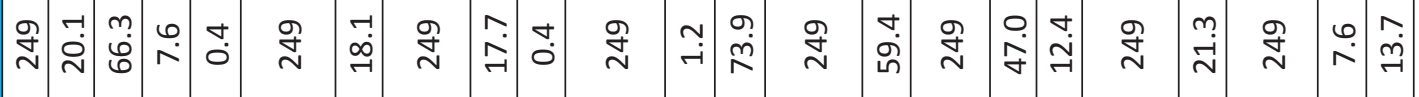

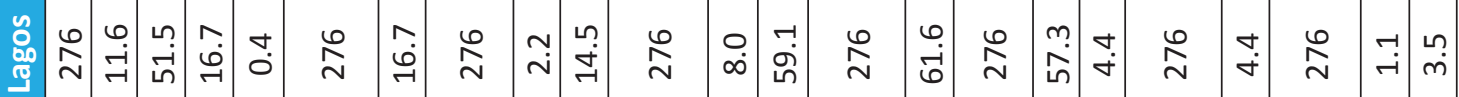

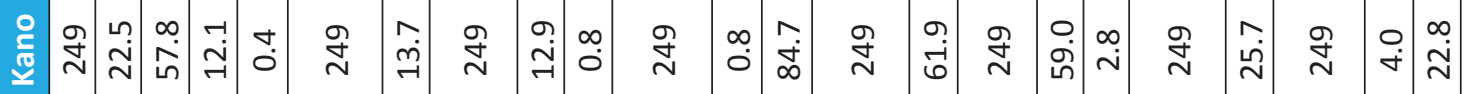
恶

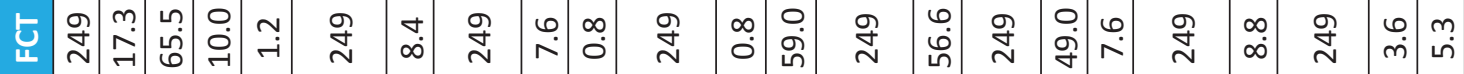

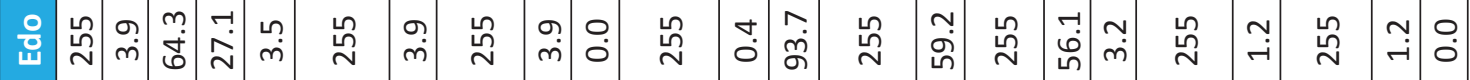

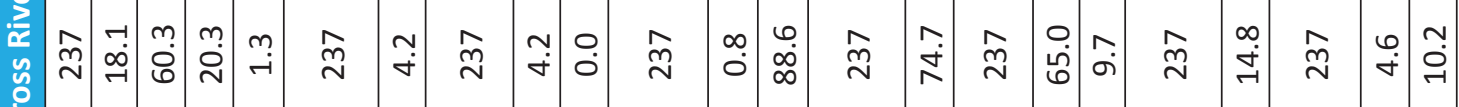
운

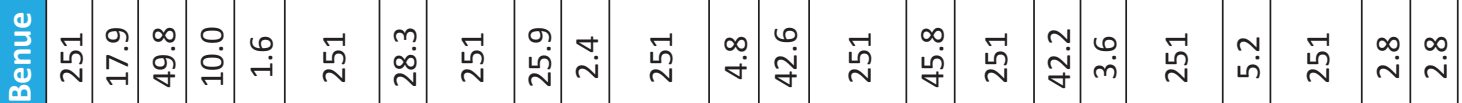

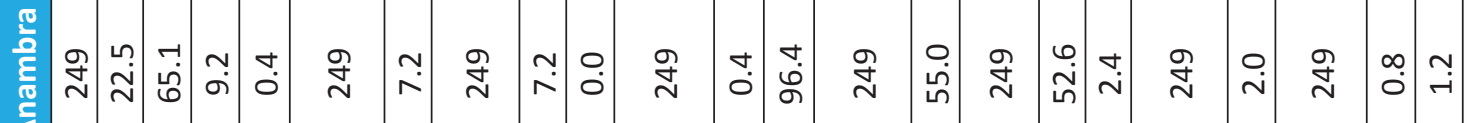

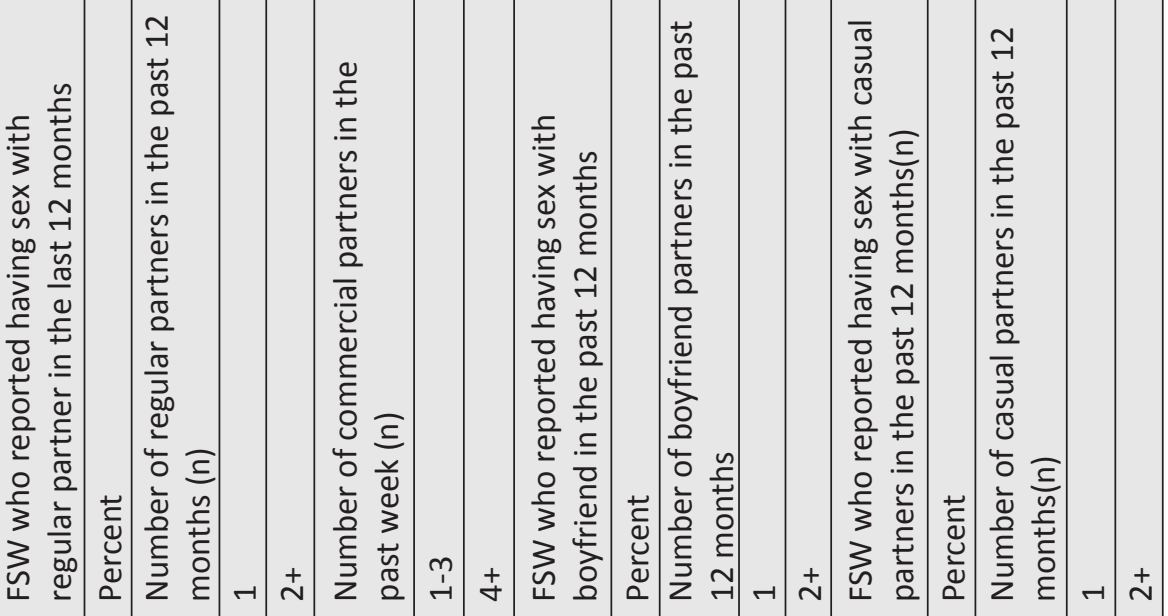




\begin{tabular}{|c|c|c|c|c|c|c|c|c|c|c|c|c|c|c|c|c|}
\hline $\begin{array}{l}\overline{\overline{\mathrm{g}}} \\
\overline{\mathrm{g}} \\
\mathrm{\partial}\end{array}$ & 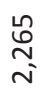 & $\begin{array}{l}\text { o. } \\
\dot{f}\end{array}$ & 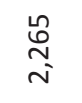 & ஜ̊ & $\stackrel{\curvearrowright}{\sim}$ & 品 & $\stackrel{\text { 年 }}{\rightarrow}$ & \begin{tabular}{|l}
$\stackrel{n}{0}$ \\
$\infty$ \\
$m$
\end{tabular} & $\underset{\sim}{\stackrel{\sim}{\sim}}$ & ヘิ & $\underset{\sim}{\stackrel{N}{\sim}}$ & กั & $\stackrel{\mathbb{N}}{\sim}$ & 盀 & $\stackrel{\mathbb{N}}{\mathbb{N}}$ & $\stackrel{9}{\widehat{\sigma}}$ \\
\hline 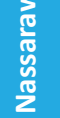 & $\stackrel{g}{\sim}$ & $\begin{array}{l}\text { Oें } \\
\text { ge }\end{array}$ & $\stackrel{\text { I }}{\sim}$ & ָ̊ & ஜ & 亗 & $\stackrel{n}{\stackrel{n}{G}}$ & $\overrightarrow{\stackrel{n}{n}}$ & $\stackrel{\infty}{\stackrel{\infty}{\sim}}$ & ָั & $\stackrel{\infty}{\sim}$ & $\underset{\sim}{\stackrel{n}{N}}$ & กี & $\stackrel{m}{r}$ & nn & ì \\
\hline 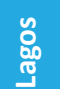 & $\stackrel{\circlearrowright}{\sim}$ & $\begin{array}{l}\text { ठ̊ } \\
\dot{f}\end{array}$ & $\stackrel{\circlearrowright}{\stackrel{\sim}{~}}$ & नें & $\mathscr{q}$ & $\begin{array}{l}\stackrel{n}{n} \\
\tilde{n}\end{array}$ & 今ે & $\begin{array}{l}\infty \\
\text { in } \\
\text { in }\end{array}$ & $\stackrel{?}{\stackrel{ᄀ}{7}}$ & ભm & $\stackrel{?}{7}$ & $\begin{array}{l}\mathscr{L} \\
\stackrel{\omega}{N}\end{array}$ & テ & : & ユ & $\underset{\substack{\infty \\
\sim}}{m}$ \\
\hline 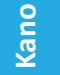 & $\stackrel{g}{d}$ & $\begin{array}{l}\stackrel{\infty}{\circ} \\
\stackrel{\leftrightarrow}{\circ}\end{array}$ & $\stackrel{g}{\sim}$ & 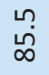 & mे & $\begin{array}{l}\infty \\
\underset{-}{-}\end{array}$ & $\stackrel{\infty}{\infty}$ & 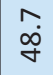 & $\stackrel{\text { 亗 }}{\rightarrow}$ & $\hat{\mathfrak{N}}$ & 岂 & $\stackrel{\llcorner}{\underset{\sim}{\sim}}$ & \& & $\begin{array}{l}\text { nू } \\
\text { n' }\end{array}$ & ఫే & $\begin{array}{l}\text { J } \\
\sigma\end{array}$ \\
\hline 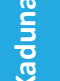 & 只 & $\begin{array}{l}\circ \\
\sigma_{\infty}\end{array}$ & 号 & 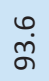 & $\tilde{N}$ & $\begin{array}{l}\stackrel{0}{\dot{y}} \\
\ddot{y}\end{array}$ & $\underset{\sim}{ \pm}$ & 它 & $\underset{్}{\stackrel{\sigma}{\sigma}}$ & $\underset{m}{m} \dot{m}$ & 웜 & 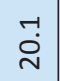 & $\vec{ન}$ & $\begin{array}{c}\infty \\
\stackrel{\infty}{\infty} \\
\stackrel{n}{n}\end{array}$ & $\stackrel{\vec{f}}{\vec{f}}$ & $\stackrel{\stackrel{\sim}{\sim}}{\sim}$ \\
\hline 는 & $\stackrel{g}{\sim}$ & $\begin{array}{l}\infty \\
\dot{\sigma} \\
\dot{\sigma}\end{array}$ & $\stackrel{g}{\sim}$ & $\begin{array}{l}\stackrel{\infty}{\sim} \\
\tilde{\sigma}\end{array}$ & $\vec{\lambda}$ & $\begin{array}{l}\stackrel{\infty}{\sim} \\
\stackrel{\sim}{n}\end{array}$ & 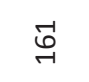 & $\stackrel{\vec{g}}{\stackrel{F}{*}}$ & $\underset{ন}{\vec{J}}$ & $\underset{\substack{\infty \\
m}}{m}$ & $\underset{\vec{J}}{\vec{J}}$ & ন্ণ & $\approx$ & $\stackrel{\bullet}{\ddot{\theta}}$ & $\approx$ & 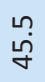 \\
\hline 움 & 足 & $\begin{array}{l}\text { gे } \\
\text { }\end{array}$ & $\stackrel{\leftrightarrow}{\sim}$ & 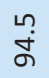 & 우 & $\stackrel{\circ}{\circ}$ & 웅 & $\begin{array}{l}0 \\
\text { மூ }\end{array}$ & 곡 & 岇 & 苛 & $\begin{array}{l}6 \\
\infty \\
\infty\end{array}$ & $m$ & ¿. & $m$ & ㅇ. \\
\hline $\begin{array}{l}\frac{3}{a x} \\
\frac{n}{0}\end{array}$ & $\stackrel{\hat{n}}{\sim}$ & $\underset{n}{n}$ & $\stackrel{\hat{N}}{\sim}$ & 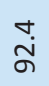 & 우 & $\stackrel{\circ}{\text { iे }}$ & $\stackrel{\infty}{-\infty}$ & $\vec{i}$ & $\underset{ન}{\stackrel{ }{A}}$ & $\stackrel{+}{\stackrel{+}{\sim}}$ & 今 & $\stackrel{\circ}{\circ}$ & $\stackrel{\llcorner}{m}$ & $\begin{array}{l}0 \\
\infty \\
0 \\
0\end{array}$ & $\stackrel{\stackrel{n}{m}}{n^{\prime}}$ & in \\
\hline בె๊ & 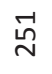 & ت્ & ڤ્న & $\begin{array}{l}\text { ఫे } \\
\dot{\infty}\end{array}$ & ㄱ. & 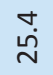 & ర్త & 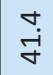 & $\stackrel{\stackrel{n}{7}}{\rightarrow}$ & 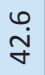 & 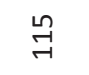 & $\vec{m}$ & $\stackrel{m}{\sim}$ & 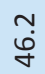 & $\stackrel{m}{\rightarrow}$ & ָூ \\
\hline 造 & $\stackrel{\text { I }}{\sim}$ & ָ̃ & $\stackrel{\text { I }}{\sim}$ & $\begin{array}{l}\text { \&̊ } \\
\dot{8}\end{array}$ & $\stackrel{\infty}{\sim}$ & $\underset{m}{m}$ & กู & t. & 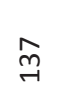 & 我 & $\widehat{m}$ & ஸ̊ & in & : & in & : \\
\hline 选 & 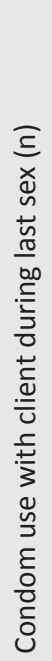 & 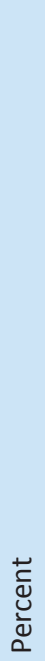 & 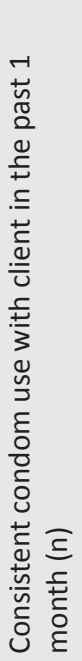 & 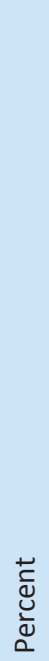 & 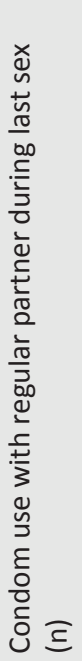 & 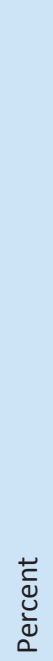 & 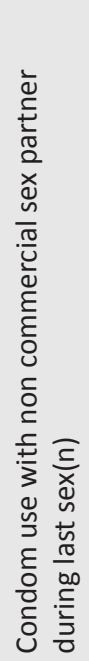 & 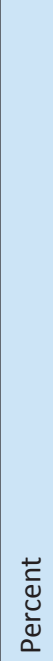 & 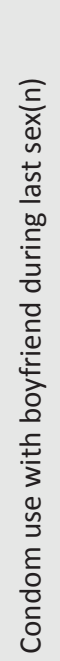 & 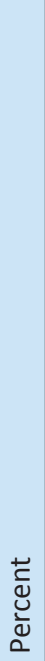 & 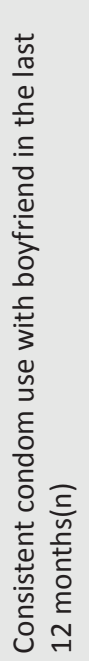 & 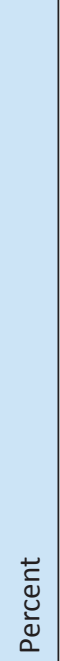 & 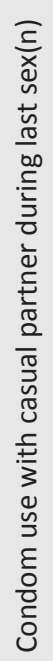 & 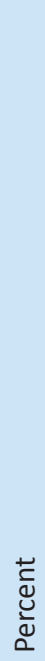 & 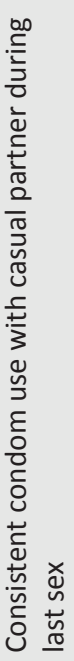 & 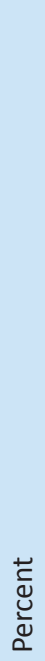 \\
\hline
\end{tabular}




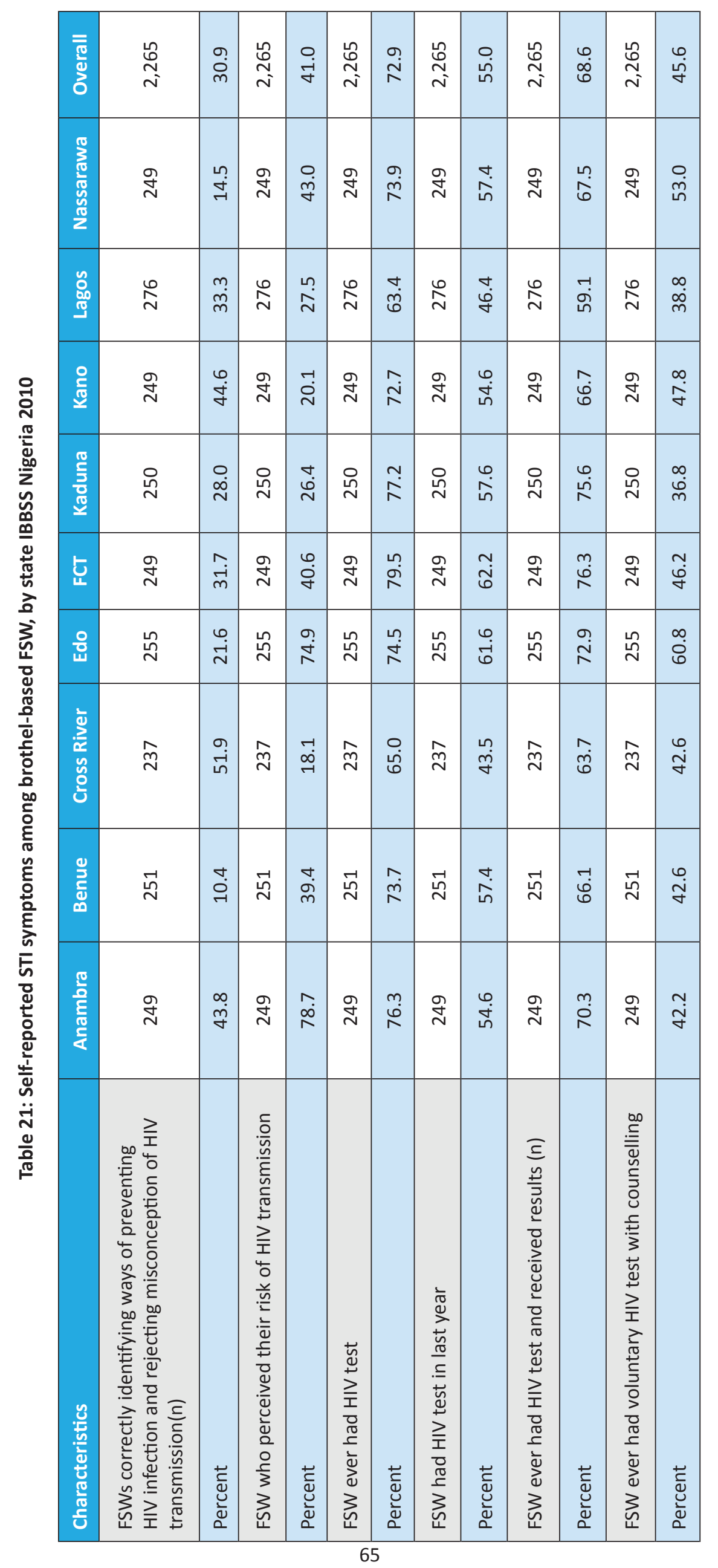




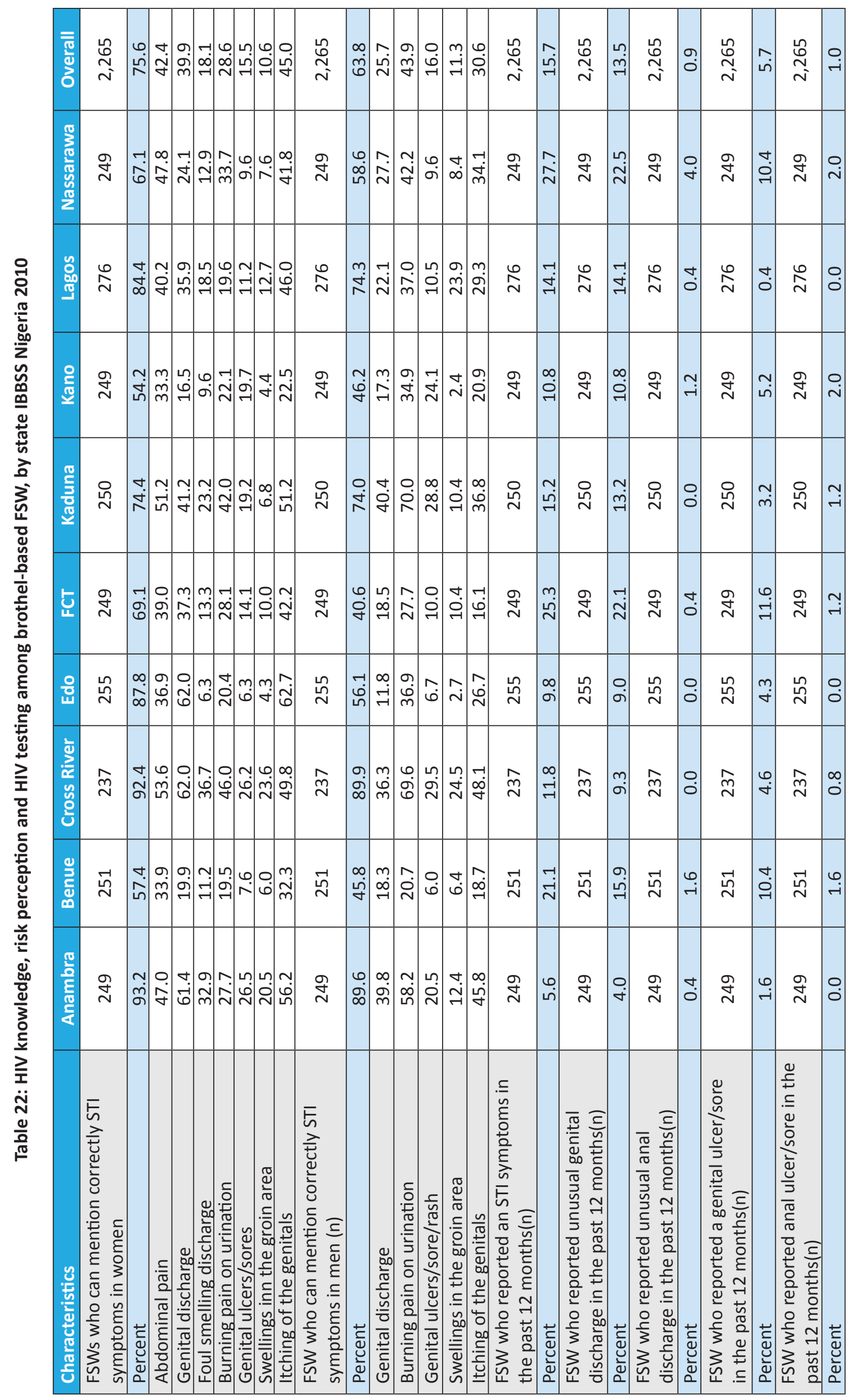




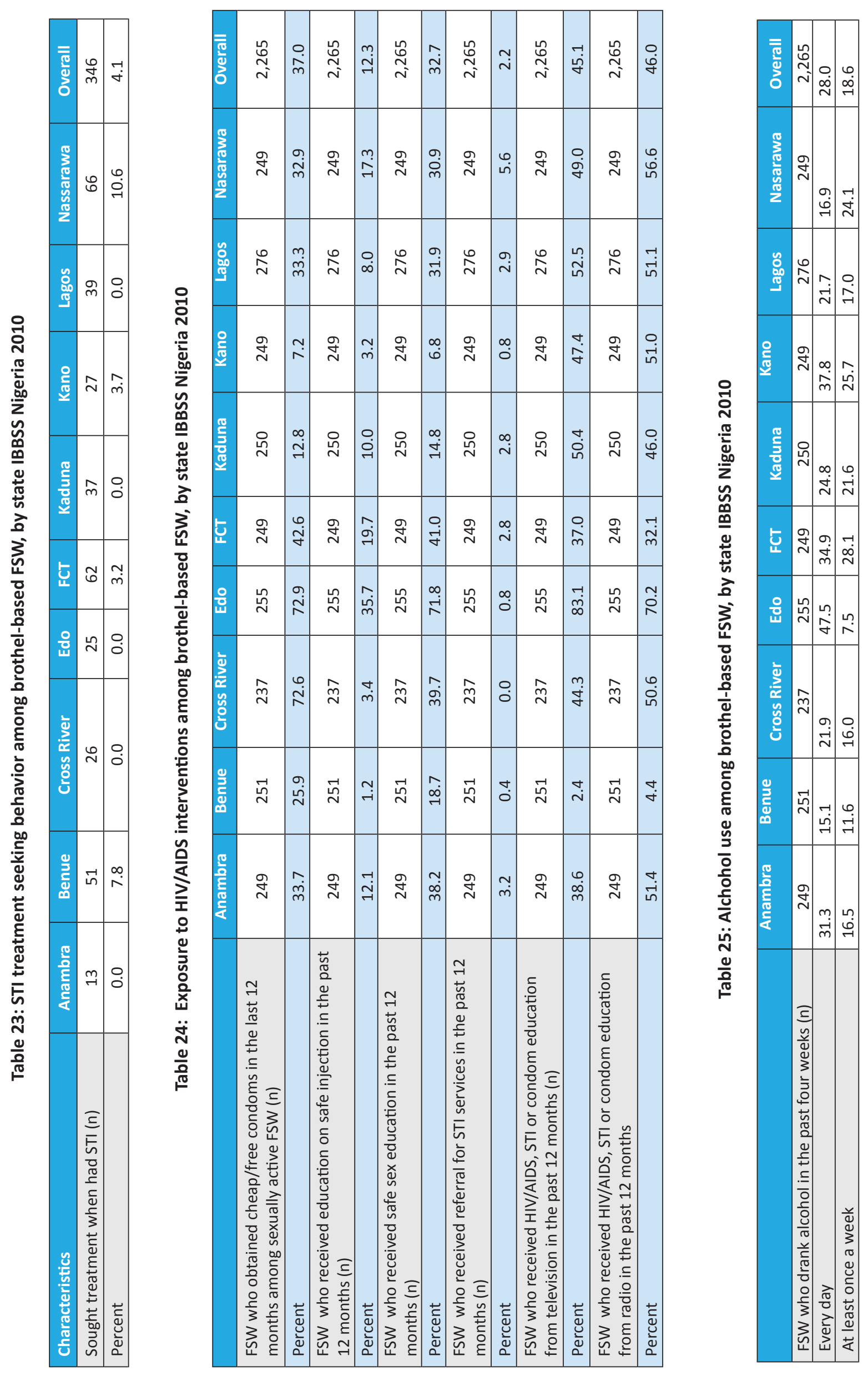


8.2.2 Non-brothel-based female sex workers

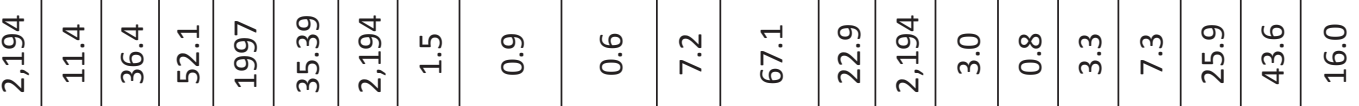

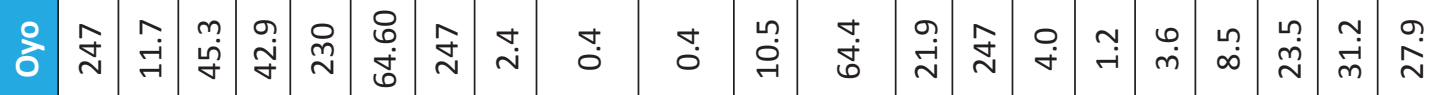

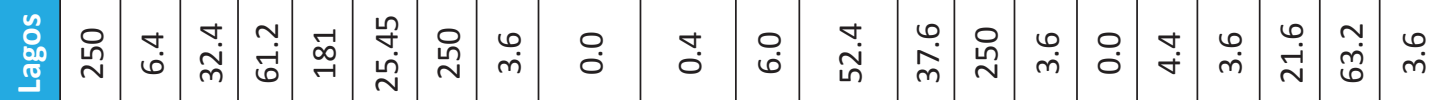

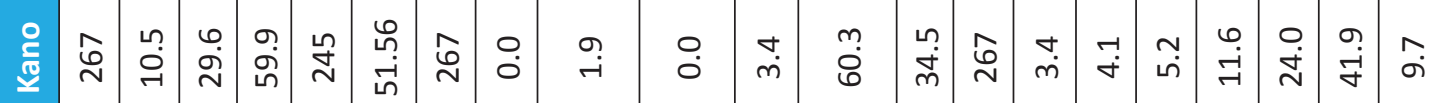

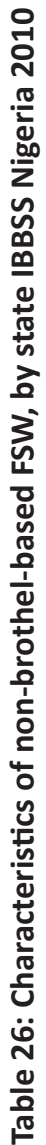

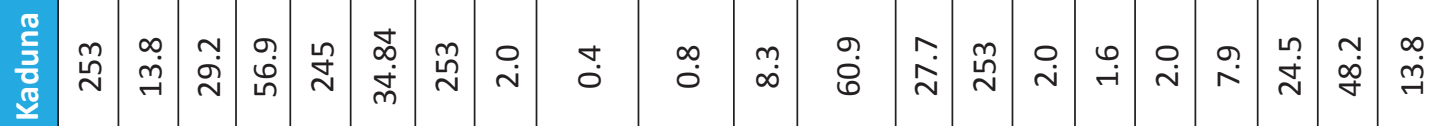

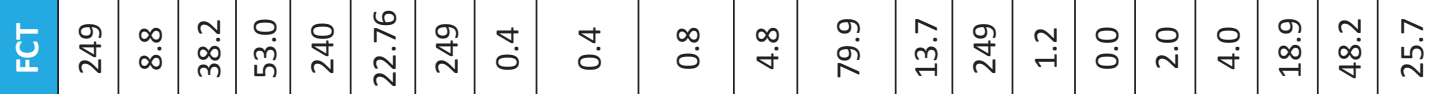

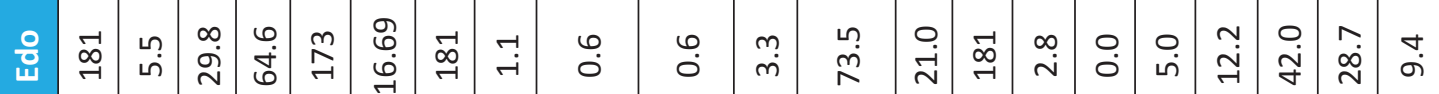

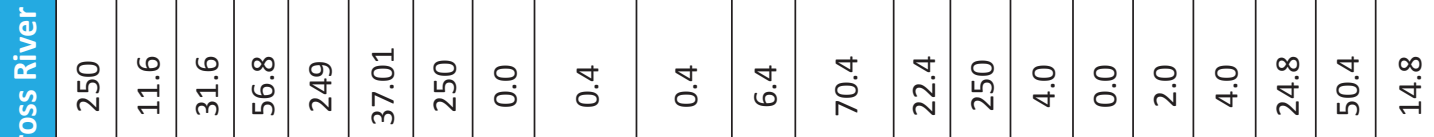

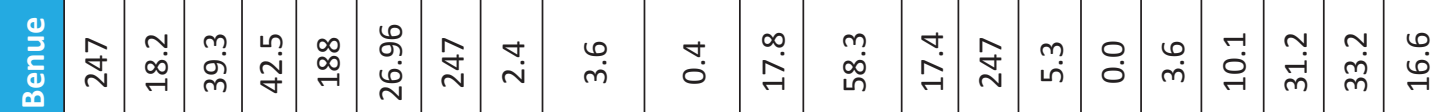

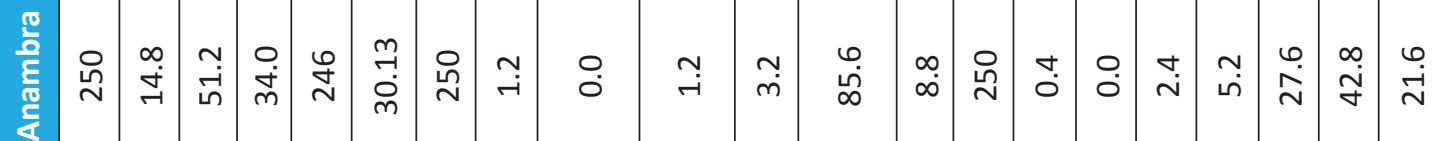

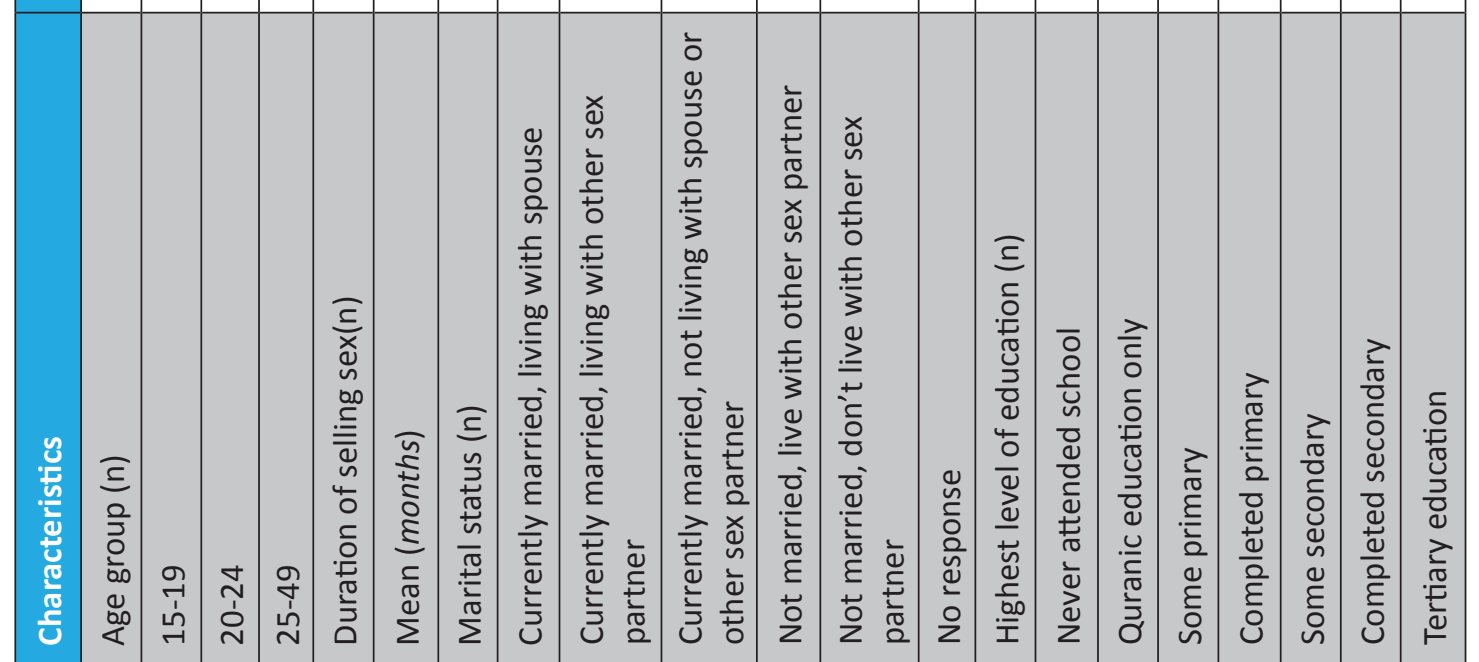




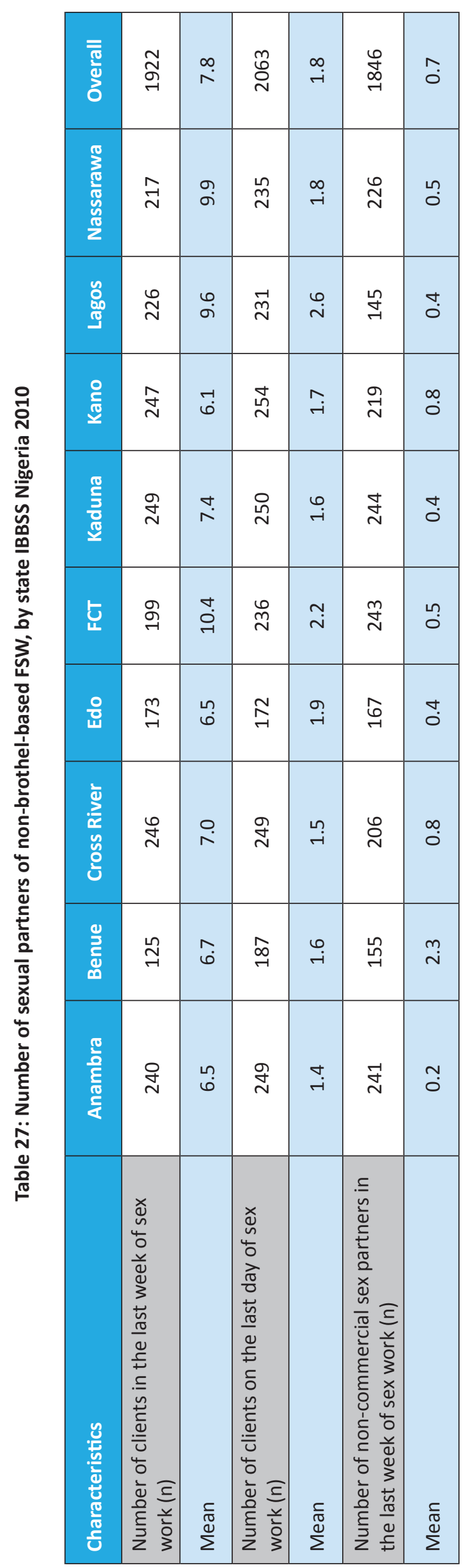




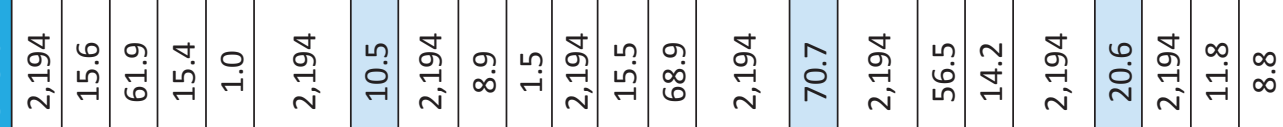

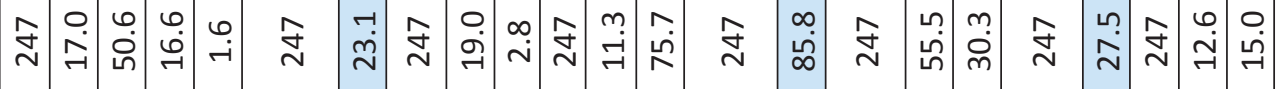

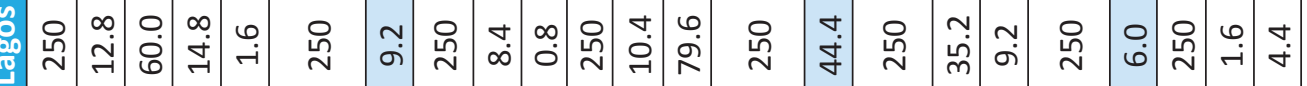

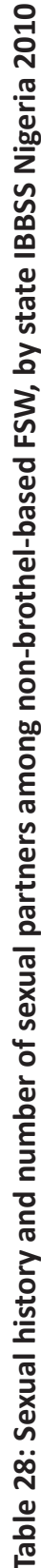

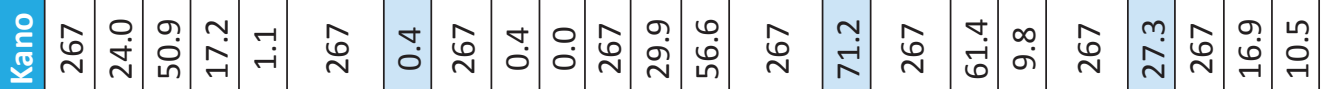

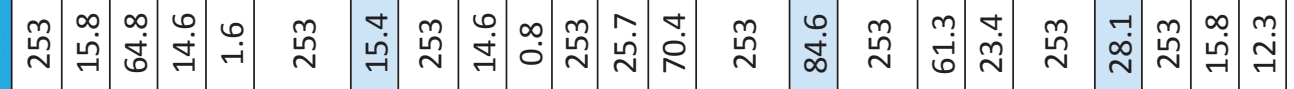

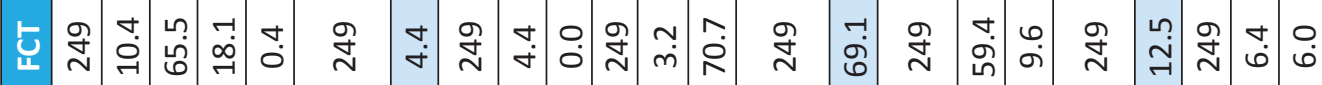

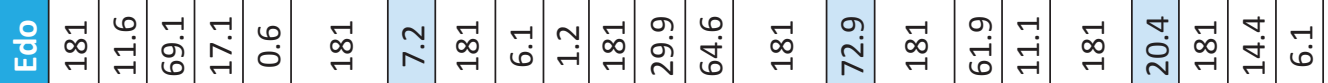

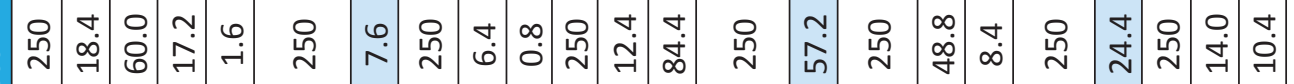

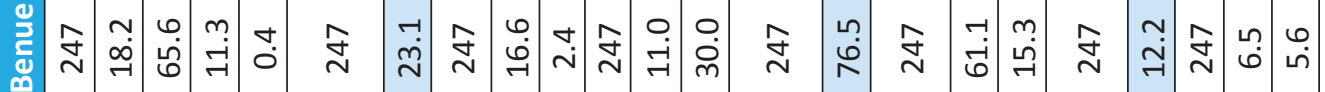

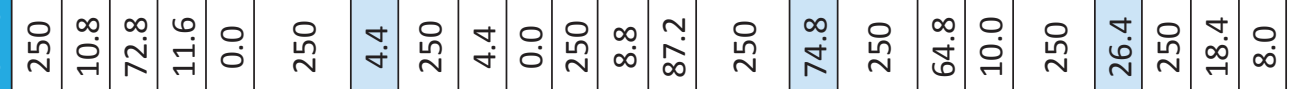

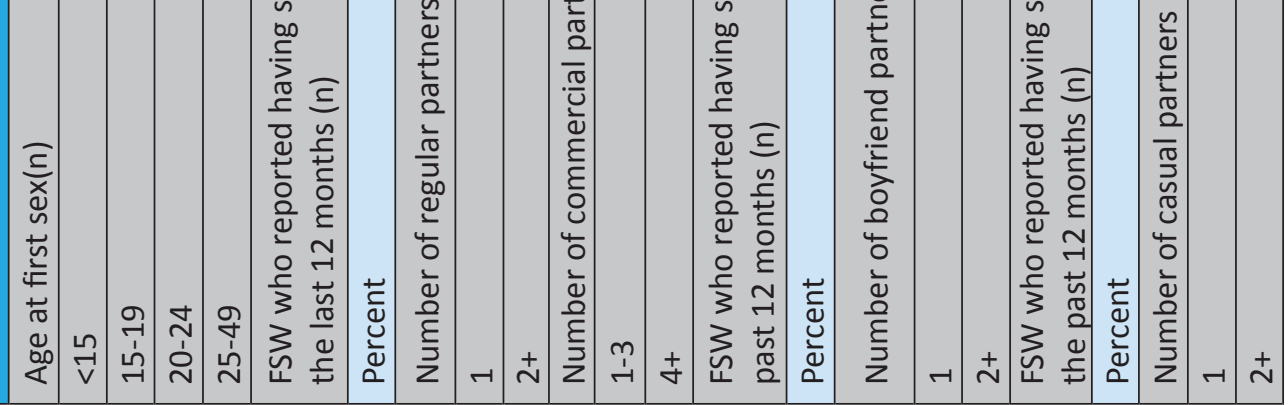




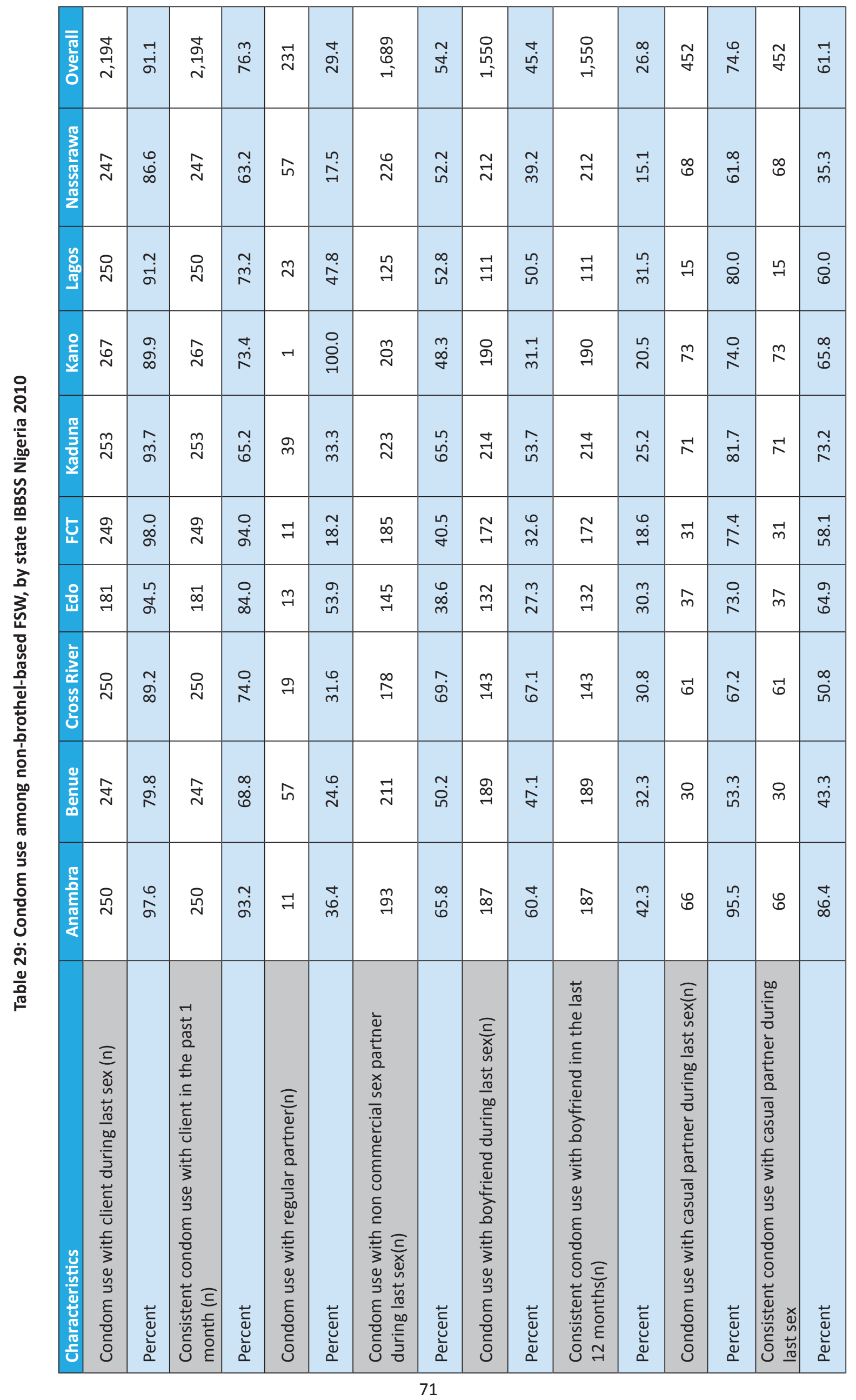




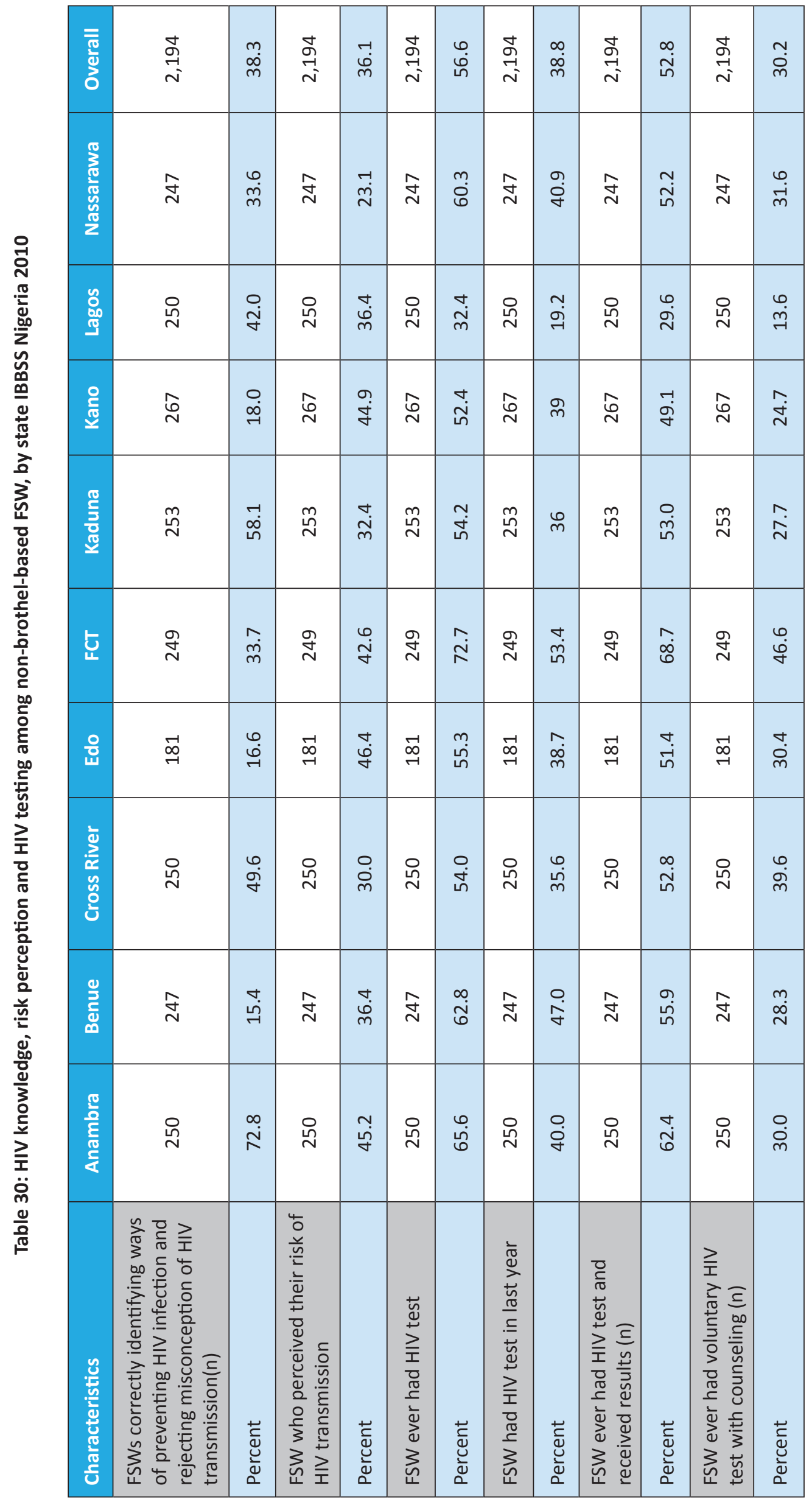




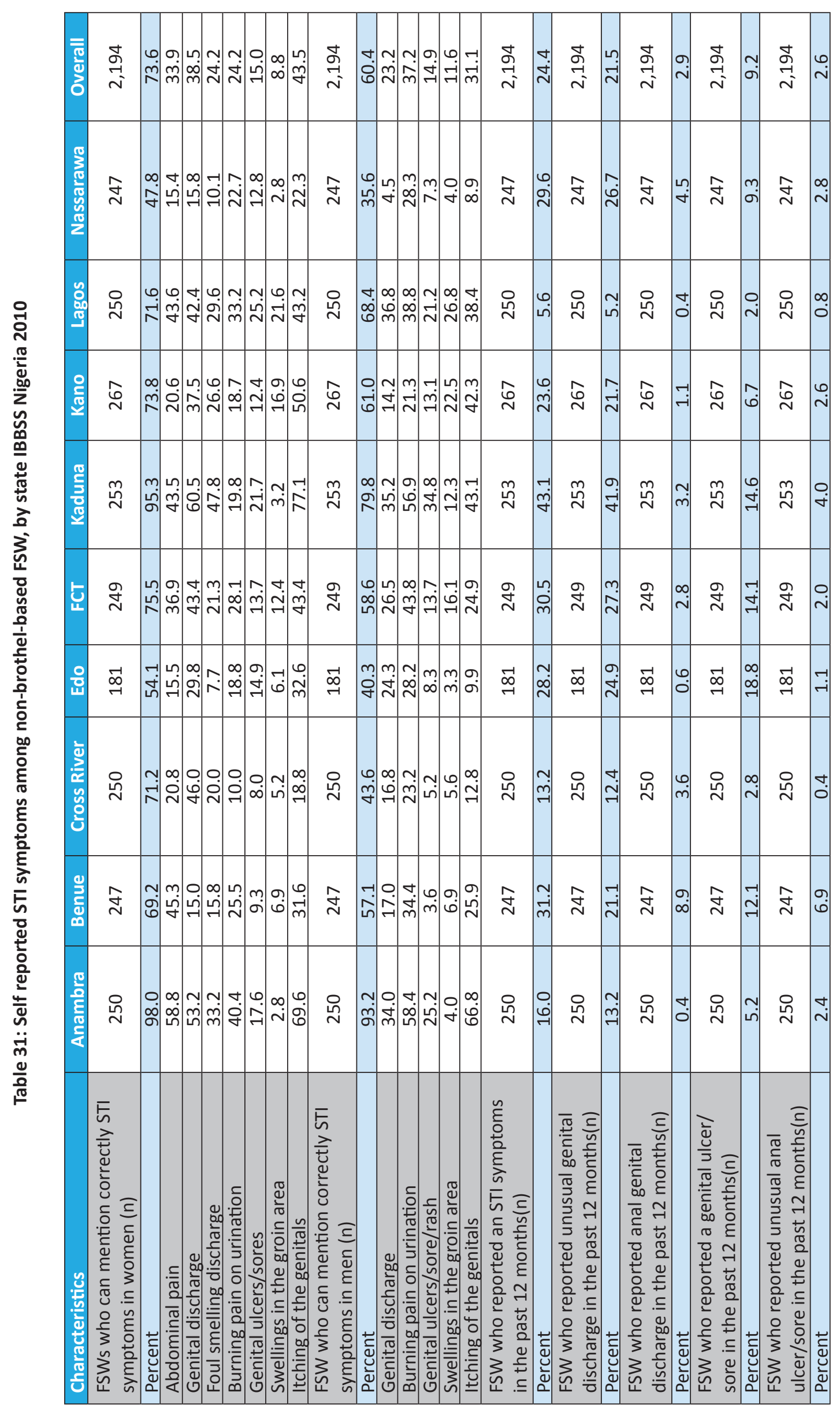




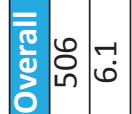

说:

율

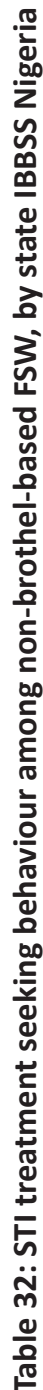

웅

韵吅士

는청

옹 ज为

焉

ल ले

는

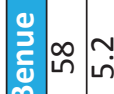

En

这

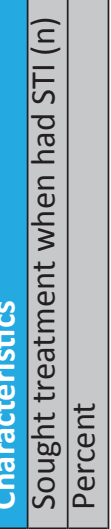

Oे

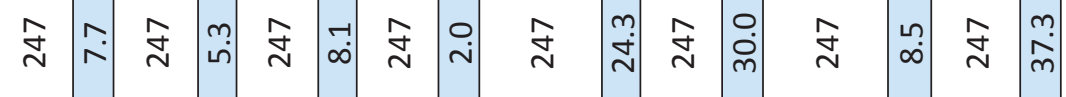

总 品

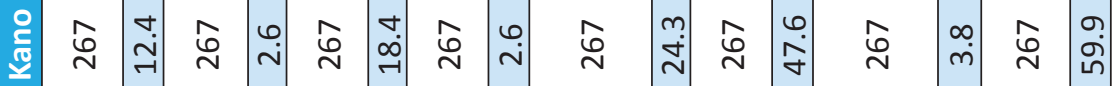

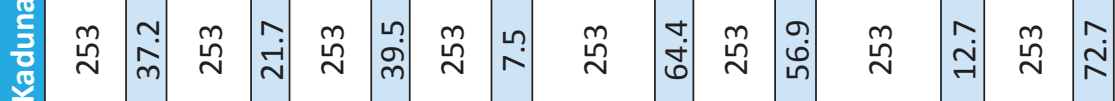

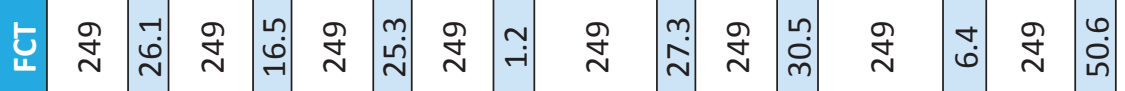

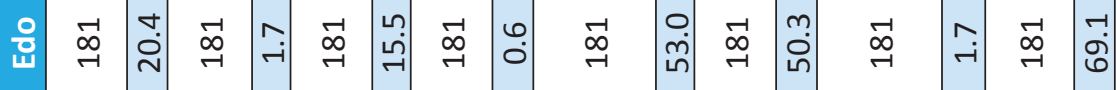

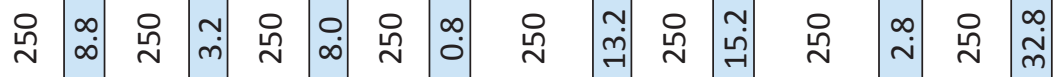

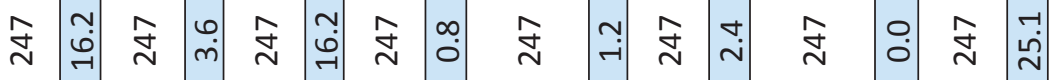
号 竞 员

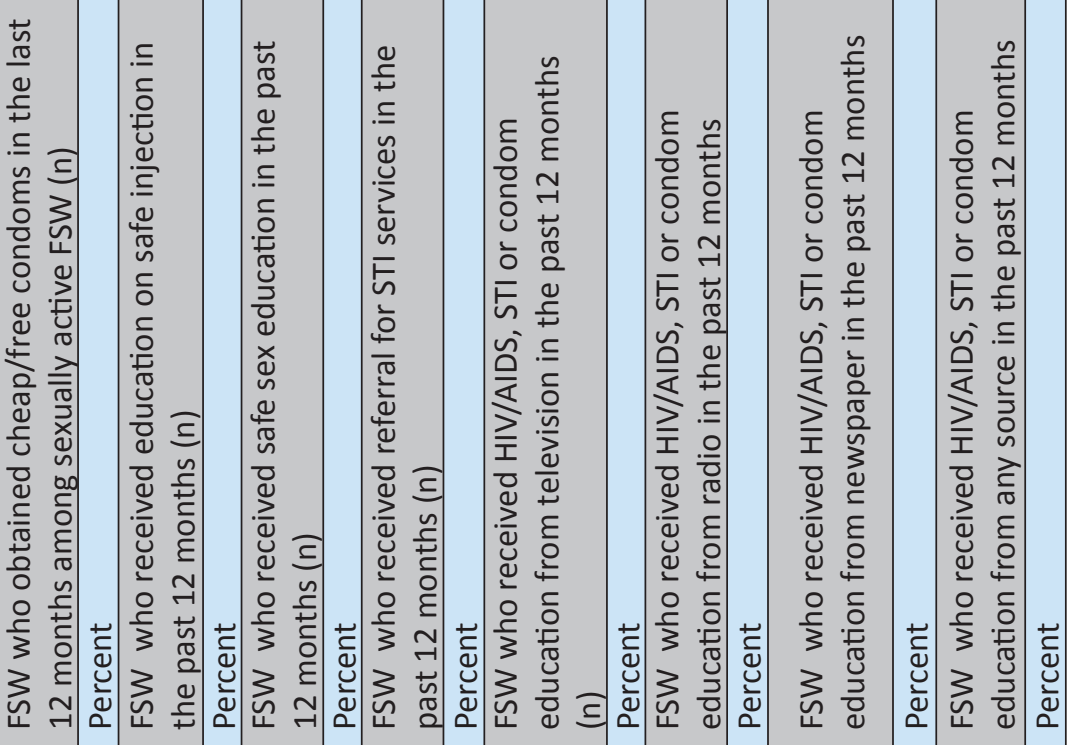




\begin{tabular}{|c|c|c|c|}
\hline 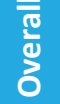 & $\begin{array}{l}\stackrel{\sim}{0} \\
\stackrel{N}{N}\end{array}$ & $\begin{array}{l}\circ \\
\stackrel{\infty}{N}\end{array}$ & $\begin{array}{l}\varphi \\
\stackrel{\infty}{\rightarrow}\end{array}$ \\
\hline 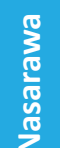 & $\stackrel{\text { ㅁ }}{\sim}$ & $\begin{array}{l}\stackrel{\sigma}{0} \\
\dot{\sigma}\end{array}$ & $\stackrel{-1}{\sim}$ \\
\hline $\begin{array}{l}\text { 总 } \\
\text { తo }\end{array}$ & $\stackrel{\bullet}{\stackrel{0}{~}}$ & $\hat{i}$ & $\stackrel{\circ}{\stackrel{\circ}{A}}$ \\
\hline 兽 & $\stackrel{\text { I }}{\sim}$ & $\stackrel{\infty}{\stackrel{\infty}{m}}$ & 点 \\
\hline 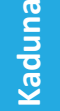 & $\stackrel{\stackrel{\circ}{N}}{ }$ & $\stackrel{\infty}{\underset{\sim}{\sim}}$ & $\begin{array}{l}\stackrel{\bullet}{\sim} \\
\stackrel{-}{n}\end{array}$ \\
\hline 는 & $\stackrel{\text { ㄱ }}{\sim}$ & $\underset{\dot{m}}{\dot{m}}$ & $\stackrel{-1}{\stackrel{\infty}{N}}$ \\
\hline 윰 & $\stackrel{\stackrel{n}{N}}{N}$ & $\stackrel{\stackrel{n}{f}}{\stackrel{f}{f}}$ & $\stackrel{\stackrel{n}{r}}{r}$ \\
\hline 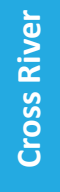 & $\stackrel{\hat{N}}{n}$ & $\stackrel{\leftrightarrow}{\vec{N}}$ & $\begin{array}{l}\circ \\
\stackrel{\leftrightarrow}{\oplus}\end{array}$ \\
\hline 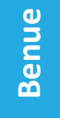 & 島 & 름 & $\begin{array}{l}0 \\
\stackrel{-}{-}\end{array}$ \\
\hline 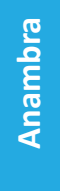 & $\stackrel{g}{\sim}$ & $\stackrel{m}{m}$ & $\begin{array}{l}\stackrel{\sim}{0} \\
\stackrel{\leftrightarrow}{-1}\end{array}$ \\
\hline & 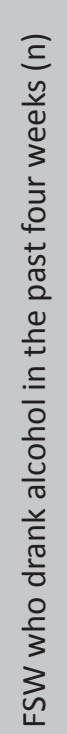 & 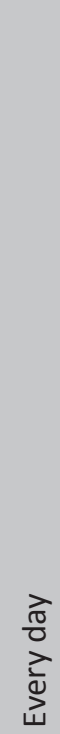 & 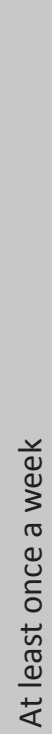 \\
\hline
\end{tabular}




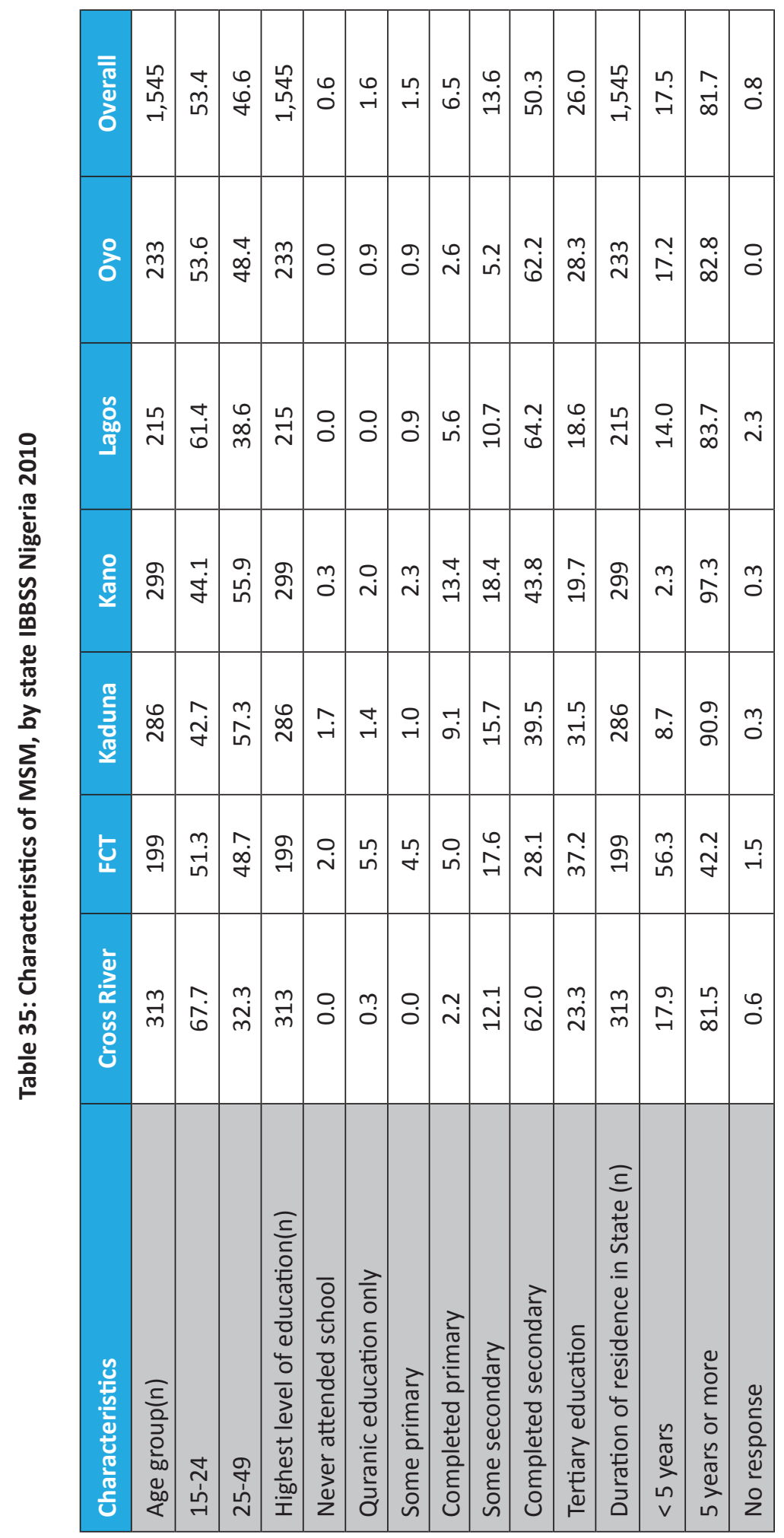


b

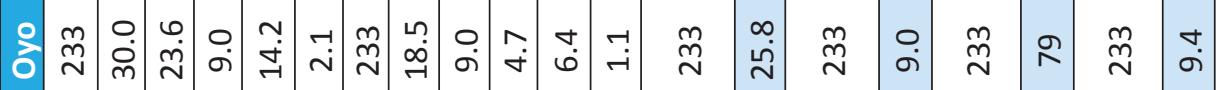

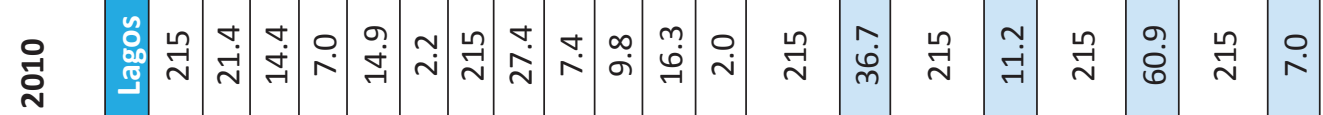

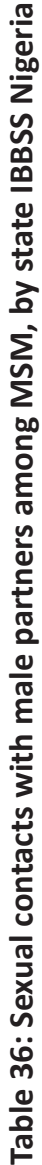

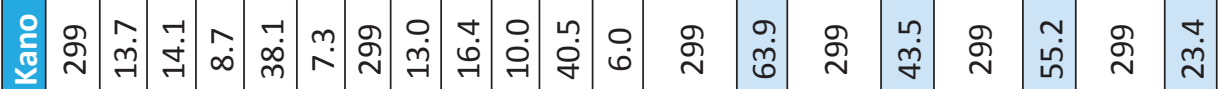

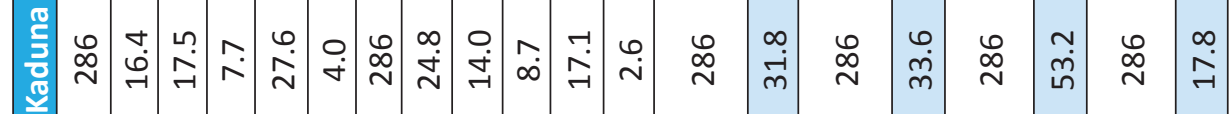

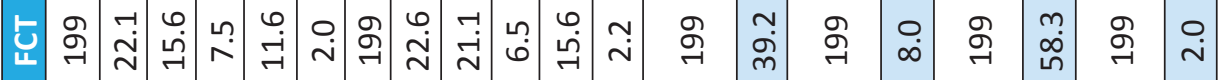

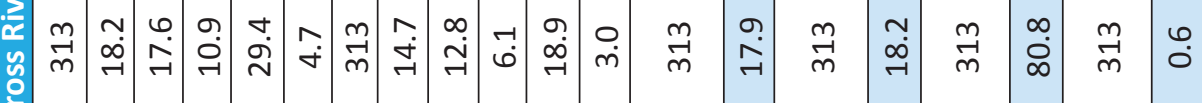

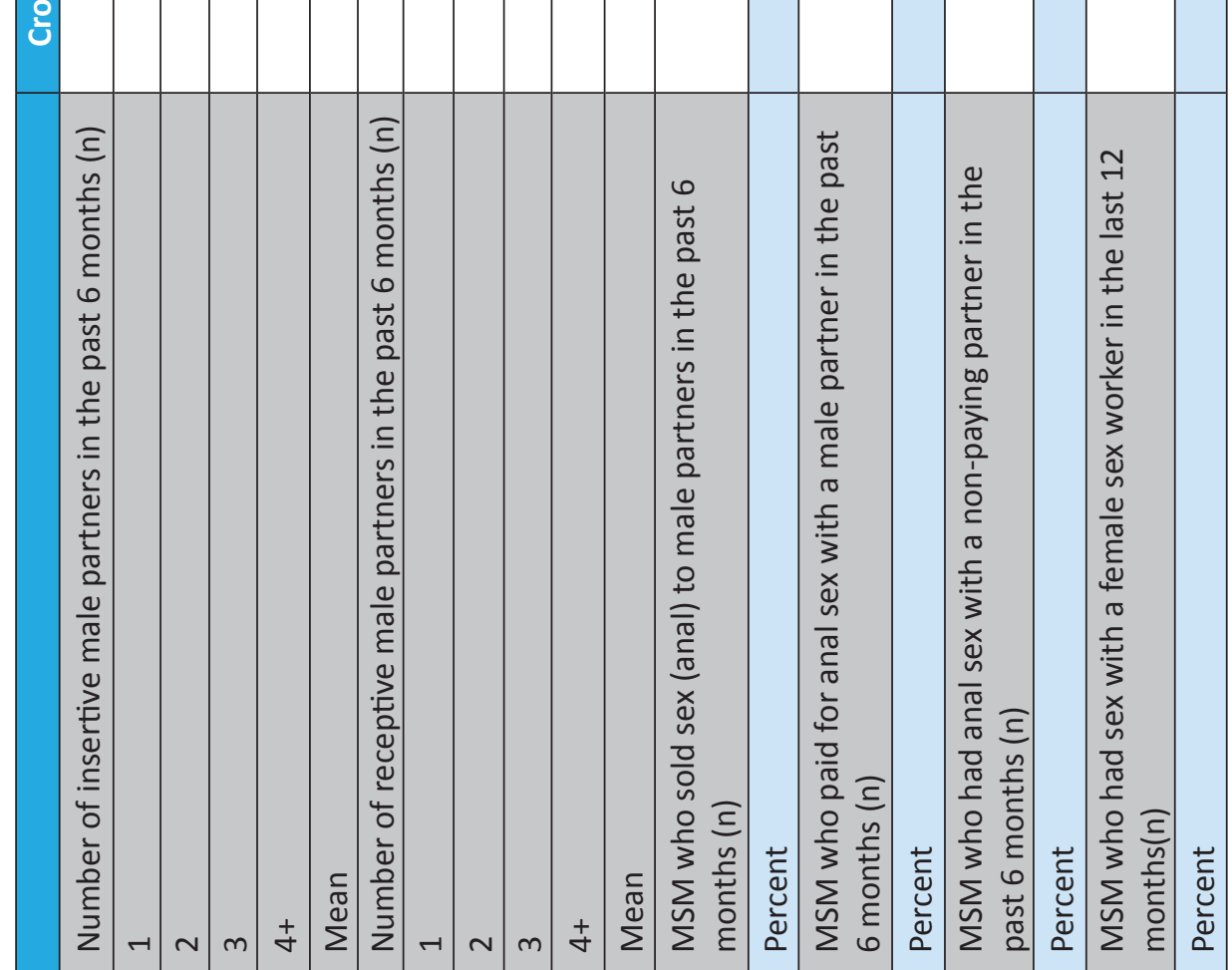




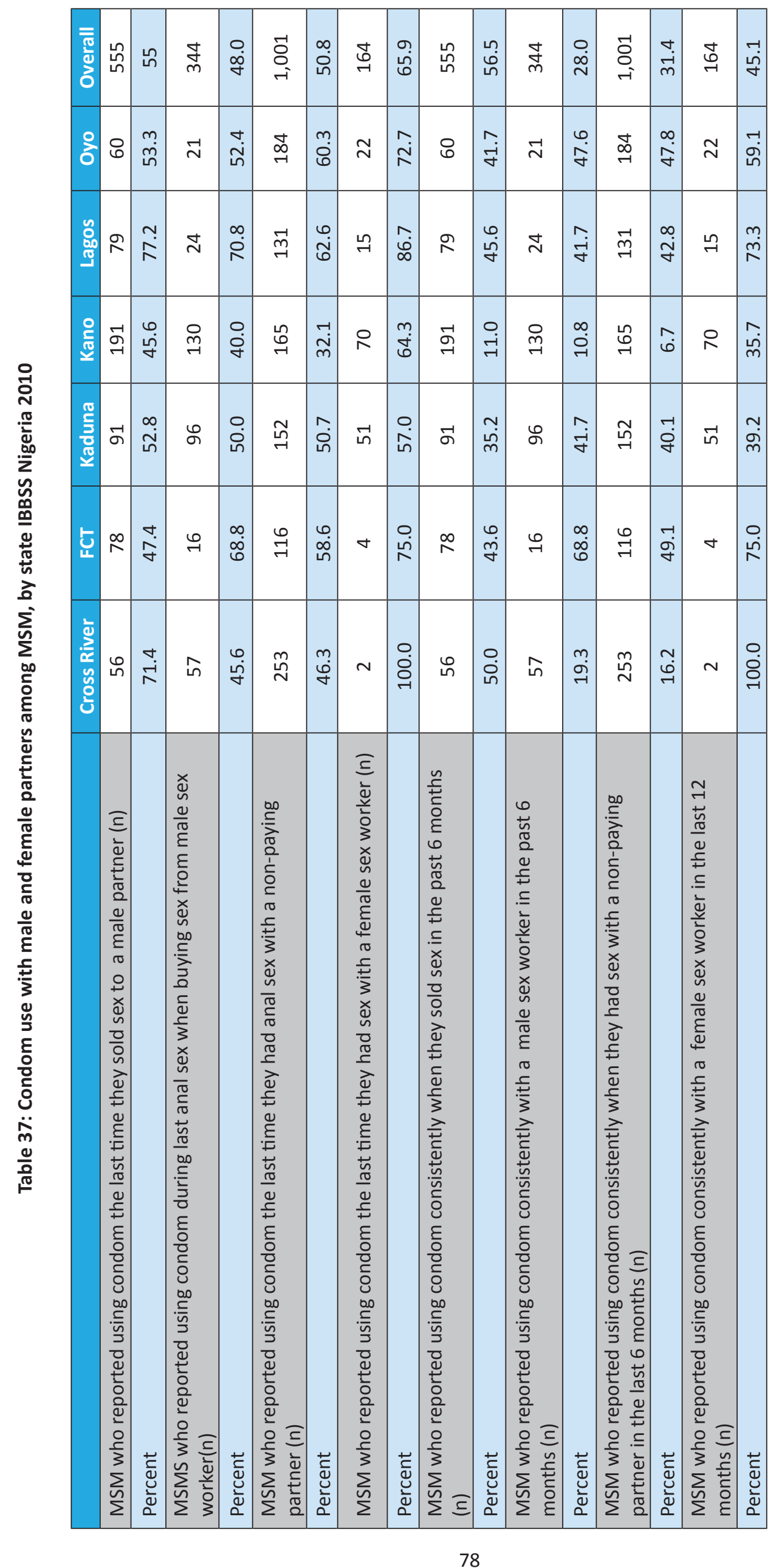




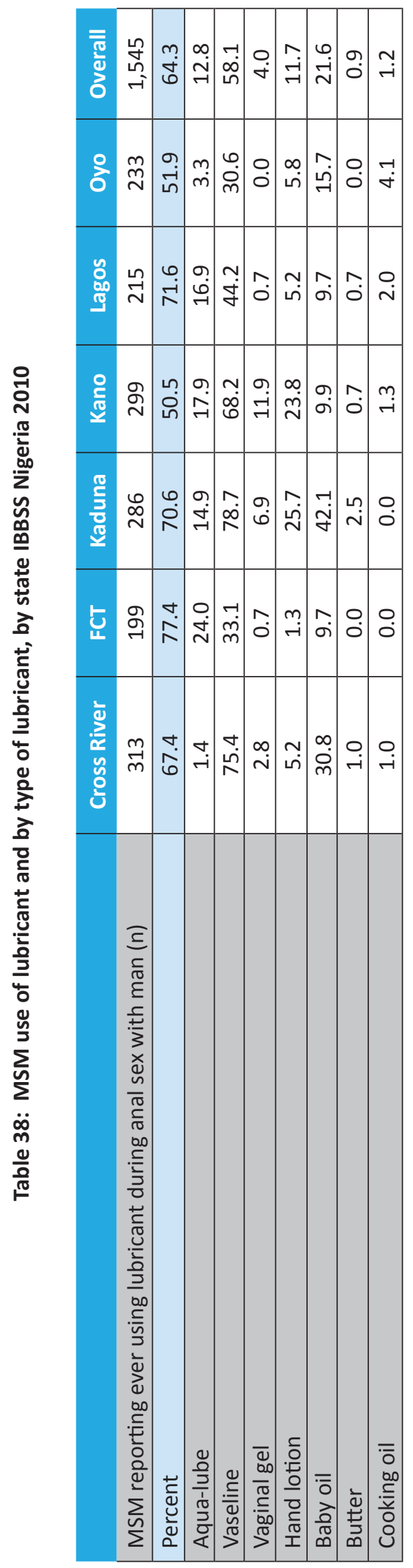
年

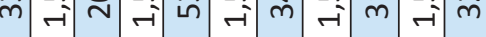

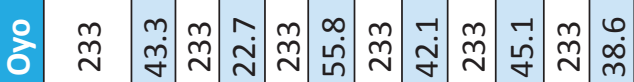

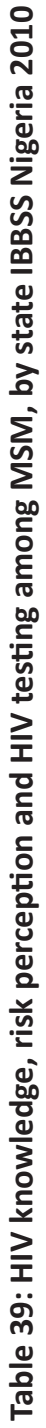

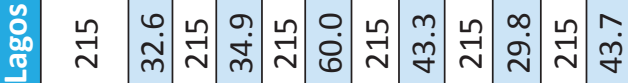

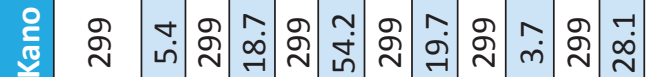

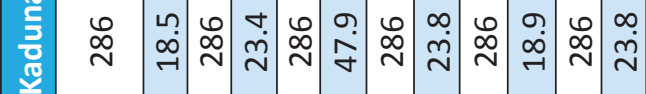

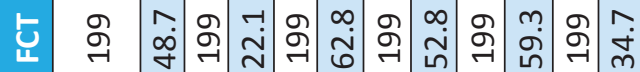

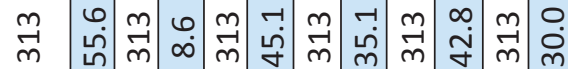

(1)

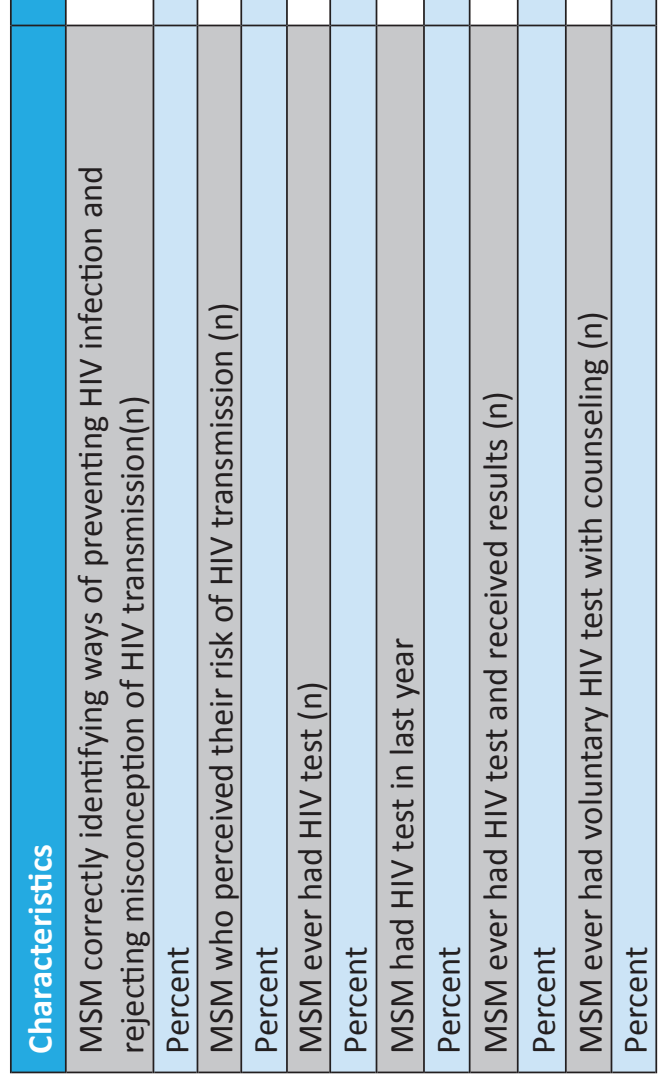




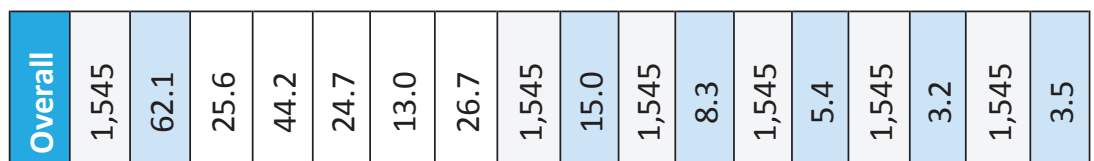

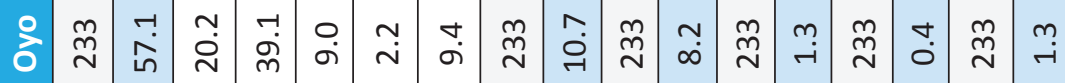

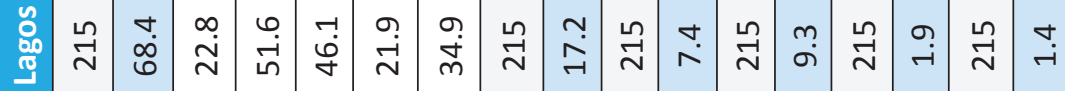

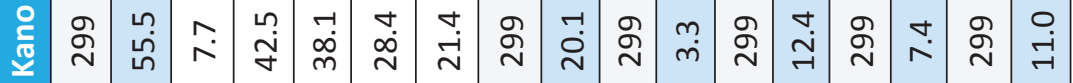

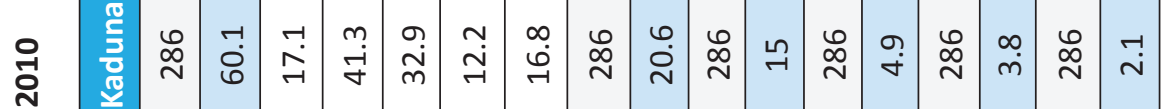

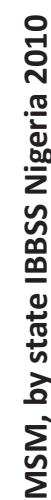

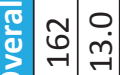

วิำ

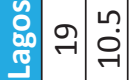

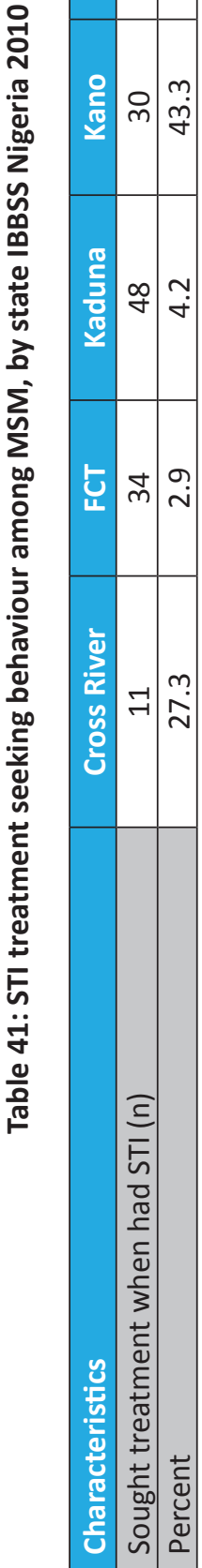

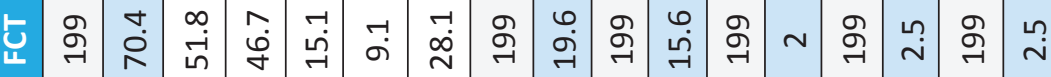

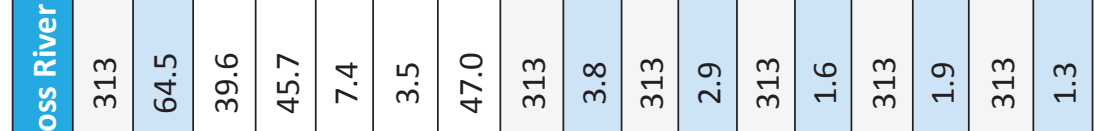

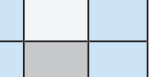

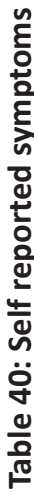

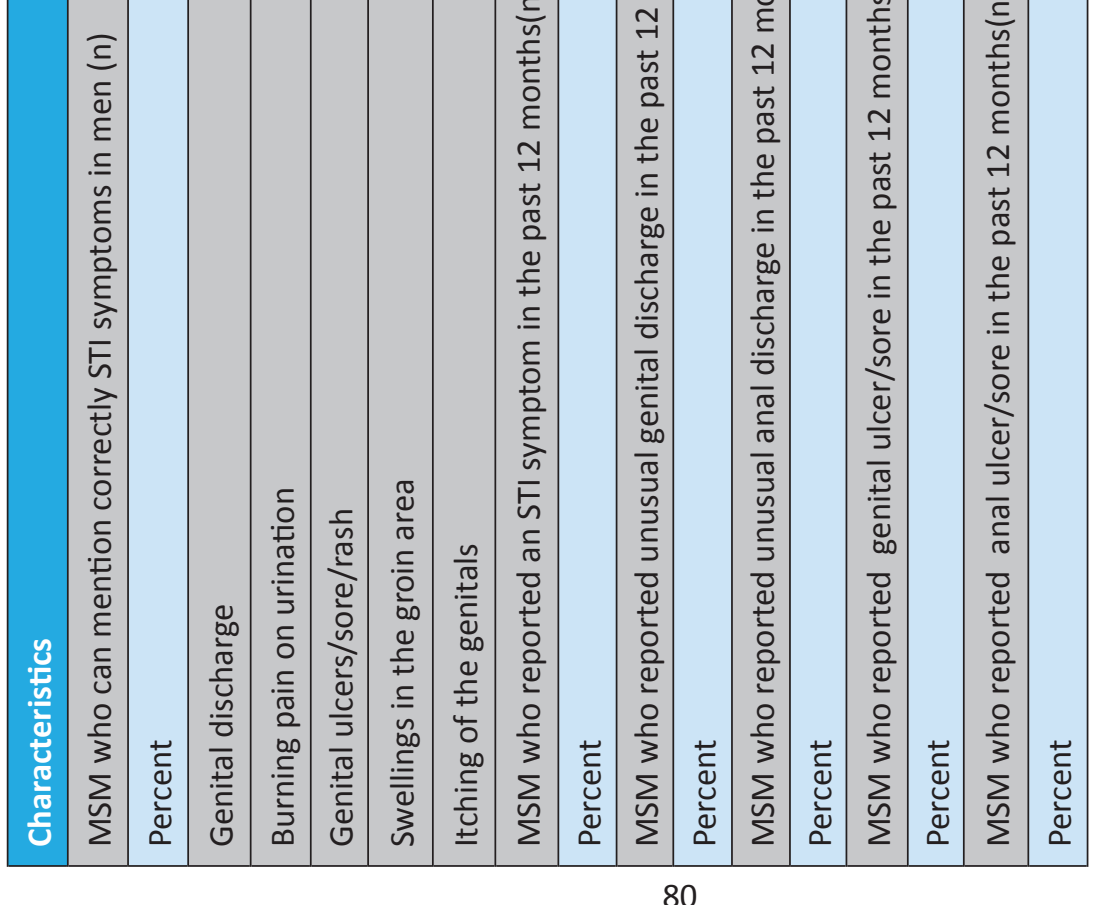




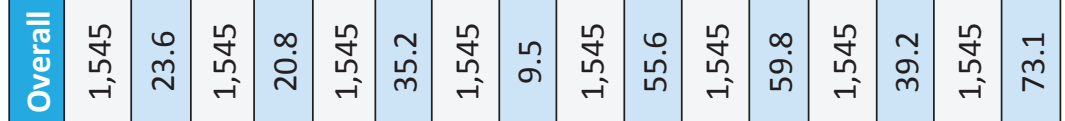

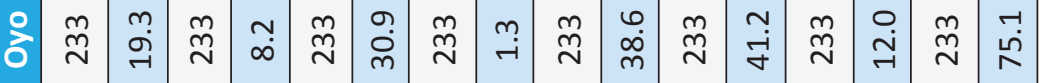

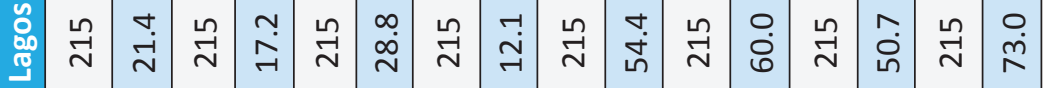

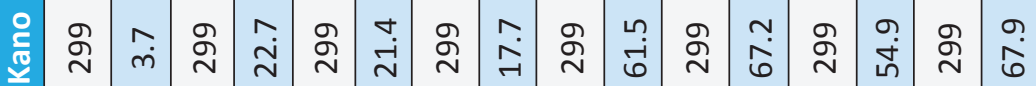

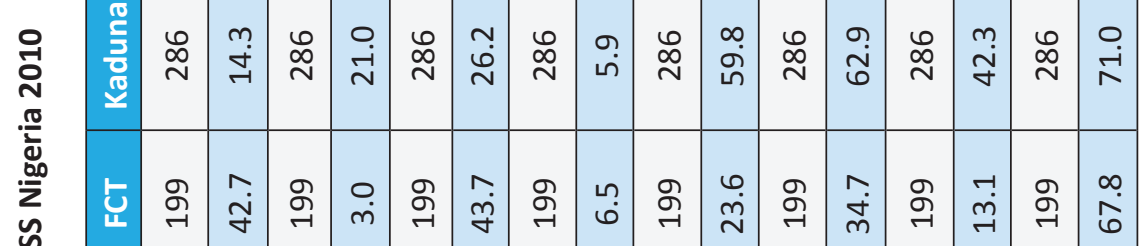

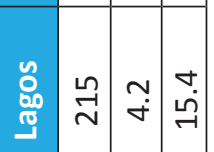

商

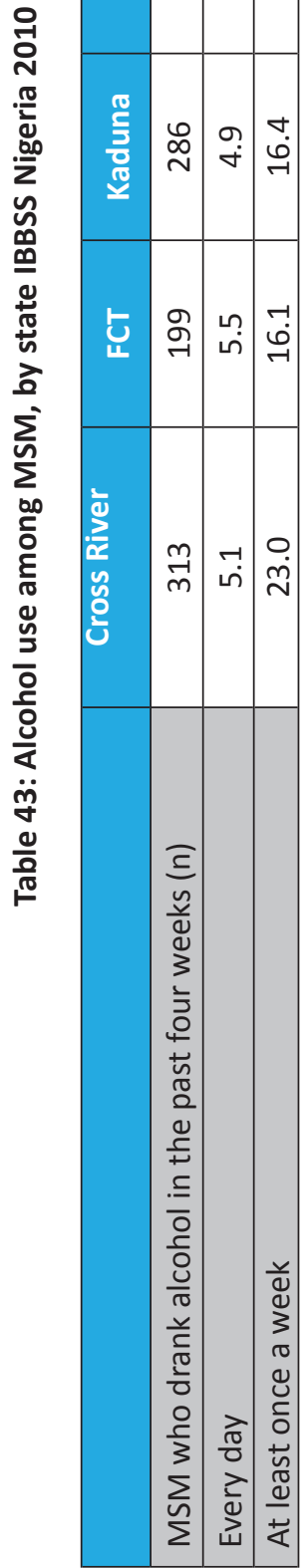

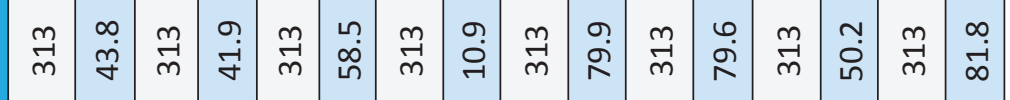

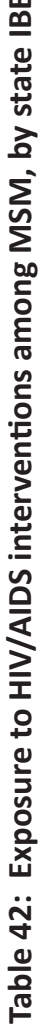
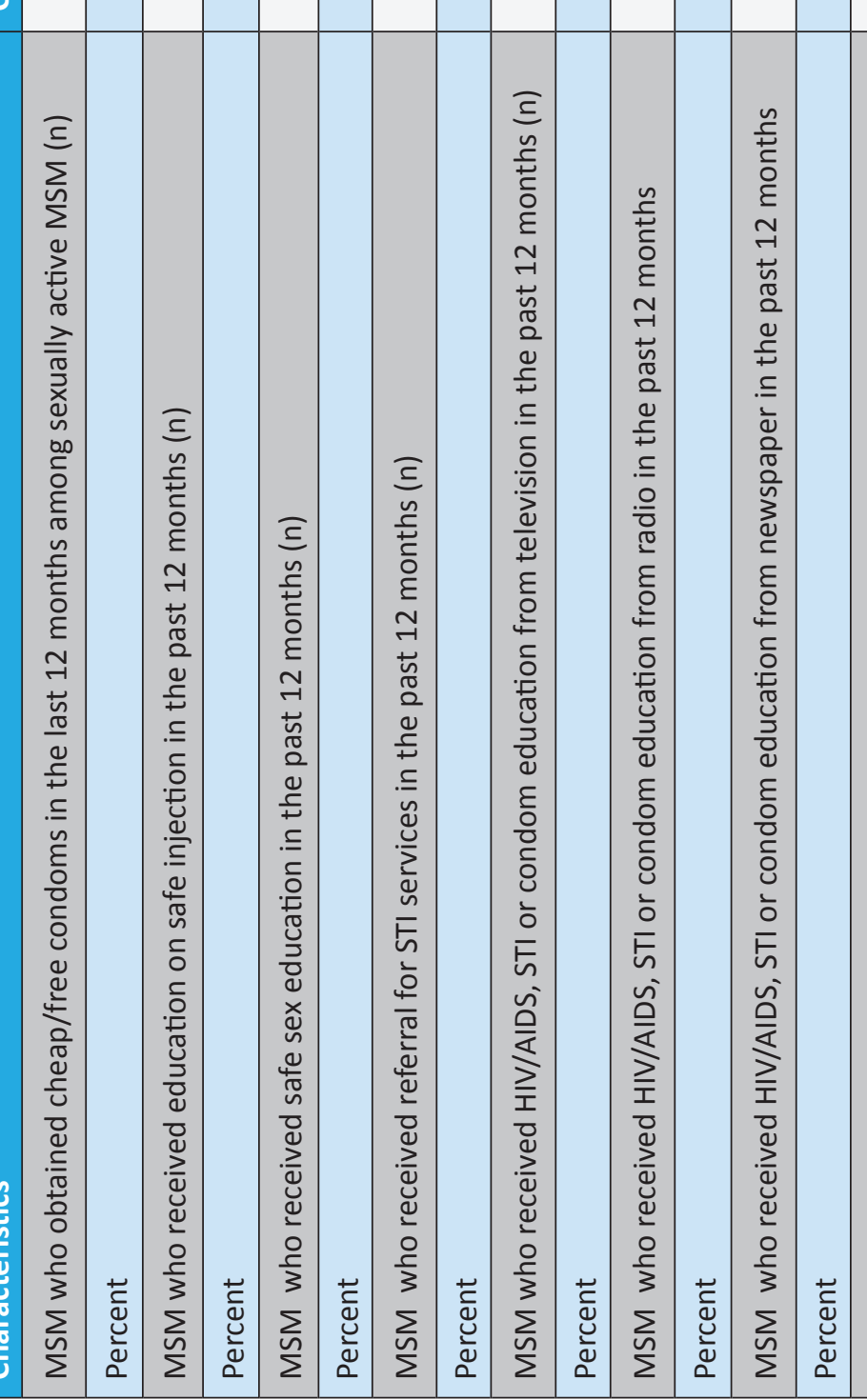

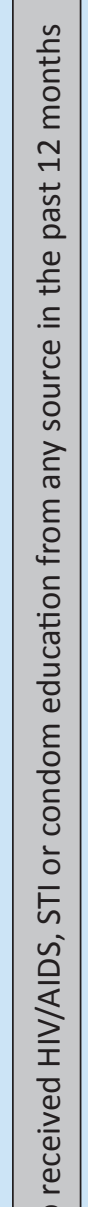

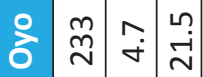




\subsubsection{Armed Forces}

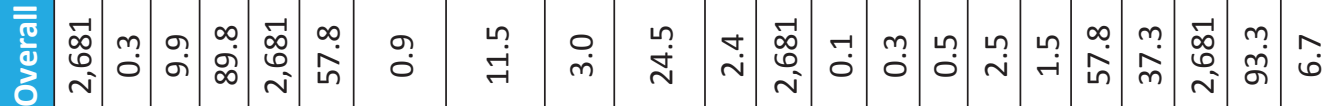

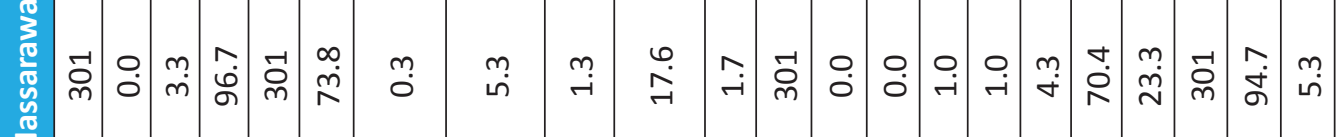

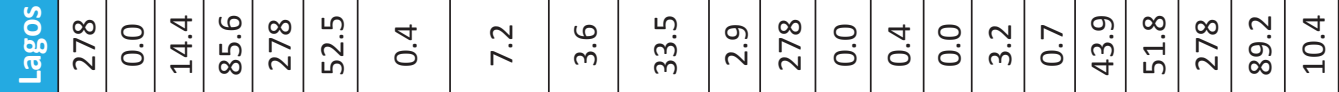

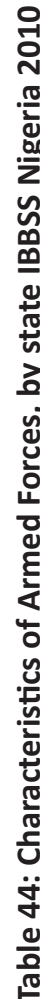

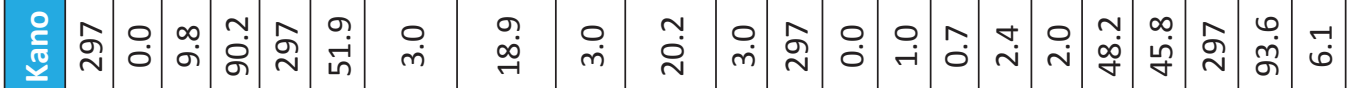

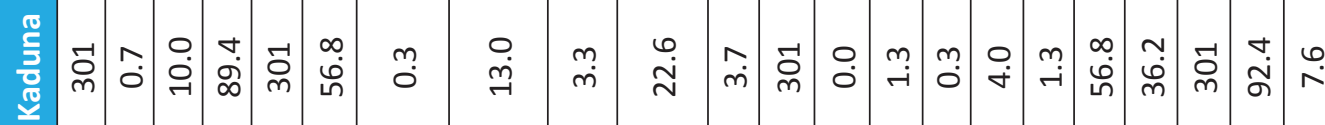

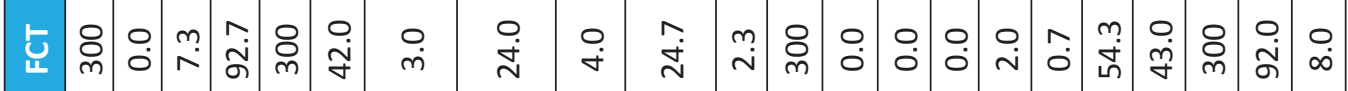

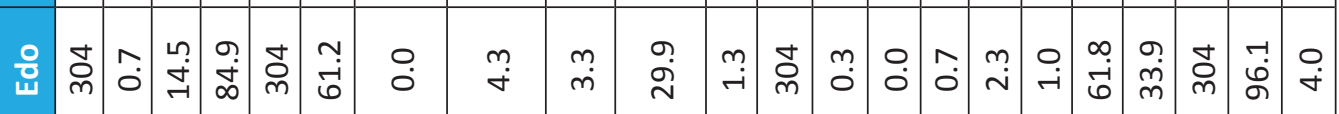

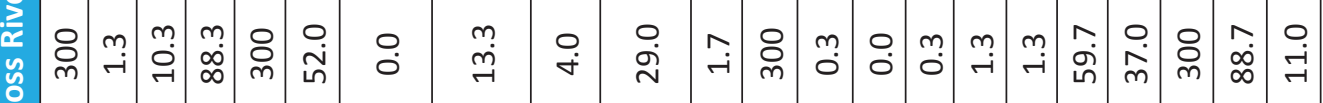

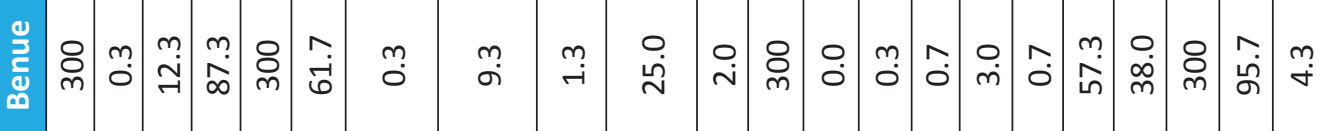

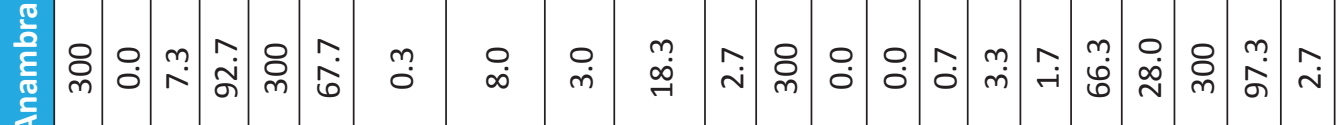

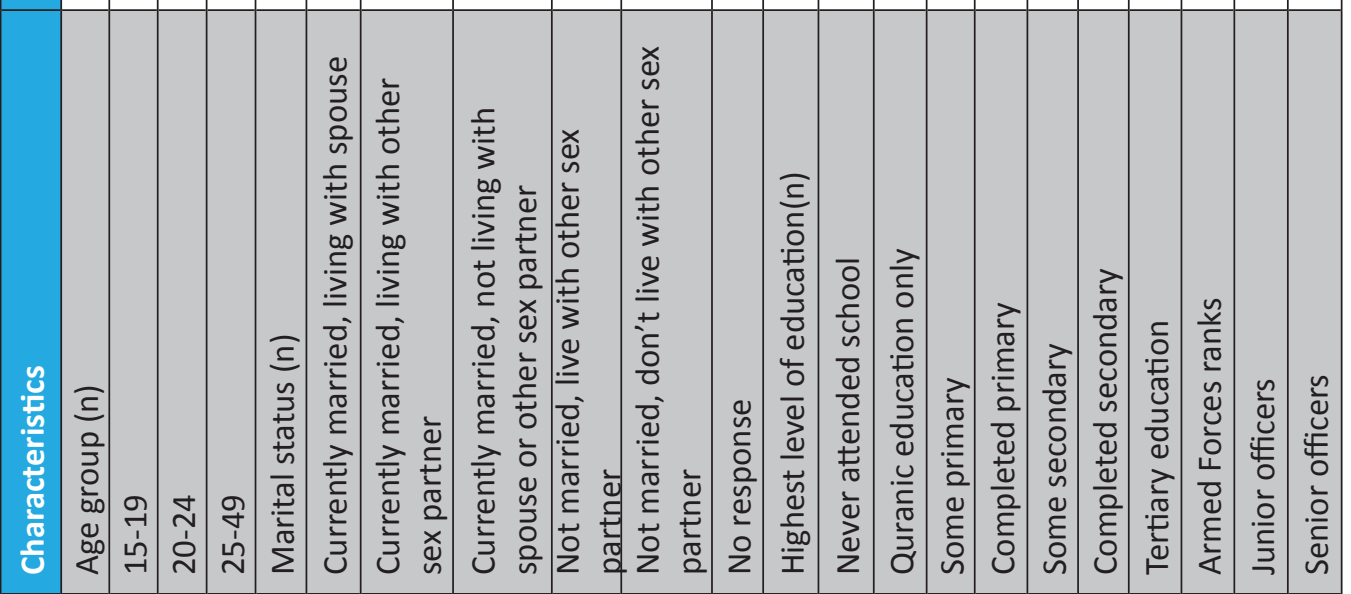




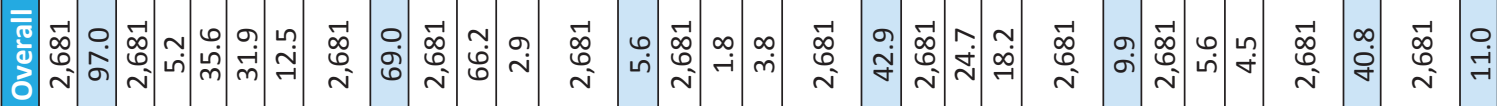

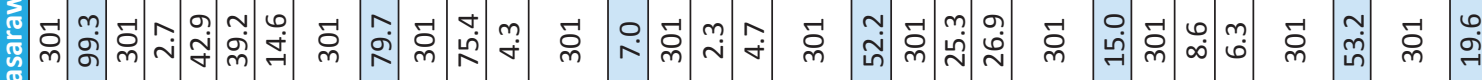

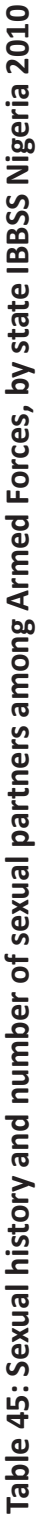

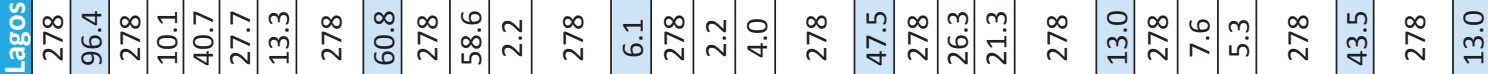

ঐ)

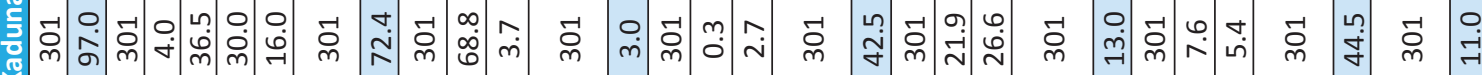

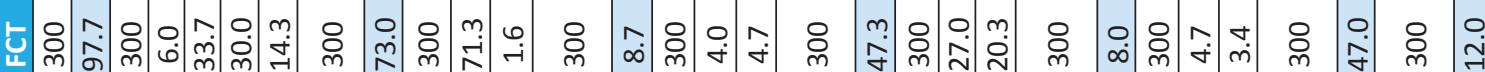

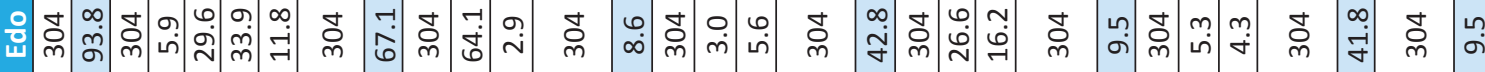

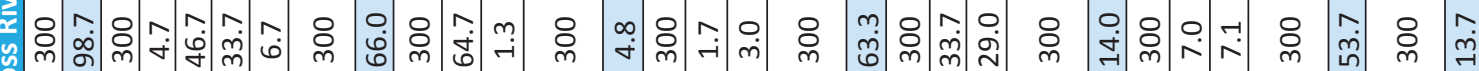
는

률

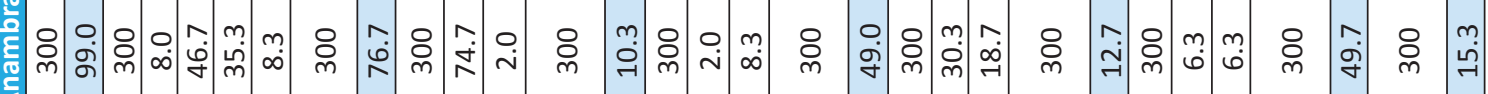

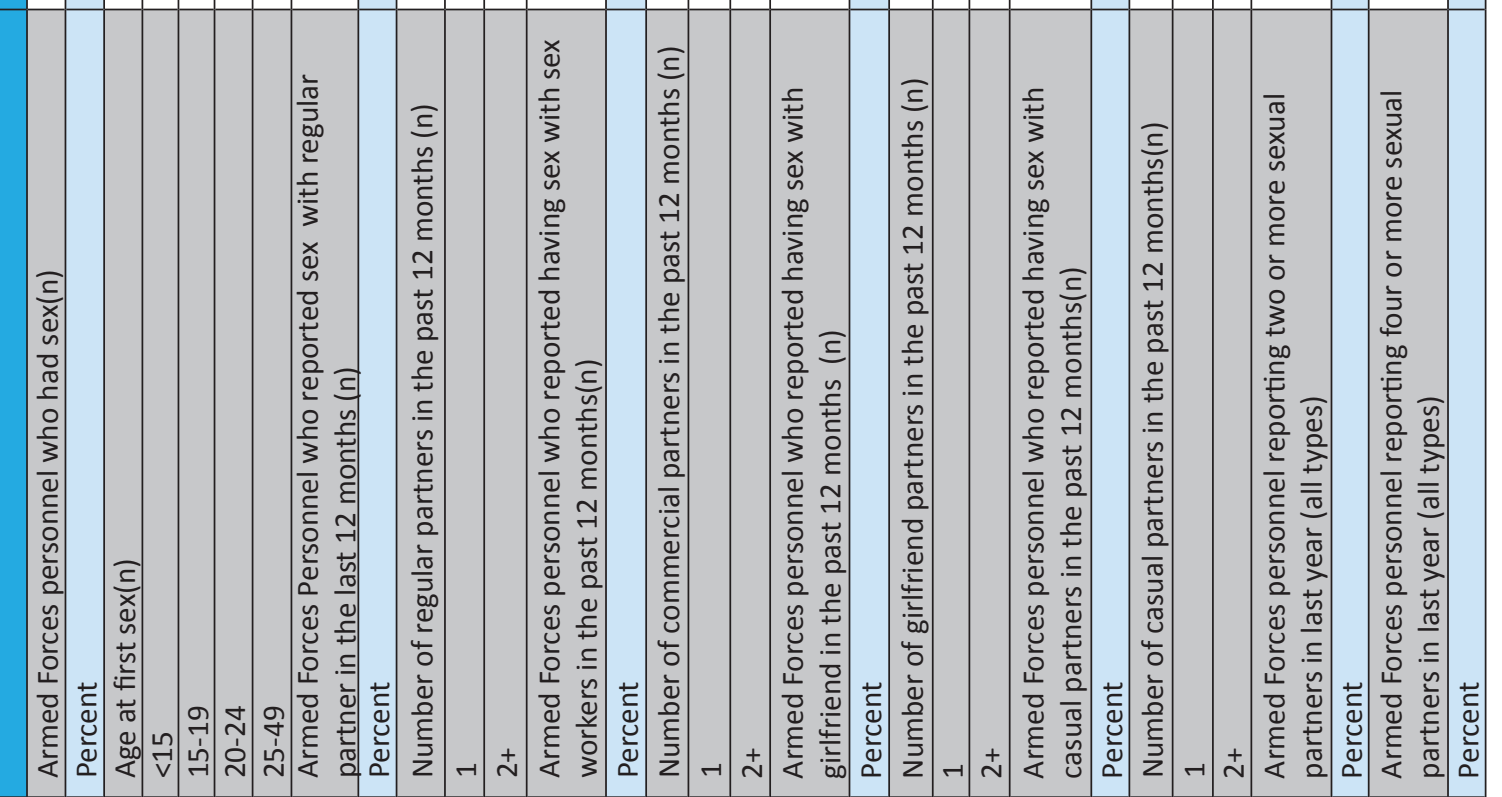




\begin{tabular}{|c|c|c|c|c|c|c|c|c|c|c|c|c|c|c|c|c|}
\hline $\begin{array}{l}\overline{\bar{c}} \\
\text { वेँ } \\
\text { ठ }\end{array}$ & 윰 & $\underset{\infty}{m}$ & 号 & $\stackrel{m}{\stackrel{n}{N}}$ & 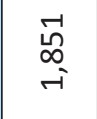 & $\stackrel{\infty}{\underset{\sim}{\sim}}$ & $\begin{array}{l}\vec{n} \\
\text { ஸे } \\
\rightarrow-1\end{array}$ & $\stackrel{\circ}{\dot{m}}$ & $\begin{array}{l}\stackrel{0}{\mathrm{C}} \\
\stackrel{-1}{-1}\end{array}$ & $\hat{\tilde{\theta}}$ & $\begin{array}{l}\text { 옥 } \\
\text { ㄱ- }\end{array}$ & $\stackrel{2}{\tilde{f}}$ & $\underset{\sim}{\stackrel{\leftrightarrow}{N}}$ & $\stackrel{-1}{-1}$ & 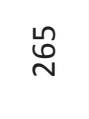 & $\stackrel{-1}{N}$ \\
\hline 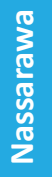 & $\ddot{\sim}$ & ஸٌ & $\vec{N}$ & ஜ̊ & $\stackrel{\text { }}{\sim}$ & $\stackrel{\stackrel{n}{\sim}}{\stackrel{f}{H}}$ & $\stackrel{\text { }}{\sim}$ & $\hat{i}$ & ก & $\begin{array}{l}\ddot{0} \\
\dot{\infty}\end{array}$ & $\stackrel{\text { ڤ }}{\rightarrow}$ & ㅁ. & $\stackrel{\mathscr{\sigma}}{\sigma}$ & नें & ஜ & $\stackrel{\infty}{\stackrel{n}{\wedge}}$ \\
\hline 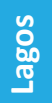 & ને & ने & ને & ने & 임 & 몸 & ఠ్ర & $\stackrel{\circ}{\dot{m}}$ & $\stackrel{N}{\vec{r}}$ & 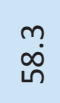 & $\stackrel{\widetilde{m}}{\rightarrow}$ & 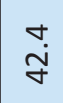 & $\stackrel{m}{m}$ & $\stackrel{\infty}{\stackrel{\infty}{\wedge}}$ & $\stackrel{m}{m}$ & ఫ̊ં \\
\hline 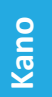 & $\nabla$ & $\underset{-1}{8}$ & $\nabla$ & $\underset{-1}{8}$ & 유 & $\stackrel{\mu}{\sigma}$ & ஓ & $\stackrel{\circ}{m}$ & R & $\stackrel{-1}{\hat{\sigma}}$ & R & $\stackrel{0}{\ddot{m}}$ & เn & 8 & in & $\begin{array}{l}0 \\
\stackrel{0}{0}\end{array}$ \\
\hline 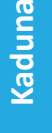 & $\sigma$ & $\begin{array}{l}\text { r } \\
\infty \\
\infty\end{array}$ & $\sigma$ & $\begin{array}{l}\text { r } \\
\infty \\
\infty\end{array}$ & $\stackrel{\infty}{\sim}$ & $\stackrel{+}{\underset{\sim}{ت}}$ & $\stackrel{\infty}{\sim}$ & $\stackrel{-1}{+}$ & $\stackrel{\infty}{\underset{\sim}{*}}$ & 유 & $\stackrel{\infty}{\underset{\sim}{\sim}}$ & $\stackrel{\stackrel{n}{\sim}}{\stackrel{m}{m}}$ & ウి & $\stackrel{\infty}{\stackrel{\infty}{\top}}$ & ஜ & 옴 \\
\hline 는 & $\ddot{v}$ & $\stackrel{\vec{n}}{n}$ & $\stackrel{\sim}{N}$ & ○्ं & 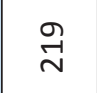 & $\underset{\sim}{\stackrel{m}{\sim}}$ & 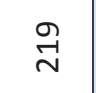 & $\hat{i}$ & $\stackrel{\mathcal{F}}{\sim}$ & $\stackrel{\circ}{\text { กீ }}$ & $\stackrel{\sim}{\neg}$ & $\stackrel{r}{\infty}$ & $\stackrel{\sim}{\sim}$ & $\underset{\infty}{m}$ & $\stackrel{d}{\sim}$ & $\stackrel{\sim}{\Gamma}$ \\
\hline 윰 & $\ddot{v}$ & $\begin{array}{l}\infty \\
\stackrel{\infty}{\infty}\end{array}$ & $\stackrel{\sim}{N}$ & $\stackrel{\vec{n}}{\sim}$ & ১্ & $\stackrel{\infty}{\underset{\sim}{\sim}}$ & ১্ & $\stackrel{\vec{m}}{m}$ & 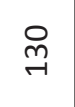 & $\begin{array}{l}\stackrel{g}{0} \\
\dot{\theta}\end{array}$ & 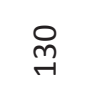 & $\begin{array}{l}\mathfrak{N} \\
\text { in }\end{array}$ & 尺 & ळి & શ & ळి \\
\hline 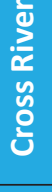 & 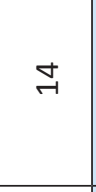 & જે & $\vec{\neg}$ & ڤે & $\stackrel{\infty}{\stackrel{-}{\sigma}}$ & $\underset{\stackrel{0}{-}}{\stackrel{-}{\rightarrow}}$ & $\stackrel{\infty}{\stackrel{-}{\sigma}}$ & $\stackrel{\circ}{\circ}$ & 号 & 8 & 익 & $\begin{array}{l}\infty \\
\dot{g}\end{array}$ & F & $\stackrel{\sim}{n}$ & F & $\hat{\ddot{g}}$ \\
\hline 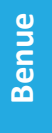 & $\sim$ & ㅇํ & $\sim$ & 吕 & $\stackrel{m}{\underset{-}{-}}$ & 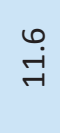 & $\stackrel{m}{\underset{-}{-}}$ & $\stackrel{+}{6}$ & $\stackrel{\text { ㅁ }}{+}$ & 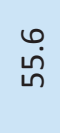 & $\stackrel{\text { นn }}{*}$ & $\stackrel{+}{\dot{J}}$ & $\wedge$ & $\stackrel{+}{i}$ & $r$ & $\stackrel{-1}{i}$ \\
\hline 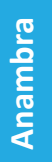 & $\vec{m}$ & $\begin{array}{l}\stackrel{\sigma}{\not ்} \\
\underset{\infty}{ }\end{array}$ & $\vec{m}$ & $\stackrel{+}{\stackrel{2}{\wedge}}$ & 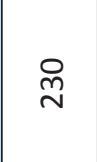 & $\underset{\infty}{m}$ & 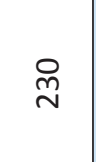 & $\tilde{N}$ & $\underset{\sim}{\stackrel{f}{-}}$ & $\begin{array}{l}0 \\
\dot{0}\end{array}$ & 今 & $\begin{array}{l}\text { ำ } \\
\text { กิ }\end{array}$ & $\stackrel{\infty}{m}$ & $\stackrel{\sim}{\sim}$ & $\stackrel{\infty}{m}$ & $\hat{n}$ \\
\hline 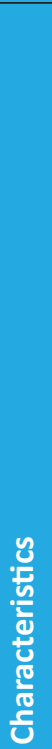 & 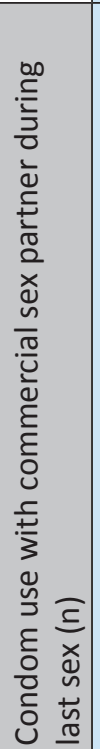 & 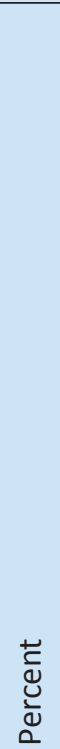 & 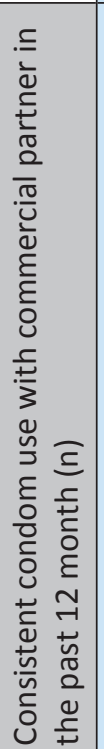 & 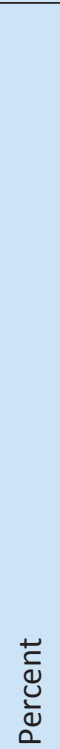 & 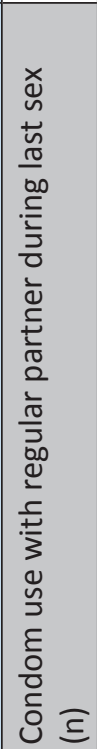 & 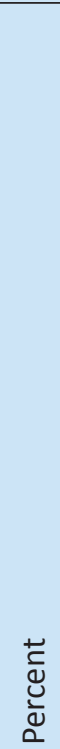 & 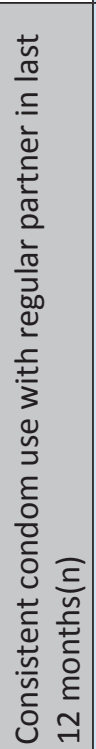 & 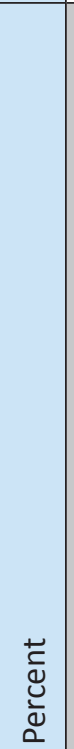 & 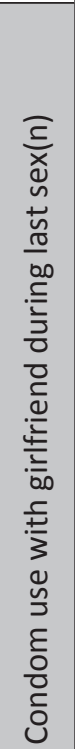 & 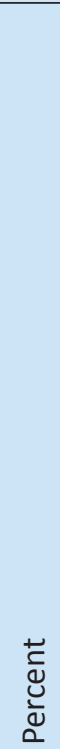 & 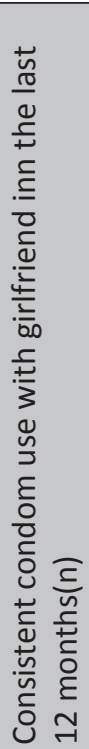 & 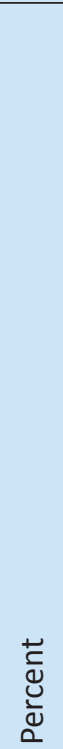 & 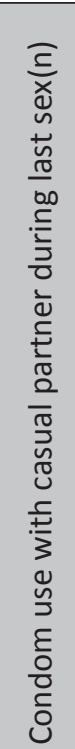 & 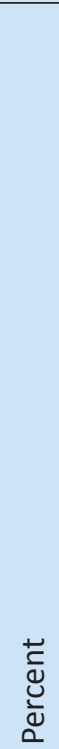 & 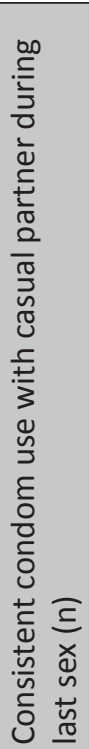 & 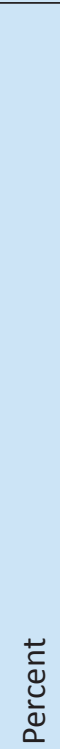 \\
\hline
\end{tabular}




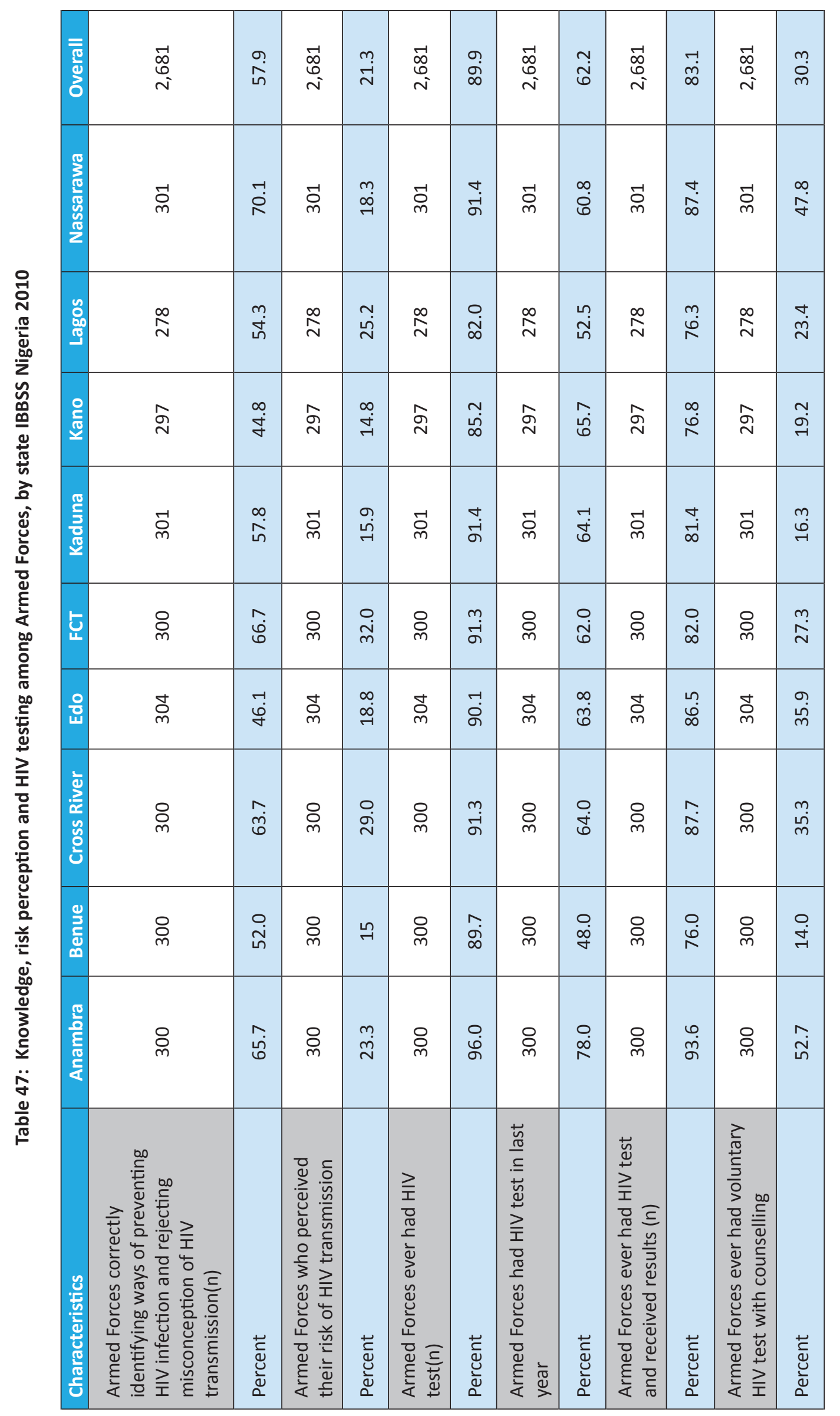




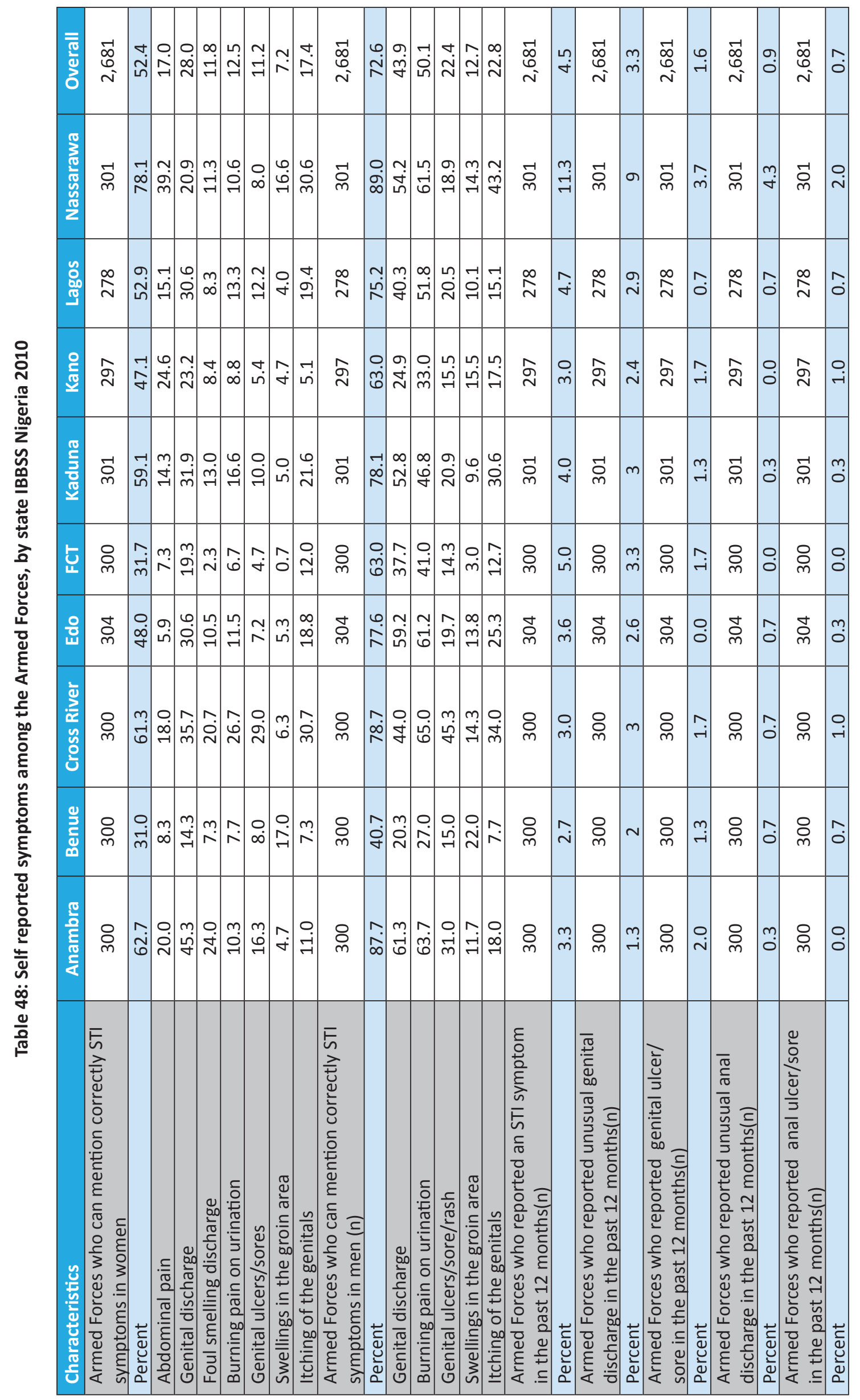


웣

율

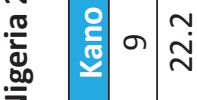

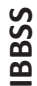

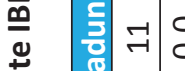

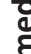

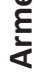

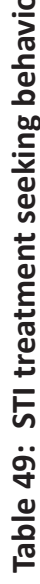

운 $\infty \stackrel{0}{0}$

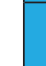

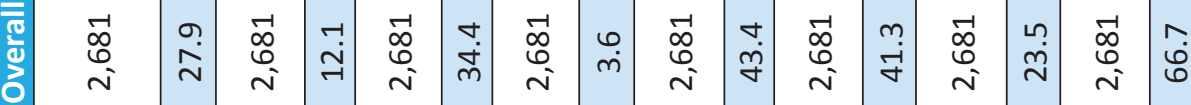

$\vec{\Delta}$

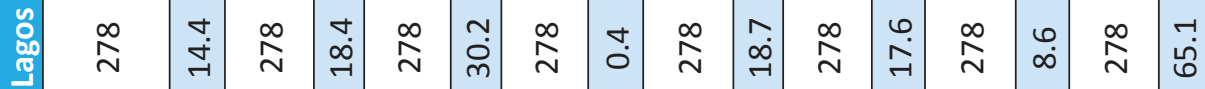

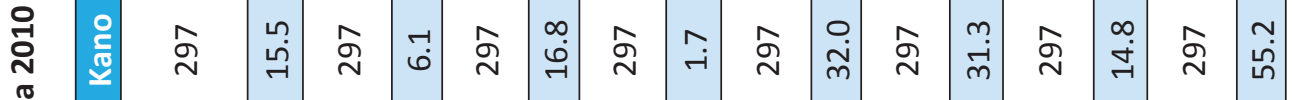

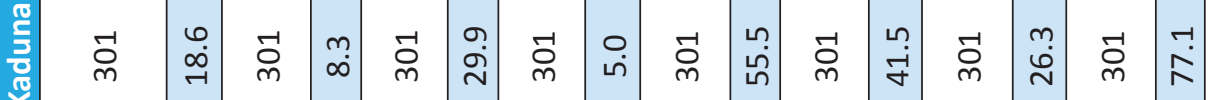

동

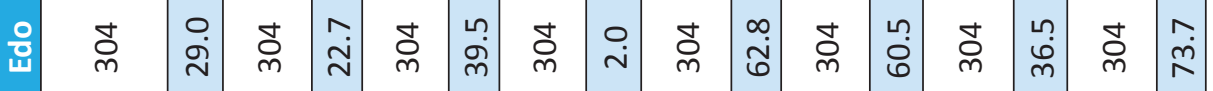
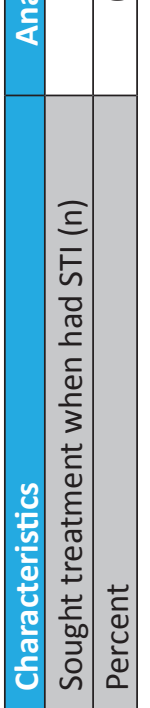

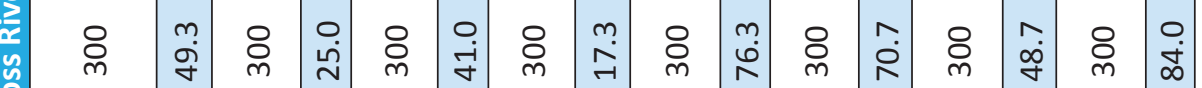

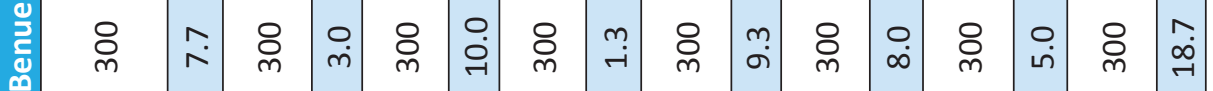

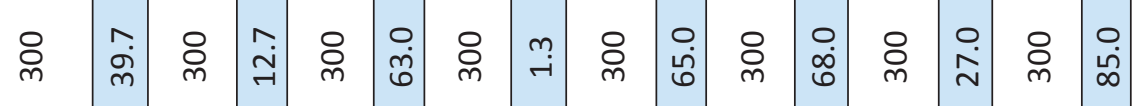

\begin{tabular}{|c|c|c|c|c|c|c|c|c|c|c|}
\hline 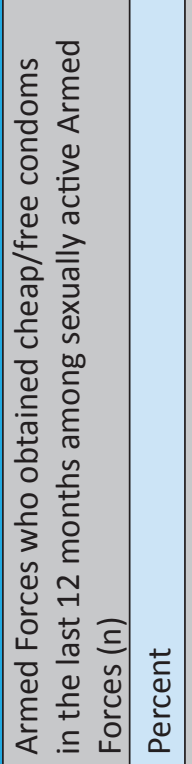 & 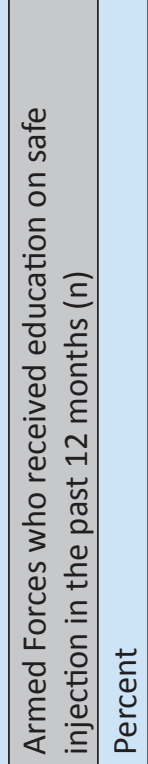 & 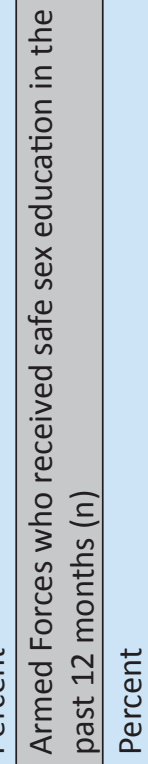 & 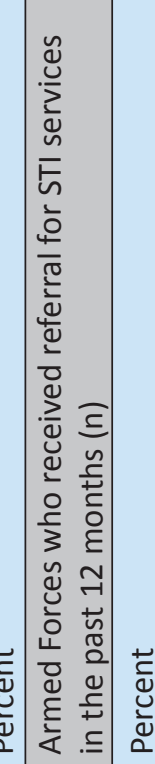 & 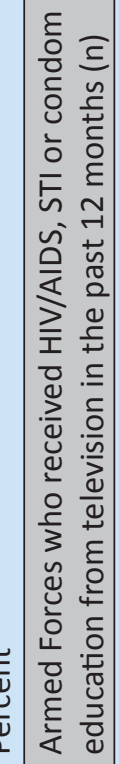 & 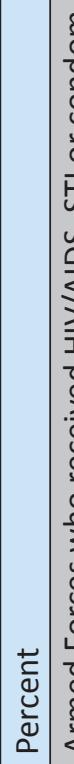 & 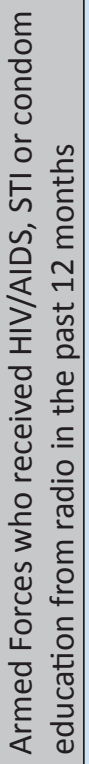 & & 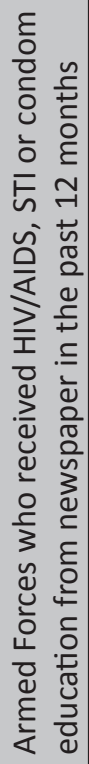 & & 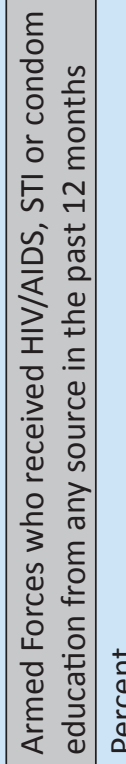 \\
\hline
\end{tabular}




\begin{tabular}{|c|c|c|c|}
\hline $\begin{array}{l}\overline{\overline{0}} \\
\overline{0} \\
\text { ठे }\end{array}$ & $\begin{array}{l}\vec{\infty} \\
0 \\
\stackrel{i}{N}\end{array}$ & $\stackrel{\varphi}{\varphi}$ & $\stackrel{m}{\underset{+}{+}}$ \\
\hline 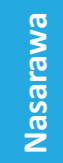 & 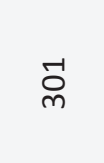 & $\stackrel{m}{m}$ & $\begin{array}{l}g \\
\dot{\varphi}\end{array}$ \\
\hline $\begin{array}{l}\text { 总 } \\
\text { ]ే }\end{array}$ & $\stackrel{\infty}{\stackrel{\sim}{\sim}}$ & $\stackrel{?}{r}$ & $\stackrel{\sim}{\varrho}$ \\
\hline 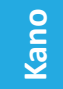 & Әे & $\stackrel{+}{-}$ & $\begin{array}{l}\infty \\
\stackrel{0}{-}\end{array}$ \\
\hline 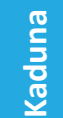 & - & 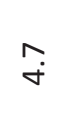 & $\stackrel{\circ}{\underset{\sim}{+}}$ \\
\hline 난 & ৪্ল & $\hat{\theta}$ & $\stackrel{\circ}{\underset{\sim}{ }}$ \\
\hline 움 & ఫ্ల & $\stackrel{\sim}{\sigma}$ & $\begin{array}{l}\infty \\
\text { n் }\end{array}$ \\
\hline 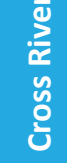 & ষ্ল & $\stackrel{m}{\varphi}$ & 오 \\
\hline लّ & ষ্ল & $\stackrel{0}{0}$ & $\hat{n}$ \\
\hline 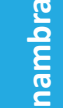 & ষ্ল & $\stackrel{n}{\underset{\sim}{\sim}}$ & $\stackrel{m}{\stackrel{n}{N}}$ \\
\hline & 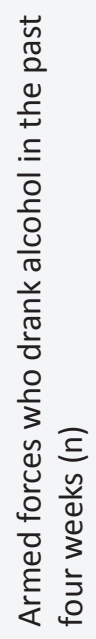 & 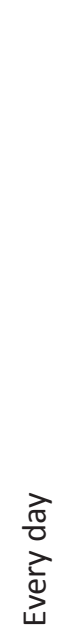 & 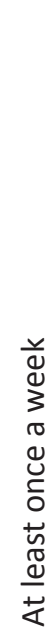 \\
\hline
\end{tabular}




\subsubsection{Police}

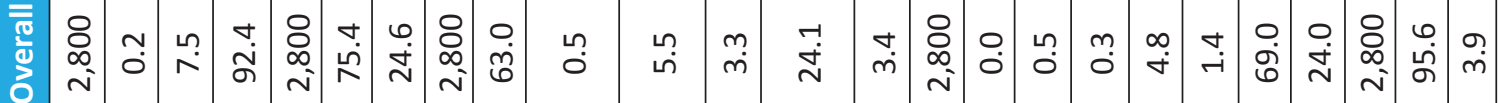

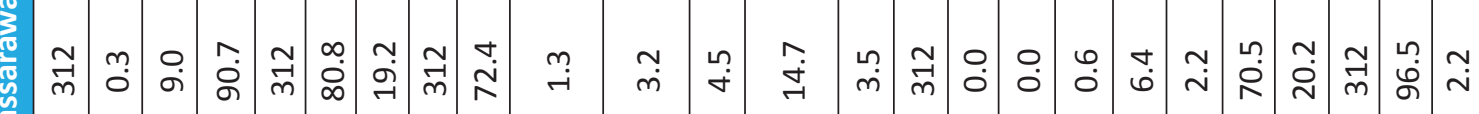

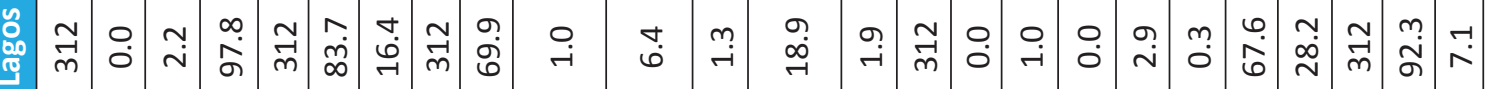

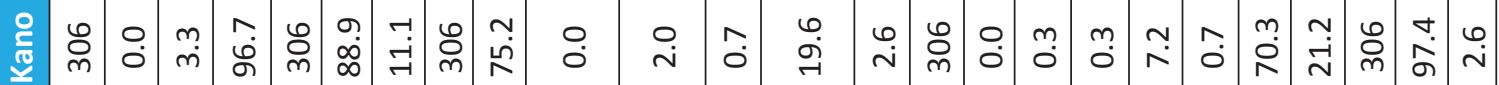

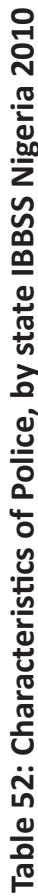

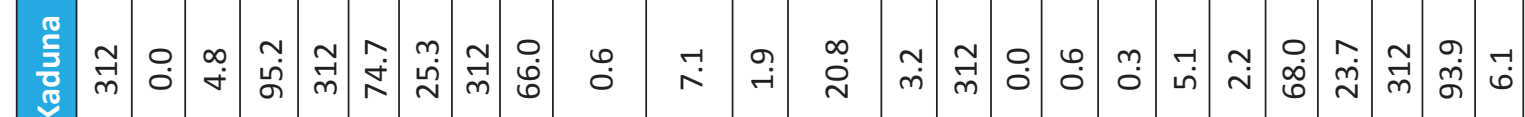

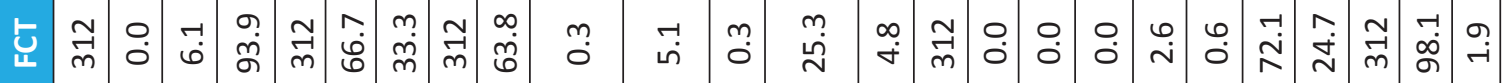

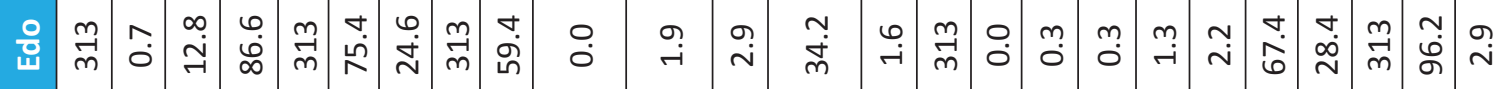

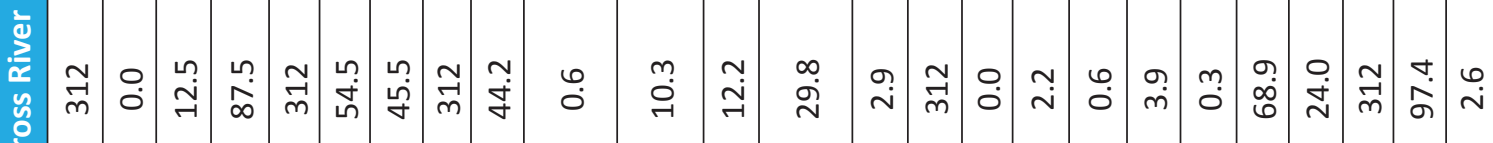
บ

ஓे

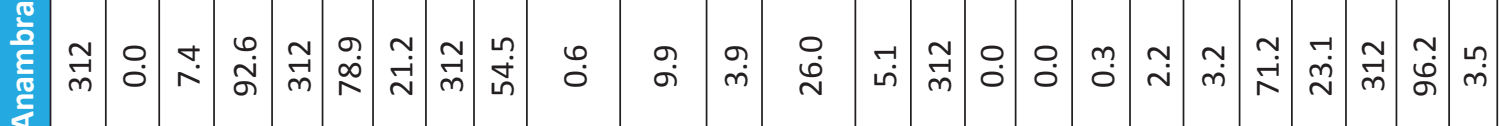

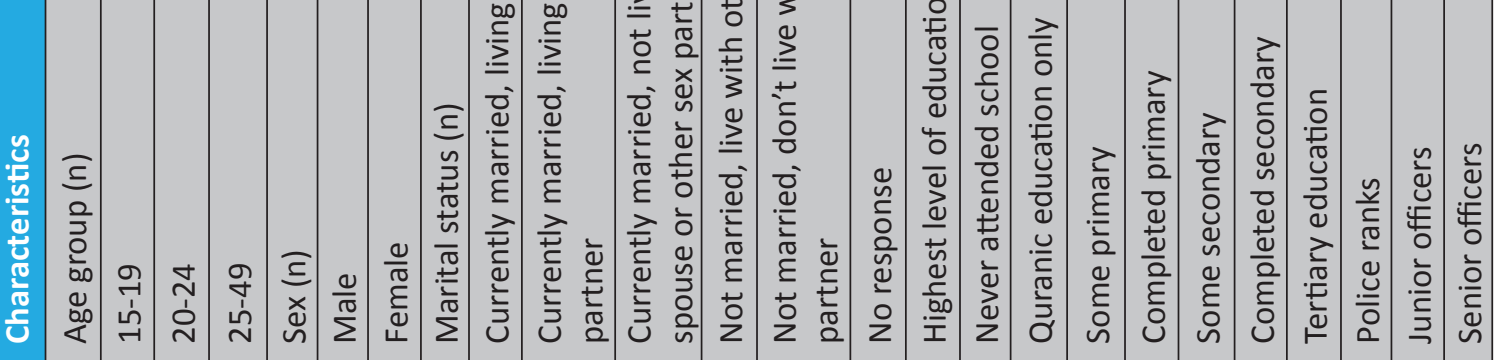




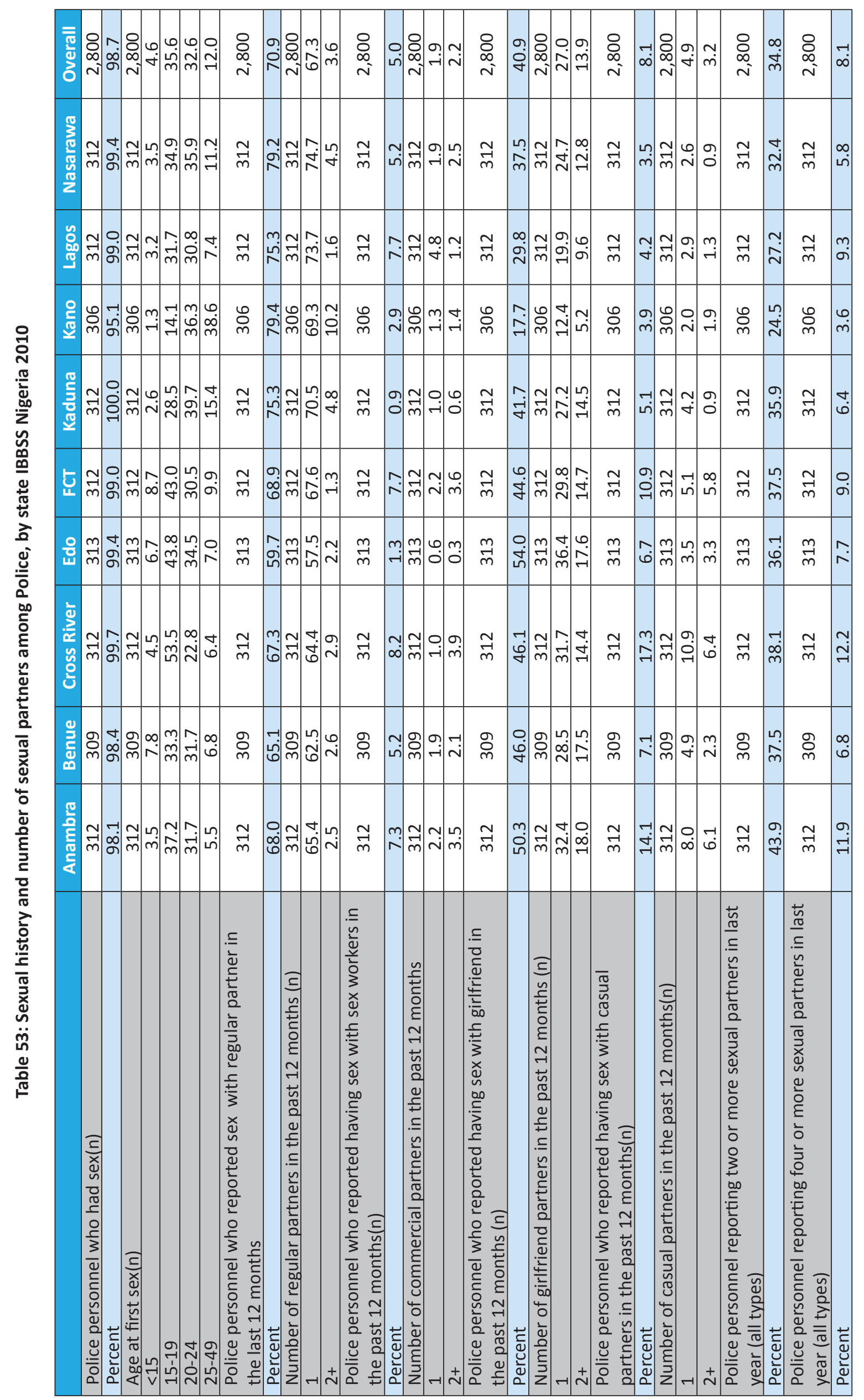




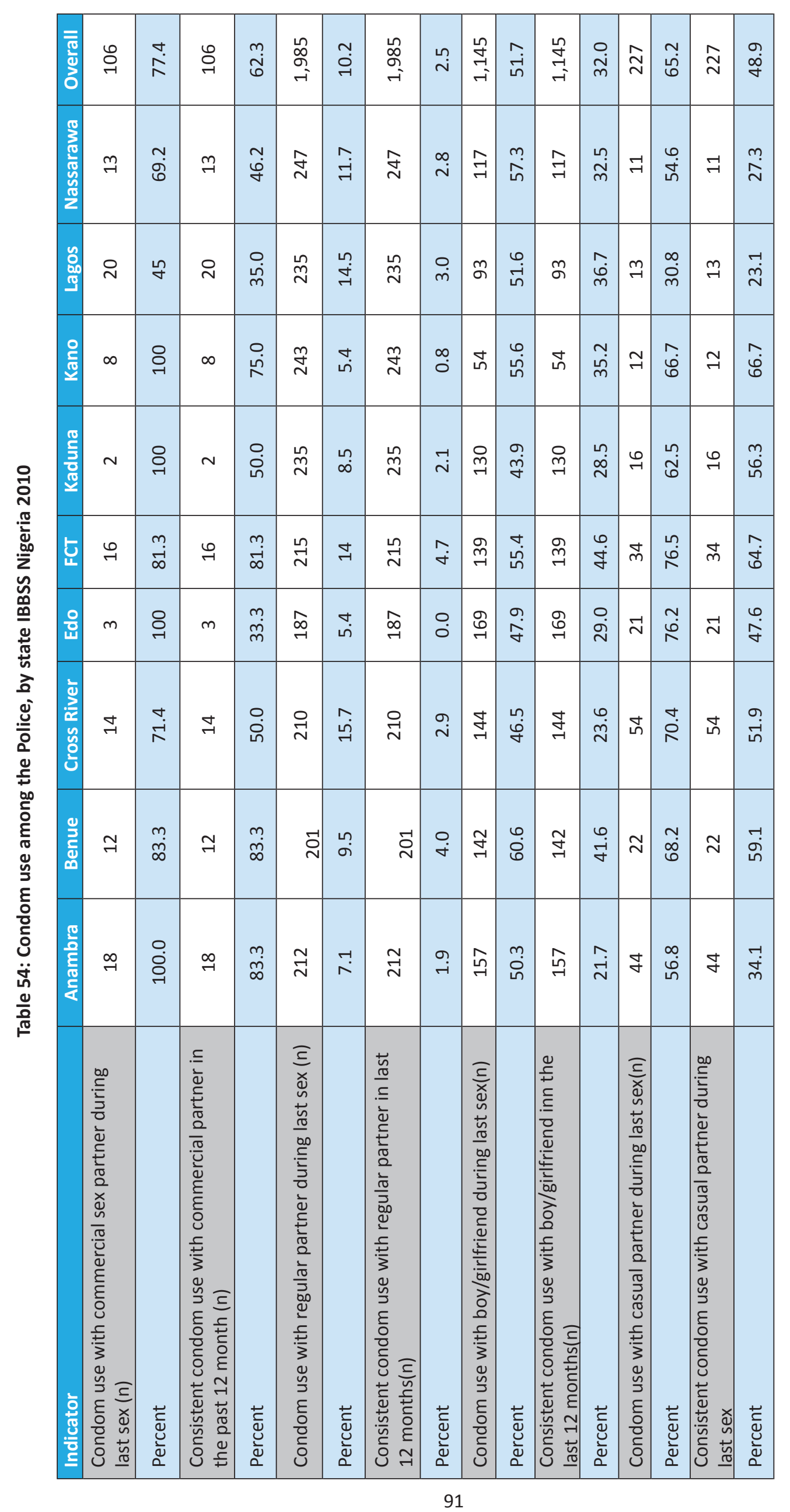




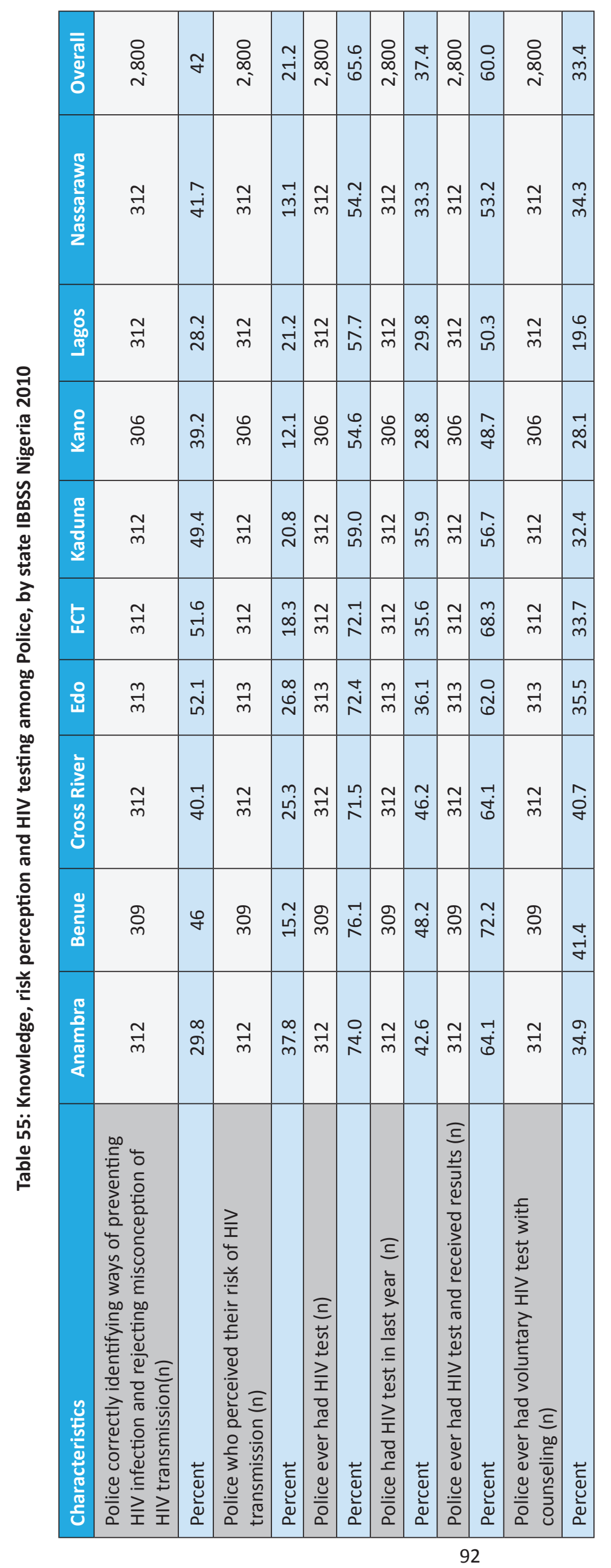




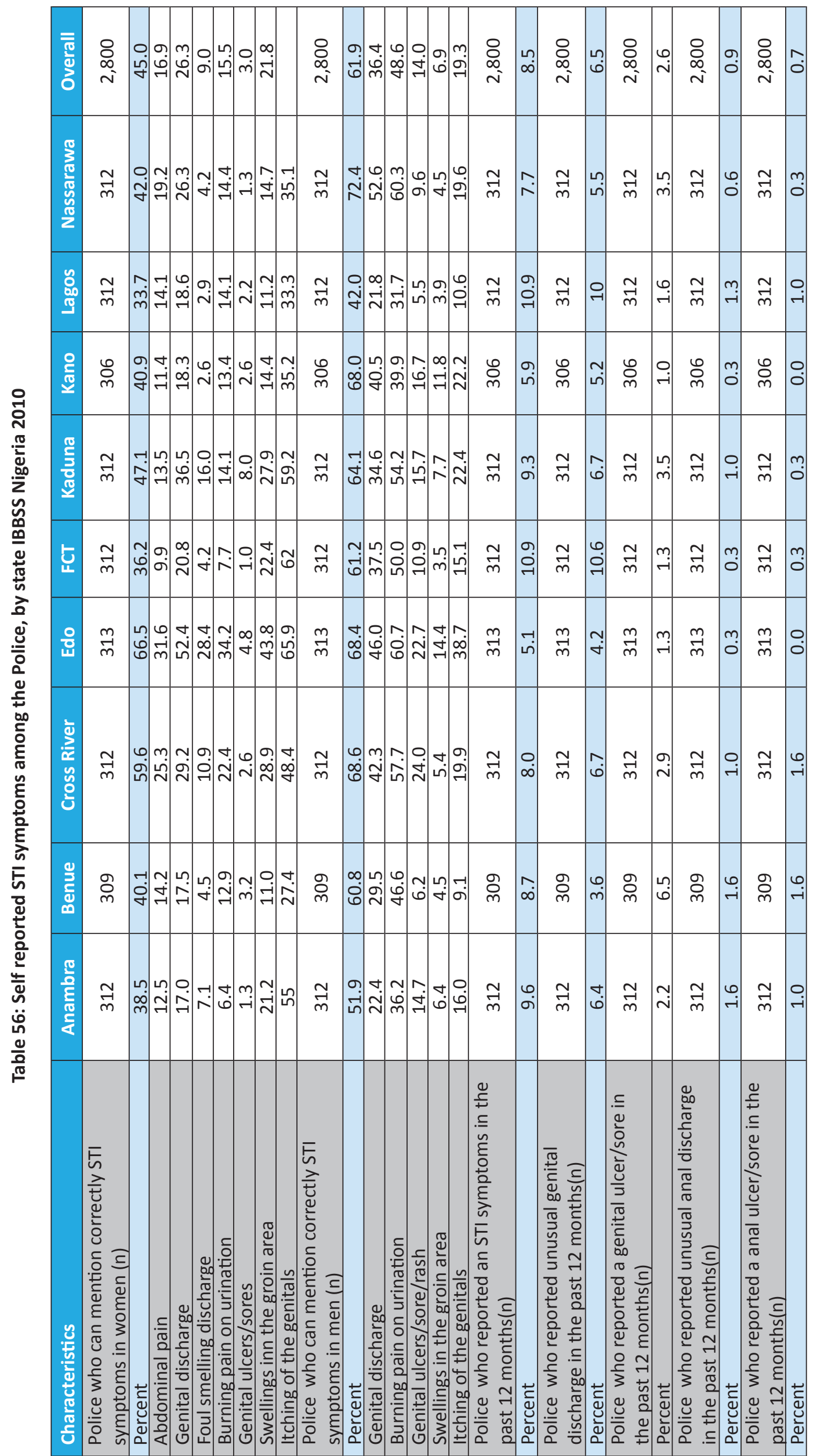




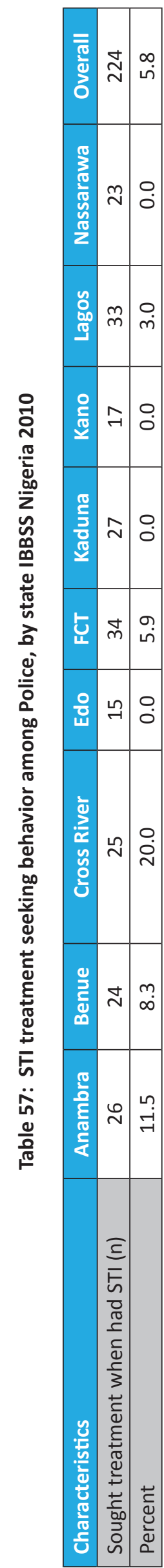

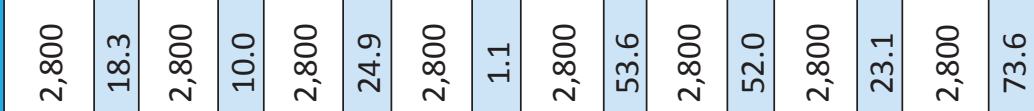

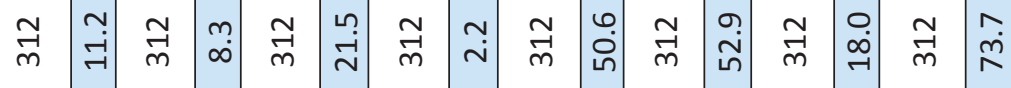

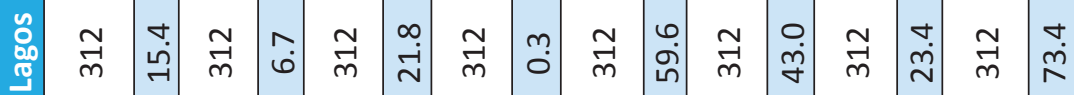

일

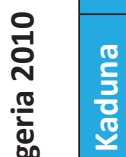

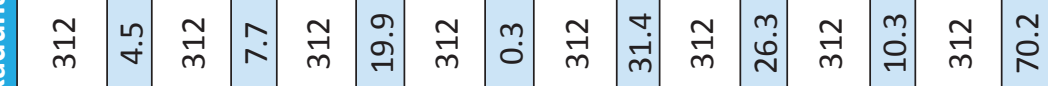

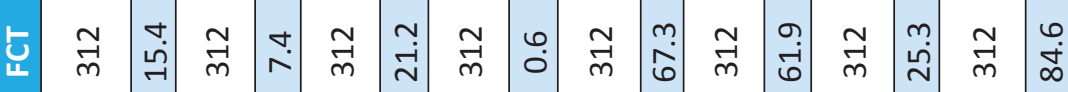

离

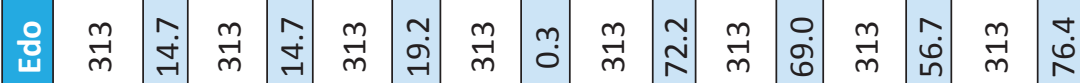

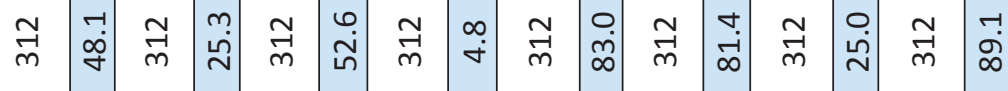

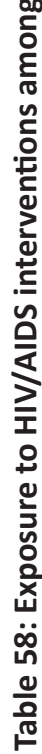

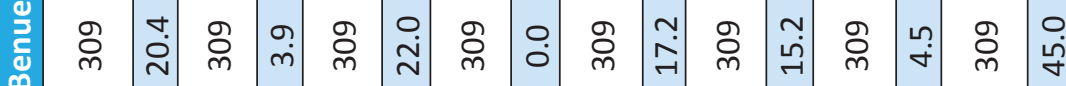

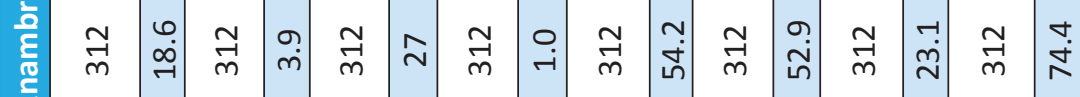

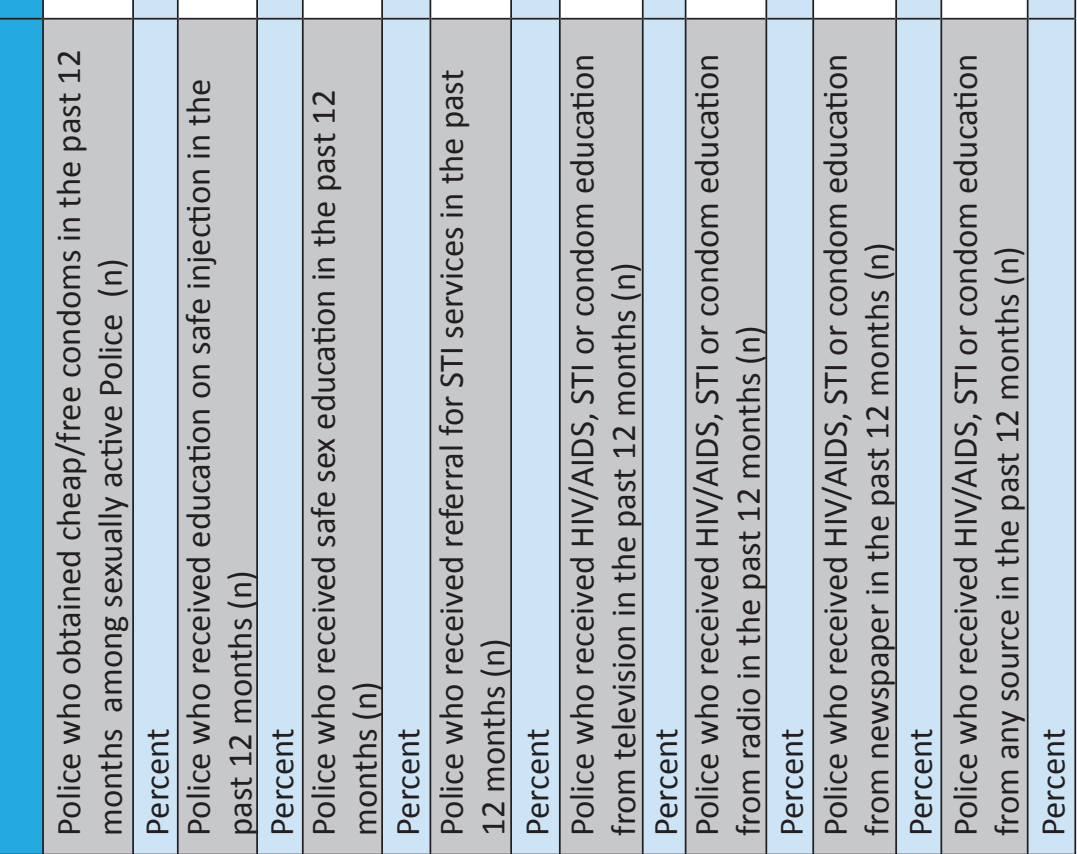




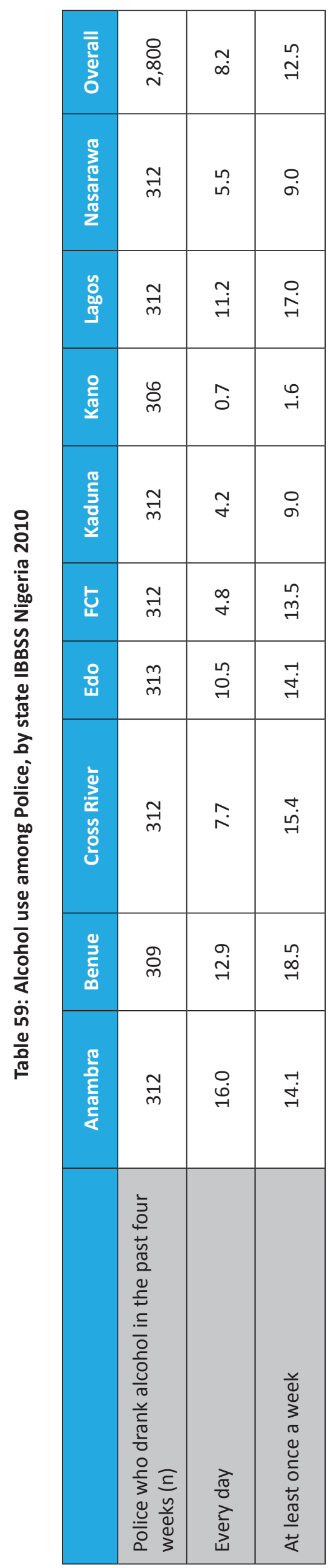




\subsubsection{Transport workers}

\begin{tabular}{|c|c|c|c|c|c|c|c|c|c|c|c|c|c|c|c|c|c|c|c|c|c|c|}
\hline 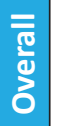 & $\begin{array}{l}\hat{n} \\
\alpha \\
- \\
-1\end{array}$ & $\underset{\sim}{-}$ & $\hat{\sigma}$ & $\begin{array}{l}n \\
\infty \\
\infty\end{array}$ & $\begin{array}{l}\hat{n} \\
\alpha \\
\rightarrow-1\end{array}$ & $\begin{array}{l}\infty \\
\tilde{\sigma}\end{array} \mid$ & $\underset{\sim}{\sim}$ & $\stackrel{m}{i}$ & ڤ̆ & $\begin{array}{l}\infty \\
\stackrel{\sim}{N}\end{array}$ & $\stackrel{\sim}{\sim}$ & $\begin{array}{l}\hat{n} \\
\stackrel{-}{-1}\end{array}$ & $\stackrel{\infty}{-}$ & $\stackrel{\bullet}{\bullet}$ & $\begin{array}{l}0 \\
\dot{0}\end{array}$ & $\begin{array}{l}0 \\
\stackrel{\sim}{N}\end{array}$ & $\begin{array}{l}\stackrel{\sim}{\circ} \\
\stackrel{\sim}{2}\end{array}$ & $\begin{array}{l}\dot{\varphi} \\
\stackrel{m}{m}\end{array}$ & $\begin{array}{l}9 \\
\infty\end{array}$ & $\begin{array}{l}\hat{n} \\
\stackrel{-}{-}\end{array}$ & $\begin{array}{l}\stackrel{\dot{n}}{m} \\
\stackrel{m}{m}\end{array}$ & $\stackrel{\dot{\oplus}}{\ddot{\theta}}$ \\
\hline $\begin{array}{l}\frac{10}{3} \\
\frac{3}{20} \\
\frac{10}{20} \\
0 \\
\frac{10}{2}\end{array}$ & $\stackrel{n}{\sim}$ & $\stackrel{\infty}{\sim}$ & $\begin{array}{l}0 \\
\overrightarrow{-} \\
\overrightarrow{-}\end{array}$ & $\begin{array}{l}\dot{\varphi} \\
\dot{\infty}\end{array}$ & $\stackrel{\sim}{\sim}$ & Na & $\stackrel{?}{r}$ & $\hat{m}$ & $\stackrel{\grave{\sigma}}{ }$ & $\stackrel{+}{\vec{N}}$ & $\hat{\sim}$ & $\stackrel{\sim}{\sim}$ & $\begin{array}{l}+ \\
\infty\end{array}$ & \begin{tabular}{l}
\multirow{H}{\sim}{} \\
$\rightarrow$
\end{tabular} & $\begin{array}{l}+ \\
\infty\end{array}$ & $\stackrel{\vec{i}}{\stackrel{\sim}{N}}$ & $\begin{array}{l}\vec{\leftrightarrow} \\
\stackrel{\sim}{n}\end{array}$ & 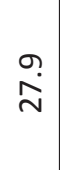 & $\stackrel{+}{r}$ & $\stackrel{\sim}{\sim}$ & $\hat{i}$ & $\begin{array}{l}9 \\
\overrightarrow{6}\end{array}$ \\
\hline 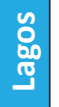 & $\vec{\sim}$ & $\stackrel{\circ}{\circ}$ & n̊ & $\begin{array}{l}\stackrel{\sim}{0} \\
\dot{\sigma}\end{array}$ & $\vec{\sim}$ & $\begin{array}{l}\infty \\
\stackrel{0}{ }\end{array}$ & $\stackrel{0}{0}$ & $\stackrel{\text { ğ }}{0}$ & $\stackrel{m}{i}$ & $\begin{array}{l}\mathscr{\varphi} \\
\dot{\vec{\sim}}\end{array}$ & gh & $\stackrel{\overbrace{}}{\sim}$ & $\stackrel{\infty}{-i}$ & $\stackrel{\sim}{m}$ & $\stackrel{m}{r}$ & $\stackrel{\sim}{\stackrel{\sim}{\sim}}$ & $\begin{array}{l}\vec{t} \\
\dot{\sigma}\end{array}$ & $\vec{c} \cdot \vec{m}$ & $\stackrel{\hat{m}}{\stackrel{m}{-}}$ & $\vec{\sim}$ & 官 & $\stackrel{\circ}{n ் n}$ \\
\hline 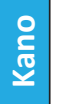 & $\stackrel{\infty}{\stackrel{\sim}{N}}$ & $\stackrel{ナ}{-}$ & $\underset{\infty}{m}$ & ஓ் & $\begin{array}{l}\infty \\
\vec{\sim}\end{array}$ & $\begin{array}{l}0 \\
\stackrel{0}{N}\end{array}$ & $\because$ & $\ddot{O}$ & $\stackrel{\llcorner}{0}$ & $\stackrel{\triangleright}{\stackrel{\sim}{N}}$ & $\stackrel{\bullet}{\stackrel{f}{*}}$ & $\stackrel{\infty}{\sim}$ & $\underset{\sim}{+}$ & $\underset{\sim}{\stackrel{\sim}{ন}}$ & $\stackrel{\infty}{\wedge}$ & $\vec{i}$ & 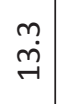 & 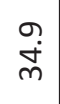 & $\stackrel{-1}{+}$ & $\stackrel{\infty}{\stackrel{\infty}{\sim}}$ & $\overrightarrow{\substack{1 \\
m}}$ & $\stackrel{\sigma}{\vec{\theta}}$ \\
\hline 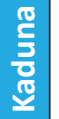 & 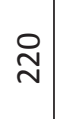 & $\stackrel{n}{0}$ & $\begin{array}{c}\stackrel{m}{\mathrm{H}} \\
\underset{H}{2}\end{array}$ & 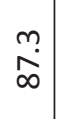 & $\stackrel{\sim}{\sim}$ & $\stackrel{+}{\vec{N}}$ & $\begin{array}{l}\stackrel{9}{0} \\
0\end{array}$ & $\stackrel{+}{6}$ & $\stackrel{\text { กn }}{\circ}$ & $\begin{array}{l}\infty \\
\dot{\omega} \\
\ddot{r}\end{array}$ & $\stackrel{\vec{f}}{+}$ & $\stackrel{\text { N }}{\text { N }}$ & $\stackrel{0}{\circ}$ & 齐 & $\begin{array}{l}+ \\
\dot{0}\end{array}$ & $\begin{array}{l}\circ \\
\stackrel{\sim}{N}\end{array}$ & $\begin{array}{l}0 \\
\ddot{H} \\
\vec{H}\end{array}$ & $\stackrel{\vec{i}}{m}$ & $\begin{array}{l}9 \\
\stackrel{9}{\circ}\end{array}$ & $\stackrel{\underset{N}{\sim}}{ }$ & $\begin{array}{l}0 \\
\stackrel{m}{m}\end{array}$ & $\begin{array}{l}\circ \\
\stackrel{1}{ }\end{array}$ \\
\hline 는 & $\stackrel{\overbrace{}}{\sim}$ & $\stackrel{+}{\leftrightarrow}$ & :- & $\begin{array}{l}0 \\
\infty \\
\infty\end{array}$ & $\vec{\sim}$ & $\begin{array}{l}0 \\
\ddot{\theta}\end{array}$ & O̊ & $\stackrel{\varphi}{\dot{r}}$ & $\stackrel{\sim}{m}$ & $\stackrel{m}{\sim}$ & $\stackrel{\overrightarrow{+}}{+}$ & $\stackrel{\overbrace{}}{\sim}$ & $\stackrel{m}{\sim}$ & $\stackrel{\sim}{\infty}$ & $\begin{array}{l}0 \\
\sigma\end{array}$ & $\underset{\mathfrak{m}}{\stackrel{m}{\sim}}$ & $\hat{\ddot{g}}$ & $\stackrel{\sim}{\stackrel{\sim}{\mathcal{F}}}$ & $\underset{⿱}{\stackrel{\sim}{-}}$ & $\stackrel{\vec{\sim}}{\sim}$ & $\begin{array}{l}\circ \\
\dot{\nu}\end{array}$ & $\stackrel{\vec{n}}{\stackrel{n}{n}}$ \\
\hline 움 & 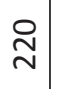 & $\begin{array}{l}\mathscr{0} \\
\dot{m}\end{array}$ & $\stackrel{2}{\curvearrowright}$ & $\begin{array}{l}0 \\
\infty \\
\infty\end{array}$ & $\stackrel{\sim}{\sim}$ & $\begin{array}{l}\text { பூ } \\
\text { ஸ் }\end{array}$ & $\stackrel{0}{\circ}$ & $\stackrel{\infty}{-i}$ & $\ddot{\sigma}$ & $\hat{\sim}$ & ọ & 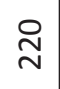 & $\stackrel{+}{-}$ & $\stackrel{n}{0}$ & ตุ & $\hat{\sim}$ & 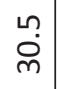 & $\begin{array}{c}\infty \\
\dot{m}\end{array}$ & $\stackrel{m}{r}$ & $\stackrel{\text { }}{\text { N }}$ & $\begin{array}{l}\text { ติં } \\
\text { กิ่ }\end{array}$ & $\begin{array}{l}\varphi \\
\dot{m} \\
m\end{array}$ \\
\hline 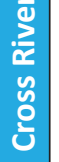 & $\vec{\sim}$ & $\stackrel{\sigma}{0}$ & $\begin{array}{l}\dot{\sigma} \\
\dot{\sigma}\end{array}$ & $\begin{array}{l}\text { Ln } \\
\text { ळ. }\end{array}$ & $\stackrel{\vec{\sim}}{\mathbf{N}}$ & $\hat{\circ}$ & $\stackrel{0}{\circ}$ & $\stackrel{+}{+}$ & $\vec{\sigma}$ & $\begin{array}{l}\vec{b} \\
\dot{m}\end{array}$ & $\hat{i}$ & $\stackrel{\rightarrow}{\sim}$ & $\begin{array}{l}0 \\
0\end{array}$ & $\stackrel{n}{0}$ & $\stackrel{\vec{r}}{+}$ & $\begin{array}{l}\text { Na } \\
\text { Эุ }\end{array}$ & $\stackrel{\sim}{\stackrel{\sim}{\sim}}$ & $\begin{array}{l}0 \\
\stackrel{i}{\sigma} \\
\end{array}$ & 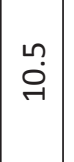 & $\stackrel{\vec{\sim}}{\sim}$ & $\begin{array}{l}\overrightarrow{0} \\
\dot{m}\end{array}$ & $\begin{array}{l}\circ \\
\dot{0}\end{array}$ \\
\hline 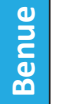 & $\stackrel{\text { Dे }}{\text {. }}$ & $\stackrel{m}{6}$ & $\begin{array}{l}\stackrel{0}{\mathfrak{I}} \\
\underset{\exists}{|c|}\end{array}$ & $\underset{\infty}{\stackrel{\sim}{i}}$ & 㝏 & $\begin{array}{l}\infty \\
\dot{f} \\
\end{array}$ & 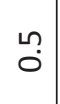 & تr & $\begin{array}{l}\infty \\
\infty \\
\infty\end{array}$ & $\stackrel{\sim}{\sim}$ & $\hat{r}$ & 오 & $\stackrel{0}{-i}$ & $\stackrel{\circ}{\circ}$ & 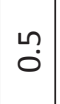 & Nָ & $\begin{array}{l}\infty \\
m \\
m\end{array}$ & $\stackrel{\sim}{\stackrel{y}{Y}}$ & $\stackrel{\vec{Z}}{\underset{7}{\prime}}$ & $\stackrel{\sim}{\hat{~}}$ & $\overrightarrow{\dot{n}}$ & 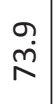 \\
\hline
\end{tabular}

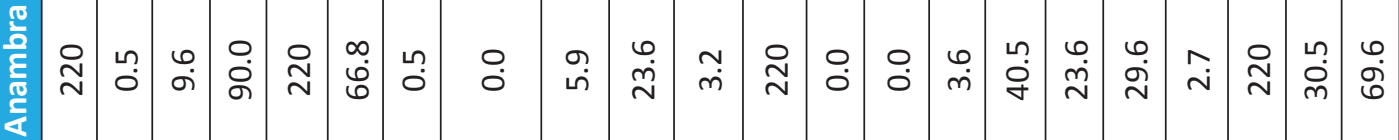

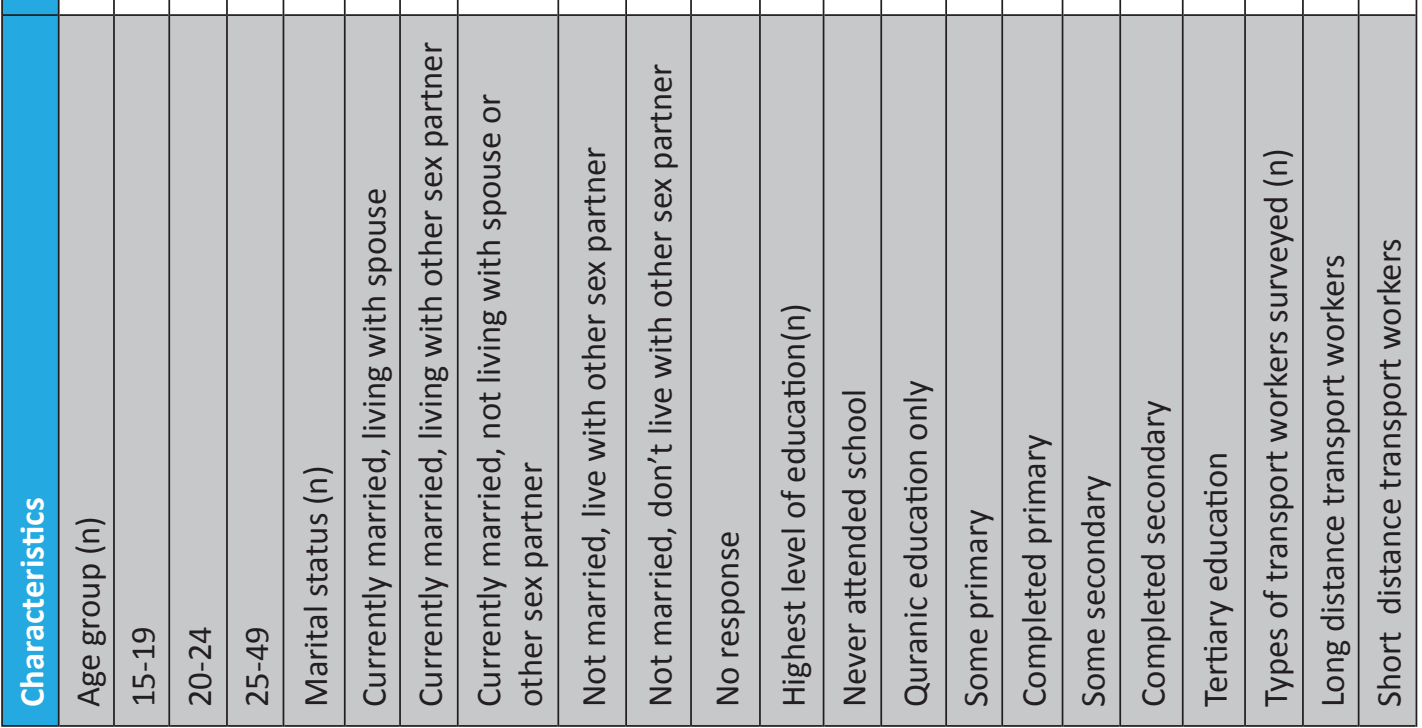




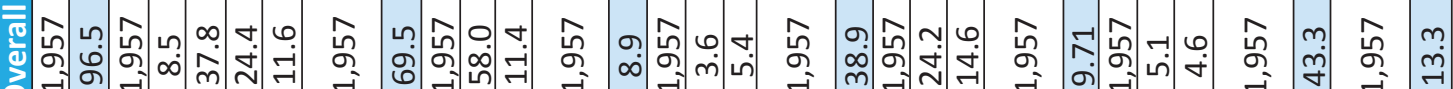

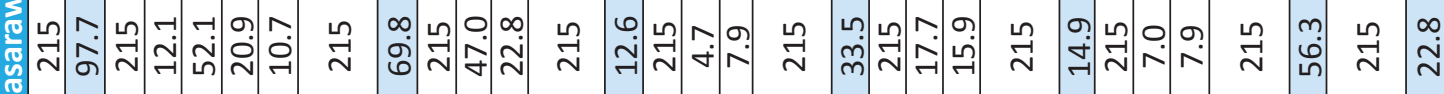

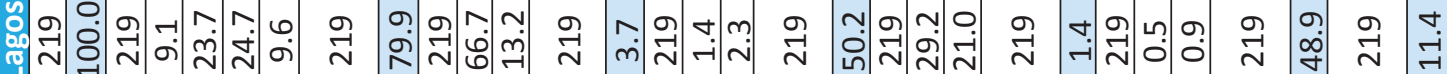

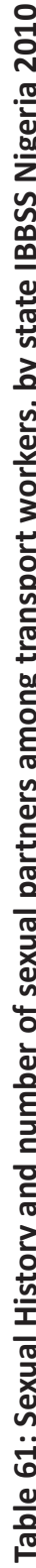

일

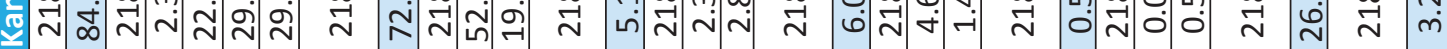

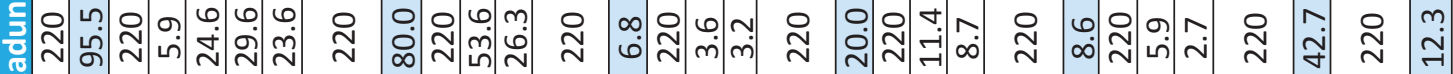

프

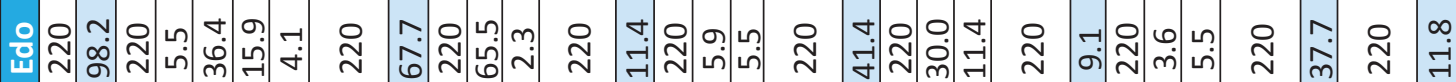

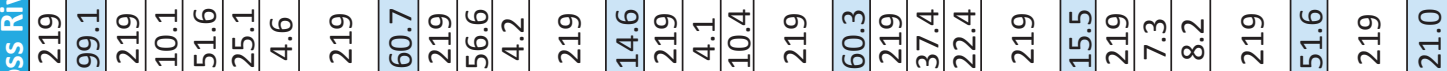
원

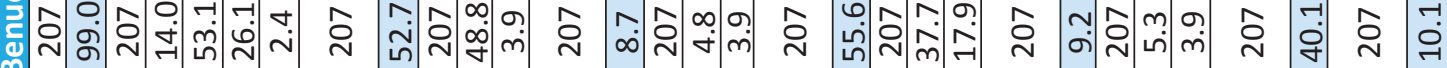

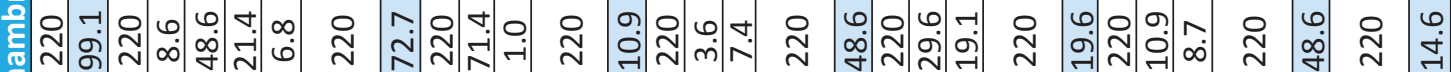

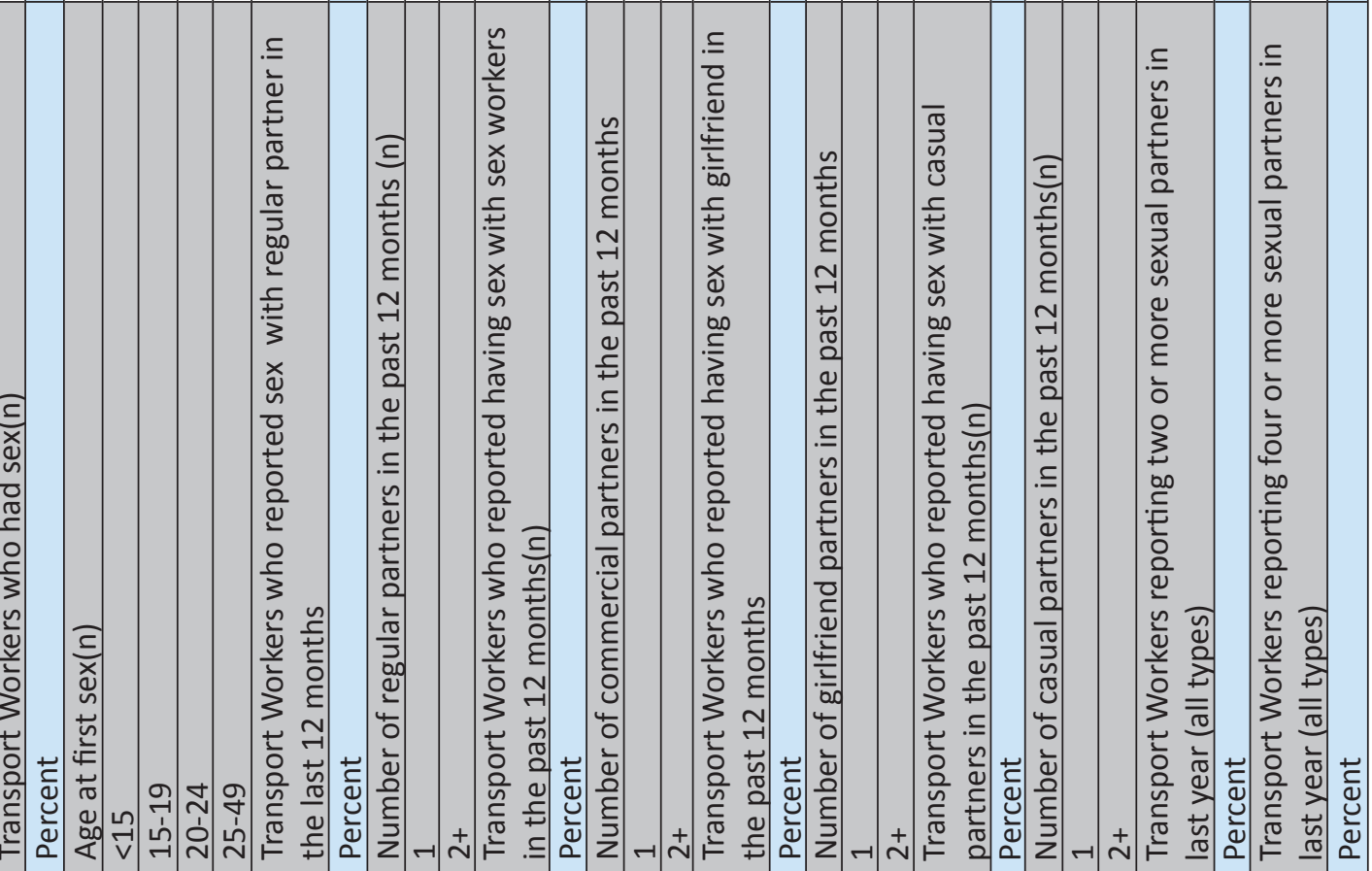




\begin{tabular}{|c|c|c|c|c|c|c|c|c|c|c|c|c|c|c|c|c|}
\hline 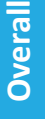 & 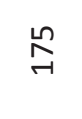 & $\begin{array}{l}0 \\
\dot{\infty} \\
\dot{\infty}\end{array}$ & 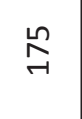 & 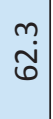 & $\begin{array}{l}\stackrel{\circ}{0} \\
\underset{\sim}{\rightarrow} \\
-\end{array}$ & $\hat{\infty}$ & 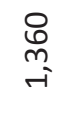 & 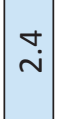 & $\vec{\varphi}$ & $\begin{array}{l}\infty \\
\dot{f} \\
\dot{f}\end{array}$ & $\stackrel{\overrightarrow{0}}{\circ}$ & $\begin{array}{l}0 \\
\infty \\
\infty \\
\sim\end{array}$ & প్ & 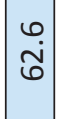 & Яి & $\stackrel{-}{\mathfrak{i}}$ \\
\hline 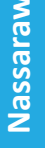 & $\grave{\sim}$ & 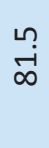 & 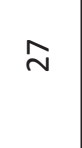 & $\begin{array}{l}0 \\
\hat{m} \\
m\end{array}$ & 号 & $\stackrel{m}{\sigma}$ & 号 & $\mid \begin{array}{l}0 \\
\dot{N}\end{array}$ & $\stackrel{N}{N}$ & 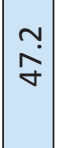 & $\mathbb{N}$ & $\begin{array}{c}m \\
m \\
m\end{array}$ & $\tilde{m}$ & $\mid \begin{array}{l}\infty \\
\infty \\
0 \\
0\end{array}$ & $\tilde{m}$ & $\mid \begin{array}{l}\dot{d} \\
\dot{m}\end{array}$ \\
\hline $\begin{array}{l}\text { 总 } \\
\text { 亗 }\end{array}$ & $\infty$ & $\underset{\infty}{\stackrel{n}{\infty}}$ & $\infty$ & $\stackrel{n}{\sim}$ & $\underset{\sim}{\stackrel{\sim}{\sim}}$ & $\begin{array}{l}6 \\
\infty \\
\infty\end{array}$ & 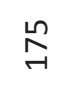 & $\begin{array}{l}0 \\
\dot{\nabla}\end{array}$ & $\stackrel{ }{\rightarrow}$ & $\begin{array}{c}\sim \\
\infty \\
\dot{\sigma}\end{array}$ & 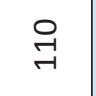 & 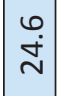 & $m$ & $\begin{array}{r}\hat{g} \\
\dot{6}\end{array}$ & $m$ & $\begin{array}{l}1 \\
\dot{0}\end{array}$ \\
\hline 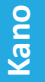 & $\exists$ & $\begin{array}{l}\text { த̊ } \\
\text { gे }\end{array}$ & $\vec{ન}$ & $\begin{array}{l}\infty \\
\dot{\infty} \\
\infty\end{array}$ & 占 & $\stackrel{\stackrel{n}{\sim}}{\sim}$ & 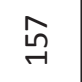 & 品 & $\stackrel{m}{\rightarrow}$ & $\begin{array}{l}0 \\
\dot{\infty} \\
\dot{\infty}\end{array}$ & $\stackrel{m}{\rightarrow}$ & $\begin{array}{l}\mathscr{\sigma} \\
\tilde{n} \\
n\end{array}$ & $r$ & 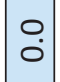 & $r$ & 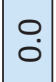 \\
\hline 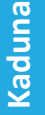 & $\stackrel{\text { 几 }}{\rightarrow}$ & $\widehat{\varphi}$ & 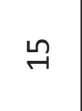 & $\begin{array}{c}m \\
m \\
\vec{r}\end{array}$ & 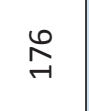 & $\stackrel{m}{\varphi}$ & $\stackrel{0}{\stackrel{0}{-}}$ & $\mid \begin{array}{l}0 \\
0 \\
0\end{array}$ & F & $\begin{array}{l}\text { g̊ } \\
\dot{q}\end{array}$ & Z & 号 & 9 & $\overrightarrow{\mathfrak{z}}$ & 9 & 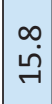 \\
\hline t. & $\stackrel{\sim}{\sim}$ & $\begin{array}{l}m \\
\tilde{n}\end{array}$ & $\stackrel{\llcorner}{\sim}$ & $\begin{array}{l}\hat{b} \\
\infty\end{array}$ & ઊ̆ & $\begin{array}{l}\underset{6}{+} \\
\underset{\sim}{\sim}\end{array}$ & ઊુ & $\begin{array}{l}\stackrel{0}{r} \\
\dot{f}\end{array}$ & $\curvearrowright$ & $\begin{array}{l}\infty \\
\text { in } \\
\text { กิ }\end{array}$ & $\curvearrowright$ & $\begin{array}{l}\hat{i} \\
\dot{m}\end{array}$ & ને & $\mid \begin{array}{c}n \\
\tilde{n} \\
0\end{array}$ & ને & $\begin{array}{l}-1 \\
\dot{y}\end{array}$ \\
\hline 윰 & $\stackrel{\Perp}{\sim}$ & $\begin{array}{l}0 \\
\infty \\
\infty\end{array}$ & $\stackrel{\stackrel{n}{\sim}}{ }$ & $\begin{array}{l}0 \\
\dot{\infty}\end{array}$ & $\underset{\sim}{\stackrel{g}{-}}$ & 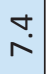 & $\stackrel{g}{\underset{ }{-}}$ & $\begin{array}{l}0 \\
i\end{array}$ & б̆ & $\mid \begin{array}{l}0 \\
\dot{m} \\
m\end{array}$ & ने & $\stackrel{0}{\stackrel{i}{N}}$ & $\stackrel{\sim}{ }$ & $\mid \begin{array}{l}0 \\
0 \\
\infty\end{array}$ & i & $\begin{array}{l}0 \\
0 \\
\infty\end{array}$ \\
\hline 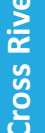 & $\tilde{m}$ & $\begin{array}{c}-1 \\
\infty \\
\infty\end{array}$ & $\tilde{m}$ & 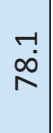 & $\stackrel{m}{\rightarrow}$ & $\stackrel{n}{\sim}$ & $\stackrel{m}{\rightarrow}$ & $\left|\begin{array}{l}0 \\
\dot{m}\end{array}\right|$ & $\stackrel{\tilde{M}}{\rightarrow}$ & $\mid \begin{array}{l}n \\
0 \\
\sigma\end{array}$ & $\stackrel{\widetilde{M}}{\rightarrow}$ & 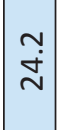 & 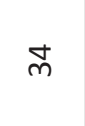 & $\left|\begin{array}{c}\infty \\
\dot{\vec{b}}\end{array}\right|$ & मे & 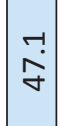 \\
\hline 总 & $\stackrel{\infty}{\rightarrow}$ & $\begin{array}{l}0 \\
\text { ஸ่ } \\
\text { ஸे }\end{array}$ & $\stackrel{\infty}{\sim}$ & 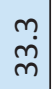 & 음 & $\begin{array}{l}0 \\
\stackrel{6}{\leftrightarrow} \\
\sim\end{array}$ & 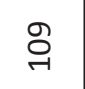 & $\mid \begin{array}{l}0 \\
\dot{\nabla}\end{array}$ & $\stackrel{\text { 극 }}{ન}$ & \begin{tabular}{|c|}
$\stackrel{n}{m}$ \\
$\dot{v}$
\end{tabular} & 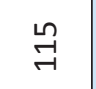 & $\begin{array}{c}m \\
\dot{m}\end{array}$ & ને & $\begin{array}{c}\mathfrak{N} \\
\tilde{n}\end{array}$ & ન & $\underset{\mathcal{H}}{\stackrel{-}{\mathcal{H}}}$ \\
\hline 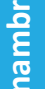 & $\stackrel{d}{\sim}$ & $\begin{array}{l}0 \\
\dot{0} \\
0 \\
\end{array}$ & $\stackrel{\searrow}{\sim}$ & Na & $\underset{\leftrightarrow}{\stackrel{\leftrightarrow}{-}}$ & $\begin{array}{c}\infty \\
\infty \\
\infty\end{array}$ & : & O̊. & 욱 & $\mid \begin{array}{c}m \\
\infty \\
m\end{array}$ & 웍 & 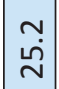 & $\stackrel{m}{q}$ & \begin{tabular}{|c|}
$n$ \\
0 \\
0 \\
0
\end{tabular} & $\stackrel{m}{q}$ & 主 \\
\hline 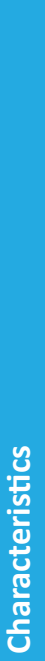 & 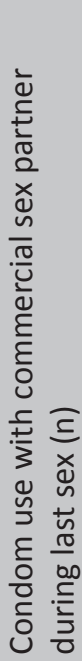 & $\mid \begin{array}{l}\vec{c} \\
\bar{d} \\
\underline{v} \\
\mathbb{v}\end{array}$ & 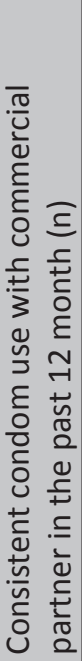 & $\begin{array}{l}\stackrel{\vec{c}}{\bar{d}} \\
\stackrel{\underline{v}}{\underline{v}}\end{array}$ & 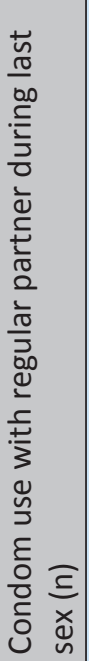 & $\begin{array}{l}\overrightarrow{\mathbf{v}} \\
\mathbf{d} \\
\underline{v}\end{array}$ & 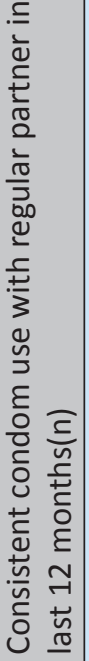 & 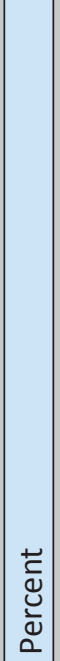 & 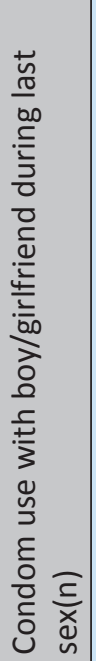 & 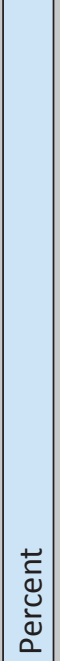 & 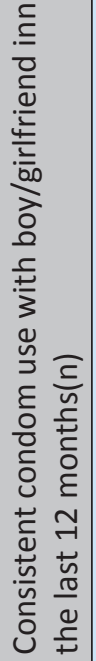 & $\mid \begin{array}{l}\vec{v} \\
\bar{d} \\
\underline{u} \\
\alpha\end{array}$ & 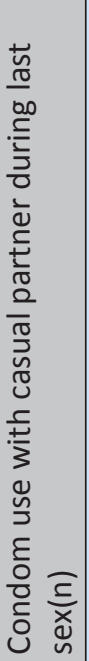 & $\left|\begin{array}{l}\vec{v} \\
\bar{u} \\
\frac{u}{u} \\
\alpha\end{array}\right|$ & 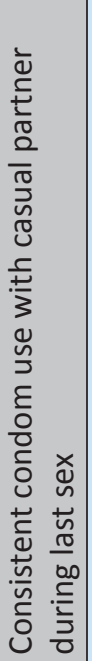 & 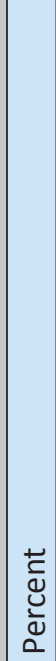 \\
\hline
\end{tabular}




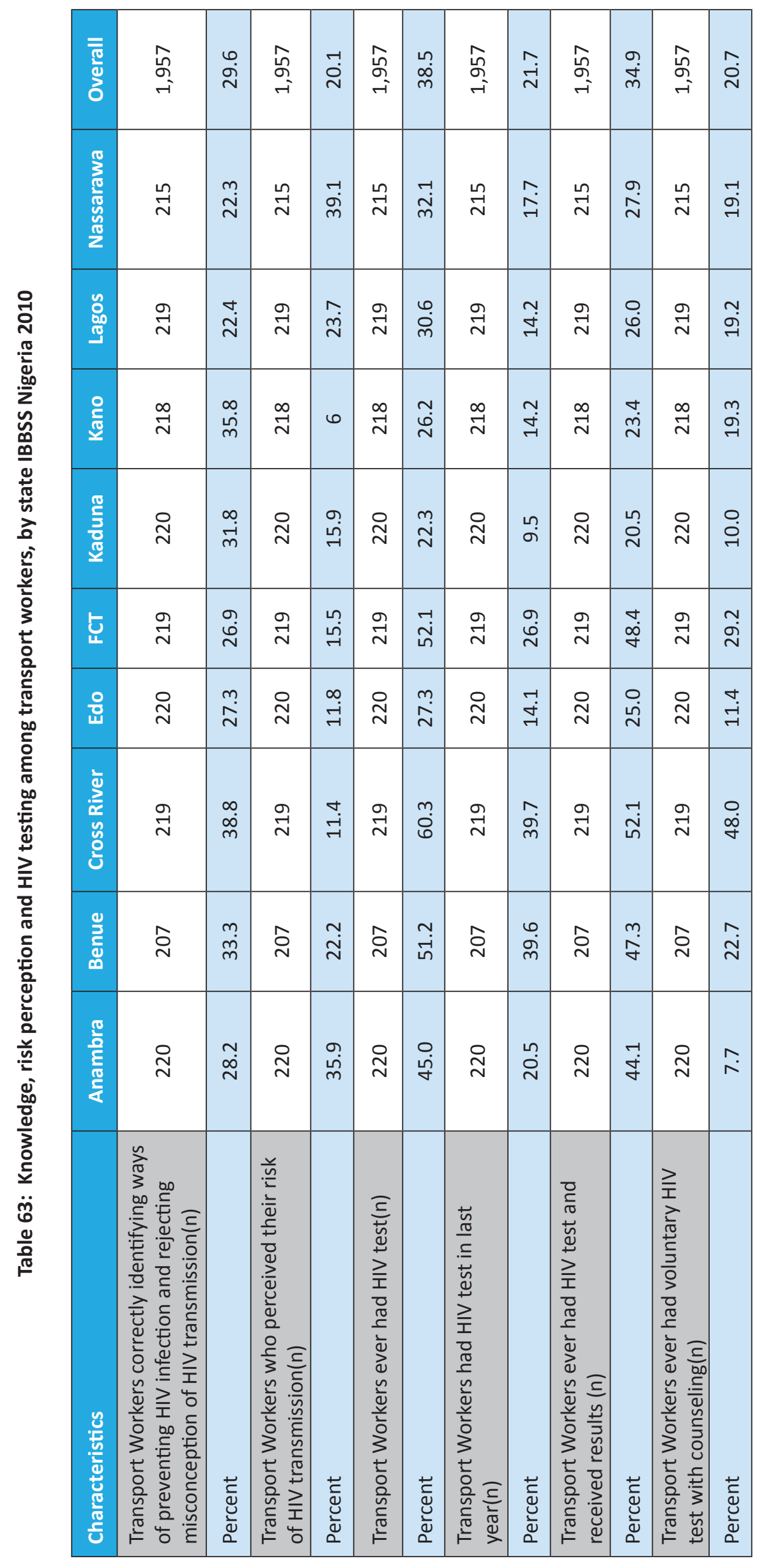




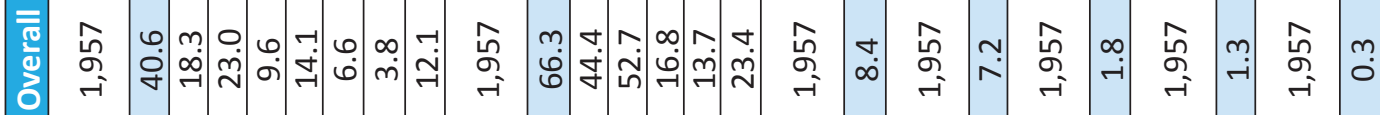

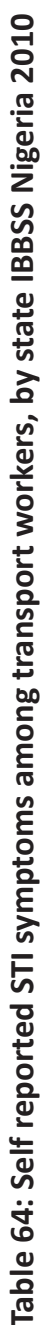

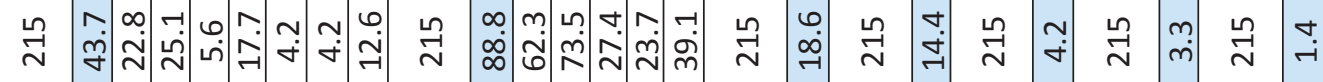

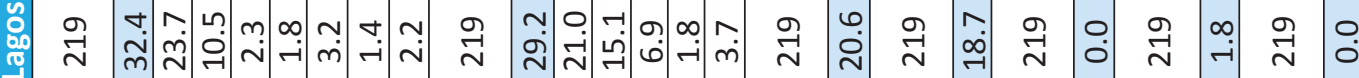

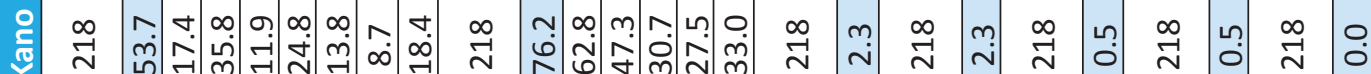

ลे

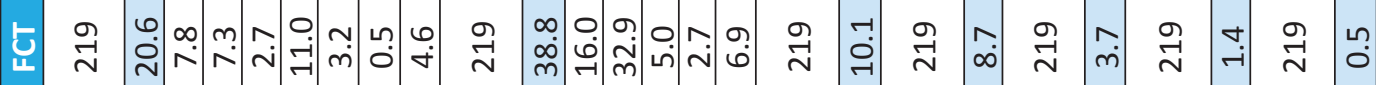

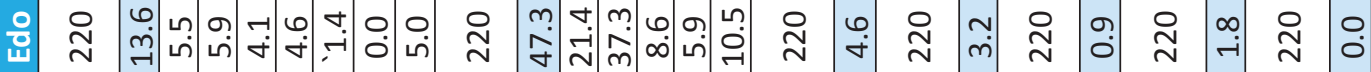

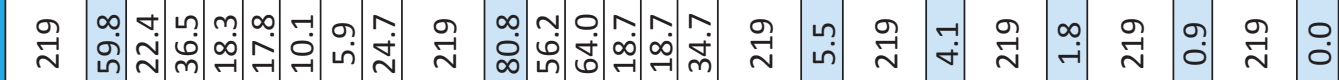

는

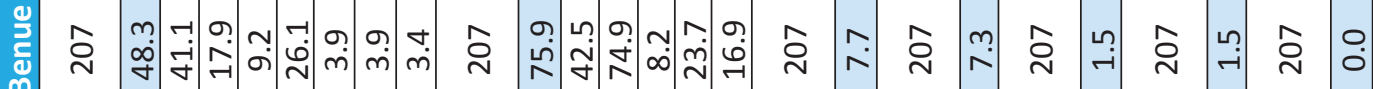

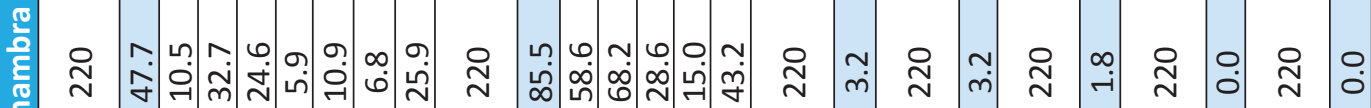

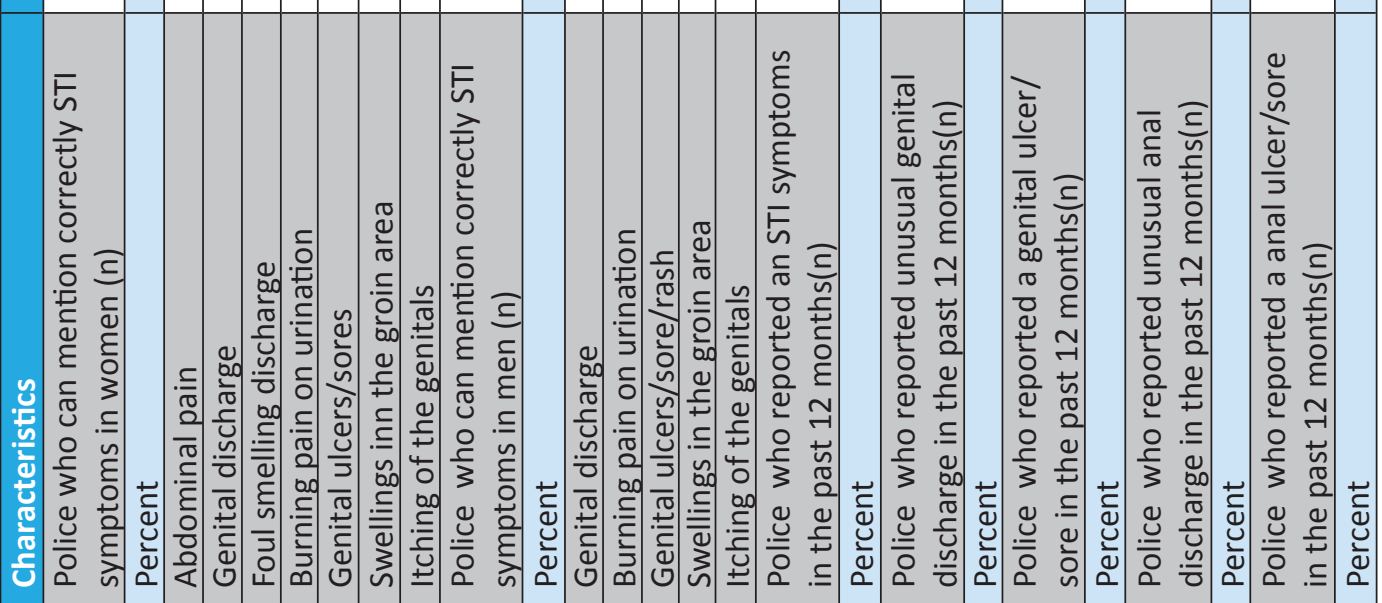




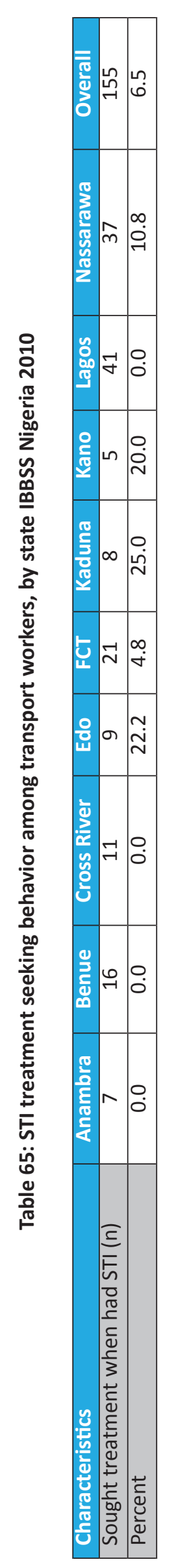

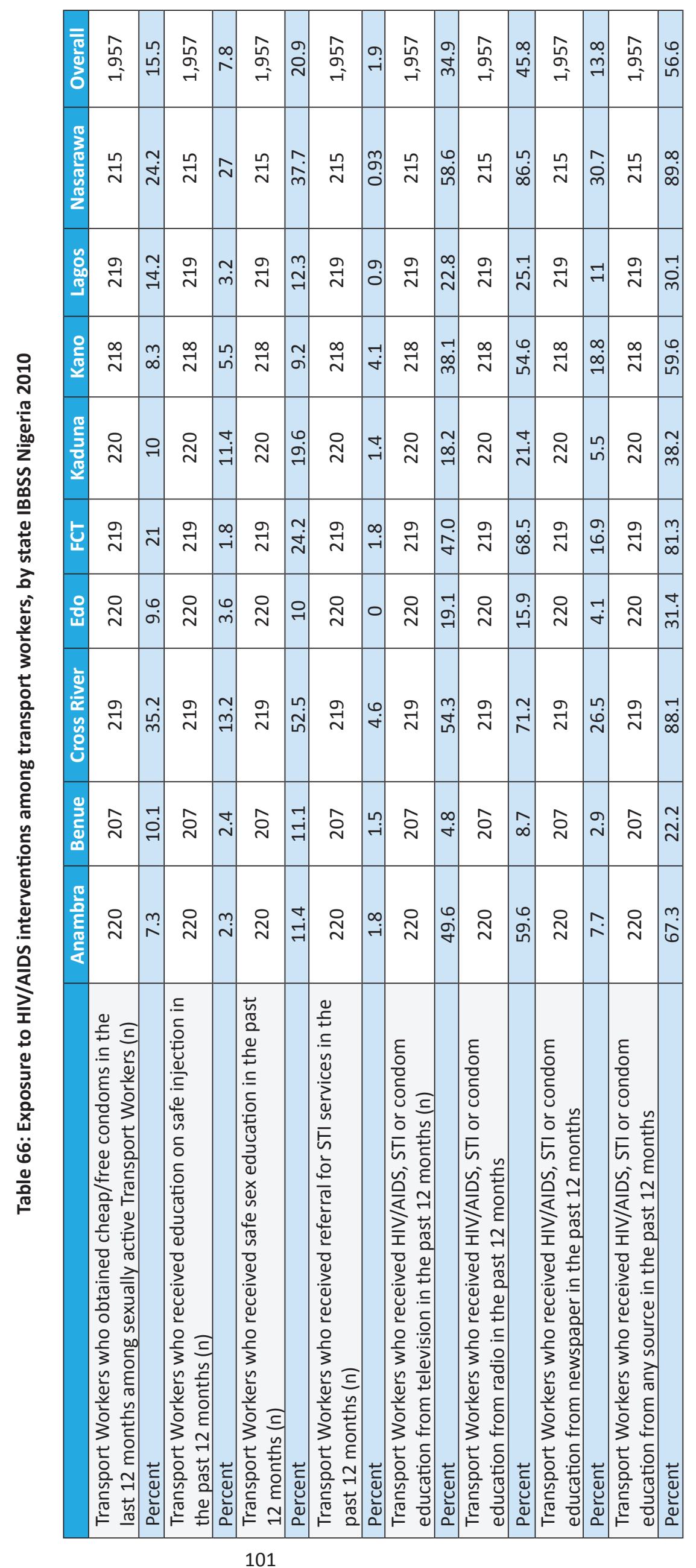




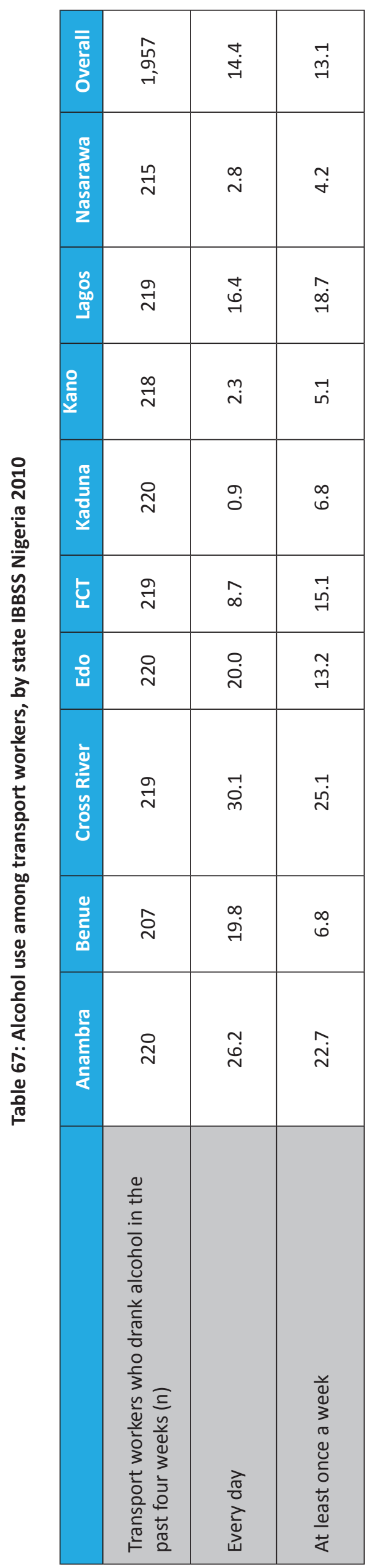




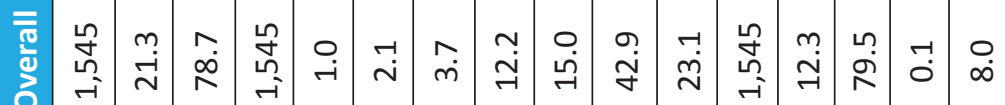

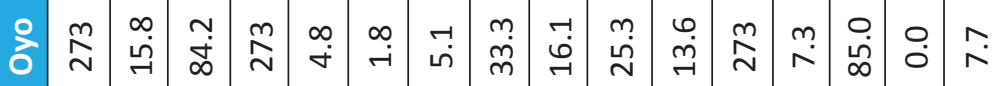

品

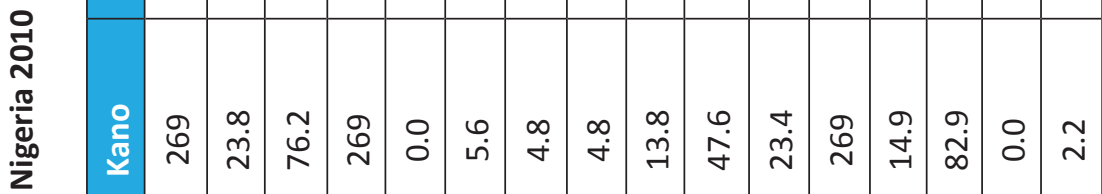

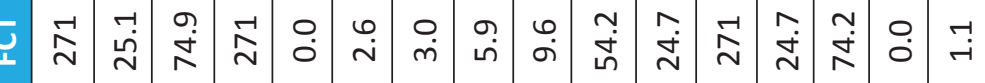

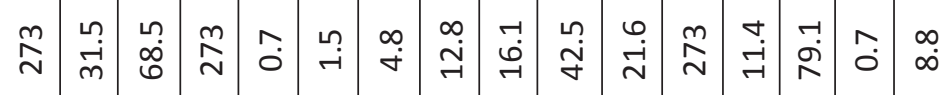

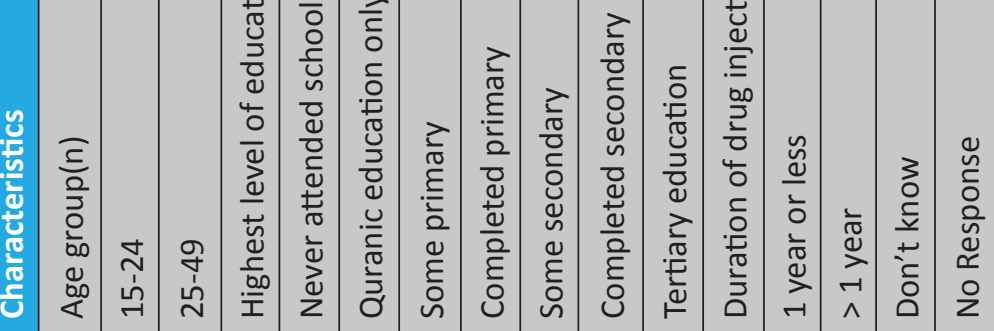




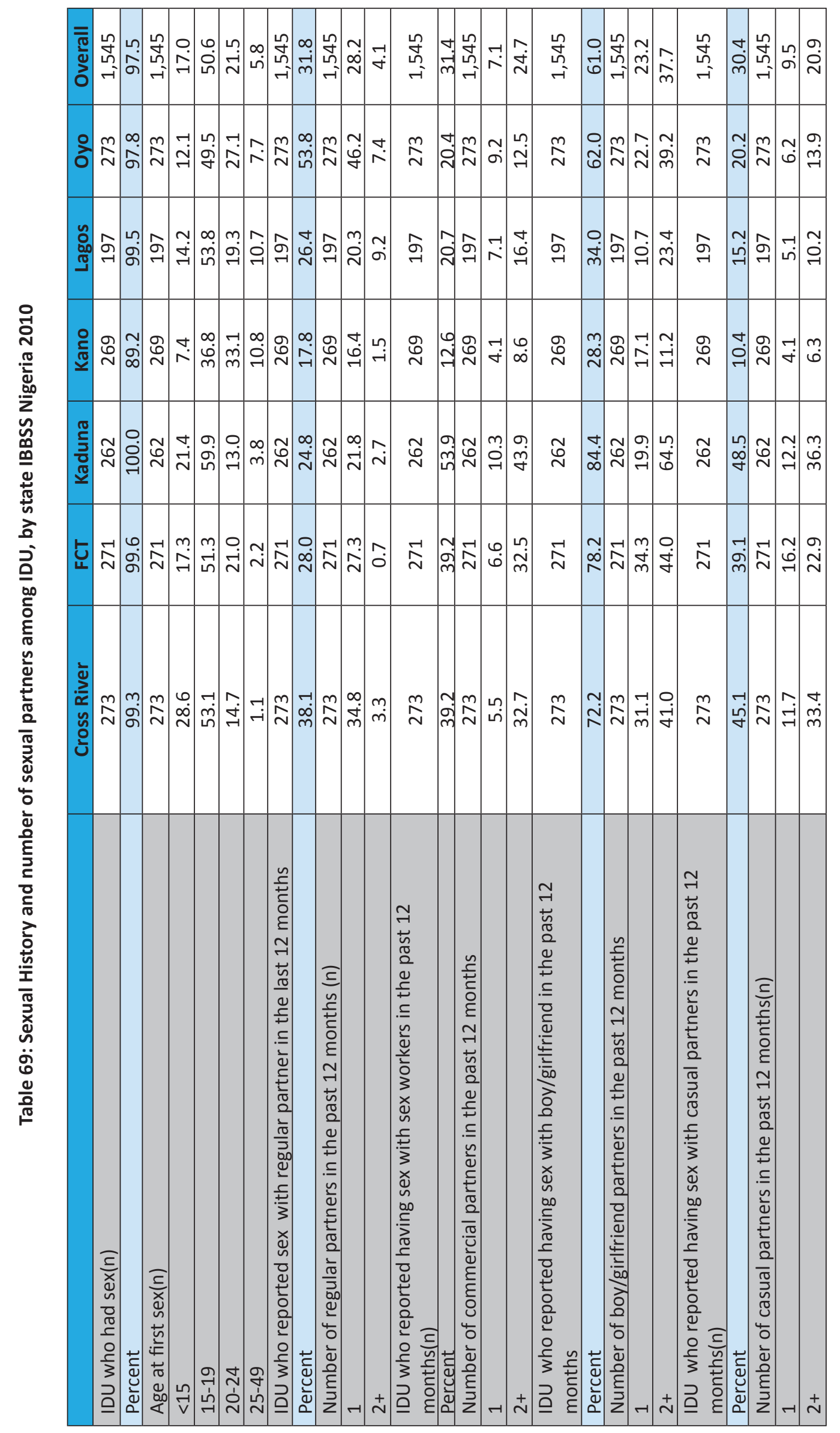




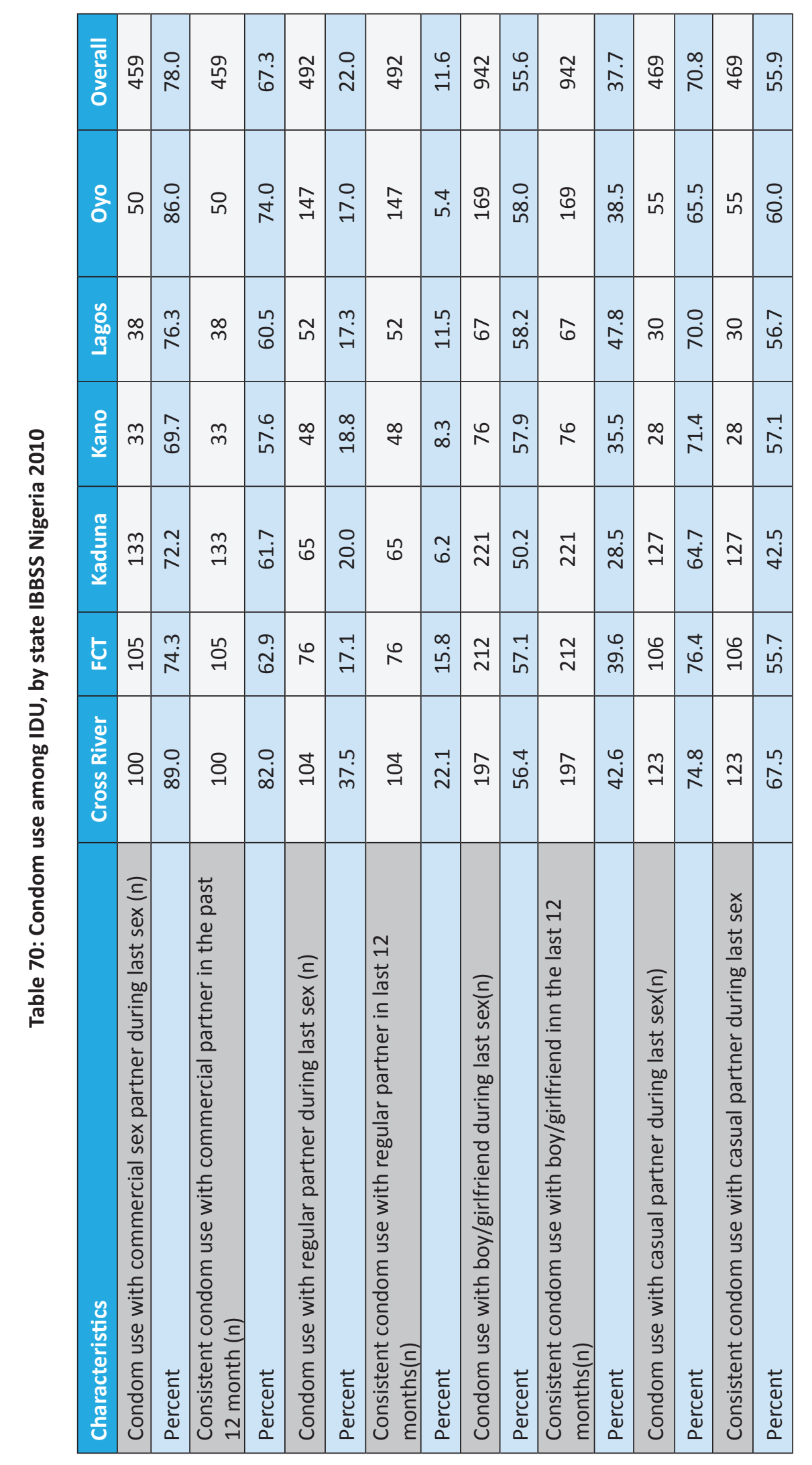




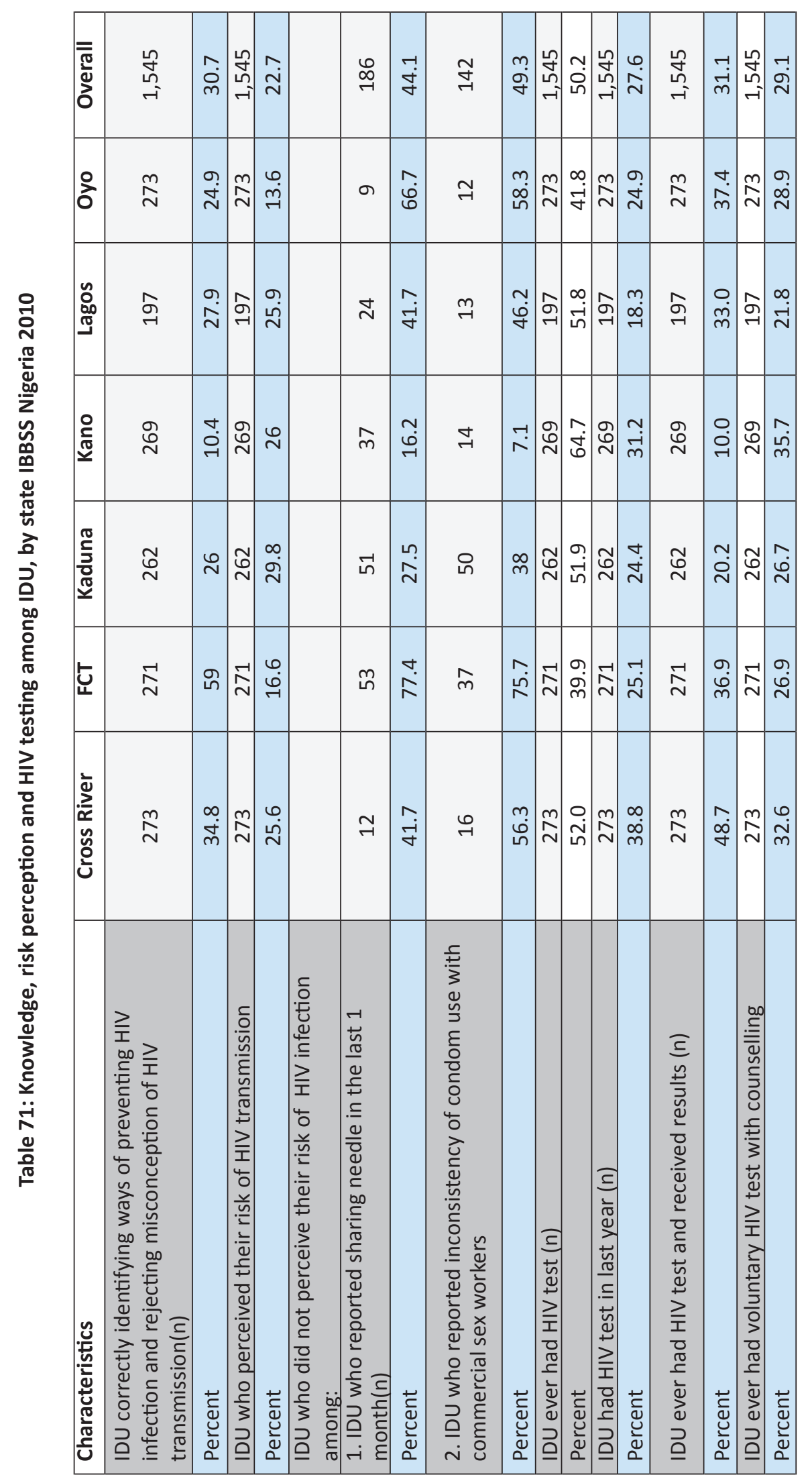




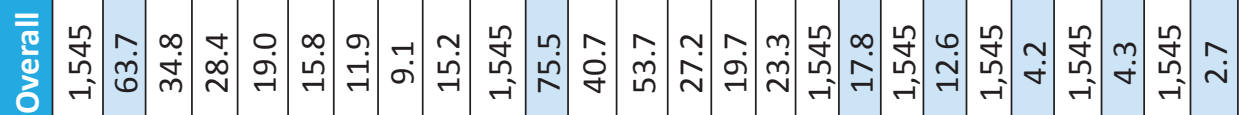

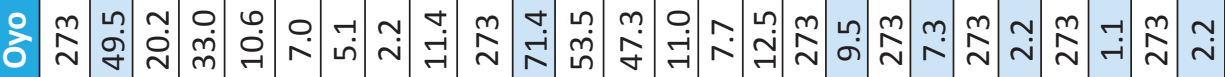

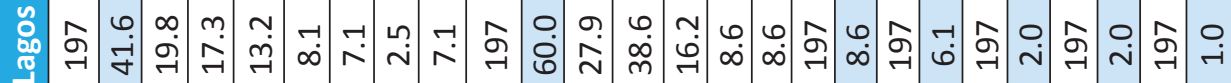

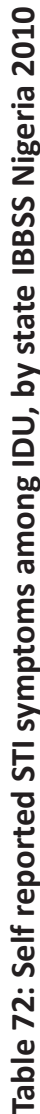

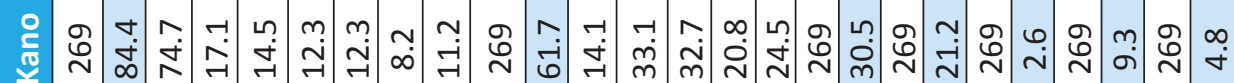

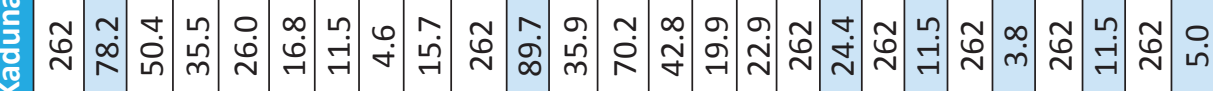

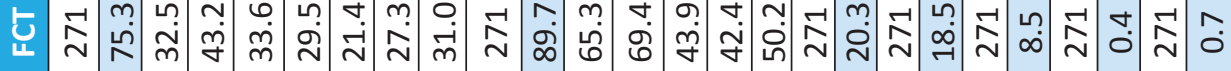

舟 号

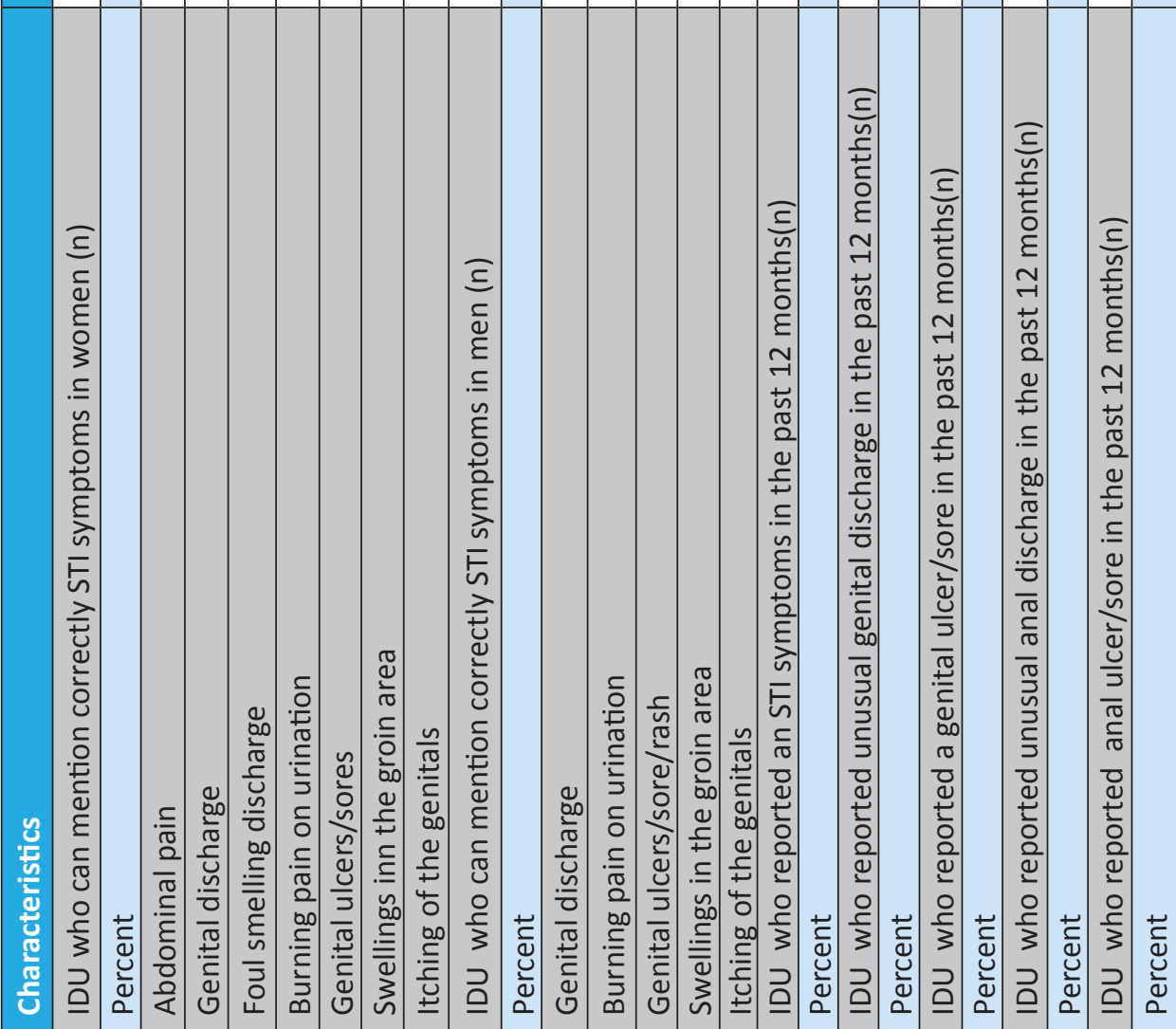




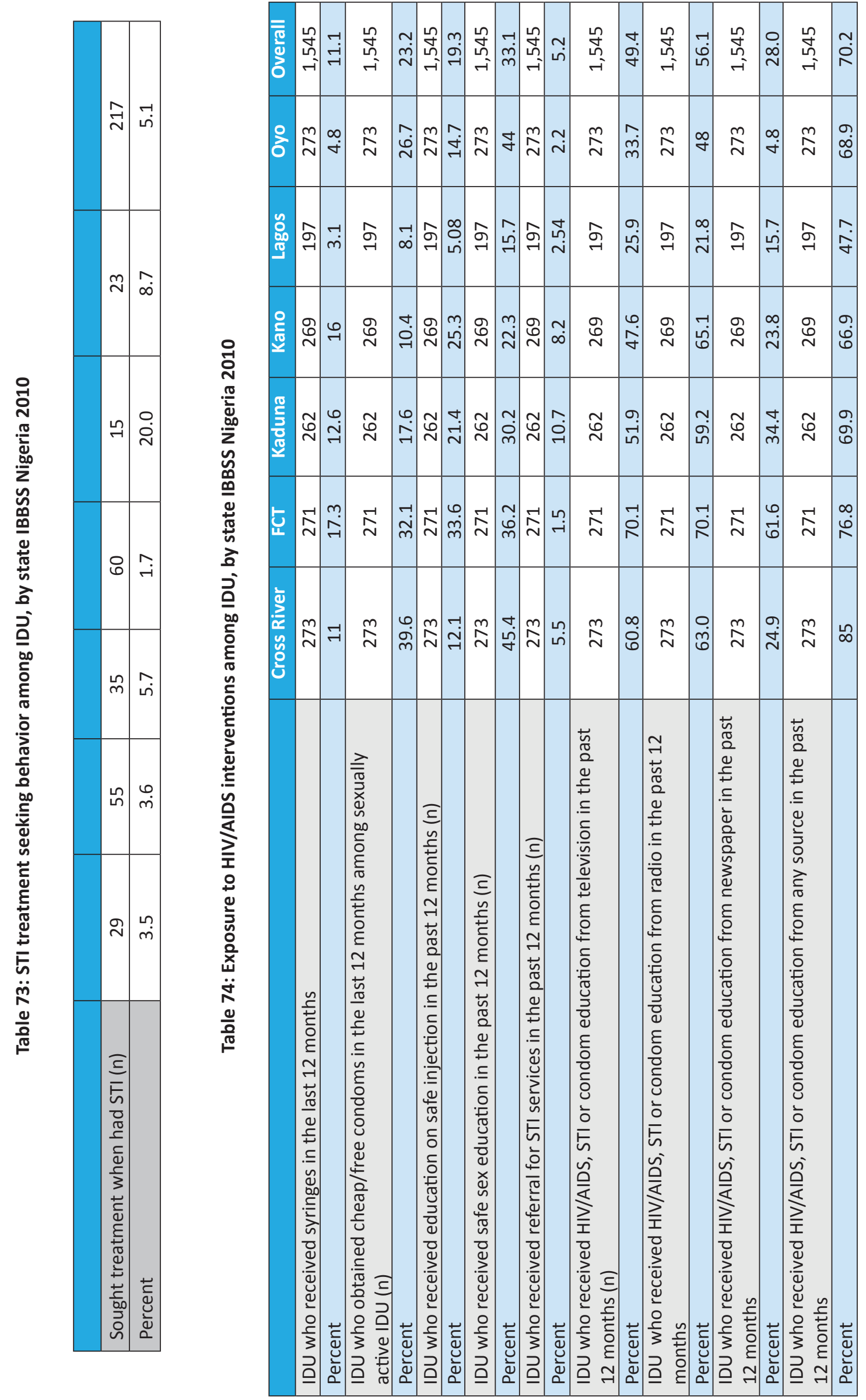




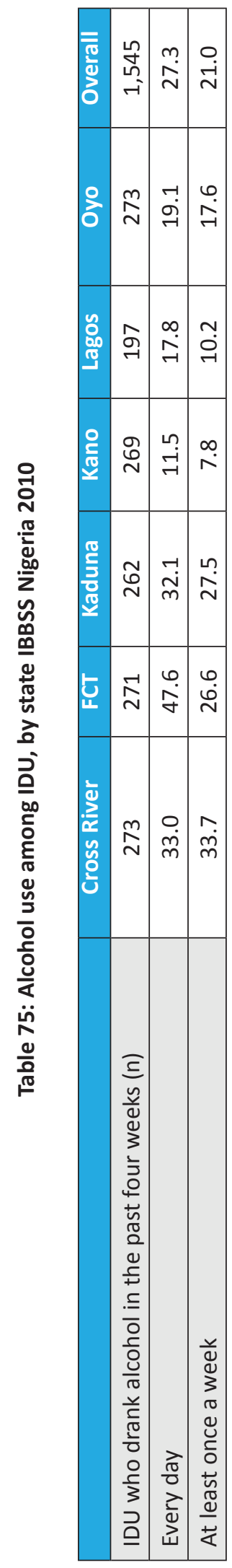

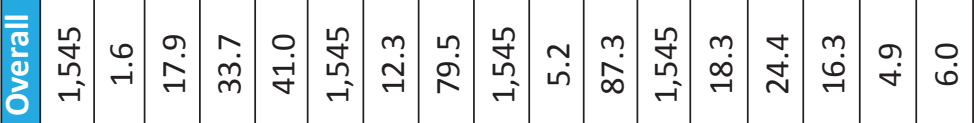

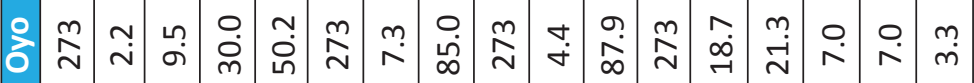
总

号

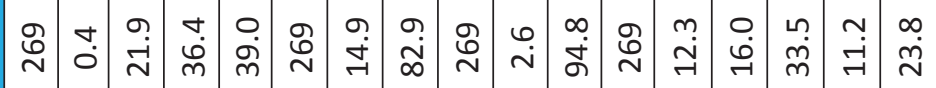

管

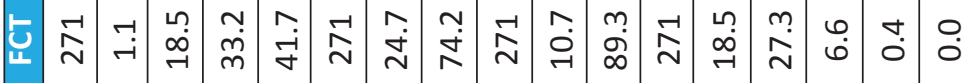

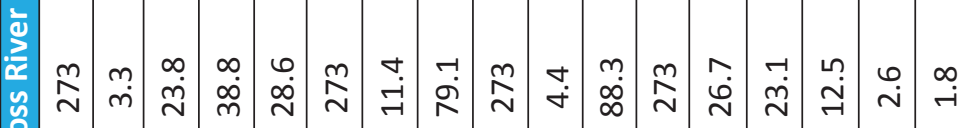

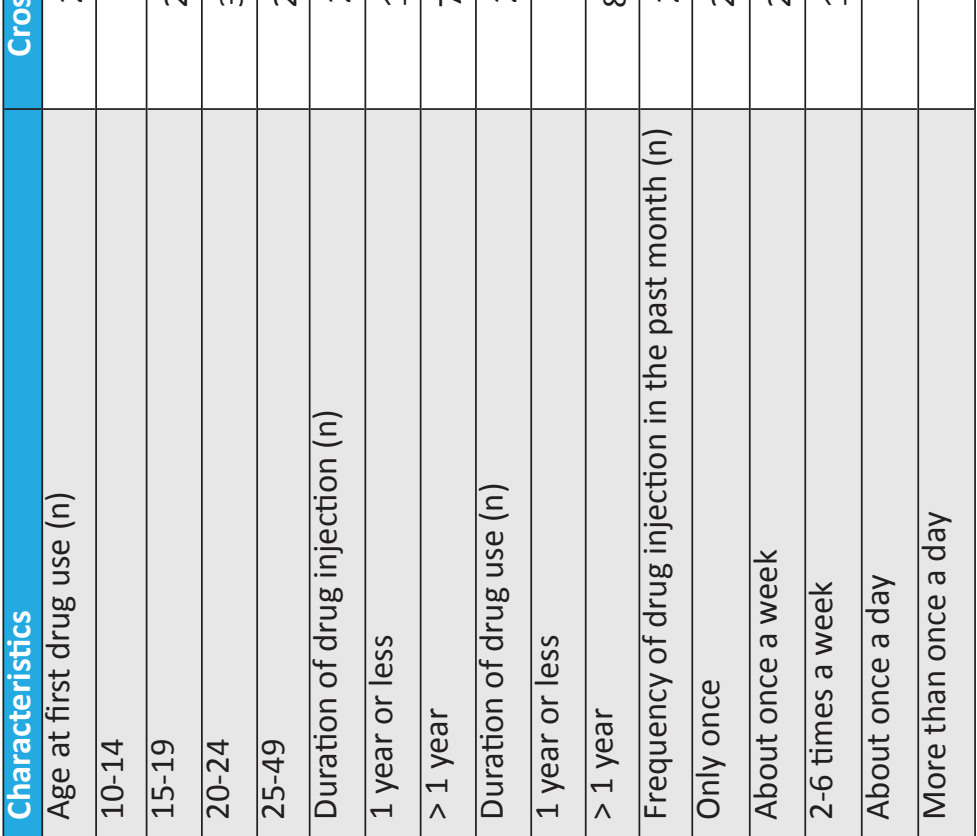




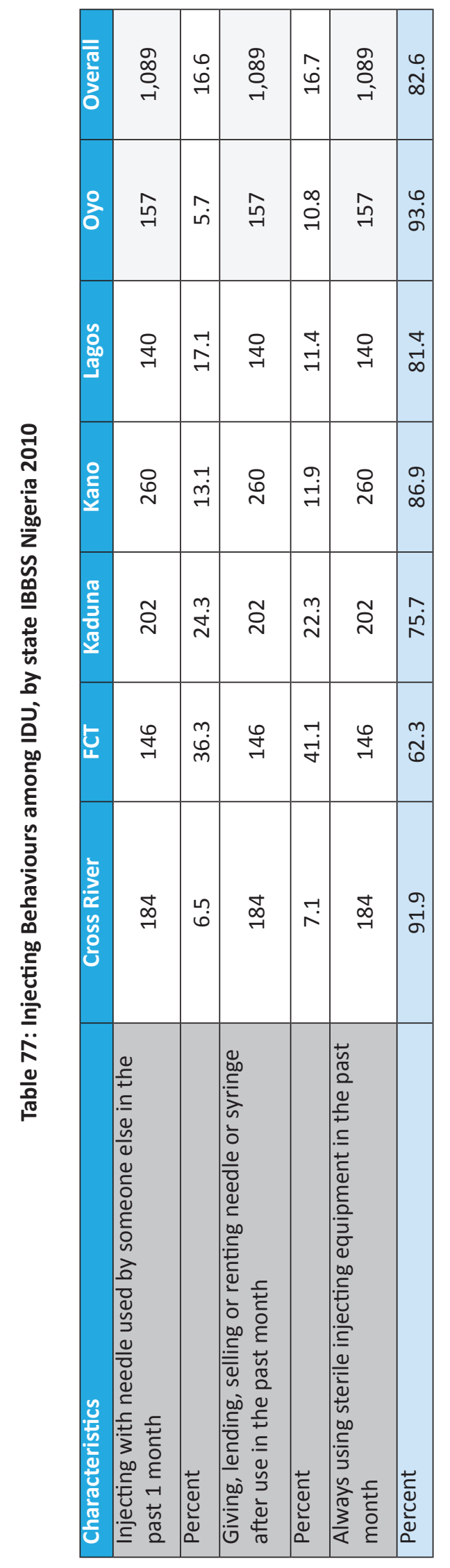




\subsection{Appendix III: List of contributors}

\begin{tabular}{|c|c|}
\hline \multicolumn{2}{|c|}{$\mathrm{FMOH}$} \\
\hline 1 & Dr Kabiru Monsur - Director of Public Health \\
\hline 2 & Dr. W. I Balami - National Coordinator \\
\hline 3 & Dr E. B. A Coker - Former NC \\
\hline 4 & Dr Aderemi Azeez - Head Strategic Information branch \\
\hline 5 & Dr. Issa B. Kawu - Head Surveillance \\
\hline 6 & Mr Alexander Onwuchekwa - Desk officer IBBSS \\
\hline 7 & Dr. Ade Bashorun Desk officer NARHS \\
\hline 8 & Br Gabriel Ikwulono Desk officer ANC Survey \\
\hline 9 & Perpetual Amobi \\
\hline \multicolumn{2}{|c|}{ FHI/GHAIN } \\
\hline 1 & Prof Otto Chabikuli \\
\hline 2 & Dr. Chiho Suzuki \\
\hline 3 & Dr Christoph Hamelmann \\
\hline 4 & Dr Bolatito Aiyenigba \\
\hline 5 & Titilope Badru \\
\hline 6 & Dr Ochanya Idoko \\
\hline 7 & Dr. Titilayo Aghoghovbia \\
\hline 8 & Gina Etheredge \\
\hline 9 & Amina Kasim \\
\hline \multicolumn{2}{|c|}{ ENR/SFH } \\
\hline 1 & Dr. Jenifer Anyanti \\
\hline 2 & Dr. Adebayo Samson \\
\hline 3 & Mr Onoriode Ezire \\
\hline 4 & Zana Somda \\
\hline 5 & Mr Richard Fakolade \\
\hline 6 & Omokhudu Idogho \\
\hline \multicolumn{2}{|c|}{ ENR/Pop Council } \\
\hline 1 & Sylvia Adebajo \\
\hline 2 & Apera lorwakwagh \\
\hline 3 & Emeka Nwachukwu \\
\hline 4 & Bayo Ajala \\
\hline 5 & Lolade Abiodun \\
\hline \multicolumn{2}{|c|}{ Other Technical Committed members } \\
\hline 1 & Dr Eloike Tony \\
\hline 2 & Dr. Lydia Abia Bassey \\
\hline 3 & Dr Ifeadike Chigozie \\
\hline 4 & Mr Ifeanyi Orazulike \\
\hline 5 & Dr. Kayode Osungbade \\
\hline 6 & Prof K. Sabitu \\
\hline 7 & Mr Fashina N. A \\
\hline 8 & Dr Tunde Adedokun \\
\hline 9 & Mr Adekanmbi Lasupo Taiwo \\
\hline 10 & Mr Ogboi Sonny Johnbull \\
\hline 11 & Dr. Adedeji A.A. \\
\hline 12 & Dr Kola Oyedeji \\
\hline 13 & Dr Lawal R.A \\
\hline 14 & Dr Simeon Ekanem (Army focal person) \\
\hline 15 & Dr Grace Okudo (Police focal person) \\
\hline 16 & McPaul Okoye (USAID) \\
\hline 17 & Dr Niyi Ogundiran (WHO) \\
\hline 18 & Dr Kofo Odeyemi \\
\hline 19 & Dr Gideon Oju \\
\hline 20 & Mr Usman Kolapo (NPC) \\
\hline
\end{tabular}





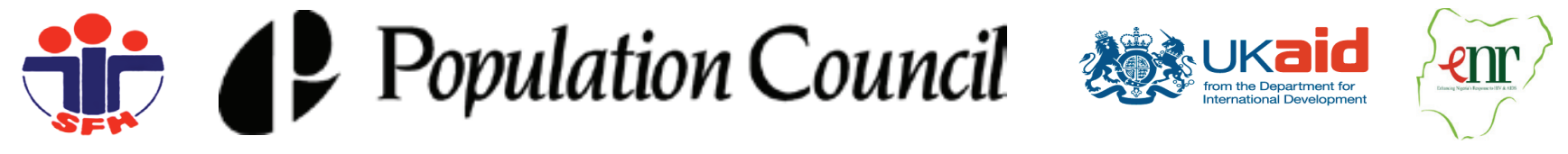

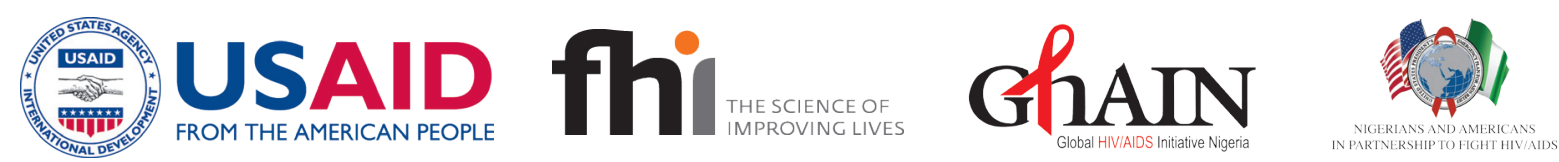

